Eston Almança dos Santos

\title{
Reduzindo a Volatilidade de Requisitos com o volaRE
}

Tese apresentada à Escola Politécnica da Universidade de São Paulo para obtenção do título de Doutor em Engenharia 

Eston Almança dos Santos

\section{Reduzindo a Volatilidade de Requisitos com o volaRE}

Tese apresentada à Escola Politécnica da Universidade de São Paulo para obtenção do título de Doutor em Engenharia

Área de concentração:

Engenharia de Controle e Automação

Mecânica

Orientador:

Prof. Dr. José Reinaldo Silva

São Paulo

2008 
Este exemplar foi revisado e alterado em relação à versão original, sob responsabilidade única do autor e com a anuência de seu orientador.

São Paulo, 12 de junho de 2008.

Eston Almança dos Santos

Autor

José Reinaldo Silva

Orientador

\section{FICHA CATALOGRÁFICA}

\section{Santos, Eston Almança dos}

Reduzindo a volatilidade de requisitos com o volaRE / E.A.

dos Santos. - São Paulo, 2008.

232 p. Edição Revisada.

Tese (Doutorado) - Escola Politécnica da Universidade de São Paulo. Departamento de Engenharia Mecatrônica e de Sistemas Mecânicos.

1. Engenharia (Design) 2. Engenharia de requisitos I. Universidade de São Paulo. Escola Politécnica. Departamento de Engenharia Mecatrônica e Sistemas Mecânicos. Il.t. 



\section{Agradecimentos}

Durante a minha vida muitas mudanças ocorreram e nem sempre foi possível prever todas, principalmente aquelas que me trouxeram as melhores experiências. Este trabalho foi motivado por essas mudanças, que certamente foram proporcionadas por Deus, a quem primeiramente agradeço.

A concretização desta tese contou com o apoio e colaboração de muitos. Reconheço que não teria condições de citar todos, porém agradeço a eles pelas valiosas contribuições.

Agradeço ao Prof. José Reinaldo Silva, pela orientação do trabalho e, sobretudo, pela amizade.

Pelo apoio financeiro do CNPq durante a pesquisa.

Ao pessoal do d-lab, agradeço pelo companheirismo e apoio. Ao Tiago pela condução e implementação do itSIMPLE, que contou com o apoio do Vitor e Fernando. Ao Daniel, Diogo e Melina, pela dedicação no projeto eDrugControl.

Para os comandantes e oficiais dos hospitais militares, assim como aos profissionais dos hospitais privados e públicos, seguem meus agradecimentos pela receptividade e atenção durante as visitas, motivadas pelo eDrugControl.

Aos profissionais e pesquisadores que participaram da seção Automação na Farmácia Hospitalar no evento Robótica 2006.

Um reconhecimento para os colaboradores da thinkUP, que participaram em conjunto com o d-lab no concurso inSites. Em especial, agradeço ao Daniel pelo apoio e dedicação nos projetos.

No projeto eCampeonatos, agradeço ao Renato, Michel, Rodrigo e Fernando, que contribuíram para o desenvolvimento da ferramenta. Para a equipe da Secretaria de 
Esportes e Lazer da Cidade de São Paulo, segue meu reconhecimento pela atenção e apoio durante o tempo de realização do projeto.

Por fim, agradeço imensamente à minha família, que esteve junto durante estes anos apoiando, incondicionalmente, em todos os momentos, sobretudo naqueles mais difíceis. Em especial, agradeço a Paula pelo carinho e compreensão, para quem dedico este trabalho. 


\section{Resumo}

A oferta de bens e serviços para atendimento da demanda dos consumidores atuais tem uma forte base na personalização, ou seja, na busca da satisfação individual dos clientes. Essa tem sido a forma que as empresas tem encontrado para se diferenciar. Para tanto, as organizações necessitam de modelos de negócios que permitam ajustar seus processos com as freqüentes necessidades de mudanças. A metodologia utilizada foi a observação de estudo de casos com projetos de Inovação Tecnológica, que possuem altos índices na característica de mudança dos requisitos. A proposta deste trabalho é permitir que essa volatilidade seja identificada na fase de eliciação de requisitos, com base nas intenções de cada envolvido no processo de engenharia de requisitos, e que tais solicitações possam ser melhor compreendidas através da prototipação baseada nas perspectivas dos participantes: de negócio, operacional, de design e gerencial. Como resultado foi definido o volaRE, que permite se conhecer a volatilidade de um requisito, com base nas características definidas do mesmo, ainda na fase de eliciação.

Palavras-chave: Volatilidade de requisitos. Engenharia de requisitos. Eliciação de requisitos. Intenção. Perspectivas. 



\section{Abstract}

Current consumers have demanded a special attention in the production and distribution of goods and services which have turned organizations to mass customization, looking for an individual satisfaction of their customers. This has been the form that companies have found to differentiate themselves. Therefore, the integration of business and productive processes must be adaptable to the frequent changes in the company's environment. The used methodology was the observation of cases study with of Technological Innovation projects, which have high rates of requirements changes. The proposal of this work is that this volatility could be identified in the requirements elicitation phase, based on the intent of each involved in the process of requirements engineering, and that such requests can be better understood through perspectives prototyping based of those participants: business, operational, design and management. As result volaRE was defined, that lets to know the requirement's volatility, based on defined characteristics, yet at elicitation phase.

Keywords: Requirements volatility. Requirements engineering. Requirements elicitation. Intention. Perspectives. 



\section{Sumário}

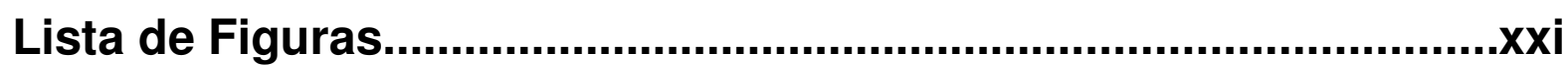

Lista de Tabelas......................................................................................

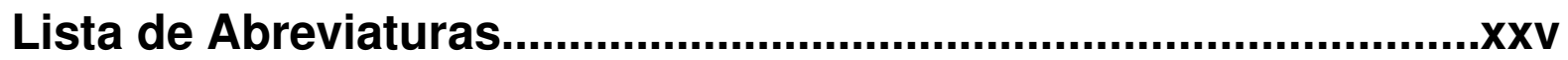

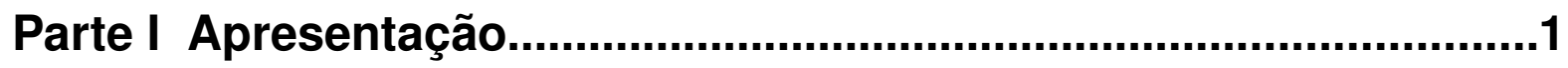

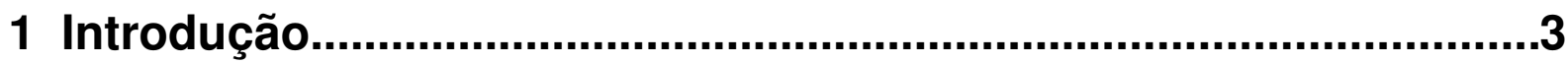

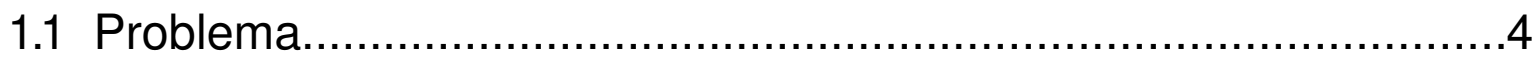

1.2 Justificativa

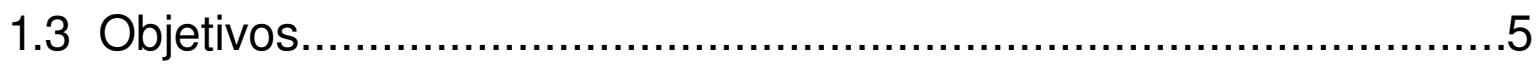

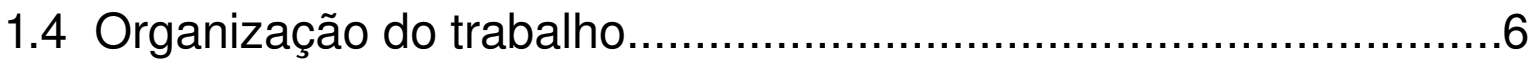

Parte II Desenvolvimento........................................................................7

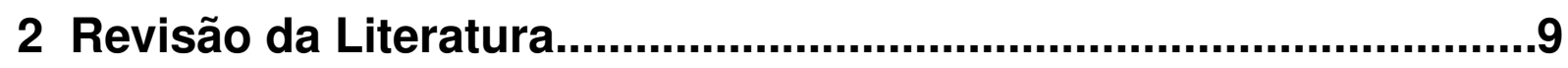

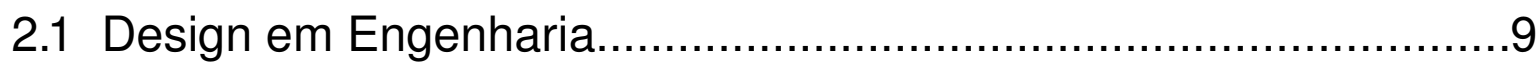

2.1.1 Mudanças no Processo de Design................................................13

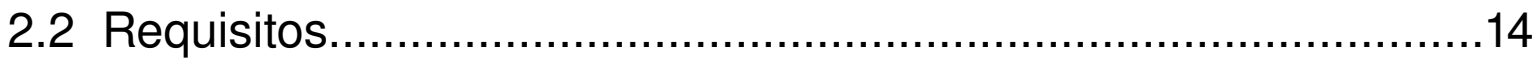

2.2.1 Mudanças nos Requisitos........................................................17

2.2.2 Gerenciamento de Requisitos..................................................19

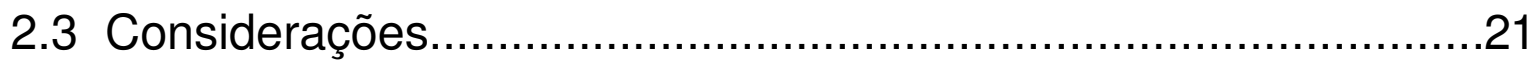

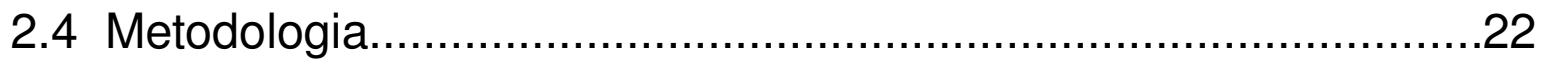

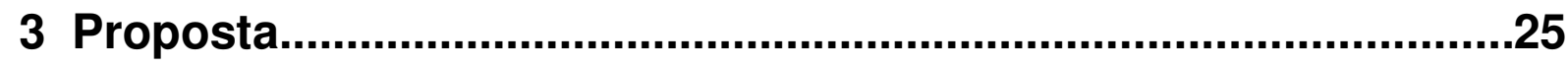

3.1 Perspectivas na Eliciação de Requisitos.......................................25

3.2 Observação da Prototipação baseada em Perspectivas...............26

3.2.1 Perspectiva do Negócio - O projeto eDrugControl............................28

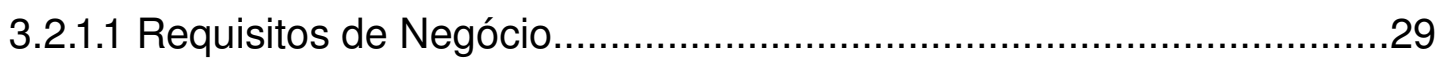




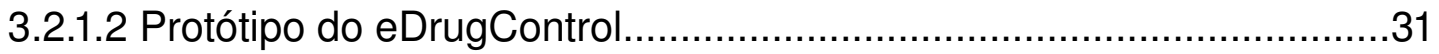

3.2.2 Perspectiva de Design - O projeto itSIMPLE................................32

3.2.2.1 Requisitos de Design..................................................................33

3.2.2.2 Protótipo do itSIMPLE................................................................

3.2.3 Perspectiva Operacional - O projeto eCampeonatos....................35

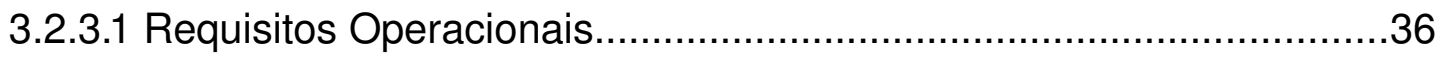

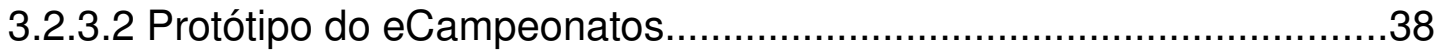

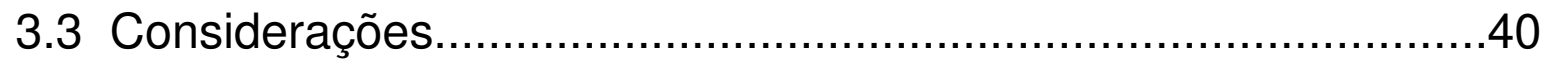

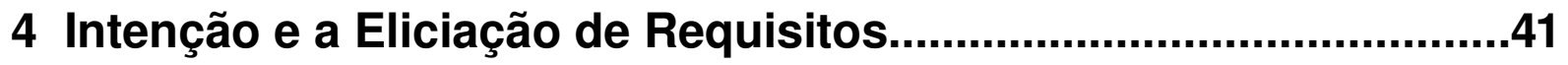

4.1 Observando a Intenção dos requisitos nas Perspectivas............42

4.2 Intenção na Perspectiva do Negócio............................................44

4.2.1 Definição da intenção na Perspectiva do Negócio........................45

4.2.2 Aplicação da intenção nos Requisitos de Negócios.......................46

4.3 Intenção na Perspectiva Operacional........................................49

4.3.1 Definição da intenção na Perspectiva Operacional........................49

4.3.2 Aplicação da intenção nos Requisitos Operacionais.....................51

4.4 Intenção na Perspectiva de Design............................................53

4.4.1 Definição da intenção na Perspectiva de Design..........................54

4.4.2 Aplicação da intenção nos Requisitos de Design........................55

4.5 Intenção na Perspectiva Gerencial..........................................58

4.5.1 Definição da intenção na Perspectiva Gerencial..........................58

4.5.2 Aplicação da intenção nos Requisitos Gerenciais.........................60

5 Identificando a Volatilidade de Requisitos com o volaRE............63

5.1 Índice de Aprovação da Perspectiva do Requisito.......................63

5.2 Definição do volaRE...............................................................64

5.3 Exemplo de identificação de volatilidade com o volaRE..............66

5.3.1 Aplicando o volaRE nos Requisitos de Negócio.............................66

5.3.1.1 Índice de Aprovação das Perspectivas no Requisito de Negócio.......66 
5.3.1.2 Cálculo da volatilidade do Requisito de Negócio. .68

5.3.2 Aplicando o volaRE nos Requisitos Operacionais.......................68

5.3.2.1 Índice de Aprovação das Perspectivas no Requisito Operacional.....69

5.3.2.2 Cálculo da volatilidade do Requisito Operacional.............................70

5.3.3 Aplicando o volaRE nos Requisitos de Design.............................70

5.3.3.1 Índice de Aprovação das Perspectivas no Requisito de Design........71

5.3.3.2 Cálculo da volatilidade do Requisito de Design...............................72

5.3.4 Aplicando o volaRE nos Requisitos Gerenciais...........................73

5.3.4.1 Índice de Aprovação das Perspectivas no Requisito Gerencial..........73

5.3.4.2 Cálculo da volatilidade do Requisito de Negócio.............................74

Parte III Contribuição.................................................................77

6 Resultados e Discussão..............................................................79

6.1 Prototipação Baseada em Perspectivas.......................................79

6.1.1 Perspectivas utilizadas na Prototipação........................................80

6.1.2 Perspectiva do Negócio - O projeto eDrugControl.........................81

6.1.3 Perspectiva de Design - O projeto itSIMPLE..............................83

6.1.4 Perspectiva Operacional - O projeto eCampeonatos....................84

6.2 Intenção e Eliciação de Requisitos.............................................86

6.3 volaRE - Identificando a Volatilidade de Requisitos..................89

6.4 Aplicações da Proposta..............................................................91

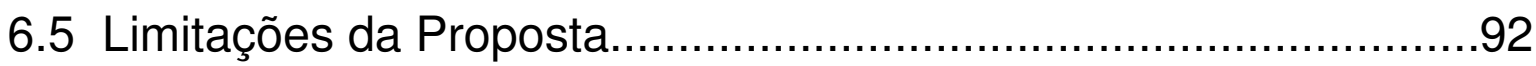

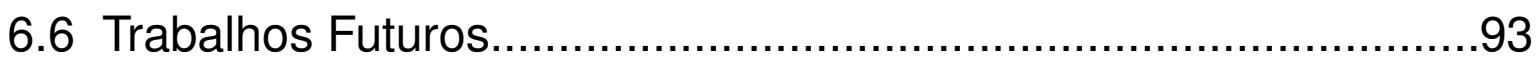

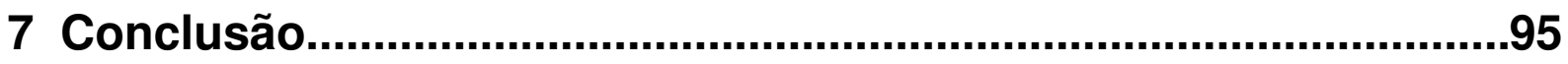

Referências...................................................................................97

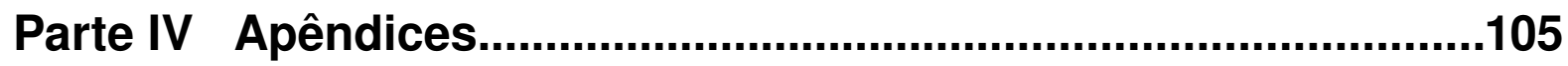

Apêndice A - Template Operacional...............................................107

A.1 Componentes de Software .............................................107

Apêndice B - Template de Negócio...................................................109 
Apêndice C - Template de Design..................................................111

Apêndice D - Negócios com o eDrugControl................................113

D.1 Descrição dos Produtos .........................................................114

D.2 Descrição dos Serviços ................................................115

D.3 Descrição do Problema Resolvido .........................................116

D.4 Análise do Mercado Potencial .............................................119

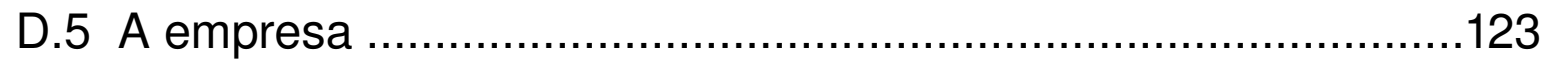

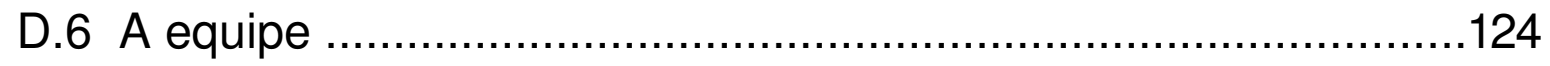

Apêndice E - Artigo do eDrugControl...........................................125

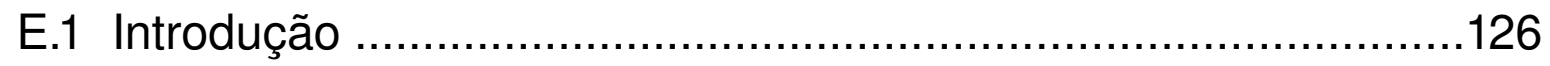

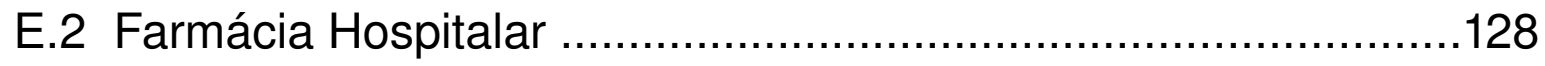

E.2.1 A assistência farmacêutica junto às unidades do hospital ..........130

E.2.1.1 Ambulatório ............................................................................130

E.2.1.2 Serviço de arquivo médico e de estatística - SAME ........................131

E.2.2 Farmacovigilância .............................................................131

E.3 Erro Médico...................................................................133

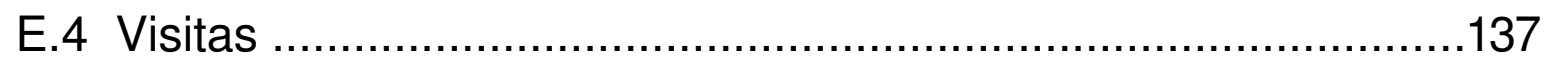

E.5 Solução e Discussão ......................................................138

E.6 Referências .........................................................................143

Apêndice F - Negócios com o eCampeonatos..............................145

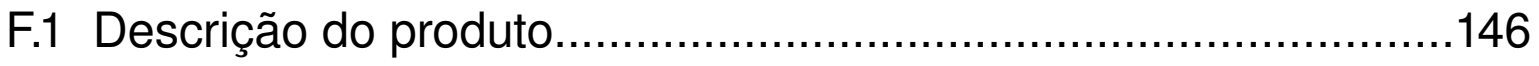

F.2 Descrição do problema resolvido ….......................................147

F.3 Análise do mercado potencial ...........................................147

F.3.1 Prefeituras aplicam em esporte menos de 1\% das despesas .....148

F.3.2 Municípios maiores recebem mais valores da União e estados ..149

F.3.3 Poucos projetos e programas esportivos para deficientes ..........150

F.3.4 6,4\% das prefeituras não promoveram eventos em 2003.............151 
F.3.5 Ginásios são recursos esportivos municipais mais presentes ...152 F.4 Análise SWOT .....................................................................153

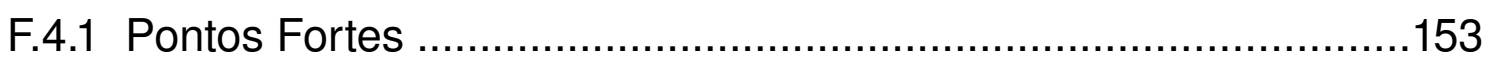

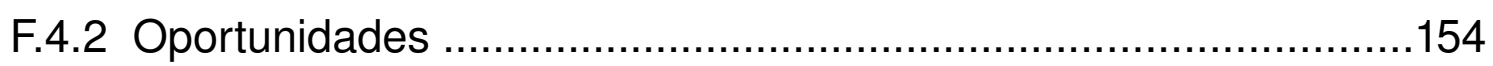

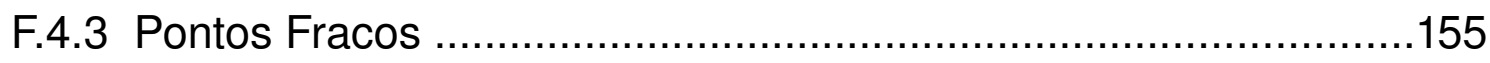

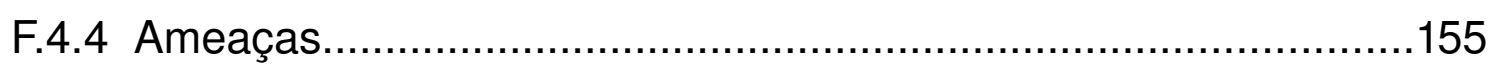

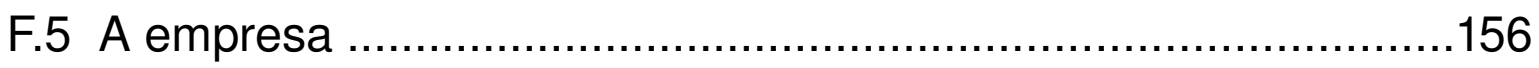

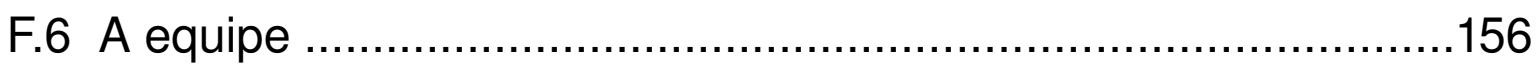

Apêndice G - Artigo do eCampeonatos.......................................157

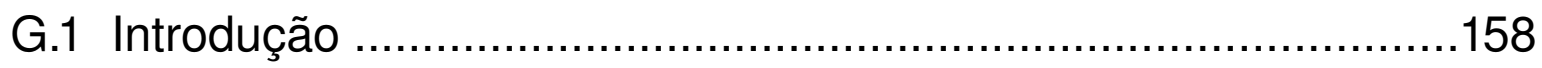

G.2 Tecnologia da Informação (TI) .......................................159

G.2.1 Estratégias de Uso da TI na Administração Pública ...................159

G.2.2 Importância da Informação na Organização .............................160

G.3 Governo Eletrônico ............................................................161

G.3.1 Objetivos para a implantação do Governo Eletrônico .................161

G.3.2 O Governo Eletrônico segundo seu relacionamento ..................162

G.3.3 O Governo Eletrônico segundo sua evolução ...........................162

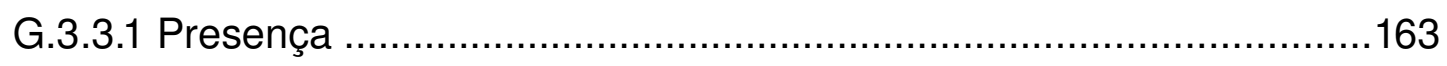

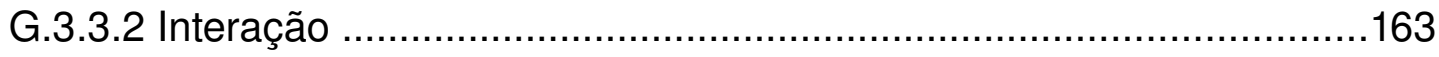

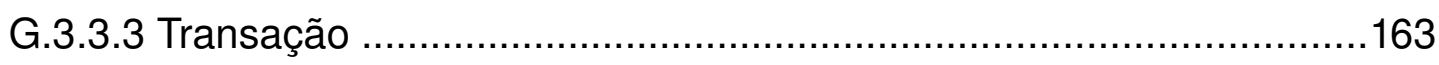

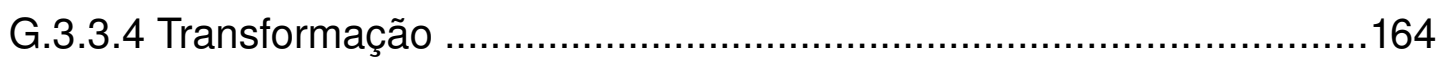

G.3.4 Obstáculos para a implantação do Governo Eletrônico .............164

G.4 Estudo de Caso: Os Jogos da Cidade de São Paulo ...............165

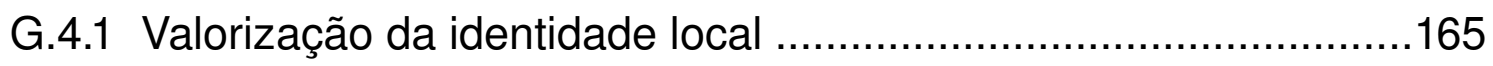

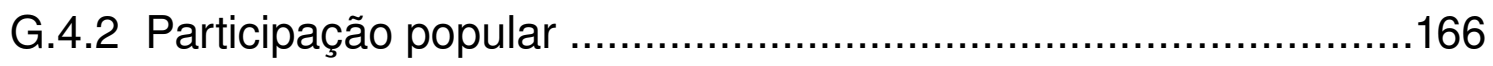

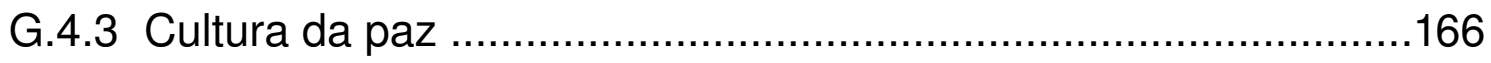

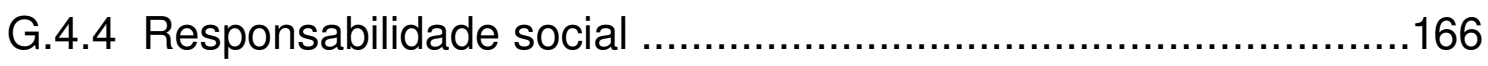

G.4.5 Jogos da Cidade antes do eCampeonatos .............................168

G.4.5.1 Inscrição dos atletas .................................................................168 
G.4.5.2 Cadastro dos locais dos jogos com agenda de disponibilidade .....169

G.4.5.3 Geração da tabela dos jogos ...................................................169

G.4.5.4 Divulgação dos resultados e geração das próximas fases ............170

G.4.5.5 Número de Jogos ..................................................................170

G.4.6 Jogos da Cidade testando o eCampeonatos ...........................170

G.4.6.1 Inscrição dos atletas ..............................................................171

G.4.6.2 Cadastro dos locais dos jogos com agenda de disponibilidade .....171

G.4.6.3 Geração da tabela dos jogos ..................................................171

G.4.6.4 Divulgação dos resultados e geração das próximas fases ............172

G.4.6.5 Número de Jogos ...............................................................172

G.4.7 Jogos da Cidade com o eCampeonatos ................................172

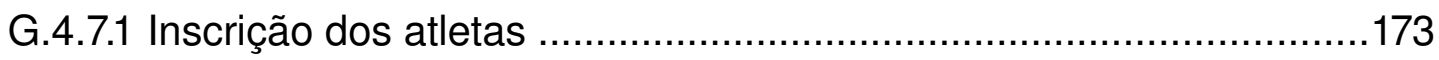

G.4.7.2 Cadastro dos locais dos jogos com agenda de disponibilidade .....173

G.4.7.3 Geração da tabela dos jogos .................................................173

G.4.7.4 Divulgação dos resultados e geração das próximas fases .............175

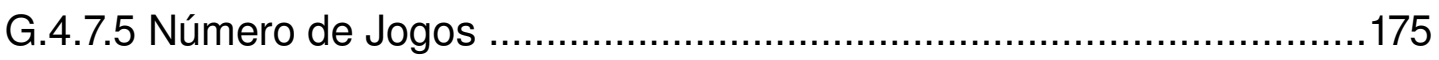

G.5 Considerações finais ...............................................176

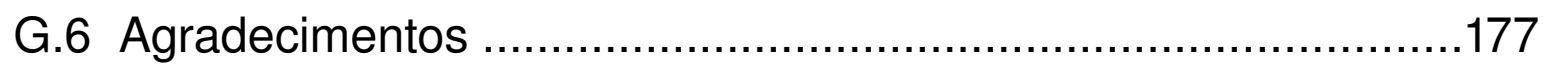

G.7 Referências ................................................................177

Apêndice H - Negócios com o itSIMPLE........................................179

H.1 Descrição do produto .........................................................180

H.2 Descrição dos serviços ................................................181

H.3 Descrição do problema resolvido .......................................182

H.4 Análise do mercado potencial ...............................................184

H.5 Melhorias Planejadas ........................................................186

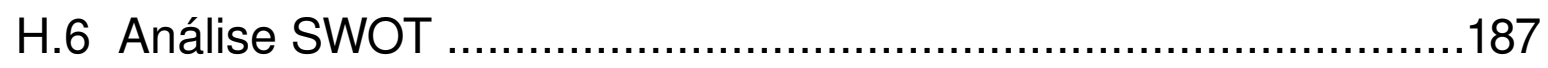

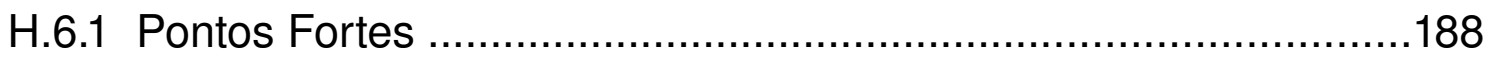

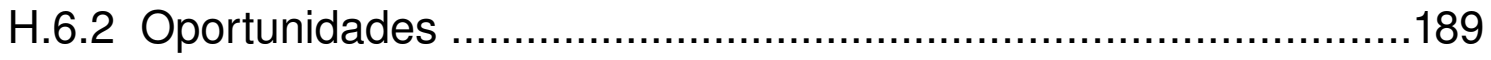

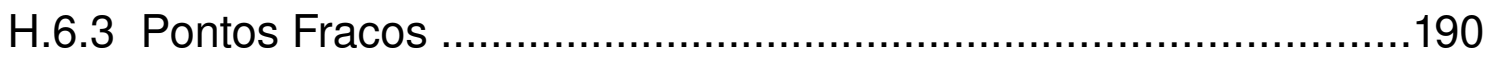




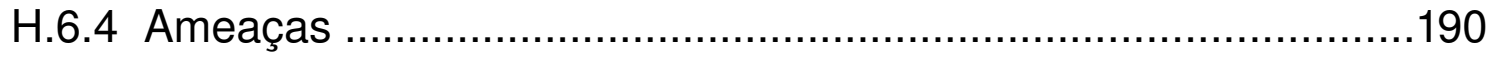

H.7 A empresa .............................................................. 192

H.8 A equipe ................................................................ 192

Apêndice I - Artigo do itSIMPLE..................................................193

I.1 Introdução ..................................................................194

I.2 A Representação em XML .............................................196

I.3 Verificação de Requisitos baseada em Viewpoints ...................197

I.4 Um Ambiente Gráfico para Modelagem e Análise de Sistemas .200

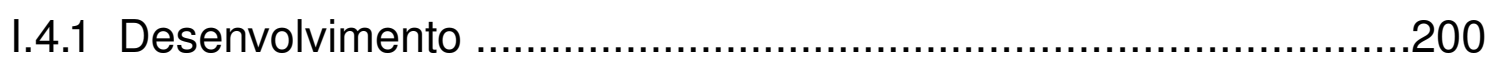

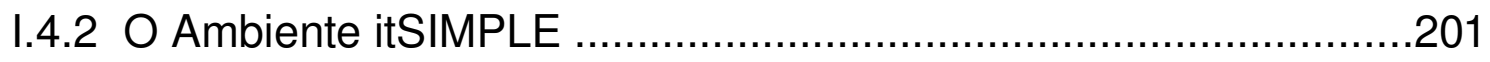

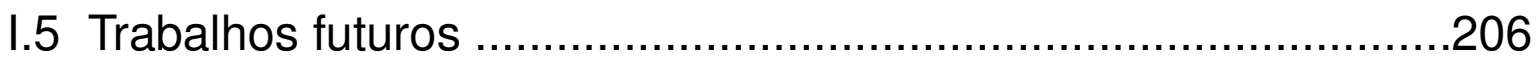

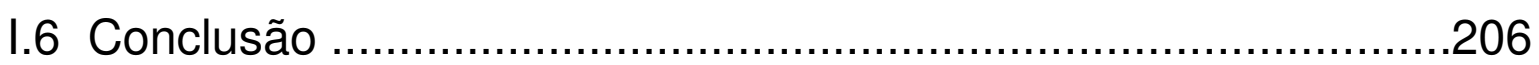

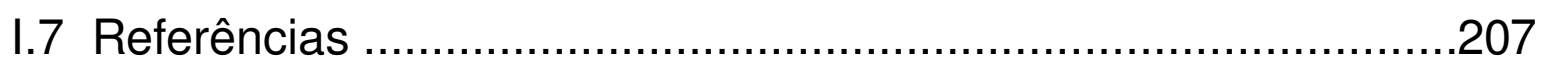

Apêndice J - Resultado do Concurso IBM inSites.........................209

J.1 eDrugControl..............................................................210

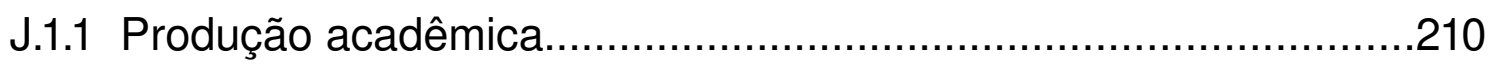

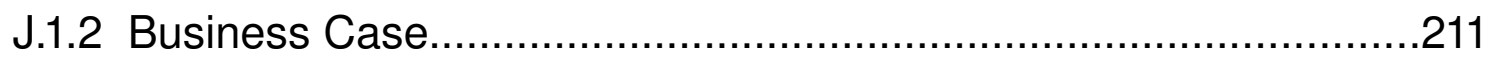

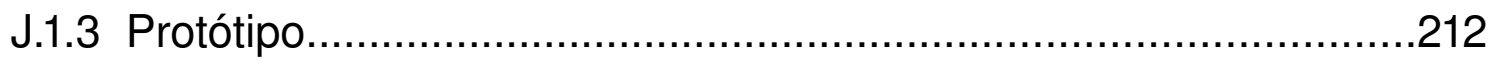

J.1.4 Resultado no concurso IBM inSites.........................................213

J.2 itSIMPLE..................................................................215

J.2.1 Produção acadêmica..............................................................216

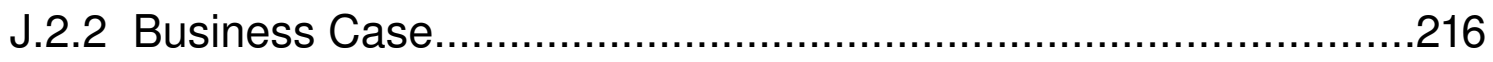

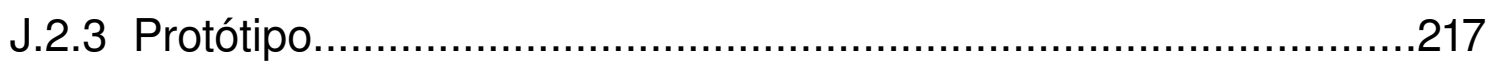

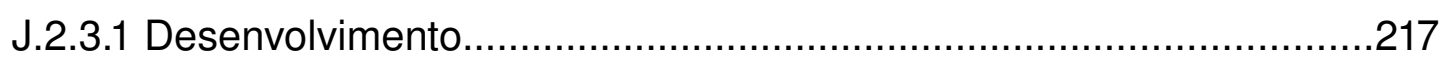

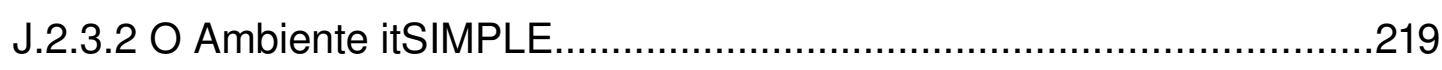

J.2.4 Resultado no concurso IBM inSites........................................222

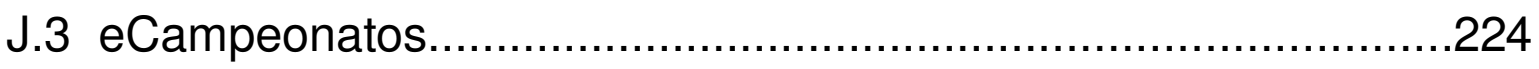

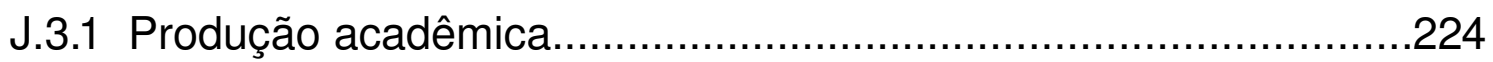




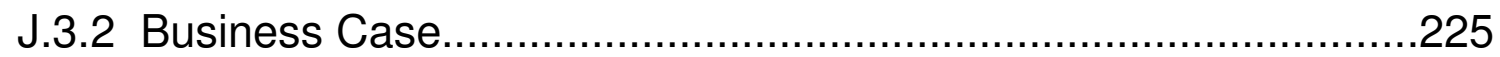

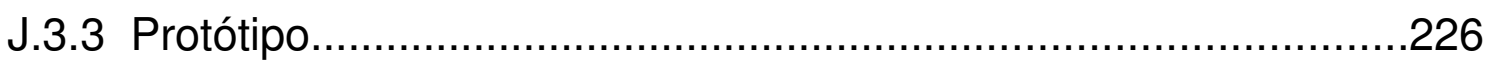

J.3.3.1 O Assistente de Competições......................................................226

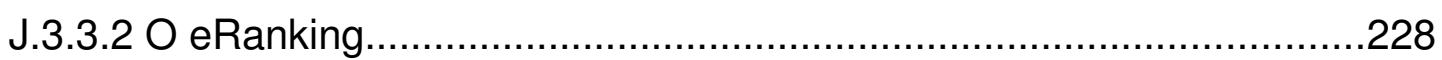

J.3.4 Resultado no concurso IBM inSites........................................229

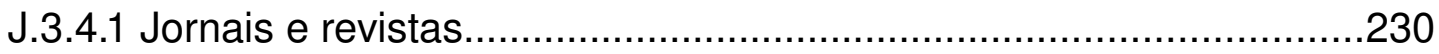

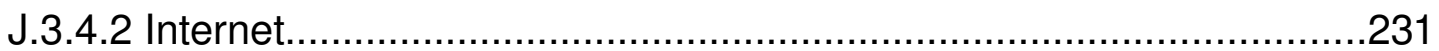

J.4 Referências....................................................................232 


\section{Lista de Figuras}

Figura 2.1: Classificação do Design. Adaptado de Bertoline e Nasman, 1996...........11

Figura 2.2: Os envolvidos no design. Adaptado de Dym e Little, 2000......................11

Figura 2.3: Engenharia de Requisitos. Adaptado de Sommerville e Sawyer, 1997...16

Figura 3.1: Perspectivas na Eliciação de Requisitos...............................................26

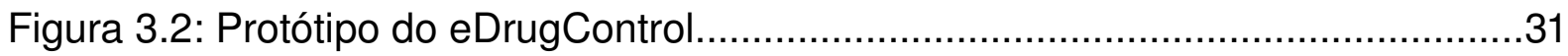

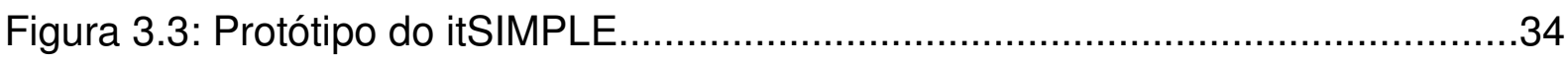

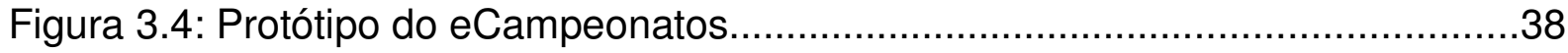

Figura 3.5: Protótipo do portal eCampeonatos.....................................................39

Figura 4.1: Perspectivas da Eliciação de Requisitos, com a Perspectiva Gerencial.. 43

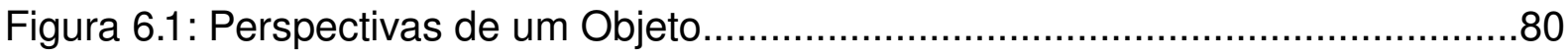

Figura 6.2: Perspectivas de Observação de um Projeto.............................................. 81

Figura 6.3: Perspectivas da Eliciação de Requisitos, com a Perspectiva Gerencial.. 86

Figura 6.4: Cálculo do volaRE dos requisitos observados.....................................90

Figura C.1: Regiões do template de design.....................................................112

Figura E.1: Relação entre erros de medicação e eventos adversos (IOM, 2006).....134

Figura E.2: Possíveis causas de erro (De Carvalho, 2002)...................................136

Figura G.1: Perfil do projeto Jogos da Cidade como Governo Eletrônico..................174

Figura G.2: Dados dos Jogos da Cidade........................................................176

Figura H.1: Custo para corrigir erros X Fase do Projeto........................................183

Figura H.2: Crescimento médio anual da área de TI de 2005 até 2009..................184

Figura I.1: A integração de linguagens no itSIMPLE (Santos et al., 2005)..............197

Figura I.2: Exemplo de Caso de Uso do problema clássico de elevadores...............202

Figura I.3: Diagrama de Classes do problema clássico dos Elevadores..................203

Figura I.4: Diagrama de Estados da classe Passageiro dos Elevadores..................204

Figura I.5: Exemplo de Diagrama de Objetos do problema dos Elevadores............205

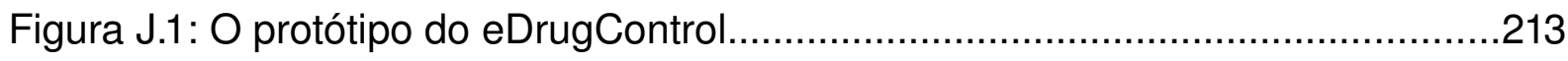

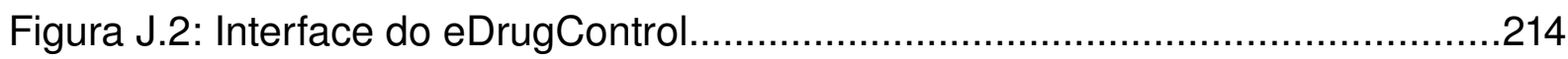




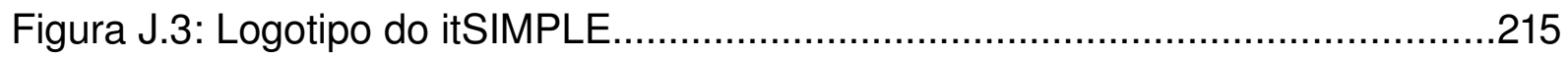

Figura J.4: Exemplo de Caso de Uso do problema clássico de elevadores.............219

Figura J.5: Diagrama de Classes do problema clássico dos Elevadores..................220

Figura J.6: Diagrama de Estados da classe Passageiro dos Elevadores.................221

Figura J.7: Exemplo de Diagrama de Objetos do problema dos Elevadores...........222

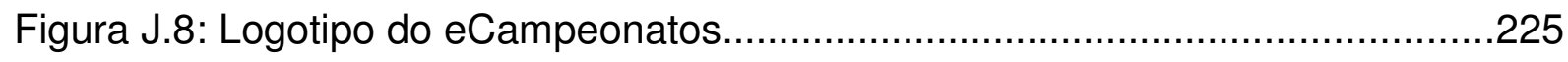

Figura J.9: Home page do acesso restrito do eCampeonatos................................226

Figura J.10: O assistente de competições do eCampeonatos..................................227

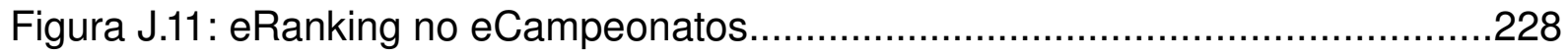

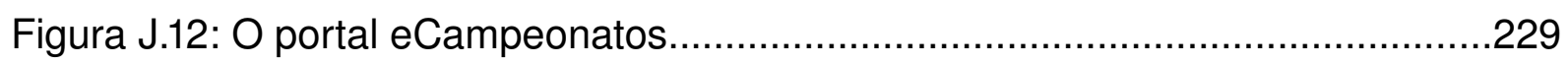




\section{Lista de Tabelas}

Tabela 1.1: CHAOS Report de 1994 a 2004. Adaptado de Standish Group, 2005.......5

Tabela 3.1: Requisitos de Negócio do eDrugControl.............................................29

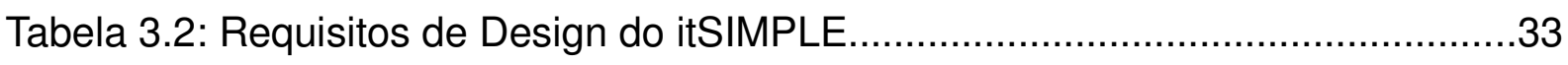

Tabela 3.3: Requisitos Operacionais do eCampeonatos.........................................37

Tabela 4.1: Visualização da intenção do requisito de negócio Neg.003.....................46

Tabela 4.2: Aplicação da Intenção de Negócio no requisito Neg.003........................48

Tabela 4.3: Visualização da intenção do requisito operacional Oper.009....................51

Tabela 4.4: Aplicação da Intenção Operacional no requisito Oper.009.......................52

Tabela 4.5: Visualização da intenção do requisito de design Des.003........................56

Tabela 4.6: Aplicação da Intenção de Design no requisito Des.003...........................57

Tabela 4.7: Visualização da intenção do requisito de negócio Ger.001.......................60

Tabela 4.8: Aplicação da Intenção Gerencial no requisito Ger.001 ...........................61

Tabela 5.1: Classificação da aprovação de um requisito............................................64

Tabela 5.2: Índice de aprovação das perspectivas no requisito Neg.003...................67

Tabela 5.3: Características não definidas das perspectivas do requisito Neg.003....67

Tabela 5.4: Índice de aprovação das perspectivas no requisito Oper.009..................69

Tabela 5.5: Características não definidas das perspectivas do requisito Oper.009...69

Tabela 5.6: Índice da aprovação das perspectivas do requisito Des.003...................71

Tabela 5.7: Características não definidas das perspectivas do requisito Des.003....72

Tabela 5.8: Índice de aprovação das perspectivas no requisito Ger.001 ....................73

Tabela 5.9: Características não definidas das perspectivas do requisito Ger.001 ......74

Tabela 6.1: Situação dos projetos de Automação da Farmácia Hospitalar..................82

Tabela 6.2: Observações das Perspectivas na Eliciação de Requisitos.......................87

Tabela 6.3: Percentual de características não percebidas por perspectiva..................88

Tabela 6.4: Índice de Aprovação das perspectivas e suas médias............................89

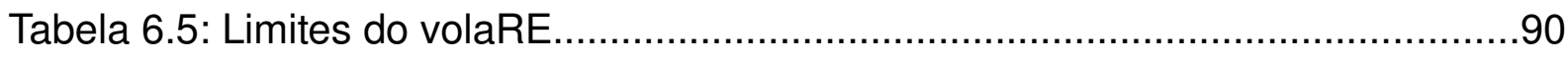

Tabela 6.6: Percentual do volaRE dos projetos observados....................................91 
Tabela 6.7: Possíveis aplicações das propostas do trabalho...................................92

Tabela A.1: Equivalências do template operacional.............................................108

Tabela D.1: Informações sobre a Farmácia Hospitalar no Brasil.............................120

Tabela E.1: Prescrição e seleção de drogas para o paciente (IOM, 2006)...............134

Tabela E.2: Dispensação do medicamento (IOM, 2006).......................................135

Tabela E.3: Administração do medicamento (IOM, 2006).......................................135

Tabela H.1: Segmentação do mercado de software e serviços no Brasil..................186

Tabela I.1: Viewpoints X Diagramas UML.......................................................199 


\title{
Lista de Abreviaturas
}

\author{
Intent $_{\text {Neg Intenção de Negócio }}$

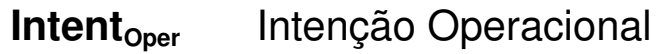 \\ Intent $_{\text {Des }}$ Intenção de Design \\ Intent $_{\text {Ger Intenção Gerencial }}$
}

volaRE Indica a volatilidade de um requisito 



\section{Parte I}

Apresentação 


\section{Introdução}

A diversidade de bens e serviços oferecidos pelas organizações tem sido ampliada, a cada dia, no sentido de atender a demanda dos consumidores atuais. Há pouco tempo não existia essa demanda, o que permitia às instituições fornecedoras desses bens e serviços maior controle na oferta dos mesmos. Segundo Pine (1993), a oferta de bens e serviços personalizados vem da necessidade das empresas em se manterem competitivas, além da demanda do mercado por produtos que atendam suas expectativas.

O processo de desenvolvimento de ambientes que permitam a criação de soluções de negócio, com as devidas verificações dos modelos gerados nas diversas fases do projeto, sobretudo aqueles modelos das fases iniciais, precisa considerar a integração dos pontos de vista envolvidos na cadeia de fornecimento, que inclui neste caso as empresas desenvolvedoras, as empresas que fabricam os bens e serviços e os consumidores finais. Ao processo que garanta a integração das etapas de fabricação, passando pelas metas definidas nos planos de negócios até a interação do consumidor final, denomina-se Design em Engenharia, que busca aplicar a automação de forma a garantir a satisfação das expectativas dos envolvidos. A grande demanda para a personalização está ligada diretamente à Engenharia de Requisitos, ou seja, um tratamento para a mudança dos requisitos é o que se pretende desenvolver neste trabalho.

Neste sentido, a proposta é possibilitar que as solicitações de mudanças nos requisitos sejam eliciadas com maior clareza, verificadas através de prototipagem com base nas necessidades de cada envolvido no processo de definição dos 
requisitos.

\subsection{Problema}

O problema da pesquisa está na tendência crescente de projetos que apresentam falhas, gerando atrasos e gastos que poderiam ser evitados caso o entendimento das necessidades fosse maximizado.

A premissa da pesquisa é a de que a falta de estruturação no levantamento de requisitos pode levar a especificações incompletas.

\subsection{Justificativa}

A relevância do tema da pesquisa se deve ao número crescente de projetos que apresentam falhas, tanto em prazos quanto em custos (BOEHM, 1995) e, segundo constatação do CHAOS Report (The Standish Group International, Inc., 1995, 2005), conforme mostra a tabela 1.1, nos últimos anos os problemas apresentados por esses projetos estão relacionados com os requisitos que possuem especificação fraca. 
Tabela 1.1: CHAOS Report de 1994 a 2004. Adaptado de Standish Group, 2005

\begin{tabular}{|l|r|r|r|r|r|r|}
\hline \multicolumn{1}{|c|}{ Projetos } & $\mathbf{1 9 9 4}$ & $\mathbf{1 9 9 6}$ & $\mathbf{1 9 9 8}$ & $\mathbf{2 0 0 0}$ & $\mathbf{2 0 0 2}$ & $\mathbf{2 0 0 4}$ \\
\hline Bem-sucedidos & $16 \%$ & $27 \%$ & $26 \%$ & $28 \%$ & $34 \%$ & $29 \%$ \\
\hline Cancelados & $31 \%$ & $40 \%$ & $28 \%$ & $23 \%$ & $15 \%$ & $18 \%$ \\
\hline Com problemas & $53 \%$ & $33 \%$ & $46 \%$ & $49 \%$ & $51 \%$ & $53 \%$ \\
\hline
\end{tabular}

Os problemas apresentados nos projetos, decorrentes da deficiência dos requisitos, geram custos elevados para a correção dos erros. Segundo Carr (2000), a correção de erros na fase de produção chega a custar 500 vezes mais do que se fosse corrigido na fase de requisitos.

\subsection{Objetivos}

Os objetivos do trabalho são:

1. Conhecer parte dos resultados que a prototipação baseada em perspectivas pode proporcionar para a fase de eliciação de requisitos;

2. Observar a intenção dos envolvidos no processo de eliciação de requisitos;

3. Reduzir a volatilidade dos requisitos através da identificação da mesma ainda na fase de eliciação de requisitos. 


\subsection{Organização do trabalho}

Na primeira parte, o trabalho é apresentado através desta introdução. Na segunda parte é detalhado o desenvolvimento da pesquisa, descrevendo a revisão da literatura, a metodologia e a proposta do trabalho. Os resultados do trabalho são apresentados e discutidos na parte III. Na última parte são encontrados os apêndices que suportam o texto desta tese. 


\section{Parte II} Desenvolvimento 


\section{Revisão da Literatura}

Este capítulo apresenta a revisão da literatura, destacando o levantamento das propostas de pesquisas encontradas que tratam desde os conceitos de Design até aqueles que abordam a característica de mudança que os requisitos apresentam.

Além da contribuição teórica acadêmica, os trabalhos e soluções propostos são apresentados, acompanhados de uma análise que mostra a relevância de cada um deles, relacionada com o tema deste trabalho.

Por fim, são exploradas as lacunas observadas nas propostas, no sentido de apontar o que seria necessário para facilitar a identificação da característica de mudança nos requisitos.

\subsection{Design em Engenharia}

A necessidade de desenvolvimento de bens de consumo e serviços acompanha a humanidade desde os primórdios. Ao processo de criação de novos artefatos, ou de adaptação dos existentes, se denomina design. Para as atividades de criação são exigidos conhecimentos e habilidades de quem as executa, de forma que a experiência desse profissional influencia muito no resultado final do artefato. 
Via de regra, novos artefatos (ou adaptação dos existentes) são solicitados por indivíduos ou organizações que, observando a demanda ou necessidade de uma parcela da população, empreendem o desenvolvimento desses bens ou serviços.

A proposta do Design ${ }^{1}$ em Engenharia é o estabelecimento de um processo que propicie um desenvolvimento de artefatos com maior aceitação, tanto pelos empreendedores quanto pela parcela da população usuária do mesmo. Este processo visa dar o suporte para as atividades de design, permitindo que as reais necessidades dos envolvidos no desenvolvimento do artefato sejam atendidas.

Assim, a disciplina de Design em Engenharia tem despertado o interesse de diversas pesquisas. Primeiro pela complexidade do tema, que exige o envolvimento de pessoas com diferentes formações, ou seja, equipes multidisciplinares. Depois, pelo fato de ainda não haver um consenso, a princípio, entre suas definições.

A justificativa para tal complexidade pode ser encontrada nas definições do termo, que é derivado da palavra design. Segundo o dicionário Webster's (1998), design é "a representação de uma idéia, uma criação ou um plano". Já Bertoline e Nasman (1996) definem design como "... o processo de conceber ou criar idéias [...] e comunicá-las com outras pessoas". Ainda segundo Bertoline e Nasman, o design pode ser classificado em artístico ou técnico, conforme ilustra a figura 2.1, onde Design em Engenharia representa o design técnico, que por sua vez está ligado com o desenvolvimento de produtos e processos, conforme afirma Ogot e Kremer (2004).

Várias definições podem ser encontradas para Design em Engenharia. Dym e Little (2000) descrevem os problemas de Design em Engenharia como tendo várias soluções possíveis e que uma solução não pode ser encontrada simplesmente com

1 No contexto deste trabalho, a palavra design será utilizada para representar criação, elaboração ou planejamento. O profissional que executa esta tarefa será chamado designer. 
a aplicação de uma fórmula matemática. Além disso, tempo e orçamento são limitações importantes para o processo de design e, em função disso, o resultado dificilmente será a melhor solução técnica, mas certamente uma solução que atenderá as restrições do projeto.

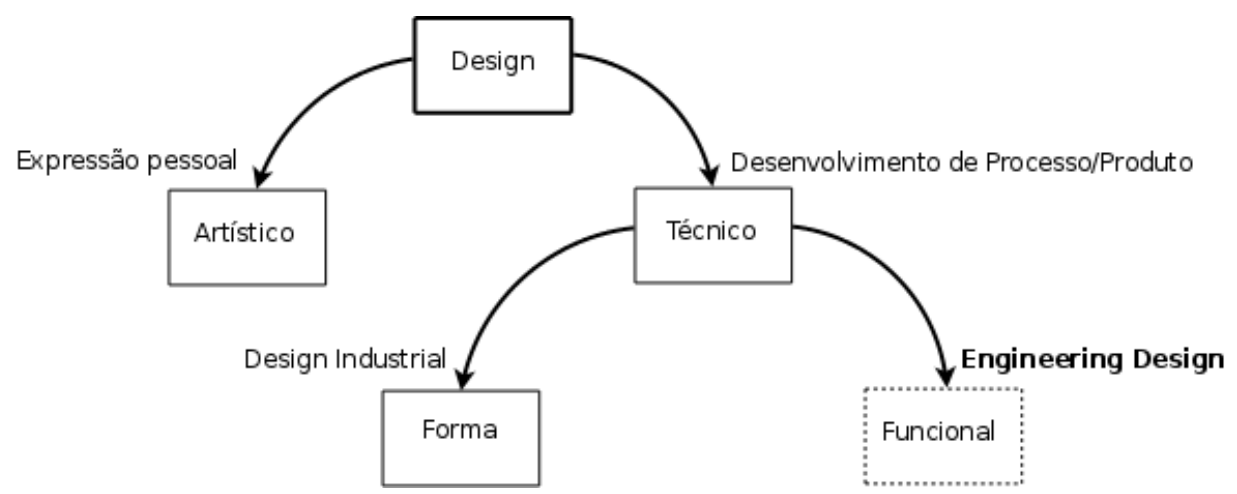

Figura 2.1: Classificação do Design. Adaptado de Bertoline e Nasman, 1996.

Dym e Little (2000) definem que esses envolvidos, conforme mostra a figura 2.2, são o cliente, cujos objetivos precisam ser esclarecidos pelo designer; o usuário, que possui suas próprias expectativas com relação ao artefato e o designer, que precisa criar algo que satisfaça todos os envolvidos.

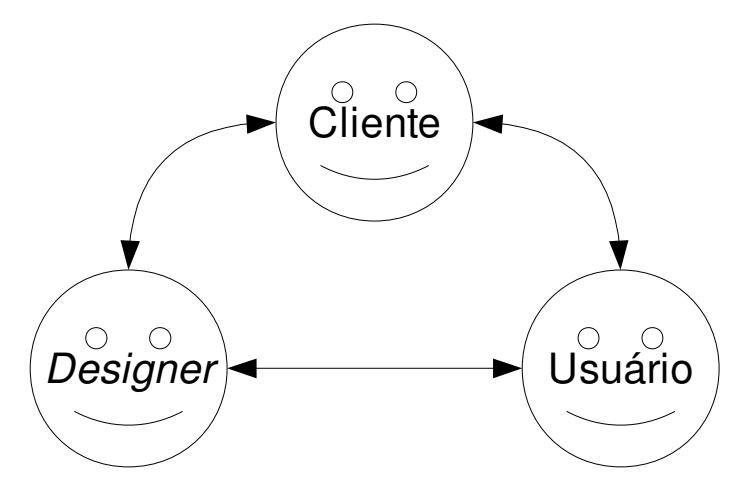

Figura 2.2: Os envolvidos no design. Adaptado de Dym e Little, 2000.

A partir da evolução da sociedade, mais e mais artefatos foram sendo 
desenvolvidos, até que recentemente bens e serviços ligados à Tecnologia da Informação se incorporaram ao nosso cotidiano. Atualmente, esses bens e serviços exercem papel essencial para alguns segmentos da indústria, e não se pode negar a importância que eles representam para a Sociedade e para o moderno processo de acumulação de riquezas.

As organizações empresariais, na sua maioria, vêem a Tecnologia da Informação como um facilitador para se buscar a melhoria de seus processos de negócio e assim permitir realizar alterações no curso das atividades empresariais no sentido de se adequar às mudanças do mercado (DAVENPORT; MARCHAND; DICKSON, 2004).

A adoção dos recursos de tecnologia, entretanto, está diretamente associada à opinião das pessoas que possuem o poder de decisão nas organizações, além de como a empresa se posiciona estrategicamente no mercado e qual o entendimento que possui sobre investimento em Tecnologia da Informação (LAURINDO, 2002).

Um fator importante quanto à adoção de recursos tecnológicos está ligado ao posicionamento dos usuários da tecnologia. Algumas pesquisas apontam que a participação deles no processo de definição é fundamental para que as soluções de tecnologia sejam efetivamente utilizadas na organização, pois Karahanna; Straub e Chervany (1999) mostram que a imposição de soluções tende ao fracasso. Além deste ponto, tais usuários detêm conhecimento do negócio que é fundamental para o desenvolvimento e aprimoramento de processos que envolvam tecnologia, pois são eles os responsáveis pelo desempenho das organizações no meio que elas operam. 


\subsubsection{Mudanças no Processo de Design}

Segundo Pine (1993), a tecnologia tem desempenhado um papel importante para o alcance da personalização de bens e serviços. Como exemplo disso, nas indústrias de manufatura podem ser encontrados processos produtivos controlados por controladores lógicos programáveis (CLP) e robôs, o que "aumenta a flexibilidade de fabricação, controlando partes a serem produzidas através de programas de computador".

Percebe-se que da necessidade de desenvolvimento de soluções em Tecnologia da Informação aderentes às expectativas do mercado somadas com a constante evolução do hardware, surgiram também várias propostas de técnicas, métodos, linguagens de programação e processos que suportam o desenvolvimento desses novos artefatos, surgindo assim o Processo Unificado de Desenvolvimento de Software (JACOBSON; BOOCH; RUMBAUGH, 1999).

Por outro lado, em função da aposta nessas tecnologias, alguns problemas surgem com a introdução dessas abordagens, pois precisam tratar de uma forma adequada a mudança dos requisitos do novo negócio, voltado para a personalização de bens e serviços. Para ilustrar, em 1995 foi constatado pelo Standish Group (The Standish Group International, Inc., 1995) que o desenvolvimento de projetos de Tecnologia da Informação se aproximava do caos. De 8.380 projetos analisados, $31 \%$ seriam cancelados antes de serem finalizados, $53 \%$ apresentariam problemas relacionados a tempo e orçamento ultrapassados, se comparados com o previsto. Somente $16 \%$ seriam concluídos com sucesso. Dos projetos que apresentariam problemas com prazo e custo, $12 \%$ se devem a especificações e requisitos incompletos e $12 \%$ à alteração nas especificações e requisitos. 
O processo de design necessita de maior auxílio nas fases iniciais de requisitos, sobretudo em função da demanda para bens e produtos que requerem um tratamento especial para os requisitos que mudam com freqüência.

\subsection{Requisitos}

Entender as necessidades para o desenvolvimento de um produto, cujo resultado seja um projeto com prazo, custo e qualidade dentro do que esperavam os interessados, tem sido uma tarefa difícil. $\mathrm{Na}$ área de desenvolvimento de software, o CHAOS Report, uma série de pesquisas do Standish Group (The Standish Group International, Inc., 1995, 2005) publicada a cada dois anos, tem apontado que os projetos falham numa combinação das variáveis prazo, custo e qualidade. Apesar dos esforços da comunidade acadêmica e do mercado, que nos anos 90 resultou na proposta do Processo Unificado de Desenvolvimento de Software (JACOBSON; BOOCH; RUMBAUGH, 1999), ainda em 2005 o CHAOS Report (The Standish Group International, Inc., 2005) continua detectando falhas, desta vez atribuídas à mudança e gerenciamento de requisitos. Neste ponto percebe-se que a proposta do Processo Unificado de Desenvolvimento de Software (JACOBSON; BOOCH; RUMBAUGH, 1999) auxilia sobremaneira o desenvolvimento de projetos de Tecnologia da Informação, porém a fase de requisitos é apoiada em representação textual do detalhamento de Casos de Uso (Use Cases).

São várias as definições de requisitos encontradas na literatura, como podem ser observadas em (THAYER; DORFMAN, 1990; SOMMERVILLE; SAWYER, 1997). 
Uma definição bem aceita na comunidade é a do IEEE $^{2}$, que define:

"Requisito é3:

1. uma condição ou capacidade necessária para um usuário resolver um problema ou atingir um objetivo;

2. uma condição ou capacidade que um sistema, ou componente dele, deve possuir para satisfazer um contrato, padrão, especificação ou outro documento formalmente imposto;

2. uma representação documentada de uma condição ou capacidade, como definido em (1) ou (2)."

Em função da complexidade das atividades relacionadas ao entendimento dos requisitos, da área de Engenharia de Software surgiu a Engenharia de Requisitos, que se propõe a sistematizar essas atividades. Várias têm sido as propostas de processos (SOMMERVILLE; SAWYER, 1997; CARLSHAMRE; REGNELL, 2000; KOTONYA; SOMMERVILLE, 1996) que apóiem tais tarefas.

2 Institute of Electrical and Electronics Engineers.

3 Tradução livre do autor. 


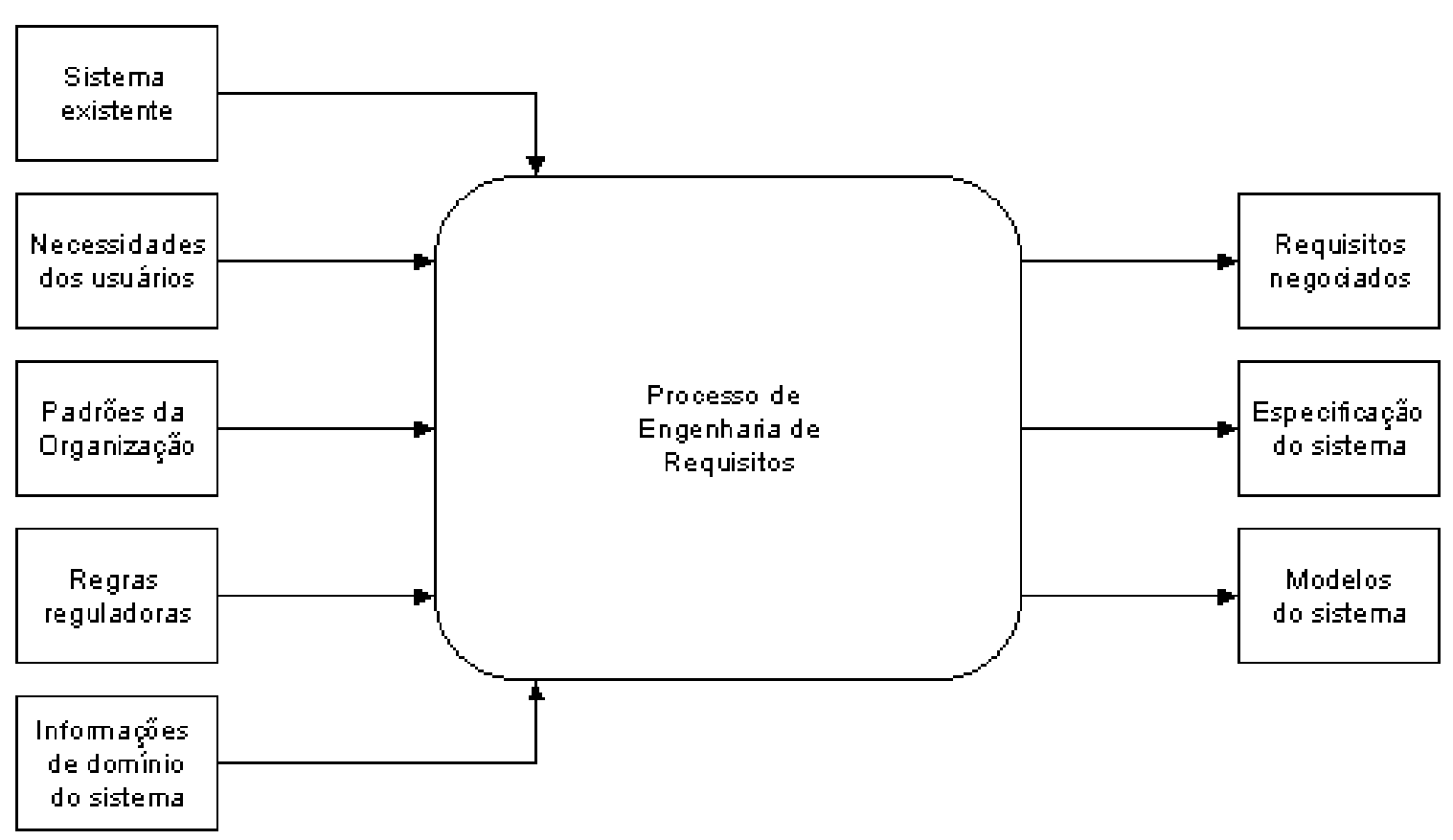

Figura 2.3: Engenharia de Requisitos. Adaptado de Sommerville e Sawyer, 1997.

No Processo de Engenharia de Requisitos, proposto por Sommerville e Sawyer (1997), são identificadas as entradas e saídas do processo, devendo resultar, sobretudo, no documento de especificação do sistema a ser desenvolvido, como ilustra a figura 2.3. Em Carlshamre e Regnell (2000) é apresentada uma comparação entre dois processos de requisitos, baseados em ciclo de vida: O REPEAT (Requirements Engineering Process At Telelogic) desenvolvido e utilizado pela Telelogic AB e o RDEM (Requirements Driven Evolution Model), criado para ser utilizado na Ericsson Radio Systems AB. As propostas focam o gerenciamento dos requisitos, em função da necessidade que as empresas possuem relacionadas a condução de seus projetos, atendendo melhor a demanda do mercado que atuam.

Segundo Carr (2000), a relação entre o custo para reparar um erro detectado nas diversas fases do ciclo de vida do desenvolvimento de um sistema aumenta a medida que as etapas vão passando. Erros corrigidos na fase de produção podem custar até 500 vezes mais do que se fosse corrigido na fase de requisitos. A causa 
raiz do sucesso ou falha no desenvolvimento de um sistema está relacionada, segundo Leffingwell e Widrig (2000), com os requisitos do sistema. Na primeira versão do CHAOS Report (The Standish Group International, Inc., 1995) foram identificados, através de 3800 respostas objetivando determinar os principais problemas encontrados no desenvolvimento de software, os dois principais problemas: especificação de requisitos e gerenciamento dos requisitos.

Isto se deve, de certa forma, à necessidade que as empresas possuem em se adequarem aos seus clientes. Ou seja, seus processos de negócios devem ter uma ligação direta com seus processos produtivos e de serviços. A observação bem feita dessa mudança do mercado pode levar a uma resposta da empresa que resulte no diferencial competitivo que a mesma busca.

\subsubsection{Mudanças nos Requisitos}

Por quê os requisitos mudam? Como afirma Hoorn (2006), "as pessoas mudam de idéia com freqüência" e, desta forma, as organizações precisam adequar seus produtos para atender a demanda gerada em função das necessidades apontadas pelas pessoas. Além disso, como ilustrado na figura 2.3, existem outros fatores que influenciam as mudanças nos requisitos. Por exemplo, os negócios da área de alimentação estão se adaptando à mudança da lei do Estado de São Paulo sobre a emissão de cupom fiscal, que a partir de pouco tempo precisarão emitir o comprovante com os dados pessoais daqueles que assim desejarem.

Os requisitos podem ser classificados quanto à sua característica de mudança: Os 
estáveis, associados àqueles requisitos que não sofrem alterações. Para exemplificar, é possível que a maioria concorde com o requisito de que uma ligação telefônica deva ser audível. Entretanto, não é de se esperar que a maioria concorde com o requisito de que uma ligação deva ser feita a partir de linha telefônica fixa, por ser mais econômica. Estes requisitos que podem mudar, pelo fato de não haver concordância entre a maioria dos envolvidos, são classificados em requisitos voláteis.

O processo de entendimento e análise das necessidades do sistema a ser especificado é a eliciação de requisitos, que busca detectar a importância de cada envolvido com o sistema e as suas reais necessidades, considerando as restrições que o projeto deve atender. Segundo Kotonya e Sommerville (1998), esta análise deve compreender: i) o entendimento do domínio da aplicação; ii) o entendimento do problema; iii) o entendimento do negócio e iv) o entendimento das necessidades e restrições.

As atividades da fase de eliciação de requisitos resultam em uma especificação preliminar que deverá ser analisada e negociada com os envolvidos e, de acordo com Nuseibeh e Easterbrook (2000), compreendem as atividades a seguir: verificação das necessidades, verificação de consistência e integridade e verificação de viabilidade.

Ainda segundo Nuseibeh e Easterbrook (2000), as técnicas de eliciação (MAIDEN; RUGG, 1996; MAIDEN; RUGG; PATEL, 1999; VAN LAMSWEERDE; DARIMONT; LETIER, 1998; SHAW; GAINES, 1996; VILLER; SOMMERVILLE, 1999) podem ser agrupadas nas seguintes classes: i) técnicas tradicionais: baseada na utilização de técnicas genéricas para coleta de dados e informações como questionários, entrevistas e a análise da documentação existente; ii) eliciação em grupo: baseada em dinâmicas de grupo e reuniões entre os interessados; iii) prototipação: técnica 
geralmente utilizada para sistemas inovadores ou quando existem muitas incertezas relacionadas com os requisitos; iv) orientada a modelo: especifica um modelo para cada tipo de informação, que direciona as atividades de eliciação de requisitos; v) cognitiva: baseada em técnicas de aquisição de conhecimento destinadas a sistema baseados em conhecimento e vi) contextuais: alternativa para as técnicas tradicionais e cognitivas, baseada em técnicas etnográficas de observação.

O principal problema observado na eliciação de requisitos, segundo Queiroz (2007), é a "distância entre domínios", ou seja, quando o conhecimento do profissional de design é pouco, ou nenhum, sobre a área na qual o problema está sendo tratado.

Algumas contribuições para a eliciação de requisitos foram propostas, no sentido de capturar a necessidade dos envolvidos segundo o seu ponto de vista. Ross e Schoman (1977) propuseram o SADT (Structured Analysis and Design Technique), Mullery (1979) propôs o CORE (COntrolled Requirement Expression), Finkelstein et al. (1992) elaboraram o VOSE (Viewpoint Oriented System Engineering) e Kotonya e Sommerville (1996) propuseram o VORD (Viewpoint Oriented System Definition).

Para Kotonya e Sommerville (1998) não existe um método ideal para a engenharia de requisitos, pois poucos métodos possuem todos os atributos necessários.

\subsubsection{Gerenciamento de Requisitos}

Em Leffingwell e Widrig (2000) pode ser encontrada uma proposta de gerenciamento de requisitos, que se baseia na formação adequada das equipes, que geralmente 
são multi-disciplinares. As equipes são agrupadas segundo sua especialização e realizam as atividades de: i) análise do problema; ii) entendimento das necessidades dos envolvidos; iii) definição do sistema; iv) gerenciamento do escopo; v) refinamento da definição do sistema e vi) construção do sistema.

Segundo Pressman (2006), o gerenciamento de requisitos visa auxiliar as equipes responsáveis pelo ciclo de vida dos requisitos nas atividades de identificação, controle e rastreamento dos requisitos e suas alterações. No mesmo sentido, Kotonya e Sommerville (1998) entendem que este é um processo de gestão das mudanças que ocorrem nos requisitos, oriundas de uma melhor compreensão das reais necessidades dos envolvidos na especificação do sistema. Segundo eles, o processo de gerenciamento de requisitos possui três pontos principais: i) gerenciamento dos requisitos negociados; ii) controle da relação de dependência entre os requisitos e iii) gerenciamento das dependências entre especificações de requisitos durante o ciclo de vida do projeto.

A medida que o entendimento do sistema pelos envolvidos evolui, assim como os ambientes político, organizacional e técnico onde o sistema está inserido, passam a acontecer mudanças nos requisitos.

A verificação dos requisitos nas diversas fases do ciclo de vida passa a ser, desta forma, um desafio. Santos (2002) propôs a verificação de requisitos a partir da estruturação de Casos de Usos, que permitiu a análise de sistemas flexíveis de manufatura (SILVA; SANTOS; VAQUERO, 2005). No mesmo sentido, uma proposta recente (VAQUERO ET AL., 2007) passa a considerar os pontos de vista dos envolvidos no projeto, uma vez que a verificação isolada dos requisitos pode gerar dificuldades na negociação dos mesmos. 


\subsection{Considerações}

Apesar dos esforços relacionados com o design e entendimento dos requisitos de um produto, verificados nas seções anteriores, em 2005 o Standish Group (The Standish Group International, Inc., 2005) divulgou o resultado do CHAOS Report, que pode ser observado na tabela 1.1 junto aos demais anos nos quais a pesquisa foi realizada.

Os dados da pesquisa mostram que os projetos que apresentam problemas com prazo e custos voltaram a representar a maioria deles. Como visto anteriormente, as duas principais causas, conforme identificou Leffingwell e Widrig (2000), são mudanças e gestão de requisitos.

As mudanças necessárias, ou seja, aquelas que acontecem por necessidades de adequação do negócio às realidades do mercado continuarão acontecendo e precisam de um tratamento diferenciado.

Os números da pesquisa do Standish Group, conforme tabela 1.1, mostram que ainda não existe um tratamento satisfatório para o gerenciamento de mudanças nos requisitos, e que as conseqüências disso pode ser o aumento do número de projetos que continuarão apresentando problemas com prazos e custos.

Observa-se que o design das soluções precisa considerar a necessidade de evolução dos produtos, que precisam se adequar às mudanças que acontecem no mercado que os demanda. Ou seja, o negócio deve ser planejado para mudanças. $O$ plano de negócios deve prever mecanismos para adequações, utilizando na medida do possível as boas práticas de negócios, hoje já disponibilizadas na forma de 
templates de negócio, tal como o MIT Process Handbook (MALONE; CROWSTON; HERMAN, 2003). O arranjo desses templates de negócio deve ser estruturado de forma a atender a missão do negócio, porém deve possuir flexibilidade para que as alterações que se fizerem necessárias ao longo da vida da organização sejam rapidamente implementadas. No mesmo sentido, a equipe de design deve proporcionar uma infra-estrutura flexível, permitindo que as necessidades de alterações do negócio e as evoluções da tecnologia sejam adequadamente desenvolvidas. Uma arquitetura baseada em frameworks, aderentes à proposta de Zachman (1999), por exemplo, podem facilitar essa flexibilidade. A utilização de componentes básicos de hardware e software, projetados para atender as necessidades do negócio, também podem facilitar as mudanças necessárias.

O conceito de reconhecimento da intenção das pessoas que escrevem textos (SAID; EVRARD, 2001; HASSAN; CHANTAL; SAID, 2007), pode ser utilizado no processo de eliciação de requisitos para auxiliar no entendimento das reais necessidades dos envolvidos na definição dos requisitos.

O desafio, portanto, é a concepção de técnicas que permitam o tratamento adequado das mudanças dos requisitos, suportados por processos de engenharia de requisitos igualmente adequados à essa realidade, permitindo assim 0 gerenciamento e a concepção de artefatos que atendam as expectativas de todos os envolvidos no processo de design.

\subsection{Metodologia}

O desenvolvimento do trabalho teve como início a coleta de dados, que se deu a 
partir da observação isolada de projetos de inovação em Tecnologia da Informação, envolvendo pesquisadores do d-lab, laboratório de Design de Sistemas do departamento de Engenharia Mecatrônica da Escola Politécnica da USP e profissionais do grupoe, empreendedores que desenvolvem atividades de pesquisa no d-lab.

Nessa etapa objetivou-se conhecer o resultado que uma proposta de prototipação baseada em perspectivas traz para a eliciação de requisitos, que é baseada em viewpoints (KOTONYA; SOMMERVILLE, 1996) e nos conceitos do design de artefatos proposto por Dym e Little (2000).

Desta forma, três projetos foram escolhidos para a coleta de dados, sendo cada um deles abordado com foco especial em uma das perspectivas pesquisadas: do negócio, da operação e de design. Estes projetos serão os estudos de caso, onde os dados neles observados servirão para validar a fórmula proposta.

O próximo passo foi identificar a intenção, com base nas propostas publicadas (SAID; EVRARD, 2001; HASSAN; CHANTAL; SAID, 2007), que os envolvidos tinham quando apresentavam as solicitações de requisitos do projeto, incluindo também as solicitações de alterações de requisitos, permitindo assim que um modelo de identificação de intenção fosse proposto para cada perspectiva.

A identificação da volatilidade dos requisitos baseada em perspectivas foi a etapa final do trabalho, que teve como objetivo minimizar a necessidade de mudança dos requisitos em função de eventual deficiência no detalhamento dos mesmos na fase de eliciação. 


\section{Proposta}

\subsection{Perspectivas na Eliciação de Requisitos}

Tomando como base os conceitos da proposta de Kotonya e Sommerville (1996), que sugerem que a definição de requisitos seja feita a partir de pontos de vista, e também de Dym e Little (2000), de que o design de artefatos considere os pontos de vista do cliente, do usuário e do designer, e neste trabalho os pontos de vistas dos envolvidos no processo de eliciação de requisitos são denominados perspectivas.

Outra motivação para se propor que a eliciação de requisitos seja feita por perspectivas vem da constatação de que as mudanças nos requisitos ocorrem, segundo Hoorn (2006), de acordo com os objetivos e prioridades das pessoas envolvidas no processo de definição dos requisitos. Sendo assim, a separação na abordagem de cada envolvido no projeto deve deixar clara a necessidade de sua perspectiva.

Os projetos foram observados segundo as perspectivas do negócio, da operação e do design, baseadas na proposta de Dym e Little (2000), ilustradas na figura 3.1. 


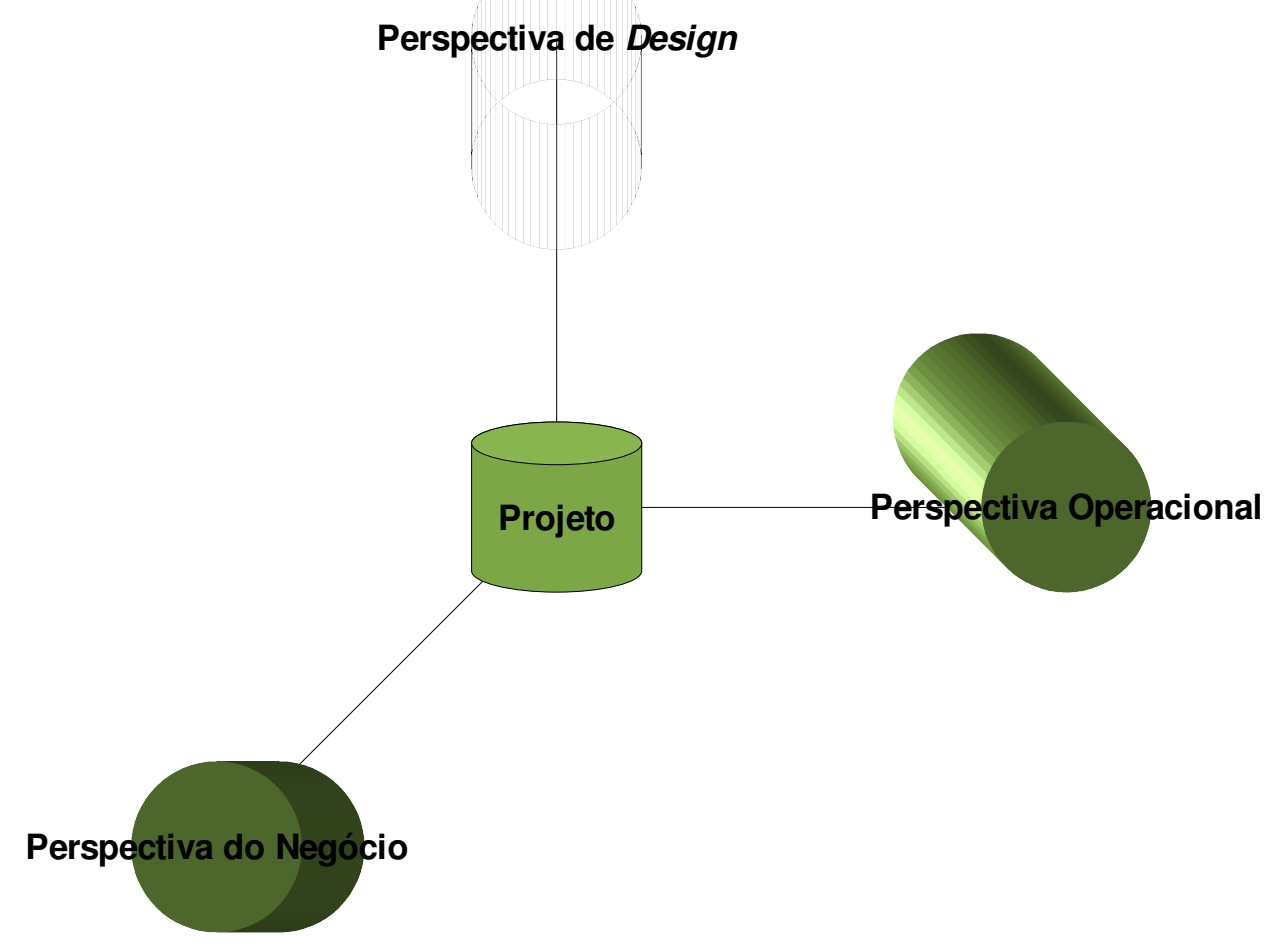

Figura 3.1: Perspectivas na Eliciação de Requisitos.

A seção a seguir apresenta a abordagem utilizada neste trabalho para compreender como a prototipação, com base nas perspectivas descritas, pode contribuir para a fase de eliciação de requisitos.

\subsection{Observação da Prototipação baseada em Perspectivas}

Com base na proposta de verificação de requisitos apresentada por Santos (2002), que permite a representação de requisitos a partir de casos de uso estruturados, este trabalho parte da hipótese de que a prototipação pode ser um mecanismo facilitador para as atividades da fase inicial do processo de engenharia de requisitos, 
a eliciação de requisitos.

Para se conhecer o resultado da aplicação da hipótese acima, foi desenvolvido um simples template de software que permite a prototipação de cadastro de informações de um projeto qualquer de Sistema de Informação. O template de software utilizado na prototipação está descrito no Apêndice A - Template Operacional, e permite que, a partir do fornecimento de uma classe e seus atributos, já se tenha o comportamento de cadastro, assim como de alteração e de pesquisa das instâncias dessa classe em um protótipo implementado em tecnologia Web.

A partir desse template de software, observou-se o desenvolvimento de três (03) projetos inovadores em Tecnologia de Informação, executados com o apoio do d-lab: o eDrugControl, que busca o desenvolvimento de novas interfaces que possam auxiliar os envolvidos nas atividades da Farmácia Hospitalar. Outro projeto é o itSIMPLE, que tem como objetivo o desenvolvimento de um ambiente de software para suportar as atividades de modelagem de sistemas de planejamento automáticos. O eCampeonatos, o último projeto observado, é uma ferramenta para organização, gerenciamento e acompanhamento de grandes eventos esportivos.

Em cada projeto buscou a observação da aplicação da prototipação dos requisitos eliciados, priorizando uma das perspectivas da eliciação de requisitos apresentadas anteriormente, que culminou com a submissão dos trabalhos no Concurso IBM inSites de Inovação Tecnológica envolvendo instituições de pesquisa e empresas, promovido pela IBM Brasil. Cada projeto resultou em um artigo sobre a contribuição acadêmica, um planejamento do negócio vislumbrado e um protótipo de software da aplicação da proposta apresentada. $\mathrm{O}$ apêndice $\mathrm{J}$ mostra o resultado obtido no Concurso IBM inSites.

As seções a seguir descrevem detalhadamente essa fase de observação, 
destacando os protótipos apresentados no Concurso IBM inSites.

\subsubsection{Perspectiva do Negócio - O projeto eDrugControl}

O eDrugControl foi criado a partir da necessidade relacionada aos erros médicos identificados na Farmácia Hospitalar. Segundo o apêndice E, denomina-se "erro médico" qualquer falha que aconteça nas fases do ciclo de tratamento de um paciente. $O$ apêndice $E$ apresenta, com detalhes, a fundamentação do projeto, que tem como proposta o desenvolvimento de interfaces que facilitem a adoção da Tecnologia da Informação pelos profissionais da área de saúde, utilizada como automação dos processos e atividades relacionadas ao tratamento de pacientes com medicamentos na Farmácia Hospitalar.

Decidiu-se que o foco do projeto seria na perspectiva do negócio, que é a Administração Hospitalar. A primeira atividade da equipe foi planejar as tarefas de levantamento de necessidades do eDrugControl, o que resultou na identificação de alguns hospitais das áreas pública, privada e militares, onde seriam agendadas visitas para se conhecer a solução adotada na prevenção do erro médico.

Nas oportunidades que aconteceram as visitas à esses hospitais, buscou-se identificar se o erro médico estava contemplado no planejamento do negócio e como estavam definidos e implementados os planos de ação de cada uma das metas.

O apêndice B mostra um guia elaborado para estruturar a observação durante as visitas nos hospitais, servindo como base para a coleta de dados. Com base nas 
informações do planejamento do negócio, eventualmente foi discutida a solução de Tecnologia da Informação que deveria suportar as atividades do corpo de profissionais, objetivando a redução do erro médico, destacando-se aqui os Requisitos de Negócio.

A seção a seguir descreve os Requisitos de Negócio identificados durante as visitas realizadas em alguns hospitais de São Paulo, no escopo do projeto eDrugControl.

\subsubsection{Requisitos de Negócio}

Os requisitos relacionados na tabela 3.1 representam o ponto de vista dos profissionais que exerciam função administrativa dos hospitais visitados. Nesta fase não há uma distinção entre os requisitos funcionais e não-funcionais.

Tabela 3.1: Requisitos de Negócio do eDrugControl

\begin{tabular}{|c|l|}
\hline Id. requisito & \multicolumn{1}{|c|}{ Descrição } \\
\hline Neg.001 & $\begin{array}{l}\text { O projeto em questão deve considerar o planejamento estratégico } \\
\text { do hospital }\end{array}$ \\
\hline Neg.002 & $\begin{array}{l}\text { A solução deve indicar uma proposta de automação com base nos } \\
\text { recursos, necessidades e objetivos da organização }\end{array}$ \\
\hline Neg.003 & $\begin{array}{l}\text { Os dados a respeito do tratamento do paciente devem ser } \\
\text { disponibilizados a medida que cada profissional envolvido com o } \\
\text { acompanhamento do tratamento tenha necessidade dos mesmos }\end{array}$ \\
\hline Neg.004 & $\begin{array}{l}\text { As informações a respeito de disponibilidade dos medicamentos } \\
\text { devem coincidir com o estoque físico }\end{array}$ \\
\hline Neg.005 & Os alertas de interação medicamentosa devem ser acionados \\
\hline & \\
\hline
\end{tabular}




\begin{tabular}{|c|l|}
\hline Id. requisito & \multicolumn{1}{|c|}{ Descrição } \\
\hline Neg.006 & $\begin{array}{l}\text { quando um profissional recomenda ou altera uma prescrição } \\
\text { solução deve possuir uma interface de fácil utilização e com } \\
\text { recursos de mobilidade }\end{array}$ \\
\hline Neg.007 & $\begin{array}{l}\text { A solução deve permitir o acesso dos profissionais a partir de } \\
\text { qualquer dispositivo que possua interface com a rede de acesso da } \\
\text { organização }\end{array}$ \\
\hline Neg.008 & $\begin{array}{l}\text { A prescrição de medicamentos deve disponibilizar um assistente, } \\
\text { pois é a atividade com maior risco para o erro médico }\end{array}$ \\
\hline
\end{tabular}

A próxima seção apresenta a interface do protótipo implementado a partir da eliciação dos Requisitos de Negócio. 


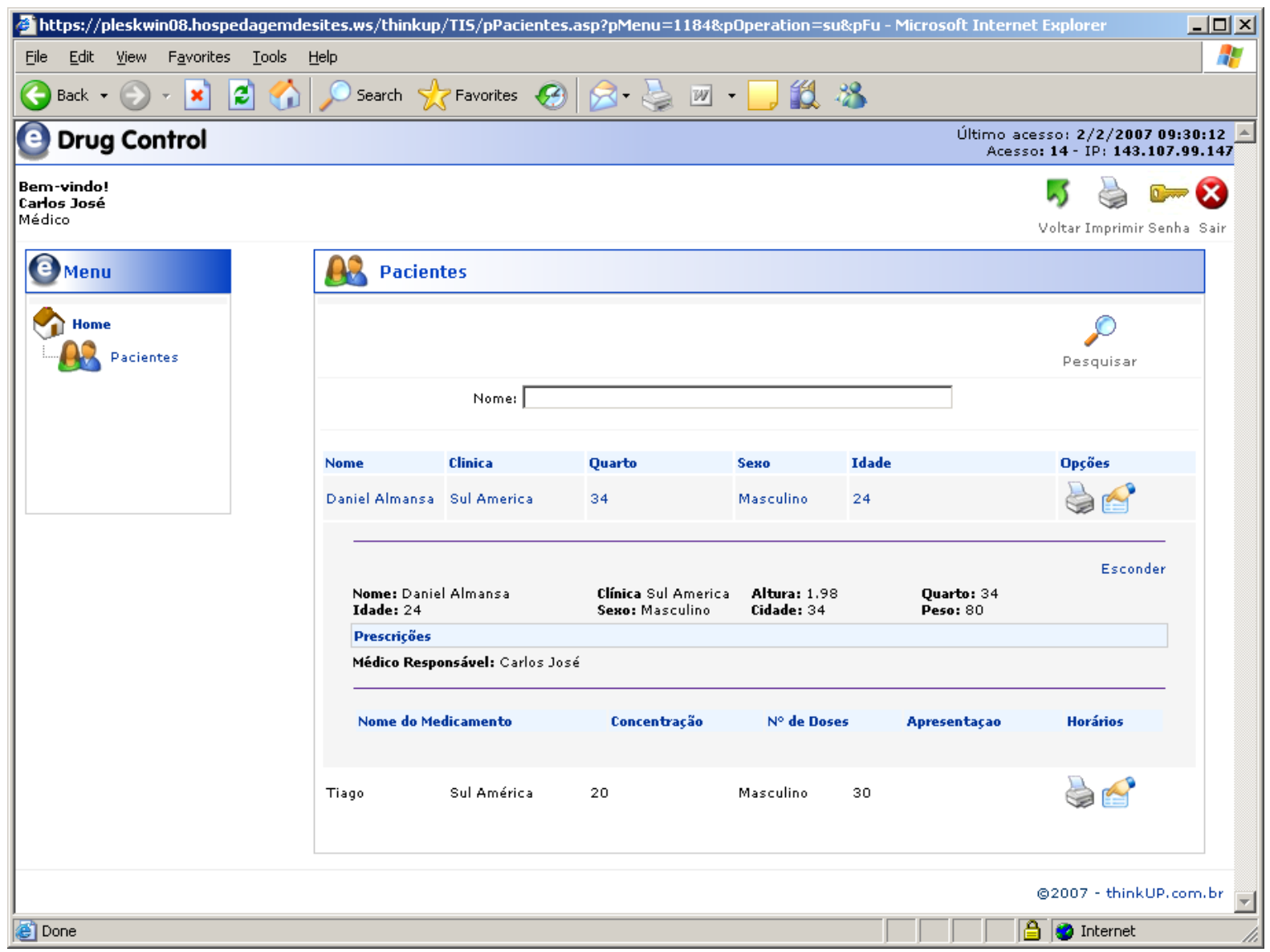

Figura 3.2: Protótipo do eDrugControl.

\subsubsection{Protótipo do eDrugControl}

Com base nos requisitos de negócio descritos na seção anterior, especificamente o requisito Neg.003, e no template de software descrito no apêndice $B$, foi elaborado um protótipo para permitir a verificação dos requisitos na fase de análise dos mesmos.

A figura 3.2 apresenta o protótipo, que permite o cadastro da classe Paciente, além das prescrições de medicamentos elaboradas durante o seu tratamento. 
$\mathrm{Na}$ interface do protótipo, neste caso do perfil de acesso dos Médicos, já seria possível acessar a solução a partir de qualquer dispositivo com interface para a Internet, uma vez que o protótipo se baseia em tecnologia Web, atendendo aqui o requisito Neg.007 descrito na tabela 3.1.

\subsubsection{Perspectiva de Design - O projeto itSIMPLE}

Uma implementação de verificação de Requisitos, conforme proposta de Santos (2002), foi desenvolvida no d-lab e continuou evoluindo para uma proposta de um ambiente para solucionar problemas de modelagem de domínios de planejamento, o itSIMPLE. Os conceitos que envolvem a ferramenta desenvolvida podem ser visualizados no apêndice I, em Silva; Santos e Vaquero (2005) e em Vaquero et al. (2007).

A observação do projeto itSIMPLE se deu sob a perspectiva de design, com base nas atividades de desenvolvimento da equipe de engenheiros do d-lab envolvida no projeto. Aqui se destaca a abordagem dada ao itSIMPLE na preparação de um protótipo que participou de uma competição internacional, apresentada no ICAPS 2005. Por ser uma solução inovadora, decidiu-se focar na interface da ferramenta, que deveria ser simples e intuitiva.

Buscou-se, durante a observação do projeto, conhecer o quanto a prototipação contribuiu para o desenvolvimento e evolução do itSIMPLE. É possível identificar os componentes de software que orientaram essa prototipação no apêndice C. 
A equipe observada é composta, basicamente, por profissionais ligados ao desenvolvimento do itSIMPLE, por isso denominados Requisitos de Design os requisitos identificados durante o desenvolvimento do projeto.

A seguir são descritos os Requisitos de Design que orientaram a implementação do itSIMPLE.

\subsubsection{Requisitos de Design}

Os requisitos relacionados na tabela 3.2 representam o ponto de vista dos profissionais que projetaram e desenvolveram a solução para modelagem de domínio de planejamento, o itSIMPLE. Nesta fase não há uma distinção entre os requisitos funcionais e não-funcionais.

Tabela 3.2: Requisitos de Design do itSIMPLE

\begin{tabular}{|c|l|}
\hline Id. requisito & \multicolumn{1}{|c|}{ Descrição } \\
\hline Des.001 & O itSIMPLE deve ser preparado para participar do ICAPS 2005 \\
\hline Des.002 & $\begin{array}{l}\text { O apelo do projeto deve ser a interface com o usuário: simples e } \\
\text { intuitiva }\end{array}$ \\
\hline Des.003 & $\begin{array}{l}\text { Todas as funções do itSIMPLE devem ser disponibilizadas na } \\
\text { mesma tela, que deve usar regiões para cada grupo de funções }\end{array}$ \\
\hline Des.004 & $\begin{array}{l}\text { O itSIMPLE deverá suportar a representação dos modelos em } \\
\text { diversas linguagens de modelagem }\end{array}$ \\
\hline Des.005 & $\begin{array}{l}\text { A simulação de modelos deve ser feita em Redes de Petri } \\
\text { Casos de Uso estruturados }\end{array}$ \\
\hline Des.006 &
\end{tabular}


Na seção a seguir é apresentada a interface do protótipo implementado para a competição do ICAPS 2005, gerado a partir da eliciação dos Requisitos de Design.

\subsubsection{Protótipo do itSIMPLE}

Os requisitos de design descritos na seção anterior, basicamente o requisito Des.004, e o template de software descrito no apêndice $C$, orientaram a elaboração do protótipo que foi apresentado no ICAPS 2005.

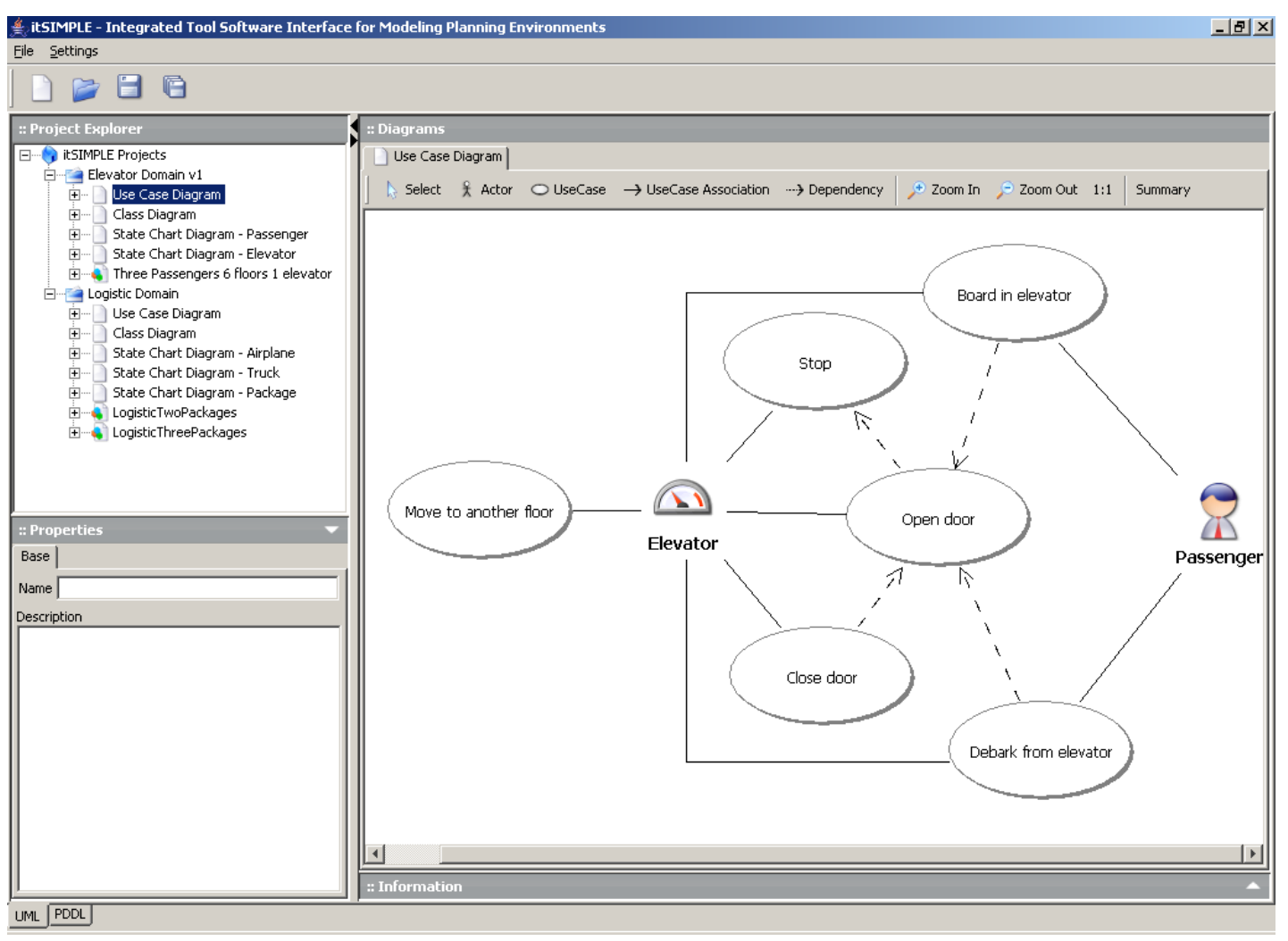

Figura 3.3: Protótipo do itSIMPLE. 
A figura 3.3 apresenta o protótipo, já evoluído, que permite a modelagem de domínio de planejamento em diagramas UML. Neste caso é apresentado o diagrama de casos de uso do domínio clássico dos elevadores. Conforme o apêndice $C$, percebese que a implementação levou em consideração o requisito Des.003, pois todas as funções de modelagem estão disponíveis na mesma tela, composta por três regiões:

- Project Explorer - permite a navegação entre os modelos e seus respectivos diagramas

- Properties - é possível definir as propriedades de cada diagrama ou modelo

- Diagrams - área de trabalho do itSIMPLE, com possibilidade de criação dos diagramas UML, contando com recursos de edição.

\subsubsection{Perspectiva Operacional - O projeto eCampeonatos}

Uma oportunidade de se conhecer os efeitos da automação na gestão pública foi identificada na Secretaria de Esportes da Cidade de São Paulo, de onde se originou o projeto eCampeonatos, que foi concebido como uma solução para a organização, administração e acompanhamento de grandes eventos esportivos, como é o caso dos Jogos da Cidade. Este evento acontecia anualmente em São Paulo e chegou a contar com a participação de mais de 40.000 atletas amadores, disputando até 13 (treze) modalidades esportivas. Os detalhes do projeto eCampeonatos, assim como os resultados de sua aplicação nos Jogos da Cidade podem ser observados no apêndice $\mathrm{G}$. 
O foco da observação deste projeto foi na perspectiva operacional, ou seja, decidiuse conhecer as necessidades dos envolvidos na organização de grandes eventos esportivos, para assim desenvolver um protótipo que atendesse a necessidade inicial e, desta forma, definir o desenvolvimento dos próximos passos do projeto.

Nas abordagens realizadas com a equipe organizadora dos Jogos da Cidade, buscou-se identificar o planejamento do evento, tomando como base os dados das edições anteriores e as informações passadas para a equipe de projeto do eCampeonatos.

No apêndice A é possível conhecer a estruturação do protótipo do eCampeonatos, que originou os requisitos da equipe organizadora dos Jogos da Cidade, segundo o ponto de vista dos profissionais envolvidos nas atividades operacionais, definindo-se assim os Requisitos Operacionais do projeto.

A seção a seguir descreve os Requisitos Operacionais do eCampeonatos.

\subsubsection{Requisitos Operacionais}

Os requisitos relacionados na tabela 3.3 representam o ponto de vista dos profissionais que executavam atividades operacionais das competições. Nesta fase não há uma distinção entre os requisitos funcionais e não-funcionais. 
Tabela 3.3: Requisitos Operacionais do eCampeonatos

\begin{tabular}{|c|l|}
\hline Id. requisito & \multicolumn{1}{|c|}{ Descrição } \\
\hline Oper.001 & $\begin{array}{l}\text { O projeto deve permitir a atualização e divulgação da tabela de } \\
\text { jogos pela Internet }\end{array}$ \\
\hline Oper.002 & $\begin{array}{l}\text { As inscriçães das equipes devem ocorrer pela Internet até o prazo } \\
\text { limite definido para a competição }\end{array}$ \\
\hline Oper.003 & $\begin{array}{l}\text { Durante a elaboração das tabelas dos jogos, a mudança dos locais } \\
\text { de disputas deve ser possibilitada }\end{array}$ \\
\hline Oper.004 & $\begin{array}{l}\text { A relação nominal dos atletas deve ser informada até a data limite } \\
\text { estabelecida no calendário da competição }\end{array}$ \\
\hline Oper.005 & $\begin{array}{l}\text { A comunicação com as equipes e atletas interessadas em participar } \\
\text { da competição deve ser feita, preferencialmente, por meio } \\
\text { eletrônico }\end{array}$ \\
\hline Oper.006 & $\begin{array}{l}\text { O lançamento do resultado dos jogos deve ser fácil e disponível } \\
\text { para qualquer dispositivo móvel com conexão de Internet }\end{array}$ \\
\hline Oper.007 & $\begin{array}{l}\text { A divulgação dos resultados dos jogos deve ser imediatamente } \\
\text { disponibilizada na Internet após o lançamento dos jogos }\end{array}$ \\
\hline Oper.008 & $\begin{array}{l}\text { O eCampeonatos deve possuir uma funcionalidade de Justiça } \\
\text { Desportiva, permitindo a punição das equipes e atletas que } \\
\text { cometerem penalidades ao regulamento da competição }\end{array}$ \\
\hline Oper.009 & $\begin{array}{l}\text { Durante a criação da competição, o eCampeonatos deve } \\
\text { possibilitar a escolha de quais modalidades e categorias poderão } \\
\text { participar, assim como a divulgação do regulamento da competição }\end{array}$ \\
\hline
\end{tabular}

$\mathrm{Na}$ seção seguinte são apresentados os protótipos do portal eCampeonatos e do assistente de competições, implementados a partir da eliciação dos Requisitos Operacionais, descritos na tabela 3.3. 


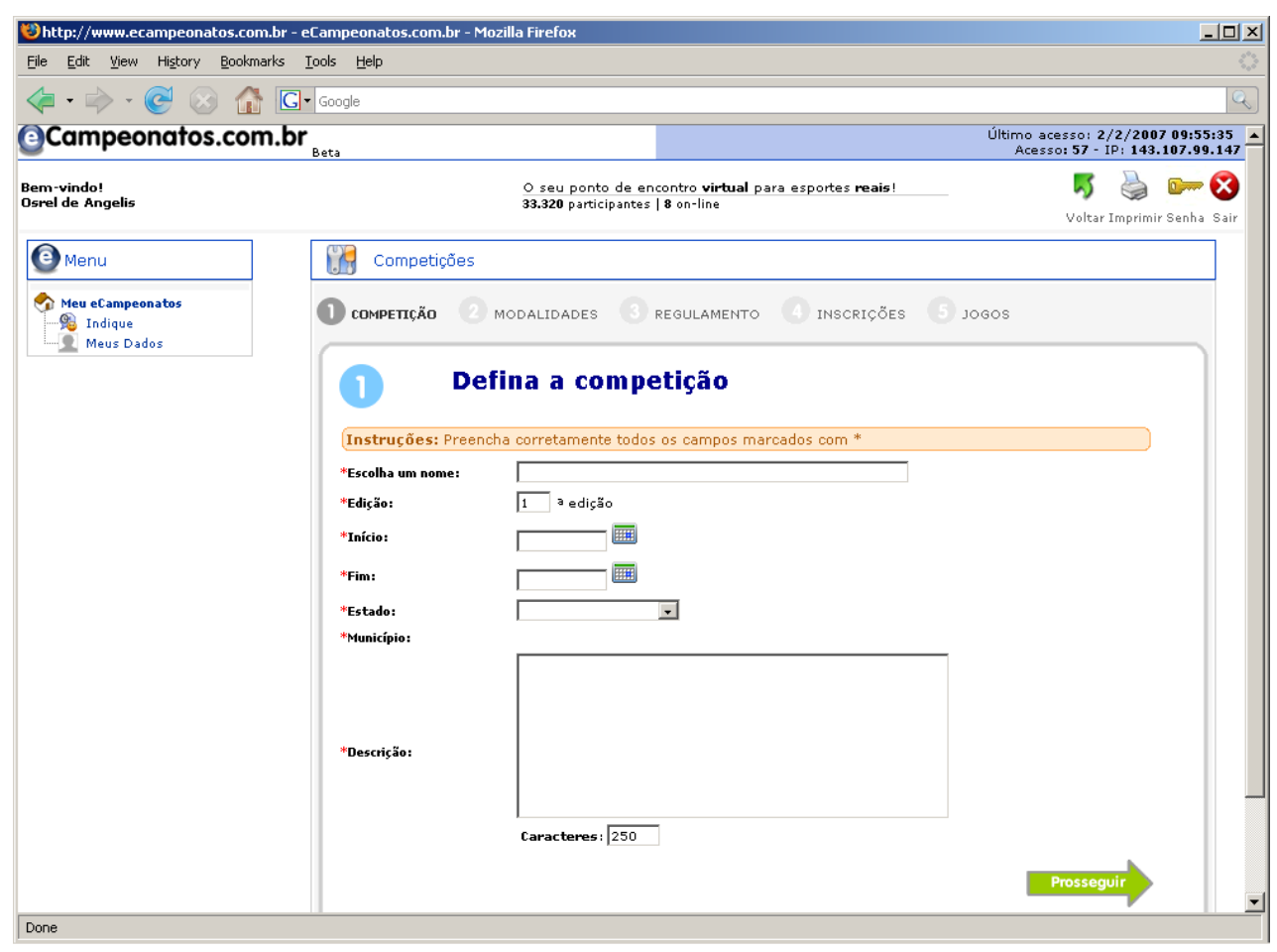

Figura 3.4: Protótipo do eCampeonatos.

\subsubsection{Protótipo do eCampeonatos}

Com base nos requisitos operacionais vistos anteriormente, foi elaborado o protótipo do eCampeonatos para dar suporte às atividades da equipe organizadora dos Jogos da Cidade da Secretaria de Esportes da cidade de São Paulo. 


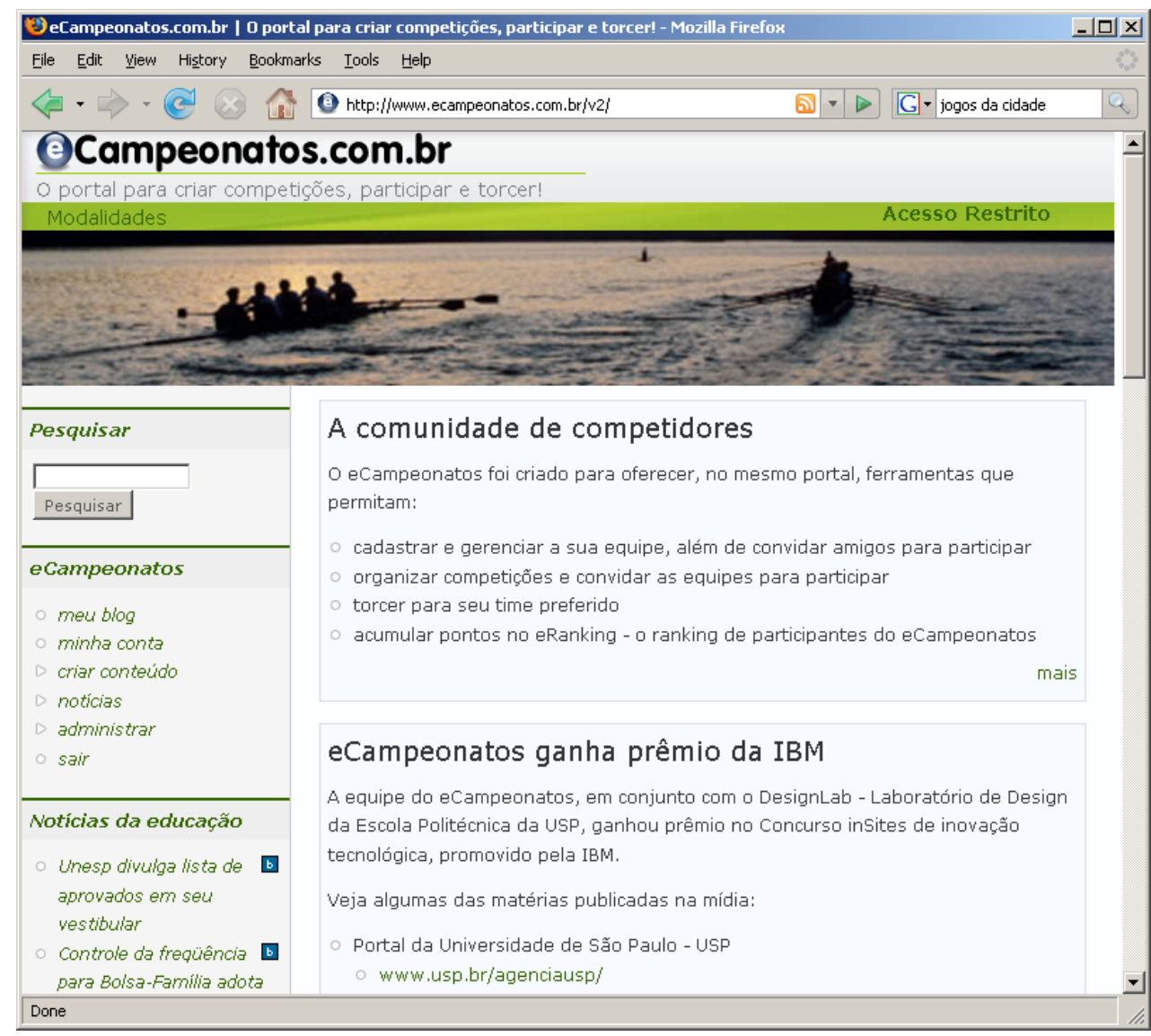

Figura 3.5: Protótipo do portal eCampeonatos.

A figura 3.4 apresenta o assistente de competição do eCampeonatos, desenvolvido como sendo uma solução para a organização de grandes competições, gerando uma contribuição para os Jogos da Cidade, uma vez que essa etapa chegou a consumir 04 (meses) da equipe. Depois do eCampeonatos, passou a ser uma questão de segundos, obviamente após informados os dados necessários para a alocação de jogos nos locais e horários de disputas.

Para a comunicação com o público, além das funcionalidades de inscrição e resultados das competições, foi desenvolvido o portal do eCampeonatos, conforme ilustra a figura 3.5. 


\subsection{Considerações}

A fase de observação permitiu conhecer como a prototipação poderia facilitar o entendimento dos requisitos dos projetos, aqui observados segundo o foco da perspectiva escolhida de cada projeto.

São apresentadas, na seqüência, as propostas para classificar os requisitos das diferentes perspectivas, identificadas neste capítulo, com base na intenção dos envolvidos e a identificação da volatilidade, ainda na fase de eliciação dos requisitos. 


\section{Intenção e a Eliciação de Requisitos}

Hoorn (2006) afirma que "as pessoas mudam de idéia o tempo todo" e que essa característica das pessoas "pode resultar em problemas quando as mesmas participam do desenvolvimento de grandes projetos baseados em computador". Por outro lado, as organizações estão inseridas no contexto competitivo do mercado, forçando-as a implementarem mudanças nos negócios para, por exemplo manter a competitividade (PINE, 1993) no mercado através do fornecimento de produtos e serviços personalizados para o seu público alvo.

Para que essas mudanças aconteçam, as pessoas responsáveis e envolvidas no processo necessitam, em primeiro lugar, comunicar claramente a necessidade da mudança e, por fim, ter a garantia de que a implementação ocorrerá de acordo com o que fora informado.

Como visto na revisão da literatura, várias técnicas de Engenharia de Requisitos foram propostas no sentido de garantir que as necessidades de mudanças sejam comunicadas e que a equipe responsável pela implementação compreenda melhor essa necessidade. No entanto, se pode observar na constatação do Standish Group (1995), que a mudança nos requisitos e seu gerenciamento têm sido a principal causa para que os projetos de Tecnologia da Informação continuem sendo entregues com problemas.

Denomina-se volatilidade essa característica de mudança dos requisitos (SOMMERVILLE; SAWYER, 1997), porém não está no escopo deste trabalho as mudanças que ocorrem para que as pessoas e as organizações continuem 
buscando seus objetivos, mas sim daquelas mudanças que poderiam ser evitadas através de uma melhor compreensão desses objetivos, ainda na fase de eliciação dos requisitos, buscando-se assim uma menor volatilidade dos requisitos encontrados nos projetos em Tecnologia da Informação.

Considerando que os requisitos continuarão mudando e que, segundo Hoorn (2006), "os objetivos pessoais dos envolvidos podem interferir na comunicação e entendimento dos requisitos", a seguir é apresentada uma proposta que visa, com base na intenção dos envolvidos na eliciação dos requisitos, observar a intenção dos envolvidos na definição de requisitos segundo as características de cada perspectiva identificada anteriormente: de negócio, de design e operacional.

Com isso será possível identificar a volatilidade dos requisitos ainda na fase de eliciação, permitindo que as mudanças sejam minimizadas em função do melhor entendimento dos objetivos desses requisitos.

\subsection{Observando a Intenção dos requisitos nas Perspectivas}

Segundo propõem Said e Evrard (2001), é possível identificar a intenção de uma pessoa ao escrever um texto, que é composta por:

- ação: que representa o que o autor quer fazer

- objetivo: é o que se espera alcançar com a realização da ação 
- significado: expressa como a ação é realizada

- razão: define porque o autor escolheu a ação

Nota-se que a ação representada por uma intenção, pode ser identificada no texto pelo verbo que a representa. No contexto deste trabalho, uma ação será equivalente a uma atividade realizada por recursos, que do ponto de vista gerencial, pode ser vista como uma tarefa.

Com o objetivo de se conhecer a intenção dos envolvidos na fase de eliciação de requisitos, segue a proposta de estruturação das perspectivas propostas no capítulo anterior, visando a identificação das características do requisito, com base nas propriedades acima expostas.

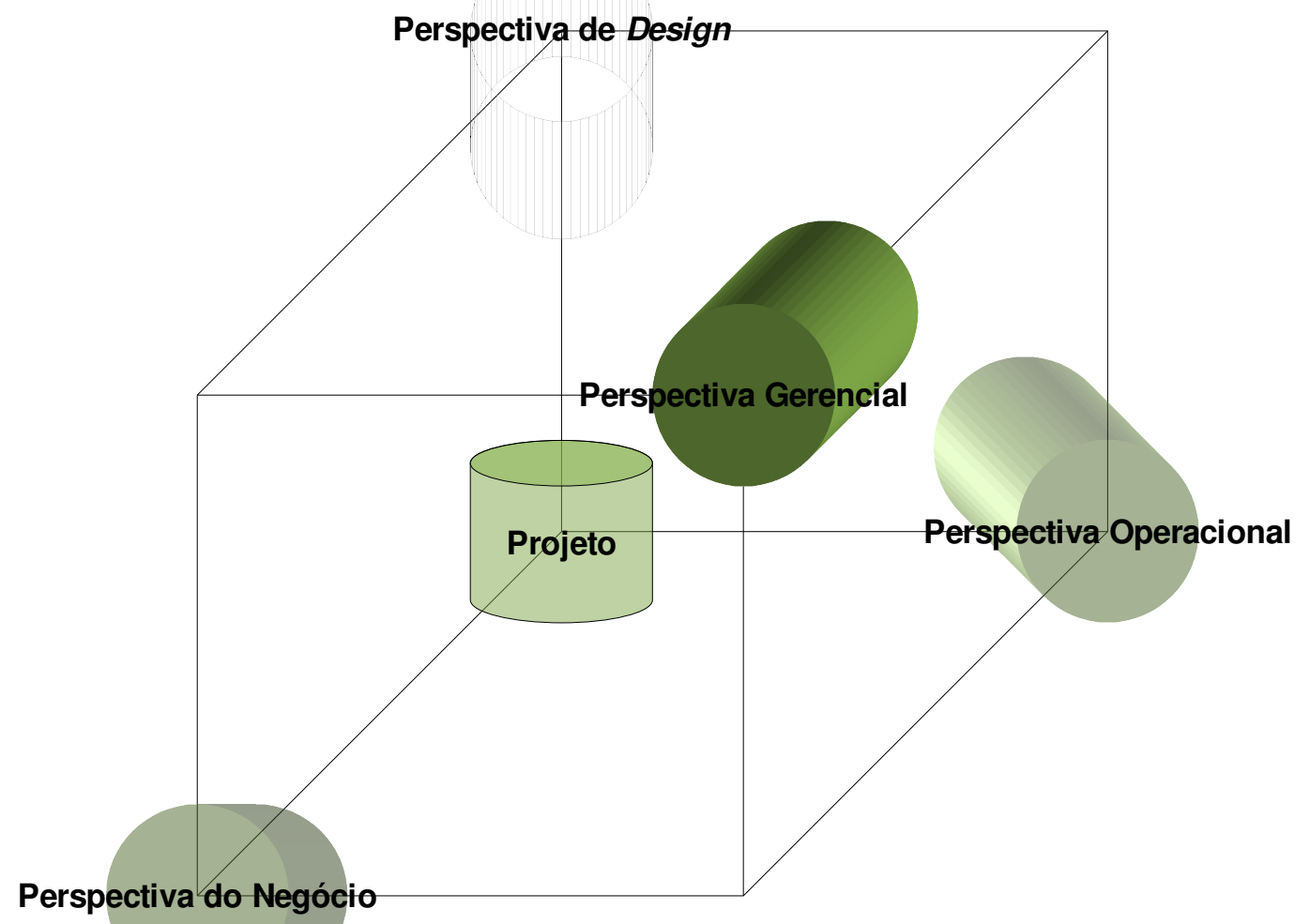

Figura 4.1: Perspectivas da Eliciação de Requisitos, com a Perspectiva Gerencial. 
Além das perspectivas apresentadas anteriormente, ou seja: do negócio, da operação e do design, foi introduzida a perspectiva gerencial em função da necessidade de se controlar o processo de eliciação de requisitos. Esta nova perspectiva pode ser vista na figura 4.1.

\subsection{Intenção na Perspectiva do Negócio}

Segundo Baron e Shane (2007), o planejamento de um negócio envolve uma série de definições que são apresentadas em um documento que serve como guia para a operação do mesmo: o plano de negócios. Este documento estrutura o negócio (BARON; SHANE, 2007) em termos de missão, objetivos, metas, planos de ação, retorno do investimento, dentre outros.

Os planos de ação são definidos para que os objetivos da organização sejam alcançados. Tais planos são constituídos por atividades que necessitam ser desempenhadas por recursos da organização que, se bem controladas e realizadas, "permitirão aos empreendedores do negócio a realização do retorno do investimento" (BARON; SHANE, 2007).

A partir desta colocação, este trabalho propõe que a eliciação de requisitos permita que as atividades a serem desempenhadas pelo negócio que está sendo definido receba um tratamento específico, permitindo à equipe responsável pela eliciação de requisitos entender melhor os Requisitos do Negócio, de um lado pelo documento de visão do negócio, que contém características que podem ser extraídas do Planejamento do Negócio conforme sugere o apêndice B, por outro lado através do 
que é esperado de cada requisito segundo o ponto de vista do empreendedor.

Segue a definição da intenção da Perspectiva do Negócio, com base nas propostas de Said e Evrard (2001) e de Hassan; Chantal e Said (2007), do que se poderia esperar do Requisito do Negócio.

\subsubsection{Definição da intenção na Perspectiva do Negócio}

A intenção do negócio, Intent ${ }_{\text {Neg}}$, pode ser definida com base no item anterior, como segue:

Intent $_{\text {Neg }}$ (Objetivo, OQueFaz, Recurso+, Resultado+, QuemComunicar+, ComoControlar)

onde:

- Objetivo: descreve qual objetivo será atingido.

- OQueFaz: representa o que deve ser feito.

- Recurso+: indica qual recurso (humano ou não) será envolvido. O sinal + indica que pode haver mais de um recurso envolvido.

- Resultado+: ilustra qual é o resultado esperado. O sinal + indica que pode haver mais de um resultado esperado. 
- QuemComunicar+: determina quem deve ser comunicado sobre o resultado. O sinal + indica que pode haver mais de um interessado no resultado.

- ComoControlar: indica como deve ser controlado.

A seção seguinte ilustra a aplicação desta definição nos Requisitos de Negócio observados no capítulo anterior.

\subsubsection{Aplicação da intenção nos Requisitos de Negócios}

Segue a aplicação da intenção na fase de eliciação de requisitos no requisito de negócio Neg.003 descrito na tabela 3.1 para exemplificação da definição do item anterior.

Tabela 4.1: Visualização da intenção do requisito de negócio Neg.003

\begin{tabular}{|c|c|c|}
\hline Intent & \multicolumn{1}{|c|}{ Trecho do requisito } & Definido \\
\hline Objetivo & & Não \\
\hline OQueFaz & $\begin{array}{l}\text { Os dados a respeito do tratamento do paciente } \\
\text { devem ser disponibilizados }\end{array}$ & Sim \\
\hline Recurso+ & & Não \\
\hline
\end{tabular}




\begin{tabular}{|c|l|c|}
\hline \multicolumn{1}{|c|}{ Intent $_{\mathrm{Neg}}$} & \multicolumn{1}{|c|}{ Trecho do requisito } & Definido \\
\hline Resultado+ & dados disponibilizados & Sim \\
\hline QuemComunicar+ & $\begin{array}{l}\text { cada profissional envolvido com o acompanhamento } \\
\text { do tratamento }\end{array}$ & Sim \\
\hline ComoControlar & & Não \\
\hline
\end{tabular}

A tabela 4.1 ilustra o requisito Neg.003, onde é possível perceber que nem todas as partes esperadas do requisito de negócio foram especificadas.

Recorrendo aos apêndices D e E, é possível identificar as partes esperadas do requisito de negócio que não foram especificadas na tabela 4.1, e com a aplicação da Intenção de Negócio, a classificação do requisito poderia ser realizada como mostra a tabela 4.2 . 
Tabela 4.2: Aplicação da Intenção de Negócio no requisito Neg.003

\begin{tabular}{|c|l|}
\hline Intent & \multicolumn{1}{|c|}{ Trecho do requisito } \\
\hline Objetivo & Reduzir erro médico \\
\hline OQueFaz & $\begin{array}{l}\text { O prontuário do paciente deve ser atualizado a cada } \\
\text { intervenção profissional e armazenado }\end{array}$ \\
\hline Recurso+ & Sistema de Informação Hospitalar \\
\hline Resultado+ & $\begin{array}{l}\text { Os dados do prontuário devem ser disponibilizados durante as } \\
\text { prescrições e administrações de medicamentos }\end{array}$ \\
\hline QuemComunicar+ & $\begin{array}{l}\text { Médicos, farmacêuticos, enfermeiros e, quando necessário, } \\
\text { paciente }\end{array}$ \\
\hline ComoControlar & $\begin{array}{l}\text { Indicadores sobre tratamento de pacientes disponíveis para o } \\
\text { administrador hospitalar }\end{array}$ \\
\hline
\end{tabular}

Com base na tabela 4.2, o detalhamento do requisito Neg.003 poderia ser 0 seguinte:

"Com o objetivo de reduzir o erro médico, o prontuário de cada paciente deve ser, a cada intervenção profissional, atualizado e armazenado no Sistema de Informação Hospitalar, além de ser disponibilizado para os médicos durante as prescrições e para os farmacêuticos e enfermeiros no momento de separação e administração dos medicamentos ao paciente. Relatórios que mostram indicadores sobre o tratamento de pacientes, incluindo os índices de erros médico, devem ser disponibilizados para o administrador hospitalar." 


\subsection{Intenção na Perspectiva Operacional}

Cada recurso responsável pela execução das atividades, desde as mais simples até as mais complexas, necessita de conhecimento para desempenhar adequadamente a sua função na organização. Segundo Hoorn (2006), além desse requisito, é preciso considerar os "objetivos pessoais" de cada recurso, pois isso pode influenciar no resultado, ou seja, é possível haver omissão de informação no caso da ausência de uma abordagem eficaz na eliciação dos requisitos.

Esta perspectiva deve considerar, exclusivamente, o ponto de vista do profissional no que diz respeito aos Requisitos Operacionais, ou seja, aqueles necessários para o desenvolvimento das atividades previstas nos planos de ação do planejamento do negócio.

De forma análoga à Perspectiva de Negócio, define-se a intenção da Perspectiva Operacional na próxima seção.

\subsubsection{Definição da intenção na Perspectiva Operacional}

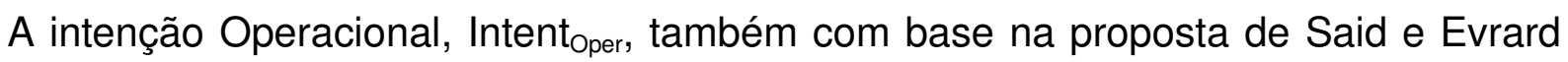
(2001) pode ser definida como segue: 
Intent $t_{\text {oper }}$ (Objetivo, OQueFaz, PreCondicao+, Resultado+, Duracao, QuemComunicar+)

onde:

- Objetivo: descreve qual objetivo será atingido.

- OQueFaz: representa o que deve ser feito.

- PreCondicao+: indica o que é necessário para realizar a operação.

- Resultado+: ilustra qual é o resultado esperado. O sinal + indica que pode haver mais de um resultado esperado.

- Duracao+: determina qual é o tempo necessário para a execução da atividade.

- QuemComunicar+: determina quem deve ser comunicado sobre o resultado. O sinal + indica que pode haver mais de um interessado no resultado.

A seção seguinte ilustra a aplicação desta definição nos Requisitos Operacionais vistos na prototipação do projeto eCampeonatos e descritos no capítulo anterior. 


\subsubsection{Aplicação da intenção nos Requisitos Operacionais}

A tabela 4.3 ilustra a a aplicação da intenção no requisito operacional Oper.009, do projeto eCampeonatos.

Tabela 4.3: Visualização da intenção do requisito operacional Oper.009

\begin{tabular}{|c|c|c|}
\hline Intent & Trecho do requisito & Definido \\
\hline Objetivo & & Não \\
\hline OQueFaz & Cria competições & Sim \\
\hline PreCondicao+ & $\begin{array}{l}\text { - Definição da lista de modalidades e } \\
\text { categorias } \\
\text { - Regulamento da competição }\end{array}$ & Sim \\
\hline Resultado+ & & Não \\
\hline Duracao & & Não \\
\hline QuemComunicar+ & & Não \\
\hline
\end{tabular}

É possível identificar que, segundo o ponto de vista operacional, o requisito Oper.009 não apresenta todas as características esperadas de um requisito operacional. 
Com base nos apêndices $F$ e $G$, é possível identificar as partes esperadas do requisito operacional que não foram especificadas na tabela 4.3, e com a aplicação da Intenção Operacional, a classificação do requisito Oper.009 seria como mostra a tabela 4.4 .

Tabela 4.4: Aplicação da Intenção Operacional no requisito Oper.009

\begin{tabular}{|c|c|}
\hline Intent ${ }_{\text {oper }}$ & Trecho do requisito \\
\hline Objetivo & $\begin{array}{l}\text { Contribuir com a diminuição da violência, envolvendo a } \\
\text { comunidade jovem nas diversas Competições criadas no } \\
\text { município }\end{array}$ \\
\hline OQueFaz & Disponibiliza um assistente para criação de competições \\
\hline PreCondicao+ & $\begin{array}{l}\text { - Definição da lista de modalidades e categorias } \\
\text { - Regulamento da competição } \\
\text { - Lista de locais de disputa, com respectiva disponibilidade } \\
\text { - Calendário da competição }\end{array}$ \\
\hline Resultado+ & $\begin{array}{l}\text { - Gera a competição } \\
\text { - Disponibiliza o regulamento da competição } \\
\text { - Libera o processo de inscrição para os interessados }\end{array}$ \\
\hline Duracao & 8 horas de 1 técnico por modalidade esportiva \\
\hline QuemComunicar+ & $\begin{array}{l}\text { - A equipe de comunicação, para divulgação da competição } \\
\text { - A equipe de técnicos, para elaboração dos regulamentos } \\
\text { das competições }\end{array}$ \\
\hline
\end{tabular}

A revisão do requisito Oper.009, segundo a tabela 4.4, poderia ser detalhado com a seguinte especificação: 
"No sentido de contribuir com a diminuição da violência, um assistente de criação de competições deve ser disponibilizado para a equipe organizadora de eventos esportivos, de forma a gerar mais competições no município, tendo como possibilidade a escolha das modalidades esportivas e respectivas categorias e a lista de locais de disputa com a agenda disponível para a competição. Com isso é possível escrever o regulamento geral da competição, incluindo os específicos de cada modalidade, levando 8 horas de 1 técnico por modalidade, fazer a divulgação na mídia e liberar o processo de inscrição dos interessados, que deve obedecer o calendário da competição."

\subsection{Intenção na Perspectiva de Design}

Gamma (1995) propõem Design Patterns para a construção de softwares a partir de componentes que implementam partes comuns encontradas em outras aplicações. Silva; Santos e Vaquero (2005) sugerem que esses componentes de software possam ser estruturados com base no ponto de vista dos envolvidos no processo de elaboração de software, sendo possível se verificar ainda na fase de especificação, que pode ser representada pela descrição estruturada dos casos de uso.

Com base nessas propostas, este trabalho propõe que a eliciação de requisitos possa utilizar-se de templates que possam representar os componentes reutilizáveis de design, permitindo à equipe responsável pela eliciação de requisitos um melhor entendimento dos Requisitos de Design, considerando as demais perspectivas já abordadas, conforme sugere o apêndice $C$, além do que é esperado de cada requisito segundo o ponto de vista da equipe de design. 
Segue a definição da intenção da Perspectiva de Design, com base nas propostas (SAID; EVRARD, 2001; HASSAN; CHANTAL; SAID, 2007) e das principais características esperadas do Requisito de Design.

\subsubsection{Definição da intenção na Perspectiva de Design}

A intenção de Design, Intent $t_{\text {Des }}$, é definida com base no item anterior, como segue:

Intent $t_{\text {Des }}($ Objetivo, OQueFaz, Recurso+, Resultado+, QuemComunicar+, Perspectiva, TipoRequisito)

onde:

- Objetivo: descreve qual objetivo será atingido.

- OQueFaz: representa o que deve ser feito.

- Recurso+: indica qual recurso (humano ou não) será envolvido. O sinal + indica que pode haver mais de um recurso envolvido.

- Resultado+: ilustra qual é o resultado esperado. O sinal + indica que pode haver mais de um resultado esperado.

- QuemComunicar+: determina quem deve ser comunicado sobre o resultado. O sinal + indica que pode haver mais de um interessado no resultado. 
- Perspectiva: representa a perspectiva que originou o requisito.

- TipoRequisito: indica qual é o tipo de requisito.

Na próxima seção é ilustrada a aplicação desta definição nos Requisitos de Design vistos na prototipação do projeto itSIMPLE, conforme ilustra o apêndice I.

\subsubsection{Aplicação da intenção nos Requisitos de Design}

Segue a aplicação da intenção na fase de eliciação de requisitos no requisito Des.003 descrito na tabela 3.2 para exemplicação da definição do item anterior. 
Tabela 4.5: Visualização da intenção do requisito de design Des.003

\begin{tabular}{|c|l|c|}
\hline Intent & \multicolumn{1}{|c|}{ Trecho do requisito } & Definido \\
\hline Objetivo & & Não \\
\hline OQueFaz & $\begin{array}{l}\text { Disponibilizar as funções do itSIMPLE na mesma } \\
\text { tela }\end{array}$ & Sim \\
\hline Recurso+ & Usar regiões para cada grupo de funções & Sim \\
\hline Resultado+ & & Não \\
\hline QuemComunicar+ & & Não \\
\hline TipoRequisito & Mesma tela (Visual - Não funcional) & Sim \\
\hline
\end{tabular}

A tabela 4.5 ilustra o requisito Des.003, onde é possível perceber que nem todas as partes esperadas do requisito de negócio foram especificadas.

Nos apêndices $\mathrm{H}$ e I, é possível identificar as partes esperadas do requisito de negócio que não foram especificadas na tabela 4.5, e com a aplicação da Intenção de Design, a classificação do requisito poderia ser realizada como mostra a tabela 4.6. 
Tabela 4.6: Aplicação da Intenção de Design no requisito Des.003

\begin{tabular}{|c|l|}
\hline Intent & \multicolumn{1}{|c|}{ Trecho do requisito } \\
\hline Objetivo & $\begin{array}{l}\text { Permitir ao designer o acesso rápido às perspectivas de } \\
\text { modelagem }\end{array}$ \\
\hline OQueFaz & $\begin{array}{l}\text { O itSIMPLE deve possuir as funções de modelagem e } \\
\text { verificação de modelos }\end{array}$ \\
\hline Recurso+ & $\begin{array}{l}\text { Usar perspectivas para um grupo de funcionalidades } \\
\text { relacionadas }\end{array}$ \\
\hline Resultado+ & Funcionalidades disponibilizadas na mesma interface gráfica \\
\hline QuemComunicar+ & $\begin{array}{l}\text { O designer deve perceber o acesso fácil às diversas } \\
\text { perspectivas de modelagem }\end{array}$ \\
\hline Perspectiva & De negócio \\
\hline & Visual - Não funcional \\
\hline
\end{tabular}

O requisito Des.003, ilustrado na tabela 4.6, poderia receber o seguinte detalhamento:

"O itSIMPLE deve possuir as funções de modelagem e verificação de modelos disponibilizadas na mesma interface gráfica, permitindo que o designer perceba 0 acesso rápido às perspectivas de modelagem, que dispõem de funcionalidades relacionadas a cada perspectiva". 


\subsection{Intenção na Perspectiva Gerencial}

Permitir que os requisitos sejam eliciados e que as mudanças durante o seu ciclo de vida sejam reduzidas depende de um bom gerenciamento dos requisitos. Nesse sentido, os conceitos de gestão de projetos aplicados na fase de eliciação de requisitos podem proporcionar, segundo Franco (2007), um melhor entendimento dos custos envolvidos nas futuras atividades de implementação desses requisitos.

Com o objetivo de permitir à equipe responsável pela eliciação de requisitos entender melhor os Requisitos Gerenciais, foi introduzida a perspectiva gerencial, que procura evidenciar, sobretudo, as necessidades de recursos e os custos envolvidos de cada requisito.

Segue a definição da intenção da Perspectiva Gerencial, com base nas propostas (SAID; EVRARD, 2001; HASSAN; CHANTAL; SAID, 2007) e do que se poderia esperar do Requisito Gerencial.

\subsubsection{Definição da intenção na Perspectiva Gerencial}

A intenção gerencial, Intent $t_{\text {Ger, }}$ pode ser definida com base no item anterior, como segue: 


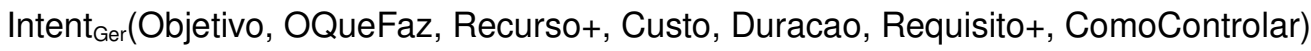

onde:

- Objetivo: descreve qual objetivo será atingido.

- OQueFaz: representa o que deve ser feito.

- Recurso+: indica qual recurso (humano ou não) será envolvido. O sinal + indica que pode haver mais de um recurso envolvido.

- Custo: mostra uma idéia de custo para implementação do requisito.

- Duracao: indica uma previsão de tempo para execução da atividade.

- Requisito+: mostra a relação dependência entre este e os demais requisitos. O sinal + indica que pode haver mais de um requisito relacionado.

- ComoControlar: indica como deve ser controlado.

A seção seguinte ilustra a aplicação desta definição nos Requisitos Gerenciais, derivados dos Requisitos de Negócio observados no capítulo anterior. 


\subsubsection{Aplicação da intenção nos Requisitos Gerenciais}

Para a aplicação da intenção nos requisitos gerenciais, foi tomado como base 0 requisito de negócio Neg.003 descrito na tabela 3.1, gerando o requisito gerencial Ger.001, para exemplicação da definição do item anterior.

Tabela 4.7: Visualização da intenção do requisito de negócio Ger.001

\begin{tabular}{|c|c|c|}
\hline Intent ${ }_{\text {Ger }}$ & Trecho do requisito & Definido \\
\hline Objetivo & Não & Sim \\
\hline OQueFaz & devem ser disponibilizados & Não \\
\hline Recurso+ & & Não \\
\hline Custo & & Não \\
\hline Duracao & & Não \\
\hline Requisito+ & & Não \\
\hline ComoControlar & & \\
\hline
\end{tabular}


Na tabela 4.7 é ilustrado o requisito Ger.001, derivado do requisito de negócio Neg.003. Do ponto de vista gerencial, constata-se que nem todas as características foram definidas.

Nos apêndices $D$ e E é possível encontrar as partes esperadas do requisito gerencial que não foram especificadas na tabela 4.7, e com a aplicação da Intenção Gerencial, a classificação do requisito poderia ser realizada como mostra a tabela 4.8.

Tabela 4.8: Aplicação da Intenção Gerencial no requisito Ger.001

\begin{tabular}{|c|c|}
\hline Intent $_{\mathrm{Ger}}$ & Trecho do requisito \\
\hline Objetivo & Reduzir erro médico \\
\hline OQueFaz & $\begin{array}{l}\text { O prontuário do paciente deve ser atualizado a cada } \\
\text { intervenção profissionail }\end{array}$ \\
\hline Recurso+ & Médicos, farmacêuticos, enfermeiros e paciente \\
\hline Custo & $\begin{array}{l}\text { Custo dos profissionais, dos medicamentos e da internação } \\
\text { do paciente }\end{array}$ \\
\hline Duracao & $\begin{array}{l}\text { O intervalo entre as prescrições de medicamentos varia de } 4 \text { a } \\
8 \text { horas }\end{array}$ \\
\hline Requisito+ & $\begin{array}{l}\text { - Neg.004 (Ger.001 depende) } \\
\text { - Neg.005 (Ger.001 depende) } \\
\text { - Neg.006 (depende do Ger.001) } \\
\text { - Neg.007 (depende do Ger.001) } \\
\text { - Neg.008 (depende do Ger.001) }\end{array}$ \\
\hline ComoControlar & $\begin{array}{l}\text { Indicadores sobre tratamento de pacientes disponíveis para o } \\
\text { administrador hospitalar }\end{array}$ \\
\hline
\end{tabular}


Com base na tabela 4.8, o detalhamento do requisito Ger.001 poderia ser o seguinte:

"Com o objetivo de reduzir o erro médico, o prontuário de cada paciente deve ser atualizado a cada intervenção profissional, além de ser disponibilizado para os médicos durante as prescrições e para os farmacêuticos e enfermeiros no momento de separação e administração dos medicamentos ao paciente. Relatórios que mostram indicadores sobre o tratamento de pacientes, incluindo os índices de erros médico, devem ser disponibilizados para o administrador hospitalar. $\mathrm{O}$ custo das atividades relacionadas com o tratamento do paciente depende dos custos dos profissionais, dos medicamentos e da internação do paciente, e a duração deve obedecer o intervalo entre as prescrições de medicamentos, que varia entre 4 e 8 horas. Existe dependência entre este e outros requisitos." 


\section{Identificando a Volatilidade de Requisitos com 0 volaRE}

A característica de mudança dos requisitos é esperada para aqueles que emergem das necessidades de evolução dos bens e serviços com os quais estão relacionados. Segundo Hoorn et al. (2007), a volatilidade dos requisitos de um produto, aqueles que sofrem alterações em função das mudanças no contexto da operação, pode ser prevista comparando-se com a volatilidade observada em alguns domínios de aplicações estudados.

Neste capítulo é apresentado o volaRE, uma proposta que permite se conhecer a volatilidade de um requisito e um mecanismo que permite reduzir essa volatilidade ainda na fase de eliciação de requisitos.

\section{1 Índice de Aprovação da Perspectiva do Requisito}

O requisito originado por uma perspectiva, ainda na fase de eliciação, será submetido à aprovação das perspectivas, que fazem uma classificação quanto a estar ou não de acordo com a definição do requisito.

Com base na proposta de Hoorn (2006), a classificação do requisito pode ser feita seguindo uma escala de aprovação, possuindo um valor associado a cada 
possibilidade.

A tabela 5.1 mostra as possibilidades de aprovação de um requisito, que recebe um valor maior a medida que a aprovação é maior.

Tabela 5.1: Classificação da aprovação de um requisito

\begin{tabular}{|l|c|}
\hline \multicolumn{1}{|c|}{ Classificação da Aprovação } & Valor associado \\
\hline Concordo totalmente & 1,0 \\
\hline Concordo & 0,8 \\
\hline Concordo um pouco & 0,6 \\
\hline Discordo um pouco & 0,4 \\
\hline Discordo & 0,2 \\
\hline Discordo totalmente & 0,1 \\
\hline
\end{tabular}

Com a apresentação do Índice de Aprovação da Perspectiva, é possível definir a volatilidade do requisito, o volaRE, como mostra a seção a seguir.

\subsection{Definição do volaRE}

O volaRE é definido como sendo a somatória da razão entre o número de características não definidas (Tni) do respectivo requisito pelo número de características (Tn), considerando o Índice de Aprovação da Perspectiva (Pn) e o número de perspectivas (Np). A equação eq.(5.1) mostra esta definição. 


$$
\operatorname{volaRE}=\frac{\sum_{1 . . N p}^{n}\left(\frac{T n i}{T n}\right) *\left(\frac{1}{P n}\right)}{N p}
$$

onde:

- volaRE: volatilidade do requisito

- Tni: número de características não definidas da perspectiva

- Tn: número total de características da intenção da perspectiva

- $\mathbf{n}$ : a perspectiva sendo calculada

- Pn: Índice de aprovação da perspectiva, variando de 0,1 a 1

- Np: número de perspectivas

Da equação eq.(5.1) pode-se concluir que quanto maior Tni e menor Pn, maior será a volatilidade do requisito. 


\subsection{Exemplo de identificação de volatilidade com o volaRE}

Para exemplificar a identificação da volatilidade, foi aplicado o volaRE nos requisitos ilustrados no capítulo anterior, separando-se por perspectiva, como segue.

\subsubsection{Aplicando o volaRE nos Requisitos de Negócio}

Considerando o requisito de negócio visto na perspectiva de negócio, o requisito Neg.003, como ilustra a tabela 3.1, faz-se a classificação da aprovação das perspectivas para encontrar o índice de aprovação de cada uma delas e, assim, calcula-se a volatilidade, conforme a equação eq.(5.1).

\subsubsection{1 Índice de Aprovação das Perspectivas no Requisito de Negócio}

A tabela 5.2 mostra a classificação da aprovação das perspectivas, que torna evidente a falta de definição de algumas características de cada intenção, tomando como base a perspectiva de negócio, quando se aplica a intenção de negócio ilustrada na tabela 4.1. 
Tabela 5.2: Índice de aprovação das perspectivas no requisito Neg.003

\begin{tabular}{|l|l|c|l|l|}
\hline Perspectiva & \multicolumn{1}{|c|}{ Aprovação } & Índice & \multicolumn{1}{|c|}{ Justificativa } \\
\hline Negócio & Concordo & 0,8 & $\begin{array}{l}\text { É necessário definir quais } \\
\text { profissionais estarão envolvidos com o } \\
\text { tratamento do paciente }\end{array}$ \\
\hline Operacional & Concordo um pouco & 0,6 & $\begin{array}{l}\text { Faltou definir quais dados são } \\
\text { necessário e qual o limite de tempo } \\
\text { para ser fornecido aos interessados }\end{array}$ \\
\hline Design & Concordo um pouco & 0,6 & $\begin{array}{l}\text { Faltou definir a forma na qual os } \\
\text { dados serão disponibilizados }\end{array}$ \\
\hline Gerencial & Concordo um pouco & 0,6 & $\begin{array}{l}\text { É necessário definir estimativa de } \\
\text { prazo para a coleta e disponibilização } \\
\text { dos dados do paciente }\end{array}$ \\
\hline
\end{tabular}

$\mathrm{Na}$ tabela 5.3 verifica-se o número de características não definidas da intenção de cada perspectiva, para o requisito de negócio Neg.003.

Tabela 5.3: Características não definidas das perspectivas do requisito Neg.003

\begin{tabular}{|l|c|c|c|}
\hline \multicolumn{1}{|c|}{ Perspectiva } & Tni & Tn & Tni / Tn \\
\hline Negócio & 3 & 6 & 0,50 \\
\hline Operacional & 3 & 6 & 0,50 \\
\hline Design & 4 & 7 & 0,57 \\
\hline Gerencial & 6 & 7 & 0,86 \\
\hline
\end{tabular}




\subsubsection{Cálculo da volatilidade do Requisito de Negócio}

Aplicando os valores das tabelas 5.2 e 5.3 na equação eq.(5.1), temos que a volatilidade do requisito de negócio Neg.003 é:

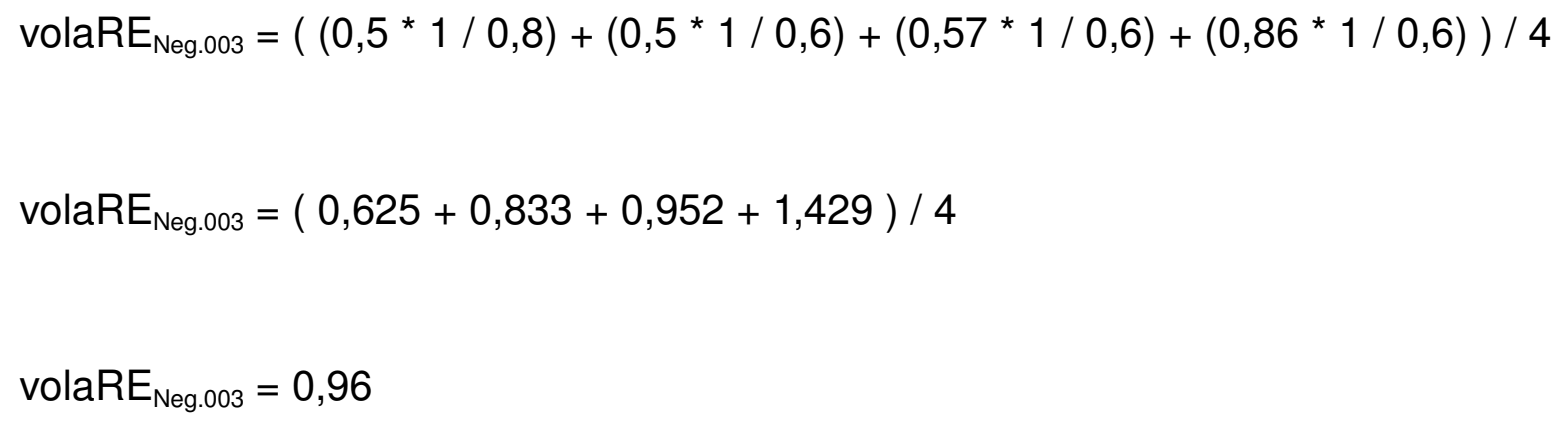

\subsubsection{Aplicando o volaRE nos Requisitos Operacionais}

Para o cálculo do volaRE dos requisitos operacionais, foi considerado o requisito Oper.009 ilustrado na tabela 3.3, faz-se a classificação da aprovação das perspectivas para encontrar o índice de aprovação de cada uma delas e, assim, calcula-se a volatilidade, conforme a equação eq.(5.1). 


\subsubsection{1 Índice de Aprovação das Perspectivas no Requisito Operacional}

A tabela 5.4 mostra a classificação da aprovação das perspectivas, que torna evidente a falta de definição de algumas características de cada intenção, tomando como base a perspectiva operacional, quando se aplica a intenção operacional ilustrada na tabela 4.3.

Tabela 5.4: Índice de aprovação das perspectivas no requisito Oper.009

\begin{tabular}{|l|l|c|l|l|}
\hline Perspectiva & \multicolumn{1}{|c|}{ Aprovação } & Índice & \multicolumn{1}{|c|}{ Justificativa } \\
\hline Operacional & Concordo um pouco & 0,6 & $\begin{array}{l}\text { Faltou a definição de quem será } \\
\text { comunicado e qual é o resultado }\end{array}$ \\
\hline Negócio & Discordo um pouco & 0,4 & $\begin{array}{l}\text { Faltou definir os recursos, o resultado e } \\
\text { como controlar a criação de } \\
\text { competições }\end{array}$ \\
\hline Design & Discordo um pouco & 0,4 & $\begin{array}{l}\text { Faltou definir os recursos, o resultado e } \\
\text { quem deve ser comunicado sobre a } \\
\text { criação de competições }\end{array}$ \\
\hline Gerencial & Discordo um pouco & 0,4 & $\begin{array}{l}\text { É necessário definir estimativa de } \\
\text { prazo, a dependência entre os } \\
\text { requisitos e os recursos envolvidos }\end{array}$ \\
\hline
\end{tabular}

Na tabela 5.5, verifica-se o número de características não definidas da intenção de cada perspectiva, para o requisito operacional Oper.009.

Tabela 5.5: Características não definidas das perspectivas do requisito Oper.009

\begin{tabular}{|l|c|c|c|}
\hline \multicolumn{1}{|c|}{ Perspectiva } & Tni & Tn & Tni / Tn \\
\hline Operacional & 4 & 6 & 0,67 \\
\hline
\end{tabular}




\begin{tabular}{|l|c|c|c|}
\hline \multicolumn{1}{|c|}{ Perspectiva } & Tni & Tn & Tni / Tn \\
\hline Negócio & 5 & 6 & 0,83 \\
\hline Design & 6 & 7 & 0,86 \\
\hline Gerencial & 6 & 7 & 0,86 \\
\hline
\end{tabular}

\subsubsection{Cálculo da volatilidade do Requisito Operacional}

Aplicando os valores das tabelas 5.4 e 5.5 na equação eq.(5.1), temos que a volatilidade do requisito operacional Oper.009 é:

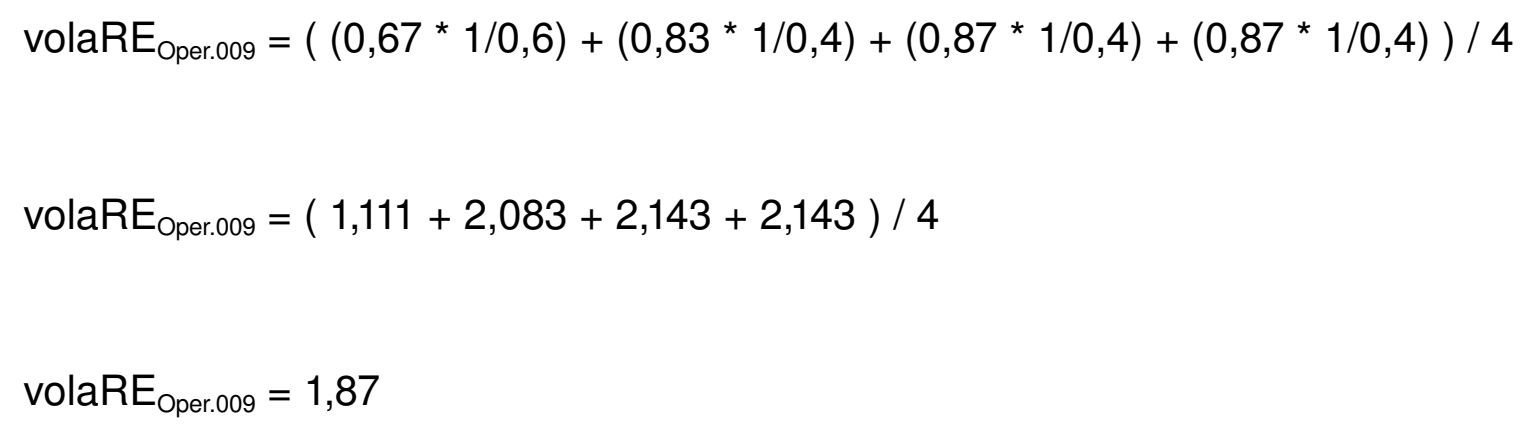

\subsubsection{Aplicando o volaRE nos Requisitos de Design}

Considerando o requisito de design visto na perspectiva de design, o requisito 
Des.003, como ilustra a tabela 3.2, faz-se a classificação da aprovação das perspectivas para encontrar o índice de aprovação de cada uma delas e, assim, calcula-se a volatilidade, conforme a equação eq.(5.1).

\subsubsection{1 Índice de Aprovação das Perspectivas no Requisito de Design}

A tabela 5.6 mostra a classificação da aprovação das perspectivas, que torna evidente a falta de definição de algumas características de cada intenção, tomando como base a perspectiva de design, quando se aplica a intenção de design ilustrada na tabela 4.5 .

Tabela 5.6: Índice da aprovação das perspectivas do requisito Des.003

\begin{tabular}{|l|l|c|l|l|}
\hline Perspectiva & \multicolumn{1}{|c|}{ Aprovação } & Índice & \multicolumn{1}{|c|}{ Justificativa } \\
\hline Design & Concordo & 0,8 & É necessário o resultado esperado \\
\hline Operacional & Discordo & 0,2 & $\begin{array}{l}\text { Faltou definir quais funções serão } \\
\text { disponibilizadas e quem deve ser } \\
\text { avisado, além do resultado esperado }\end{array}$ \\
\hline Negócio & Concordo um pouco & 0,8 & Faltou como deve ser feito o controle \\
\hline Gerencial & Discordo um pouco & 0,4 & $\begin{array}{l}\text { Seria importante a definição das } \\
\text { funções, além da sequencia de } \\
\text { disponibilização das mesmas }\end{array}$ \\
\hline
\end{tabular}

$\mathrm{Na}$ tabela 5.7 verifica-se o número de características não definidas da intenção de cada perspectiva, para o requisito de design Des.003. 
Tabela 5.7: Características não definidas das perspectivas do requisito Des.003

\begin{tabular}{|l|c|c|c|}
\hline \multicolumn{1}{|c|}{ Perspectiva } & Tni & Tn & Tni / Tn \\
\hline Design & 4 & 7 & 0,57 \\
\hline Operacional & 5 & 6 & 0,83 \\
\hline Negócio & 4 & 6 & 0,67 \\
\hline Gerencial & 5 & 7 & 0,71 \\
\hline
\end{tabular}

\subsubsection{Cálculo da volatilidade do Requisito de Design}

Aplicando os valores das tabelas 5.6 e 5.7 na equação eq.(5.1), temos que a volatilidade do requisito de design Des.003 é:

$\operatorname{volaRE}_{\text {Des. } 003}=((0,57 * 1 / 0,8)+(0,83 * 1 / 0,2)+(0,67 * 1 / 0,8)+(0,71 * 1 / 0,4)) / 4$

volaRE $_{\text {Des. } 003}=(0,7125+4,15+0,8375+1,775) / 4$

volaRE $_{\text {Des. } 003}=1,10$ 


\subsubsection{Aplicando o volaRE nos Requisitos Gerenciais}

Considerando o requisito visto na perspectiva gerencial, o requisito Ger.001, faz-se a classificação da aprovação das perspectivas para encontrar o índice de aprovação de cada uma delas e, assim, calcula-se a volatilidade, conforme a equação eq.(5.1).

\subsubsection{1 Índice de Aprovação das Perspectivas no Requisito Gerencial}

A tabela 5.8 mostra a classificação da aprovação das perspectivas, que torna evidente a falta de definição de algumas características de cada intenção, tomando como base a perspectiva gerencial, quando se aplica a intenção gerencial ilustrada na tabela 4.7.

Tabela 5.8: Índice de aprovação das perspectivas no requisito Ger.001

\begin{tabular}{|l|l|c|l|l|}
\hline Perspectiva & \multicolumn{1}{|c|}{ Aprovação } & Índice & \multicolumn{1}{|c|}{ Justificativa } \\
\hline Gerencial & Concordo um pouco & 0,6 & $\begin{array}{l}\text { É necessário definir estimativa de } \\
\text { prazo para a coleta e disponibilização } \\
\text { dos dados do paciente }\end{array}$ \\
\hline Operacional & Concordo um pouco & 0,6 & $\begin{array}{l}\text { Faltou definir quais dados são } \\
\text { necessário e qual o limite de tempo } \\
\text { para ser fornecido aos interessados }\end{array}$ \\
\hline Design & Concordo um pouco & 0,6 & $\begin{array}{l}\text { Faltou definir a forma na qual os } \\
\text { dados serão disponibilizados }\end{array}$ \\
\hline Negócio & Concordo & 0,8 & É necessário definir quais \\
\hline
\end{tabular}




\begin{tabular}{|l|l|l|l|}
\hline Perspectiva & Aprovação & Índice & \multicolumn{1}{|c|}{ Justificativa } \\
\hline & & & $\begin{array}{l}\text { profissionais estarão envolvidos com o } \\
\text { tratamento do paciente }\end{array}$ \\
\hline
\end{tabular}

Na tabela 5.9 verifica-se o número de características não definidas da intenção de cada perspectiva, para o requisito de negócio Ger.001.

Tabela 5.9: Características não definidas das perspectivas do requisito Ger.001

\begin{tabular}{|l|c|c|c|}
\hline \multicolumn{1}{|c|}{ Perspectiva } & Tni & Tn & Tni / Tn \\
\hline Gerencial & 6 & 7 & 0,86 \\
\hline Operacional & 3 & 6 & 0,50 \\
\hline Design & 4 & 7 & 0,57 \\
\hline Negócio & 3 & 6 & 0,50 \\
\hline
\end{tabular}

\subsubsection{Cálculo da volatilidade do Requisito de Negócio}

Aplicando os valores das tabelas 5.8 e 5.9 na equação eq.(5.1), temos que a volatilidade do requisito de negócio Neg.003 é:

$$
\begin{aligned}
& \text { volaRE }_{\mathrm{Ger} .001}=((0,86 * 1 / 0,6)+(0,5 * 1 / 0,6)+(0,57 * 1 / 0,6)+(0,5 * 1 / 0,8)) / 4 \\
& \text { volaRE }_{\mathrm{Ger.001}}=(1,429+0,833+0,952+0,625) / 4
\end{aligned}
$$


volaRE $_{\text {Ger. } .001}=0,96$ 


\section{Parte III}

Contribuição 


\section{Resultados e Discussão}

O desenvolvimento do trabalho apresentado na Parte II traz resultados que serão ilustrados e discutidos neste capítulo.

\subsection{Prototipação Baseada em Perspectivas}

$\mathrm{Na}$ primeira etapa do trabalho foi apresentada a prototipação, baseada em perspectivas, de projetos desenvolvidos com a participação do d-lab e que resultou na submissão desses no concurso inSites de Inovação Tecnológica, promovido pela IBM Brasil.

O primeiro resultado foi a definição das perspectivas pelas quais os projetos seriam observados. Seguem os resultados observados e a discussão dos projetos submetidos. 


\subsubsection{Perspectivas utilizadas na Prototipação}

Com base na proposta de Dym e Little (2000), de que o design de artefatos deve considerar as necessidades daqueles que o utilizarão e, no caso e no conceito de pontos de vista nas atividades da Engenharia de Requisitos, segundo a proposta de Kotonya e Sommerville (1996), foram definidas as Perspectivas de observação.

Convencionou-se chamar perspectivas porque é uma palavra que expressa a liberdade que se buscou para a observação dos projetos, pois como se pode ver na figura 6.1, o mesmo objeto pode ser visto em perspectivas diferentes pois se deseja observar, no caso da Perspectiva "a", mais faces diferentes, se comparada a Perspectiva "b". No caso de pontos de vista, eles representariam as vistas de uma perspectiva, elaborada para se obter uma visão com detalhes do objeto.

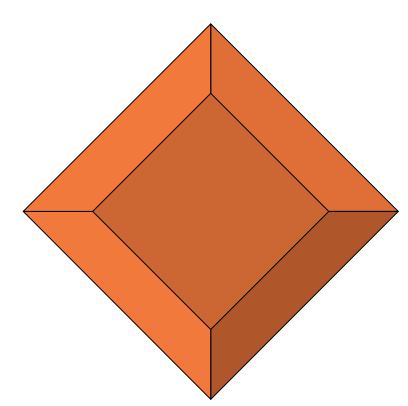

Perspectiva a

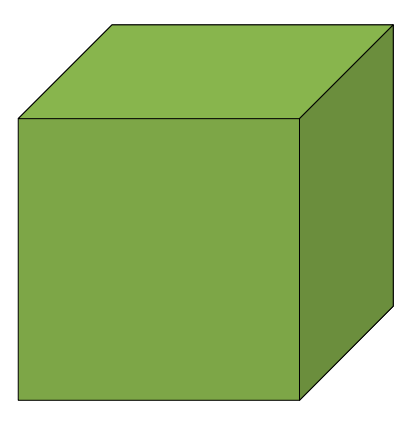

Perspectiva $b$

Figura 6.1: Perspectivas de um Objeto.

Nesse sentido, definiu-se que os projetos seriam observados, então, pelas perspectivas do Negócio, Operacional e de Design, como ilustra a figura 6.2, que é baseada na figura 4.1 . 
As próximas seções mostram os resultados da observação de projetos utilizando as perspectivas aqui apresentadas.

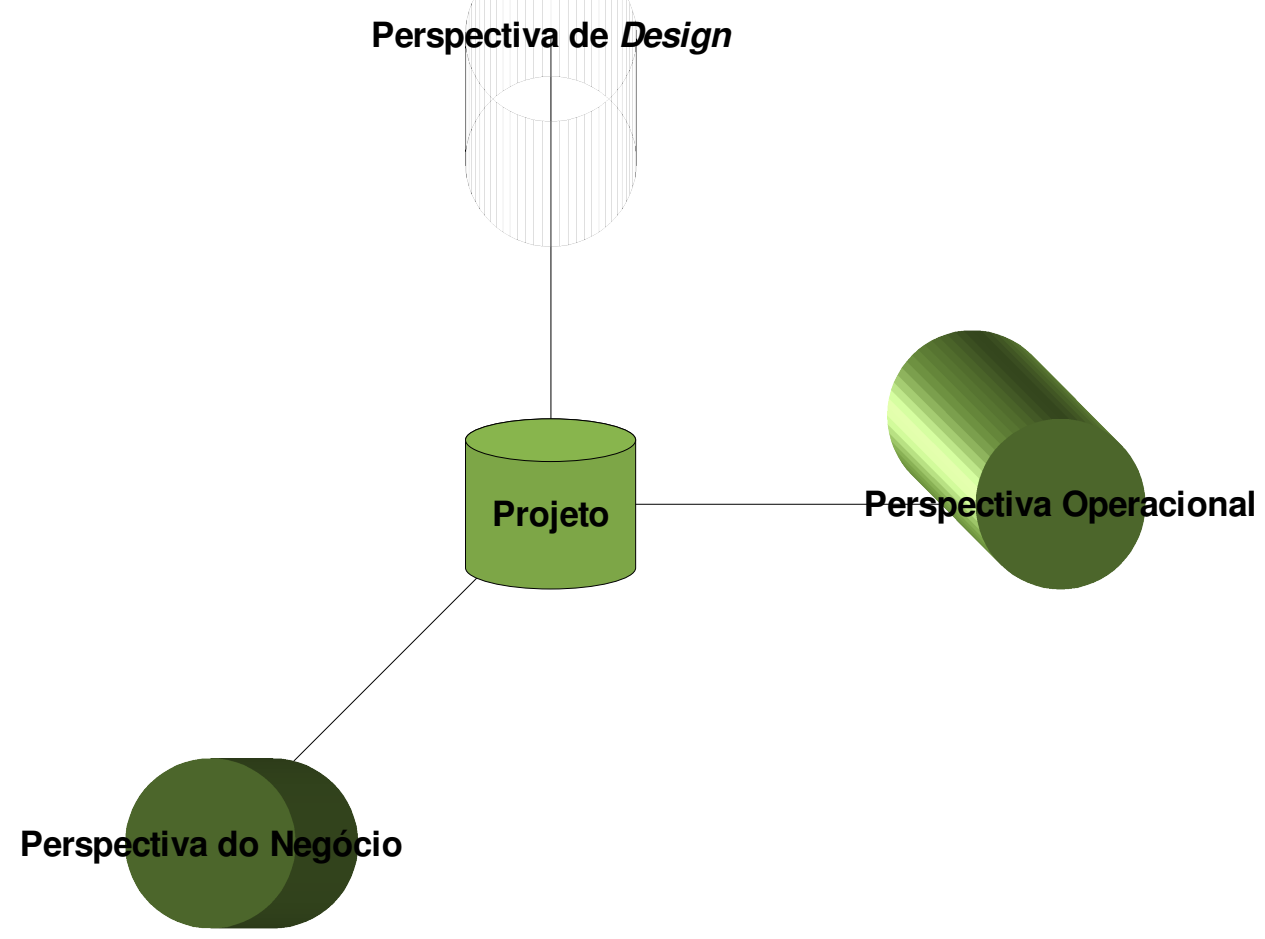

Figura 6.2: Perspectivas de Observação de um Projeto.

\subsubsection{Perspectiva do Negócio - O projeto eDrugControl}

A observação do projeto eDrugControl se deu após a elaboração do template de negócios, apresentado no apêndice $B$, que permitiu conhecer, segundo a perspectiva do negócio, a situação encontrada nos hospitais, com relação à projetos de automação para farmácia hospitalar, objetivando a redução do erro médico. 
A tabela 6.1 mostra o resultado das visitas nos hospitais de São Paulo selecionados para essa fase do projeto.

Tabela 6.1: Situação dos projetos de Automação da Farmácia Hospitalar

\begin{tabular}{|l|r|}
\hline \multicolumn{1}{|c|}{ Item observado nos hospitais } & $\%$ encontrado \\
\hline Planejamento Estratégico Hospitalar & $40 \%$ \\
\hline Definição de Processos Operacionais para os Profissionais & $20 \%$ \\
\hline Sistema de Gestão Automatizado & $20 \%$ \\
\hline Plano de Ação contra o Erro Médico & $0 \%$ \\
\hline Prescrição Eletrônica & $0 \%$ \\
\hline
\end{tabular}

Como mostra o apêndice D, o eDrugControl é um projeto que busca orientar os administradores hospitalares com relação a projetos de automação hospitalar, propondo uma solução que permita o alinhamento do planejamento do negócio e os recursos disponíveis.

Os números resultantes dessa observação mostram que, a partir do planejamento do negócio já se percebe baixos índices. No caso do planejamento estratégico, é possível que o número seja maior. Na maioria dos hospitais da rede pública não foi possível constatar se o planejamento existe.

A preparação do protótipo do projeto se deu com o objetivo de apresentação no concurso inSites, que consumiu em torno de 20 horas de atividades de interface e programação. Esse prazo foi possível porque se utilizou um framework de desenvolvimento baseado no template descrito no apêndice B. 
Além do resultado do projeto no concurso inSites, como pode ser verificado no apêndice $\mathrm{J}$, foi possível reunir alguns profissionais e pesquisadores em uma seção do evento Robótica 2006, onde foram discutidos os Impactos da Automação na Farmácia Hospitalar.

Utilizar a abordagem da Perspectiva do Negócio pode auxiliar no entendimento das reais necessidades do negócio.

\subsubsection{Perspectiva de Design - O projeto itSIMPLE}

Com o projeto itSIMPLE, a observação aconteceu na fase de preparação de um protótipo para participar do ICAPS 2005, que foi a competição internacional de inteligência artificial aplicada a planejamento automático, ocorrida em Monterey CA, EUA, em 2005. Nessa ocasião verificou-se que a maioria das ferramentas disponíveis não apresentava uma interface amigável, o que dificultava a visualização dos modelos dos sistemas de planejamento.

Assim, a estratégia foi desenvolver um ambiente para modelagem de sistemas de planejamento com forte apelo para a interface com o usuário, que deveria ser simples e intuitiva. Dessa necessidade resultou o desenvolvimento do template de design, apresentado no apêndice B.

No ICAPS 2005, o itSIMPLE conquistou o segundo lugar da competição, já na primeira participação e no ICAPS 2007 consolidou-se como o ambiente de referência para modelagem de domínios de planejamento. 
Com relação à participação do itSIMPLE no concurso inSites, buscou-se uma experiência comercial, o que resultou na preparação de um protótipo que possui uma interface para persistência dos modelos em banco de dados, utilizando uma arquitetura orientada para serviços - SOA (Service Oriented Architecture). O resultado do concurso pode ser observado no apêndice J.

Possivelmente existam limitações no template de design apresentado no apêndice $B$. Porém, a observação mostra que a prototipação facilita o entendimento das necessidades, segundo a Perspectiva de Design e a equipe do itSIMPLE aposta na possibilidade de tornar o ambiente ainda mais visual, permitindo que os modelos sejam visualizados, incluindo a animação dos mesmos, o que deve facilitar ainda mais a eliciação dos requisitos dos sistemas de planejamento automático.

\subsubsection{Perspectiva Operacional - O projeto eCampeonatos}

Durante o desenvolvimento do eCampeonatos, que é uma plataforma para criação, gerenciamento e acompanhamento de grandes eventos esportivos, foi possível observar o entendimento das necessidades da equipe organizadora, técnicos que criam as competições e tornam-nas operacionais. Essa equipe representou a Perspectiva Operacional.

Nessa etapa desenvolveu-se o template operacional, apresentado no apêndice A. A principal característica observada pela perspectiva operacional foi a necessidade de assistentes, que se aproximam mais com as necessidades do dia a dia da equipe. 
Com a disponibilização do Assistente de Criação de Competições no eCampeonatos, a equipe organizadora passou a criar competições em tempo não imaginado anteriormente. A organização do evento demandava um tempo muito grande, em torno de 04 (quatro) meses, de trabalho da equipe, resultando na tabela dos jogos. Com o assistente esse tempo passou a ser o período de processamento do algoritmo desenvolvido para alocação dos jogos nos diferentes locais de disputa, segundo a agenda de disponibilidade.

Os resultados do desenvolvimento do eCampeonatos e utilização nos Jogos da Cidade, competição esportiva de amadores da cidade de São Paulo organizada pela Secretaria de Esportes do município, podem ser observados no apêndice G. Também, o resultado da submissão do eCampeonatos no concurso inSites pode ser observada no apêndice J.

A separação do contexto dos requisitos possibilitada pela perspectiva Operacional permitiu bons resultados no eCampeonatos. É possível que o apêndice $A$ não seja o mais adequado para as necessidades diversas de prototipação, necessitando assim de evoluções. Entretanto, a observação mostra que a prototipação baseada em perspectiva facilita o entendimento das necessidades, segundo a Perspectiva de Operacional.

$\mathrm{Na}$ próxima seção são apresentados e discutidos os resultados da aplicação da intenção das perspectivas na eliciação dos requisitos observados no trabalho. 


\subsection{Intenção e Eliciação de Requisitos}

Para a definição das características que podem ser observadas a partir das perspectivas de um requisito, em função das possibilidades de mudança do mesmo, foi necessário definir a perspectiva gerencial, como mostra a figura 6.3 , baseada na figura 4.1 .

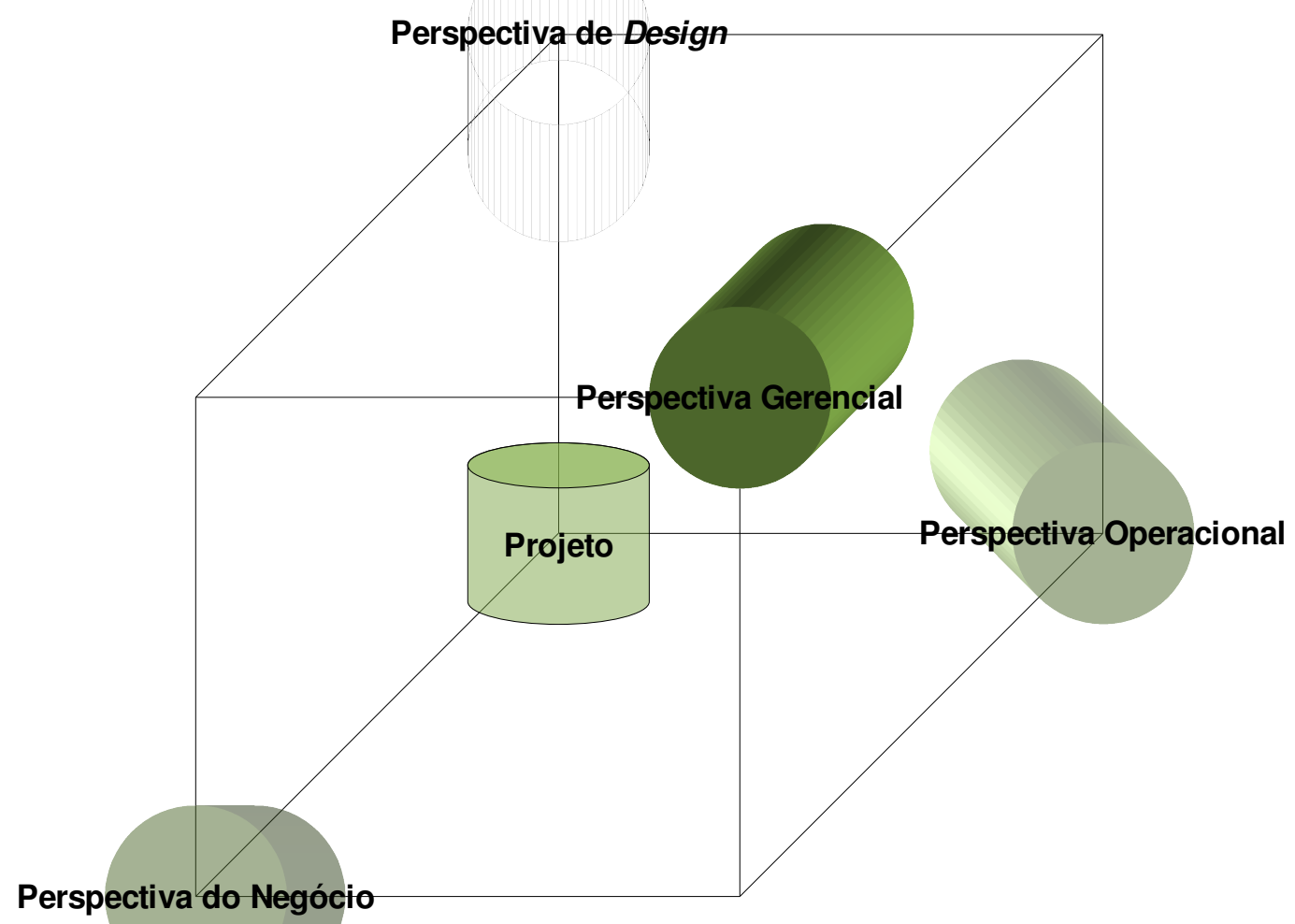

Figura 6.3: Perspectivas da Eliciação de Requisitos, com a Perspectiva Gerencial.

Desta forma, as características de cada perspectiva a serem percebidas com base nas propostas de intenção (SAID; EVRARD, 2001; HASSAN; CHANTAL; SAID, 2007), foram definidas e são resumidas na tabela 6.2. 
Analisando a tabela 6.2, para os casos nos quais as mesmas características estão presentes em $100 \%$ das perspectivas, uma possível justificativa certamente se deve à importância delas: Objetivo e OQueFaz significam, respectivamente, qual objetivo será atingido e o que deve ser feito. Segundo a proposta de Said e Evrard (2001), representam a ação e a razão.

Tabela 6.2: Observações das Perspectivas na Eliciação de Requisitos

\begin{tabular}{|l|c|c|c|r|r|}
\hline \multirow{2}{*}{ Característica } & \multicolumn{4}{|c|}{ Perspectiva } & \multirow{2}{*}{ Comum } \\
\cline { 2 - 5 } & Negócio & Operacional & Design & Gerencial & \\
\hline ComoControlar & Sim & Não & Não & Sim & $50 \%$ \\
\hline Custo & Não & Não & Não & Sim & $25 \%$ \\
\hline Duracao & Não & Sim & Não & Sim & $50 \%$ \\
\hline Objetivo & Sim & Sim & Sim & Sim & $100 \%$ \\
\hline OQueFaz & Sim & Sim & Sim & Sim & $100 \%$ \\
\hline Perspectiva & Não & Não & Sim & Não & $25 \%$ \\
\hline PreCondicao+ & Não & Sim & Não & Não & $25 \%$ \\
\hline QuemComunicar+ & Sim & Sim & Sim & Não & $75 \%$ \\
\hline Recurso+ & Sim & Não & Sim & Sim & $75 \%$ \\
\hline Requisito+ & Não & Não & Não & Sim & $25 \%$ \\
\hline Resultado+ & Sim & Sim & Sim & Não & $75 \%$ \\
\hline TipoRequisito & Não & Não & Sim & Não & $25 \%$ \\
\hline $\mathbf{1 2}$ características & $\mathbf{5 0 \%}$ & $\mathbf{5 0 \%}$ & $\mathbf{5 8 , 3 3 \%}$ & $\mathbf{5 8 , 3 3 \%}$ & --- \\
\hline
\end{tabular}

Ainda da tabela 6.2 se percebe que as características presentes em $75 \%$ das perspectivas são relacionadas ao resultado da ação e a quem deve executar e quem deve ser comunicado sobre a execução da ação, pois tem interesse. Outra informação que pode ser percebida é a quantidade de características: nas perspectivas de Design e Gerencial o número é ligeiramente maior. Isso possivelmente está relacionado com as responsabilidades de concepção e gerenciamento dessas características. 
Outro resultado relevante é a aplicação da intenção nos requisitos eliciados na etapa de prototipação dos projetos observados. A tabela 6.3 mostra a relação entre as características não percebidas pelas perspectivas para os requisitos observados na fase de prototipação dos projetos.

Tabela 6.3: Percentual de características não percebidas por perspectiva

\begin{tabular}{|l|c|c|c|c|c|}
\hline \multicolumn{1}{|c|}{ Requisito } & Negócio & Operacional & Design & Gerencial & Média \\
\hline Negócio & $50 \%$ & $50 \%$ & $57 \%$ & $86 \%$ & $\mathbf{6 1 \%}$ \\
\hline Operacional & $83 \%$ & $67 \%$ & $86 \%$ & $86 \%$ & $\mathbf{8 1 \%}$ \\
\hline Design & $67 \%$ & $83 \%$ & $57 \%$ & $71 \%$ & $\mathbf{7 0 \%}$ \\
\hline Gerencial & $50 \%$ & $50 \%$ & $57 \%$ & $86 \%$ & $\mathbf{6 1 \%}$ \\
\hline \multicolumn{1}{|c|}{ Média } & $\mathbf{6 3 \%}$ & $\mathbf{6 3 \%}$ & $\mathbf{6 4 \%}$ & $\mathbf{8 2 \%}$ & --- \\
\hline
\end{tabular}

Pode-se deduzir da tabela 6.3 que os requisitos operacionais apresentam a maior média de características não percebidas pelas perspectivas, o que pode ser explicado pela visão de execução dos envolvidos na definição desses requisitos. Já a perspectiva gerencial apresentou a maior média de características não observadas nos requisitos. Possivelmente isso se deve às responsabilidades de gestão de projetos atribuídas aos profissionais desse perspectiva e, por isso a necessidade de conhecimento dos detalhes para conduzir o projeto.

O resultado mais relevante dessa etapa foi que durante a aplicação das intenções das perspectivas, para se entender melhor os requisitos observados, $100 \%$ das características puderam ser percebidas.

A seguir são apresentados e discutidos os resultados observados no cálculo do volaRE dos requisitos observados no trabalho. 


\section{3 volaRE - Identificando a Volatilidade de Requisitos}

Para se conhecer a possibilidade de volatilidade dos requisitos, foi proposta a definição do Índice de Aprovação atribuído por cada perspectiva. A tabela 6.4 mostra os índices definidos por cada perspectiva aos requisitos em referência.

Tabela 6.4: Índice de Aprovação das perspectivas e suas médias

\begin{tabular}{|l|c|c|c|c|c|}
\hline \multicolumn{1}{|c|}{ Requisito } & Negócio & Operacional & Design & Gerencial & Média \\
\hline Negócio & 0,8 & 0,6 & 0,6 & 0,6 & $\mathbf{0 , 6 5}$ \\
\hline Operacional & 0,4 & 0,6 & 0,4 & 0,4 & $\mathbf{0 , 4 5}$ \\
\hline Design & 0,8 & 0,2 & 0,8 & 0,4 & $\mathbf{0 , 5 5}$ \\
\hline Gerencial & 0,8 & 0,6 & 0,6 & 0,6 & $\mathbf{0 , 6 5}$ \\
\hline \multicolumn{1}{|c|}{ Média } & $\mathbf{0 , 7}$ & $\mathbf{0 , 5}$ & $\mathbf{0 , 6}$ & $\mathbf{0 , 5}$ & $\mathbf{0 , 5 8}$ \\
\hline
\end{tabular}

Da tabela 6.4, verifica-se que as perspectivas Gerencial e Operacional foram as que apresentaram o menor índice de aprovação, significando que concordam menos com a definição do requisito apresentada na fase de prototipagem. Também, se pode observar que o requisito operacional apresentou o menor índice de aprovação.

A tabela 6.4 mostra uma aprovação média de 0,58 , o que mostra, de certa forma, a falta de detalhamento dos requisitos.

O trabalho também apresentou a proposta do cálculo da possível volatilidade que os requisitos podem apresentar, o volaRE, em função do índice de aprovação das perspectivas e das características não percebidas na eliciação de requisitos tradicional. A figura 6.4 mostra o cálculo do volaRE dos requisitos observados no 
trabalho.

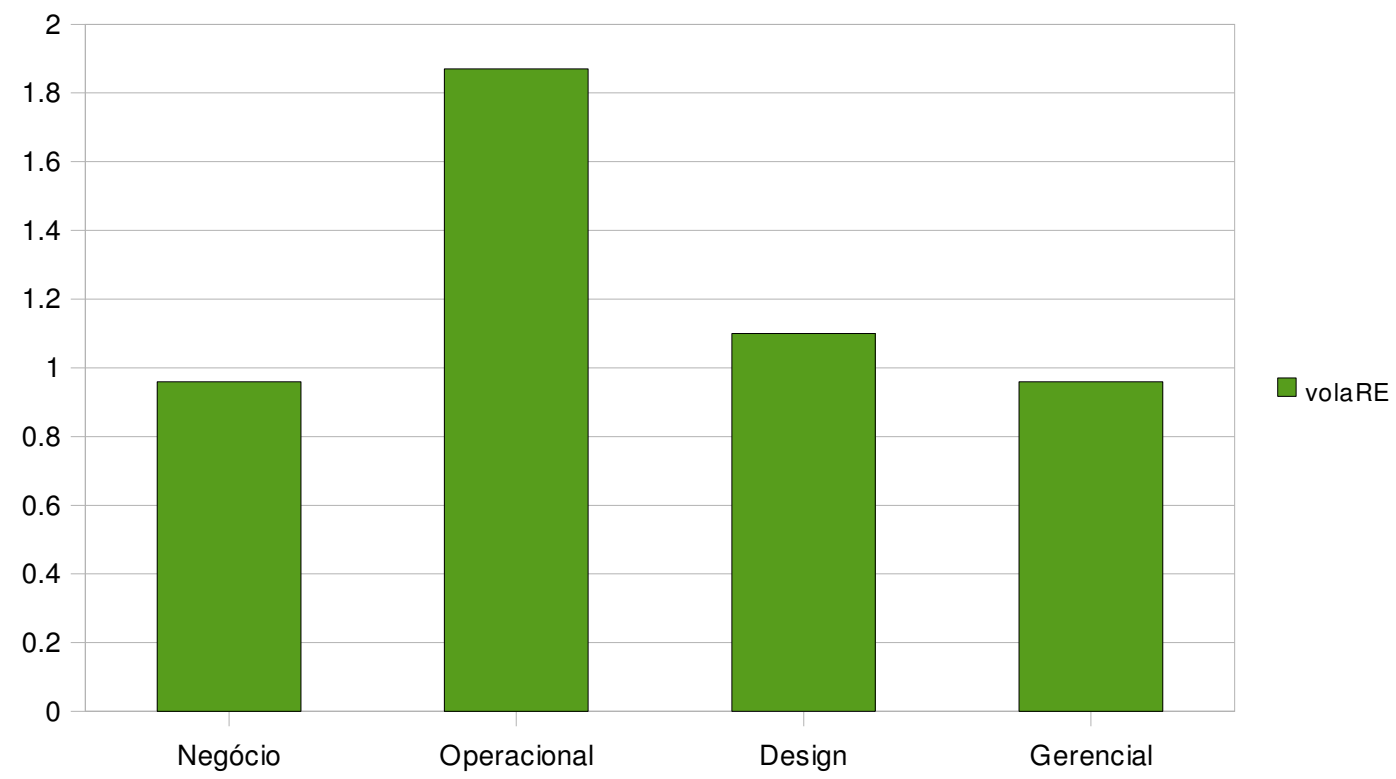

Figura 6.4: Cálculo do volaRE dos requisitos observados.

Se observa na figura 6.4 que o requisito operacional apresentou maior volaRE, seguido do requisito de design. Verificou-se com as equipes que a constatação representa a realidade, pois os requisitos que apresentaram os maiores índices de mudanças na prática foram escolhidos para as observações.

Tomando-se como base os possíveis valores do Índice de Aprovação da Perspectiva, foram aplicados seus limites e os extremos da relação Tni e Tn na equação eq.(5.1), ou seja, para cada perspectiva considerou-se a menor e maior aprovação $(0,1$ e 1) e, teoricamente, a menor e maior percepção das características das perspectivas nos requisitos. Obteve-se, assim o que mostra a tabela 6.5 .

Tabela 6.5: Limites do volaRE

\begin{tabular}{|l|c|c|c|}
\hline \multicolumn{1}{|c|}{ Limite } & Índice de aprovação & Tni / Tn & volaRE \\
\hline Inferior & 0,1 & 1 & 10 \\
\hline Superior & 1 & 0 & 0 \\
\hline
\end{tabular}


Aplicando-se os limites do volaRE na figura 6.4 , temos os percentuais de volatilidade dos requisitos observados no trabalho, que são os mesmos valores divididos por 10 . A tabela 6.6 mostra esses valores, já atribuídos aos projetos.

Tabela 6.6: Percentual do volaRE dos projetos observados

\begin{tabular}{|l|c|}
\hline \multicolumn{1}{|c|}{ Projeto } & volaRE em \% \\
\hline eDrugControl & $9,6 \%$ \\
\hline itSIMPLE & $18,7 \%$ \\
\hline eCampeonatos & $11,0 \%$ \\
\hline
\end{tabular}

Possivelmente esses valores, apesar de não ser o objetivo do trabalho, sejam válidos para projetos de Inovação Tecnológica, pois as possibilidades de mudanças são maiores, dado o caráter inovador desse tipo de produto.

Na seção seguinte são apontadas as possíveis aplicações da proposta do trabalho.

\subsection{Aplicações da Proposta}

Antecipar-se aos possíveis problemas oriundos da mudança nos requisitos é um desafio considerável. Neste sentido, as possibilidades identificadas neste trabalho podem contribuir para tal desafio, como indica a tabela 6.7. 
Tabela 6.7: Possíveis aplicações das propostas do trabalho

\begin{tabular}{|l|l|}
\hline \multicolumn{1}{|c|}{ Utilize ... } & \multicolumn{1}{c|}{$\ldots$ para ... } \\
\hline$\ldots$ perspectivas baseadas em intenção $\ldots$. & $\begin{array}{l}\ldots \text { eliciar novos requisitos. } \\
\ldots \text { analisar e/ou detalhar requisitos já } \\
\text { eliciados. } \\
\text { negociar conflitos nos requisitos. } \\
\ldots \text { resolver problemas oriundos da alta } \\
\text { volatilidade dos requisitos. }\end{array}$ \\
\hline $\begin{array}{l}\text {... a prototipação baseada em } \\
\text { perspectivas ... }\end{array}$ & $\ldots$ entender, validar e verificar requisitos. \\
\hline$\ldots$ o volaRE ... & $\begin{array}{l}\ldots \text { evitar a volatilidade dos requisitos. } \\
\ldots \text { calcular a possibilidade de volatilidade } \\
\text { de um requisito. }\end{array}$ \\
\hline
\end{tabular}

Apesar das possibilidades de aplicação da proposta, a seguir são reconhecidas algumas possíveis limitações.

\subsection{Limitações da Proposta}

Os projetos observados no trabalho pertencem a uma classe especial das aplicações em Tecnologia da Informação: os projetos de Inovação Tecnológica advindos da pesquisa aplicada. Sendo assim não seria prudente afirmar que a aplicação da proposta seja eficaz para as outras áreas de aplicações.

É possível que as características a serem observadas pelas perspectivas não sejam representativas para todas as aplicações de Tecnologia. 
Outra limitação está relacionada com a possível dificuldade de aderência à proposta do trabalho pelas equipes envolvidas nas atividades do ciclo de vida dos requisitos.

Com base nessas limitações são indicadas, na próxima seção, possíveis pesquisas para complementar a proposta apresentada no trabalho.

\subsection{Trabalhos Futuros}

Durante o desenvolvimento do trabalho, sobretudo na fase de compilação dos resultados, percebeu-se a necessidade de desenvolvimento de outras pesquisas que certamente tornariam este trabalho mais completo. Destacam-se a seguir essas necessidades.

No sentido de se possibilitar uma melhor prototipagem baseada em perspectivas, a investigação mais aprofundada em templates que generalizem as perspectivas se faz necessária, tornando assim essa proposta mais abrangente.

Um caminho possível para a generalização da eliciação de requisitos poderia ser a utilização de ontologias para a representação das características. Desenvolvimento de ontologias das perspectivas poderia facilitar o intercâmbio dos requisitos entre ferramentas de software que suportam as atividades relacionadas a requisitos.

Conhecer o impacto dos índices de volatilidade de um requisito nas diferentes perspectivas certamente tornaria a proposta mais robusta. 
É possível que uma adequação do volaRE aos processos de Engenharia de Requisitos, sobretudo nas propostas de Gerenciamento de Requisitos, possa contribuir para o melhor entendimento das mudanças $e$, conseqüentemente, possibilitar a redução da volatilidade que pode ser evitada nos requisitos.

No próximo capítulo são apresentadas as conclusões do trabalho. 


\section{Conclusão}

Neste trabalho foi pesquisado o problema de mudanças nos requisitos que definem o comportamento de produtos, em especial os sistemas baseados em software. As mudanças nos requisitos ocorrem em função das solicitações advindas do contexto no qual a organização está inserida. Atender essas solicitações requer uma flexibilidade nos processos que implementam as soluções de Tecnologia da Informação, permitindo que os envolvidos expressem suas necessidades de mudanças e que as mesmas sejam implementadas em tempo útil para os interessados.

A separação dos interessados em perspectivas de negócio, operacional, de design e gerencial, permitiu entender como a prototipação baseada em perspectivas e padrões estabelecidos de cada parte pode auxiliar no entendimento dos requisitos de projetos de Inovação Tecnológica. A classificação das características importantes de cada perspectiva, com base na intenção dos envolvidos, permitiu evidenciar que os requisitos podem ser mais claros na fase de eliciação, se estas forem executadas com base nas características que se esperam ser observadas em cada perspectiva.

Finalmente, o volaRE permitiu conhecer a possibilidade que um requisito tem em ser volátil, se forem conhecidas as características desejadas de cada perspectiva e o quanto os interessados concordam com a definição apresentada por uma das perspectivas. Isto trouxe uma contribuição para o problema de mudança nos requisitos, possibilitando que haja uma redução da volatilidade dos mesmos. 


\section{Referências}

1998. The new international Webster's comprehensive dictionary of the English language., Naples, Fl.: Trident Press International.

BARON, R.A., SHANE, S.A., 2007. Empreendedorismo uma visão do processo, São Paulo: Thomson Learning.

BERTOLINE, G.R., NASMAN, L.O., 1996. Technical graphics communication, Chicago: Irwin.

BOEHM, B.W., 1995. A Spiral Model of Software Development and Enhancement. IEEE ENGINEERING MANAGEMENT REVIEW, 23(4), p.69-81.

CARLSHAMRE, P., REGNELL, B., 2000. Requirements Lifecycle Management and Release Planning in Market-Driven Requirements Engineering Processes. Proceedings of the 11th International Workshop on Database and Expert Systems Applications Process, p.961-965.

CARR, J.J., 2000. Requirements engineering and management: the key to designing 
quality complex systems. TQM MAGAZINE -KEMPSTON THEN BRADFORDENGLISH EDITION-, 12, p.400-407.

DAVENPORT, T.H., MARCHAND, D.A., DICKSON, T., 2004. Dominando a gestão da informação, Porto Alegre: Bookman.

DYM, C.L., LITTLE, P., 2000. Engineering design : a project-based introduction, New York: John Wiley.

FINKELSTEIN, A., KRAMER, J., NUSEIBEH, B., GOEDICKE, M., 1992. Viewpoints: a framework for integrating multiple perspectives in systems development. International Journal of Software Engineering and Knowledge Engineering, v.2.

FRANCO, M.A.P., 2007. Uma abordagem baseada em atividades para gestão e determinação de custos do processo na engenharia de requisitos, Dissertação (Mestrado) - Escola Politécnica, Universidade de São Paulo, São Paulo.

GAMMA, E., 1995. Design patterns : elements of reusable object-oriented software, Reading, Mass.: Addison-Wesley. 
HASSAN, K., CHANTAL, S., SAID, T., 2007. Representing author's intentions of scientific documents. In Funchal, Portugal: INSTICC Press, p. 489-492.

HOORN, J.F., 2006. Software Requirements: Update, Upgrade, Redesign. Towards a Theory of Requirements Change, PhD Thesis. Vrije Universiteit.

HOORN, J.F., KONIJN, E.A., VAN VLIET, H., VAN DER VEER, G., 2007. Requirements change: Fears dictate the must haves; desires the won't haves. J. Syst. Softw., 80(3), p.328-355.

JACOBSON, I., BOOCH, G., RUMBAUGH, J., 1999. The unified software development process, Reading, Mass: Addison-Wesley.

KARAHANNA, E., STRAUB, D.W., CHERVANY, N.L., 1999. Information Technology Adoption Across Time: A Cross-Sectional Comparison of Pre-Adoption and Post-Adoption Beliefs. MANAGEMENT INFORMATION SYSTEMS QUARTERLY, 23(2), p.183-214.

KOTONYA, G., SOMMERVILLE, I., 1996. Requirements engineering with viewpoints. Software Engineering Journal, 11(1), p.5-18. 
techniques, Chichester; New York: J. Wiley.

LAURINDO, F.J.B., 2002. Tecnologia da informação : eficácia nas organizações, São Paulo: Futura.

LEFFINGWELL, D., WIDRIG, D., 2000. Managing software requirements : a unified approach, Reading, MA: Addison-Wesley.

MAIDEN, N.A.M., RUGG, G., 1996. ACRE: selecting methods for requirements acquisition. SOFTWARE ENGINEERING JOURNAL, 11(3), p.183-192.

MAIDEN, N., RUGG, G., PATEL, P., 1999. Guidelines for better scenarios: supporting theories and evidence. In Database and Expert Systems Applications, 1999. Proceedings. Tenth International Workshop on., p. 352-356.

MALONE, T.W., CROWSTON, K., HERMAN, G.A., 2003. Organizing Business Knowledge: The MIT Process Handbook, MIT Press.

MULLERY, G.P., 1979. CORE - a method for controlled requirement specification. In Proceedings of the 4th international conference on Software engineering. Munich, Germany: IEEE Press, p. 126-135. 
NUSEIBEH, B., EASTERBROOK, S., 2000. Requirements engineering: a roadmap. In Proceedings of the Conference on The Future of Software Engineering. Limerick, Ireland: ACM, p. 35-46.

OGOT, M.M., KREMER, G., 2004. Engineering design : a practical guide, Victoria, B.C.: Trafford.

PINE, B.J., 1993. Mass customization : the new frontier in business competition, Boston, Mass.: Harvard Business School Press.

PRESSMAN, R.S., 2006. Engenharia de software, São Paulo: McGraw-Hill.

QUEIROZ, R.A.A., 2007. Eliciação e comunicação de requisitos em domínios disjuntos: estudo de caso para a área médica, Dissertação (Mestrado) Escola Politécnica, Universidade de São Paulo, São Paulo.

ROSS, D., SCHOMAN, K., 1977. Structured Analysis for Requirements Definition. Software Engineering, IEEE Transactions on, SE-3(1), p.6-15. 
SAID, T., EVRARD, F., 2001. Intentional structures of documents. In Proceedings of the twelfth ACM conference on Hypertext and Hypermedia. Arhus, Denmark: ACM, p. 39-40.

SANTOS, E.A., 2002. Verificação de requisitos de sistemas utilizando redes de Petri, Dissertação (Mestrado) - Escola Politécnica, Universidade de São Paulo, São Paulo.

SHAW, M., GAINES, B., 1996. Requirements acquisition. Software Engineering Journal, 11(3), p.149-165.

SILVA, J.R., SANTOS, E.A., VAQUERO, T.S., 2005. Specification and Analysis for Automated Flexible Manufacturing. Proceedings of the 18th Congress of Mechanical Engineering.

SOMMERVILLE, I., SAWYER, P., 1997. Requirements engineering, Wiley New York.

THAYER, R.H., DORFMAN, M., 1990. System and software requirements engineering. In IEEE Computer Society Press tutorial. Los Alamitos, Calif.: IEEE Computer Society Press.

The Standish Group International, Inc., 2005. The CHAOS report, Dennis, MA. 
The Standish Group International, Inc., 1995. The CHAOS report, Dennis, MA.

VAN LAMSWEERDE, A., DARIMONT, R., LETIER, E., 1998. Managing Conflicts in Goal-Driven Requirements Engineering. IEEE TRANSACTIONS ON SOFTWARE ENGINEERING SE, 24(11), p.908-926.

VAQUERO, T.S., SETTE, F., SANTOS, E.A., SILVA, J.R., 2007. Integrated tools environment for modeling and analysis of automated planning systems. Proceedings of the 19th Congress of Mechanical Engineering.

VILLER, S., SOMMERVILLE, I., 1999. Social Analysis in the Requirements Engineering Process: From Ethnography to Method. In Proceedings of the 4th IEEE International Symposium on Requirements Engineering. IEEE Computer Society, p. 6-13.

ZACHMAN, J.A., 1999. A framework for information systems architecture. IBM SYSTEMS JOURNAL, 38(2/3), p.454-471. 


\section{Parte IV}

Apêndices 


\section{Apêndice A - Template Operacional}

Com base nos conceitos do framework proposto por Zachman (1999), este template foi elaborado no sentido de auxiliar as tarefas de prototipação da perspectiva operacional. Os componentes de software, aqui chamados de templates, foram desenvolvidos com o objetivo de agilizar a implementação de protótipos para verificação de requisitos na fase de eliciação.

\section{A.1 Componentes de Software}

O modelo de objetos equivalente é mapeado a partir das entidades identificadas na definição do requisito, onde:

- A entidade representa a classe

- As características, representam os atributos da classe

- As ações, representam os métodos

Desta forma, para o desenvolvimento do protótipo, a tabela A.1 mostra a equivalência da classe com os componentes de software: 
Tabela A.1: Equivalências do template operacional

\begin{tabular}{|l|l|}
\hline \multicolumn{1}{|c|}{ Característica da Classe } & \multicolumn{1}{c|}{ Componente de Software } \\
\hline Classe & Formulários para registro de informações \\
\hline Propriedades & Campos do formulário \\
\hline Métodos & Operações \\
\hline
\end{tabular}




\section{Apêndice B - Template de Negócio}

Com base no MIT Process Handbook (MALONE; CROWSTON; HERMAN, 2003) e nos conceitos de empreendedorismo, visto em (BARON; SHANE, 2007), foi definido o template de negócio para apoiar as atividades de entendimento da perspectiva de negócios.

- Resumo Executivo: Descreve o negócio, de forma sucinta e objetiva

- Forma: Texto estruturado

- Histórico, Produto e Objetivo: Mostra o histórico da unidade de negócio, o produto ou serviço e, principalmente, o objetivo do negócio.

- Forma: Texto estruturado

- Análise de Mercado: Aborda um estudo do mercado potencial para o produto ou serviço, uma análise da concorrência e o estudo de formação de preços.

- Forma: Texto estruturado, Diagrama, Planilha

- Desenvolvimento, Produção e Localização: Mostra a fase atual do desenvolvimento do produto ou serviço, como e onde serão produzidos. 
- Forma: Texto estruturado, Diagrama, Planilha

- Equipe Gerencial: Descreve a competência e responsabilidades dos membros da equipe que conduzirá o negócio.

- Forma: Texto estruturado e Diagrama (Organograma)

- Planos e Projeções Financeiras: llustra os demonstrativos financeiros, sobretudo no que diz respeito ao retorno do investimento do negócio.

- Forma: Texto estruturado e Planilha (ROI) 


\section{Apêndice C - Template de Design}

O template de design é guia que orienta o desenho de interfaces com o usuário, simples e intuitiva. Consiste em dividir o espaço da tela de apresentação em regiões, como segue:

- Menu de opções

- Região de navegação

- Região de definição de propriedades

- Região de trabalho

- Região de informação

- Região de acesso rápido

A figura C.1 mostra o conceito do template. 


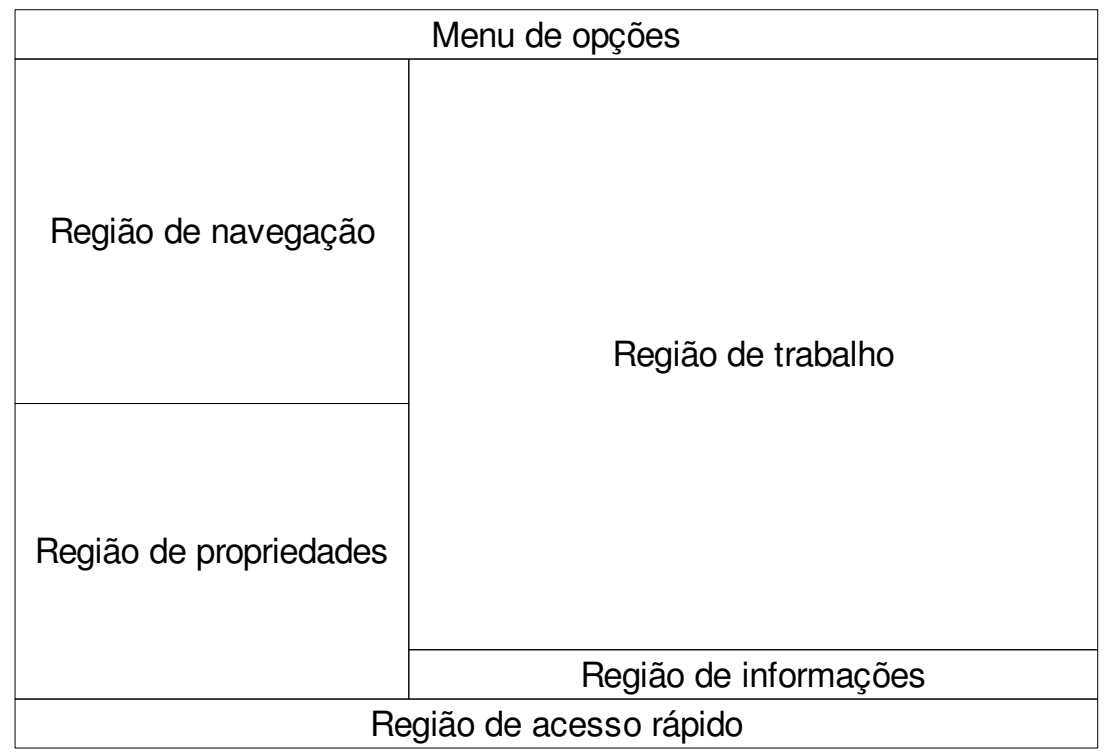

Figura C.1: Regiões do template de design. 
Apêndice D - Negócios com o eDrugControl

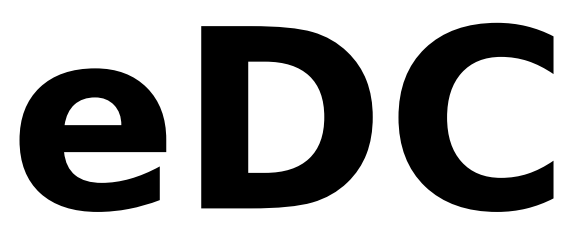

\section{electronic Drug Control}

São Paulo 


\section{D.1 Descrição dos Produtos}

O eDC é uma solução em modelagem de processos de negócios com o uso extensivo da automação como ferramenta no incremento da eficiência e eficácia em farmácias hospitalares. Sendo um sistema bastante moldável, de fácil implementação e utilização poderá ser utilizado em hospitais que possuam qualquer nível de automação de seus processos.

O serviço de assistência à saúde é cobrado por todos os seus personagens: por médicos, para aumentar a qualidade do atendimento; por administradores, para reduzir custos e aumentar margens de lucro; por agencias reguladoras, a fim de garantir padrões mínimos de qualidade e por instituições acadêmicas, para que sejam fornecidas informações e motivações à pesquisa. O eDC tende a satisfazer todas essas demandas.

Os recursos do eDC visam a melhoria do armazenamento, transporte e uso da informação necessárias para o bom funcionamento do ciclo do uso de medicamentos em um hospital. Para tal, serão necessários bancos de dados seguros, uma infra-estrutura de rede veloz e um software competente que faça do avanço tecnológico também um avanço de produtividade e facilidade.

A solução visa utilizar uma plataforma Web com interface que possua os máximos recursos em interatividade, mobilidade e facilidade de uso. Não basta que as tarefas relativas à informação sejam cumpridas de forma extremamente funcional se a acessibilidade não for adequada ao perfil dos profissionais que irão utilizá-lo. Por isso, a interface homem-máquina será a principal preocupação do desenvolvimento do eDC.

eDC possui recursos para cada etapa do ciclo do uso de medicamentos e sua função de modelagem de negócios permitirá que a solução mais adequada seja escolhida de acordo com o planejamento estratégico do hospital: sua missão, objetivos e metas a curto, médio e longo prazo.

No planejamento e aquisição, eDC terá recursos suficientes para elaborar automaticamente um pedido de compra, comunicar-se com fornecedores e mostrar ao responsável a melhor opção segundo seus critérios pré-determinados. 
A distribuição e logística, seja ela realizada por dose coletiva, individualizada ou unitária, poderá contar com diversas opções de automação que levarão a diferentes resultados no que compete a eficiência e eficácia do processo. Este setor está intimamente ligado com um solicitação, que também deverá ser eletrônica e contar com todos os recursos de interatividade.

As melhorias no setor de dispensação será o ponto forte do eDC. Os recursos disponíveis irão desde simples componentes de software que farão a contagem da quantidade disponível em cada clínica até um sistema robotizado com uso de tubos pneumáticos. Tudo aliado a um componente de prescrição eletrônica de uso extremamente simplificado.

O controle de estoque será planejado de forma a garantir total confiabilidade e segurança dos dados sem a menor necessidade de contagem visual. Estará intimamente ligado ao setor de compras e logística, mantendo a contagem física exatamente igual à exibida no software.

Para farmácias hospitalares que possuam um setor farmacotécnico, o eDC contará com um guia para a realização destas manipulações. E para os hospitais que contam com um serviço de farmácia clínica, partes do sistema de prescrição eletrônica será destinada às eventuais correções do farmacêutico e seguinte encaminhamento para o médico.

O eDC ainda contará com um arquivo onde ficarão armazenados os dados de cada paciente para fins de rastreabilidade e estudos acadêmicos. Com isso, cobriremos todas as etapas do ciclo e tornaremos o serviço de assistência à saúde mais eficiente e eficaz.

\section{D.2 Descrição dos Serviços}

Embora o eDC seja uma solução totalmente modelável e de fácil implantação, a empresa e o hospital devem tomar medidas preventivas e eventualmente corretivas para que o projeto não se torne um impecílio para o bom funcionamento da farmácia. 
A fase mais importante da construção do software será o levantamento de requisitos. Além das técnicas usuais, a empresa fará uso de um recurso que transformará o planejamento estratégico de cada centro de saúde em indicações de qual é o tipo de automação mais adequado para cada processo.

Por exemplo, o planejamento estratégico de um hospital de grande porte, cuja farmácia centralizada utiliza distribuição por dose unitária, indica que uma das metas é eliminar o atendimento devido à requisição de novos medicamentos na porta da farmácia central. Tais variáveis, quando imputadas no software de alinhamento indicarão que a melhor solução é a implantação de dispensários eletrônicos em cada clínica.

O levantamento de requisitos mostrará todas as peculiaridades do nosocômio e o alinhamento com o planejamento estratégico apontará as rotas para o início da programação e outros processos de desenvolvimento.

Após tais confecções, a empresa proverá o serviço de implantação do sistema com o treinamento de todos os profissionais usuários do sistema. Este treinamento poderá ser realizado no próprio hospital e será ministrado por pessoal especializado.

A empresa poderá realizar os eventuais serviços de manutenção e atualização do software, conforme requisição da direção de cada centro de saúde. Ao mesmo tempo, a empresa poderá emitir certificações para funcionários de TI do hospital para que estes possam realizar estas modificações.

\section{D.3 Descrição do Problema Resolvido}

Nos dias atuais, a farmácia hospitalar (FH) não detém apenas importância técnica, mas também administrativa e contábil. Cerca de $30 \%$ do orçamento de um hospital é destinado à compra de medicamentos e correlatos. Ao mesmo tempo, o volume de estudos sobre medicamentos e a exigência sobre os personagens envolvidos neste processo é cada vez maior. 
O uso de medicamentos em hospitais pode envolver de 20 a 30 etapas e qualquer uma delas está suscetível a deficiências na sua eficiência e eficácia. O eDC poderá ser útil em cada uma delas e a descrição dos problemas é encontrada a seguir.

Tudo começa com a compra dos medicamentos. Dado que um medicamento encontra-se no limite crítico de estoque, eDC poderá elaborar uma lista de compras e, associado a um banco de dados de fornecedores, poderá encaminhar um e-mail com pedido de orçamento. Poderá fazer comparações segundo pesos definidos pelo farmacêutico responsável pelo setor e exibir as possíveis escolhas. Ao simples clicar do responsável, um pedido já poderá ser encaminhado e acompanhado diariamente. Em hospitais da rede pública, os pedidos de compra correspondem ao maior desperdício de tempo e recursos humanos da $\mathrm{FH}$.

A entrada do medicamento, que será conferida junto ao pedido, será imediatamente contabilizada no estoque. Este fará uso de códigos de barras e proverá cada fármaco de uma localização específica, que preferencialmente não será a alfabética, visto que isto poderá gerar confusão com medicamentos de nomes parecidos ou idênticos (porém com concentrações diferentes).

A retirada do estoque, mediante a um pedido automático (seja ele da sala de dispensação, das clínicas ou pedidos especiais) poderá ser exibida ao funcionário pelo uso de um dispositivo móvel que poderá traçar a menor rota entre as prateleiras do almoxarifado para a retirada. Dado este rígido controle de estoque, teremos solucionado outra grande preocupação dos farmacêuticos. Este recurso abrirá portas para estudos de gestão de estoque, planejamentos e fechará qualquer possibilidade de furto de medicamentos.

Passaremos então para o processo de logística: o médico que faz as visitas aos seus pacientes internados, poderá contar com recursos de um dispositivo móvel para fazer a prescrição dos medicamentos. Nossa solução será adequada para o uso em tablets PC's que associados a uma rede Wi-Fi permitirão ao corpo clínico, uma prescrição à beira do leito.

A prescrição eletrônica anula diversos problemas relacionados à legibilidade e padronização de medicamentos. Permitirá ao médico saber se tal fármaco está disponível na farmácia, podendo imediatamente substituí-lo por um similar e poderá utilizar a prescrição do dia anterior para efetuar possíveis modificações e enviá-las à farmácia. Para garantir a minimização de todos estes problemas, garantiremos a confiabilidade e facilidade de uso do sistema. 
Portanto, o próximo grande passo da logística ocorre na farmácia. A dispensação dos medicamentos pode ser feita de diferentes formas. eDC inclui uma solução para cada tipo. Se a dispensação for feita coletivamente, cada clínica terá um controle de seu estoque não somente em número de cartelas e frascos, mas também em número de comprimidos e gotas. A baixa deste tipo de estoque será feita pela prescrição e os pedidos de reposição serão encaminhados diretamente à farmácia.

Os recursos ficam mais interessantes quando lidamos com sistema por dose unitária. A sala de dispensação normalmente possui muitos funcionários para que seja possível separar, conferir, embalar e enviar no prazo adequado (que normalmente é inviável, dado o atraso na chegada das prescrições). A solução pode englobar desde um sistema com código de barras que evite a conferência até um sistema totalmente robotizado que envie pacote separados por paciente e por horário para cada clínica utilizando-se de tubos pneumáticos.

Assim, o problema da falta de agilidade no trabalho de logística seria melhorado de acordo com as metas de cada hospital, podendo contar com diversos níveis de melhoria de acordo com o planejamento estratégico.

Algumas farmácias hospitalares contam com um setor farmacotécnico, que manipula medicamentos em posologias e formas farmacêuticas que não são encontradas no mercado. Esta produção é lenta em relação a uma simples separação na sala da dispensação, por isso merece atenção especial: nossa solução pode contar com um guia de manipulação que já calcule as quantidades corretas de cada componente e exiba para o técnico manipulador.

Em alguns casos, a FH também realiza atividades de farmácia clínica a fim de melhorar a eficácia do processo. Para estes farmacêuticos, será disponibilizado um recurso na prescrição eletrônica que permitirá o acréscimo de comentários em quaisquer campos.

Esta prescrição será reenviada ao médico, pelo meio que acharem adequado (desktop, laptop, tablet, PDA ou mesmo SmartPhone) para que este aceite ou decline as alterações sugeridas.

O ciclo de uso da medicação em hospitais termina com a administração pela equipe de enfermagem. Os problemas relacionados à falta de legibilidade da prescrição e outros elementos que podem induzir o erro podem ser resolvidos com uma relação eletrônica de quais os pacientes que devem receber medicamentos (também 
relacionados) naquele horário.

Todos os personagens do ciclo terão à disposição no eDC um guia farmacoterapêutico que irá conter as informações que julgarem interessantes como posologias usuais, formas de diluição, eventos adversos, interações medicamentosas, entre outros.

Ao mesmo tempo, cada paciente que ficar internado naquele hospital terá gravado em um banco de dados uma ficha farmacoterapêutica que armazenará cada medicamento utilizado durante sua permanência e seu detalhes como lote e validade. Assim, resolveremos o problema da rastreabilidade caso algum lote seja interditado pela ANVISA.

Os dados armazenados em cada etapa do ciclo de uso de medicamentos poderão estar disponíveis para a elaboração de relatórios de interesse seja para a administração do hospital, seja para fins acadêmicos.

Apresentados todos os problemas que serão resolvidos com a implementação do eDC, fica claro que todos os personagens do ciclo serão beneficiados. O grande tempo que seria desperdiçado no preenchimento de prescrições, separação e leitura destas será convertido em melhoria no atendimento dos pacientes, que é o foco principal do serviço de assistência à saúde.

\section{D.4 Análise do Mercado Potencial}

As tarefas de uma farmácia hospitalar envolvem planejamento, aquisição, armazenamento, distribuição, gerenciamento, seleção, farmacotécnica, informação, ensino e pesquisa. Dados encontrados em um estudo da FIOCRUZ de 2004, conforme tabela D.1, que analisou 250 hospitais em todo o Brasil, mostra informações relevantes para a análise do mercado potencial. 
Tabela D.1: Informações sobre a Farmácia Hospitalar no Brasil

\begin{tabular}{|c|c|}
\hline Informação & Percentual \\
\hline $\begin{array}{l}\text { Porcentagem de } \mathrm{FH} \text { em que há programação para abastecimento para } \\
\text { medicamentos selecionados }\end{array}$ & $7,6 \%$ \\
\hline $\begin{array}{l}\text { Porcentagem de } \mathrm{FH} \text { que utiliza a curva } \mathrm{ABC} \text { para programação, dentre } \\
\text { aqueles que possuem uma relação de produtos de compra }\end{array}$ & $30,9 \%$ \\
\hline Porcentagem de Hospitais que possuem cadastro de fornecedores & $70,0 \%$ \\
\hline $\begin{array}{l}\text { Porcentagem de Hospitais que se utilizam de banco de preços para } \\
\text { acompanhamento dos processos de compra }\end{array}$ & $15,2 \%$ \\
\hline Porcentagem de FH que possuem sistema de controle de estoque & $62,3 \%$ \\
\hline $\begin{array}{l}\text { Porcentagem de } \mathrm{FH} \text { que possuem sistema de controle de estoque } \\
\text { informatizado }\end{array}$ & $34,54 \%$ \\
\hline $\begin{array}{l}\text { Porcentagem de } \mathrm{FH} \text { onde o registro de estoque corresponde a } \\
\text { contagem física para os medicamentos estocados }\end{array}$ & $0,0 \%$ \\
\hline $\begin{array}{l}\text { Porcentagem de FH que distribui medicamentos para os pacientes } \\
\text { internados utilizando sistema de distribuição de medicamentos por } \\
\text { prescrição individualizada }\end{array}$ & $34,8 \%$ \\
\hline $\begin{array}{l}\text { Porcentagem de FH que distribui medicamentos para os pacientes } \\
\text { internados utilizando o sistema coletivo }\end{array}$ & $51,2 \%$ \\
\hline Porcentagem de $\mathrm{FH}$ que dis & $\%$ \\
\hline
\end{tabular}




\begin{tabular}{|c|c|}
\hline Informação & Percentual \\
\hline internados utilizando o sistema individualizado & \\
\hline $\begin{array}{l}\text { Porcentagem de } \mathrm{FH} \text { que distribui medicamentos para os pacientes } \\
\text { internados utilizando o sistema de dose unitária }\end{array}$ & $0,4 \%$ \\
\hline Porcentagem de FH que possuem farmácia(s) satélite(s) & $19,6 \%$ \\
\hline $\begin{array}{l}\text { Porcentagem de } \mathrm{FH} \text { que possuem recursos de informática para } \\
\text { utilização em atividades clínicas }\end{array}$ & $5,6 \%$ \\
\hline $\begin{array}{l}\text { Porcentagem de } \mathrm{FH} \text { que possuem relação de medicamentos } \\
\text { atualizada }\end{array}$ & $27,2 \%$ \\
\hline $\begin{array}{l}\text { Porcentagem de } \mathrm{FH} \text { em que existe formulário ou guia } \\
\text { farmacoterapêutico }\end{array}$ & $5,6 \%$ \\
\hline Porcentagem de FH que realiza fracionamento de medicamentos & $7,2 \%$ \\
\hline $\begin{array}{l}\text { Porcentagem de FH em que o farmacêutico participa da visita médica } \\
\text { ou realiza visita específica }\end{array}$ & $6,4 \%$ \\
\hline $\begin{array}{l}\text { Porcentagem de FH que dispõe de ficha farmacoterapêutica de } \\
\text { pacientes internados }\end{array}$ & $1,2 \%$ \\
\hline $\begin{array}{l}\text { Porcentagem de } \mathrm{FH} \text { que realiza formalmente atividades de } \\
\text { farmacovigilância }\end{array}$ & $0,4 \%$ \\
\hline
\end{tabular}




\begin{tabular}{|l|r|}
\hline \multicolumn{1}{|c|}{ Informação } & Percentual \\
\hline $\begin{array}{l}\text { Porcentagem de } \mathrm{FH} \text { que participa de atividades de pesquisa no } \\
\text { hospital }\end{array}$ & $3,2 \%$ \\
\hline
\end{tabular}

Esses dados mostram que o problema que pode ser resolvido com a utilização do sistema eDC se faz presente na grande maioria dos hospitais brasileiros. É relevante citar que a escolha dos nosocômios estudados foi aleatória, ou seja, houveram hospitais públicos, privados, universitários e/ou filantrópicos. Logo, nossa solução pode abranger todo e qualquer centro de saúde que não possua sistema informatizado.

Porém, a informática em saúde no Brasil tem evoluído bastante. Muitas empresas e hospitais tem trabalhado no sentido de aumentar o nível de automação nas mais diversas áreas conseguindo alguns bons resultados. Porém, podemos afirmar que ainda é insuficiente na opinião da maioria dos profissionais.

Podemos explicar este fato dividindo os softwares desenvolvidos em duas classes: os provenientes de empresas terceirizadas e os desenvolvidos por uma equipe própria do hospital.

No primeiro caso, os objetivos relacionados a automação não são plenamente alcançados pois a empresa contratada para a implantação não estabelece comunicação adequada com o administrador hospitalar e conseqüentemente faz um levantamento de requisitos baseada na experiência de outros sistemas já implantados. Logo, os funcionários do hospital não ficam satisfeitos pois consideram tal sistema um enlatado que não se adequa a sua realidade.

No segundo caso, os profissionais de TI do hospital são muito exigidos pelos mais diversos setores. Os funcionários de cada departamento descrevem suas necessidades e propõe soluções para serem integradas ao software. Este processo além de ser demorado, acaba por não alcançar plenamente os seus objetivos pois a parte mais importante da confecção, o levantamento de requisitos, é realizado por pessoas que não tem formação específica para tal. 
A solução aqui proposta será diferente à medida que a modelagem da solução será executada de acordo com o planejamento estratégico de cada hospital, ou seja, sua missão, seus objetivos e metas mensuráveis para curto, médio e longo prazo. Com isso, o sistema não será considerado um "enlatado" e tentará ao máximo se encaixar de forma perfeita à rotina da instituição ao mesmo tempo em que utilizará a experiência de outras a fim de garantir as soluções mais inovadoras, eficientes e eficazes.

Assim sendo, o eDC pode ser uma solução adequada tanto para substituição de sistemas já existentes, aproveitando toda a infra-estrutura de rede e computadores ou apenas para preencher lacunas onde o sistema operante não atende as funcionalidade a ele destinadas.

Dada a grande versatilidade da solução proposta, nosso mercado é abrangente no que tange a existência ou não de um sistema já operante. Ao mesmo tempo, o mercado se restringe as hospitais cujo planejamento estratégico inclui investimentos para soluções em automação.

Sabemos que grande parte das instituições não tem tal plano elaborado, mas é claro para todas elas que a automação corretamente aplicada é uma condição básica para a evolução.

\section{D.5 A empresa}

A thinkUP Engenharia de Software \& Internet, constituída em 1998 com a missão de prover soluções em Engenharia de Requisitos, focou a partir de 2003 na pesquisa e desenvolvimento de um ambiente de Design, compreendendo um investimento significativo no desenvolvimento de uma infra-estrutura de fabrica de software baseado em Internet de nova geração, a Web 2.0.

Em 2003 foi firmada uma parceria estratégica firmada com o d-lab, onde os sócios fundadores da thinkUP mantém atividades regulares de pesquisa acadêmica. Essa parceria viabilizou a concepção do ambiente de Design da thinkUP, que apóia de 
forma estrutural todos os projetos desenvolvidos na empresa.

Seguindo com o seu planejamento estratégico, em 2004 a thinkUP concebeu uma unidade de negócios para o desenvolvimento de projetos na área de bem-estar: Entretenimento e Saúde.

\section{D.6 A equipe}

A equipe esta constituída por um professor doutor, que é o orientador, dois integrantes da empresa, com qualificação de mestrado e doutorado, e dois alunos de iniciação científica. Todos os membros estão vinculados à Escola Politécnica da Universidade de São Paulo. 


\title{
Apêndice E - Artigo do eDrugControl
}

\section{A Farmácia Hospitalar no Brasil precisa de Automação}

\author{
Daniel D. Follador, Diogo S. Dutra, Melina T. Guedes, Eston A. Santos \\ d-lab - Escola Politécnica da USP \\ Av. Prof. Mello Moraes, 2231 - 05508-900 - São Paulo - SP - Brasil \\ daniel.follador@poli.usp.br, diogo.souza@poli.usp.br,
}

melina.guedes@poli.usp.br, eston@usp.br

\begin{abstract}
Now a days, the hospital pharmacy has not only know-how importance but also administrative and economics. In Brazil, a few pharmacies can reach, minimally, the basic objectives as stock control. The drugs utilization inside hospitals may require 20 to 30 steps and a fail in any of those steps is designated as medical error. At least 1.5 million Americans are sickened, injured or killed and the extra expense of treating drug-related injuries occurring in hospitals alone was estimated conservatively to be $\$ 3.5$ billion each year. The reduction of these problems converges to a solution in business process modeling with an extensive usage of automation as a tool to increase efficiency and efficacy at many aspects. The software benefits cover different control, mobility and interactivity levels, according to hospital objectives, defined in the strategic planning.
\end{abstract}

Resumo: Hoje em dia, a farmácia hospitalar ( $F H$ ) detém não apenas importância técnica, mas também administrativa e contábil. No Brasil, poucas FH conseguem alcançar metas básicas como controle de estoque. A utilização de medicamentos em hospitais pode envolver de 20 a 30 etapas e uma falha em qualquer uma destas etapas é denominada erro médico. Nos EUA, cerca de 1,5 milhões de pessoas 
adoecem por ano e os gastos extras decorrentes destes erros chegam a US $\$ 3,5$ bilhões. A minimização destes problemas converge para uma solução em modelagem de processos de negócios com o uso extensivo de automação, como uma ferramenta de incremento da eficiência e eficácia em vários sentidos. Os recursos da solução em diferentes níveis de controle, mobilidade e interatividade variam de acordo com as metas do hospital, definidas no planejamento estratégico.

\section{E.1 Introdução}

A primeira aplicação de computação na saúde foi feita por Heman Hollerith: seus cartões perfurados foram adotados para a análise de problemas ligados à epidemiologia. Nos anos seguintes, as aplicações foram todas voltadas para compilação de dados numéricos como controle de material e de folha de pagamento. Já em 1962, o Hospital Computer Project foi o primeiro projeto de informatização hospitalar nos Estados Unidos. Destacaram-se programas de admissão e alta, relatórios de laboratórios e resumos de prescrições. Hoje, a tecnologia nos permite mais.

Em um ambiente hospitalar, onde o volume de informações cresce a cada dia, em decorrência do crescente aumento do número de atendimentos e do volume de dados gerados por paciente, o tempo para recuperar resultados de exames ou prontuário do paciente aumentou proporcionalmente.

Os profissionais da saúde deste século têm diversos problemas relacionados ao gerenciamento de informações. Eles têm de se manter atualizados, coletar informações diagnósticas, tomar decisões baseadas em evidências, discutir casos clínicos com colegas, comunicar-se claramente, entre outras tarefas. Claramente, uma ferramenta automatizada se encaixa perfeitamente neste novo perfil.

"A Saúde é uma das áreas onde há maior necessidade de informação para a tomada de decisões. A Informática Médica é o campo científico que lida com recursos, dispositivos e métodos para otimizar o armazenamento, recuperação e gerenciamento de informações biomédicas. O crescimento da 
Informática Médica como uma disciplina deve-se, em grande parte: aos avanços nas tecnologias de computação e comunicação, à crescente convicção de que o conhecimento médico e as informações sobre os pacientes não são gerenciáveis por métodos tradicionais baseados em papel, e devido à certeza de que os processos de acesso ao conhecimento e tomada de decisão desempenham papel central na Medicina moderna". (SBIS, 2006)

O administrador do hospital sempre teve maior necessidade do uso do computador, tais como para planejar e controlar estoques, recursos humanos, investimentos e fluxo de caixa. Atualmente, os sistemas de informação hospitalar (SIH) têm mudado de simples programas de contas a pagar e a receber para um sistema que abrange toda a informação administrativa e assistencial de um nosocômio.

O SIH controla e racionaliza processos tais como consultas, internações, prontuários, prescrições, dietas, cirurgias, exames laboratoriais e de imagem, procedimentos de enfermagem e outros, além de apoiar e automatizar atividades administrativas como faturamento, compras, controle de estoque e custos.

O serviço de assistência a saúde é cobrado por todos os seus personagens: por médicos, para aumentar a qualidade do atendimento; por administradores, para reduzir custos e aumentar margens de lucro; por agencias reguladoras, a fim de garantir padrões mínimos de qualidade e por instituições acadêmicas, para que sejam fornecidas informações e motivações à pesquisa. Os sistemas automatizados em saúde tendem a satisfazer todas essas demandas.

A proposta deste trabalho, em particular, visa suprir as dificuldades da farmácia hospitalar $(\mathrm{FH})$ no que tange à agilidade na dispensação, controle de estoque e minimização de erros. Ao mesmo tempo, sabe-se que a FH não está sozinha no ciclo de uso de medicamentos, por isso a solução também deve abranger o departamento médico e enfermagem mantendo sempre o foco no paciente. 


\section{E.2 Farmácia Hospitalar}

Podemos conceituar atualmente a farmácia hospitalar com sendo uma "Unidade de Assistência Técnica, Administrativa e Contábil, dirigida por profissional farmacêutico, tecnicamente habilitado, que visa assistir toda a comunidade hospitalar, no âmbito do medicamento e demais produtos da área de saúde". (MAIA NETO, 2005)

Dentro deste conceito, podemos definir alguns objetivos da Farmácia Hospitalar, como: planejamento, aquisição, distribuição e controle de medicamentos e correlatos; manipulação de dose; desenvolvimento de pesquisas e trabalhos próprios ou em colaboração com profissionais de outros serviços; adequar-se aos problemas políticos, sociais, econômicos, financeiros e culturais do hospital; além de estimular a implantação e o desenvolvimento da farmácia clínica.

Os objetivos estarão resumidos a seguir:

- Planejamento e aquisição: A aquisição de qualquer produto deve ser compatível com as reais necessidades do hospital. Pois uma aquisição incompatível além de causar prejuízos, pode acarretar desperdícios. No Brasil, em apenas $7,6 \%$ das $\mathrm{FH}$ há programação para abastecimento dos medicamentos selecionados e em $15,2 \%$ há utilização de banco de preços para acompanhar o processo de compra. (FIOCRUZ, 2004).

- Distribuição (logística): A elaboração de um sistema de distribuição de medicamentos requer uma investigação, em profundidade, das atividades que possam garantir eficácia, economia e segurança. Um sistema de distribuição envolve compras, controle de estoque, armazenamento, controle de qualidade, pessoal, e uma série de outros elementos que se tornam indispensáveis e até vitais para a boa consecução do mesmo. Hoje, um sistema que vem sendo aceito e usado em muitos hospitais pela sua eficiência e redução de custos é a dose unitária. Apenas $0,4 \%$ das $\mathrm{FH}$ brasileiras são adeptas deste sistema. (FIOCRUZ, 2004).

- Controle: Aplicado aos estoques de medicamentos é de fundamental importância. O controle de estoque mostra os medicamentos que estão em falta, o quanto se consome em determinadas épocas do ano, etc. No Brasil, 
$34,58 \%$ das $\mathrm{FH}$ possuem sistema de controle de estoque informatizado no almoxarifado de medicamentos. Um dado mais preocupante: nenhuma das $\mathrm{FH}$ pesquisadas tinha a contagem física correspondente ao registro do estoque. (FIOCRUZ, 2004).

- Manipulação (farmacotécnica): A manipulação de doses em um hospital é importante, pois existem pacientes que precisam fazer uso de certos medicamentos que não estão disponíveis comercialmente. Por exemplo, pacientes pediátricos ou que estão sob uso de sondas. Dentre as $\mathrm{FH}$ brasileiras, $7,2 \%$ realiza fracionamento.

- Pesquisa: É importante que se façam estudos ininterruptamente, para que diariamente se desenvolvam novas técnicas e métodos tanto na Farmácia Hospitalar, propriamente dita, como em todos os setores, dentro e fora do hospital, onde haja participação do farmacêutico. Apenas 3,2\% das FH brasileiras participam de atividades de pesquisa no hospital (FIOCRUZ, 2004).

- Problemas políticos: O bom senso e algum conhecimento administrativo são essenciais para se conseguir lidar com problemas políticos, sociais, econômicos, financeiros e culturais em um Hospital. Afinal, há necessidade de o profissional farmacêutico exercitar-se constantemente em outras atividades, tento em vista a dinâmica exigida pela Farmácia Hospitalar. O êxito, às vezes, depende muito mais da versatilidade do profissional, do que da própria condição que a instituição oferece.

- Farmácia Clínica é responsável por desenvolver atividades que aperfeiçoem o tratamento medicamentoso do paciente, colaborando para redução do tempo de sua permanência no hospital, prestando uma colaboração destacada no contexto da instituição hospitalar. Porém, se a Farmácia Hospitalar não possuir uma estrutura suficiente, a farmácia clínica pode prejudicar a si mesma e ao próprio serviço de farmácia como um todo. Dentre as Farmácias Hospitalares brasileiras, apenas $5,6 \%$ possuem recursos de informática para a utilização em atividades clínicas (FIOCRUZ, 2004). 


\section{E.2.1 A assistência farmacêutica junto às unidades do hospital}

A atuação do profissional farmacêutico não se limita ao balcão da Farmácia. Muito pelo contrário, a dispensação representa apenas um fator isolado entre suas obrigações diárias. A mesma deve ser encarada como mais uma rotina com vigilância ininterrupta.

Em seguida, far-se-á alguns exemplos de colaborações que podem ser dadas pela Farmácia Hospitalar a algumas unidades do Hospital.

\section{E.2.1.1 Ambulatório}

Uma atividade rotineira seria a informação do arsenal de medicamentos disponíveis na Farmácia. Fica difícil para o médico, consultar o seu paciente e no momento de medicá-lo não ter conhecimento sobre a existência do medicamento na Farmácia do ambulatório. Isto porque quando a "falta" do medicamento se faz "presente", o paciente não retorna ao médico para que faça a mudança na prescrição e o resultado de tudo isso é a continuidade da "doença" no "doente". O produto final desacredita o médico, a Farmácia e todos saem prejudicados, principalmente 0 paciente que representa o objetivo único de todo o trabalho que se realiza numa instituição hospitalar. Apenas em $5,6 \%$ dos hospitais existe um guia farmacoterapêutico. (FIOCRUZ, 2004) 


\section{E.2.1.2 Serviço de arquivo médico e de estatística - SAME}

Trata-se de um setor rico em informações para todos os segmentos da instituição. Todo medicamento consumido, infecções já existentes, causa mortis, índices de mortalidade, de natalidade e de permanência, além de outros dados importantes, estão ali arquivados.

Assim sendo, representa em excelente banco de dados para desenvolvimento de pesquisas. Inúmeras dúvidas podem ser dirimidas quando se recorre ao SAME. Apenas 1,2\% dos hospitais possuem uma ficha farmacoterapêutica de pacientes internados para que possam acessar informações sobre os medicamentos consumidos durante a estadia.

\section{E.2.2 Farmacovigilância}

O conceito de farmacovigilância, segundo a ANVISA, é a Ciência relativa à detecção, avaliação, compreensão e prevenção dos efeitos adversos ou quaisquer problemas relacionados a medicamentos.

O farmacêutico hospitalar desenvolve atividades que favorecem a sua participação ativa nos programas de Farmacovigilância. Dentre as funções fundamentais da Farmácia Hospitalar, definidas pela Organização Pan-americana de Saúde (OPAS) e - Ministério da Saúde do Brasil, destacam duas atividades que podem contribuir para o estudo das reações adversas:

- Estabelecimento de um sistema racional de distribuição de medicamentos para assegurar que eles cheguem ao paciente com segurança, no horário certo e na dose adequada e, 
- Implantação de um sistema de informações sobre medicamentos.

Através dos sistemas de distribuição de medicamentos, principalmente por dose individualizada e por dose unitária, o farmacêutico não só controla a distribuição de medicamentos, mas também é responsável pelo seu uso racional na instituição hospitalar. Através das prescrições médicas arquivadas na Farmácia Hospitalar, o farmacêutico pode obter informações que permitam a suspeita de Reações Adversas a Medicamentos (RAM). Como por exemplo:

- Suspensão brusca de um medicamento;

- Substituição de um medicamento por outro;

- Súbita diminuição da dose;

- Prescrição de antihistamínico ou corticóide.

É reconhecido atualmente que todo serviço de farmácia hospitalar deve dispor de um centro de informação sobre medicamentos. Freqüentemente o farmacêutico hospitalar é consultado sobre tratamentos alternativos, interações, contra-indicações, diluição e estabilidade de medicamentos, entre outros, incluindo-se consulta sobre um possível efeito adverso. No caso de uma consulta sobre suspeita de RAM, o farmacêutico responsável pelo Centro de Informação sobre Medicamentos (CIM) deve investigar e, assim, interagir com o médico ou outro profissional de saúde na elucidação do caso. A divulgação das reações adversas registrada na literatura sobre os fármacos pertencentes ao formulário terapêutico do hospital, pode ser feita pelo CIM. Caso o hospital já tenha estruturado uma equipe multidisciplinar de Farmacovigilância, isto deverá ser feito, prioritariamente, por ela. Porém, somente $0,4 \%$ das $\mathrm{FH}$ brasileiras realizam atividades de farmacovigilância e 1,2\% contam com uma ficha farmacoterapêutica de pacientes internados, essencial para a realização da farmacovigilância (FIOCRUZ, 2004). 


\section{E.3 Erro Médico}

O progresso da medicina é inqüestionável em todos os aspectos, mas certo tipo de evento tem sido amplamente discutido e algumas vezes motivo de manchetes sensacionalistas: o erro médico. $O$ termo que é utilizado para a falha cometida por qualquer profissional da saúde, pode vir a representar maior tempo de internação, maiores custos ou até tragédia para pacientes e famílias. Entretanto, como a maioria deles está associado ao uso de medicamentos, estes podem ser minimizados.

Os termos mais comuns são:

- Erro medicamentoso: ocorrido em qualquer fase, desde a prescrição até a administração;

- Erro de prescrição: droga, dose, via de administração, concentração, velocidade de infusão incorretas ou prescrições ilegíveis;

- Evento adverso da droga: mal causado pelo uso de uma droga, variando de simples coceiras até a morte. Pode ser de dois tipos: os causados por erros e os inerentes à droga. Os causados por erros são evitáveis, e os inerentes ao próprio medicamento, são chamados de reações adversas. 


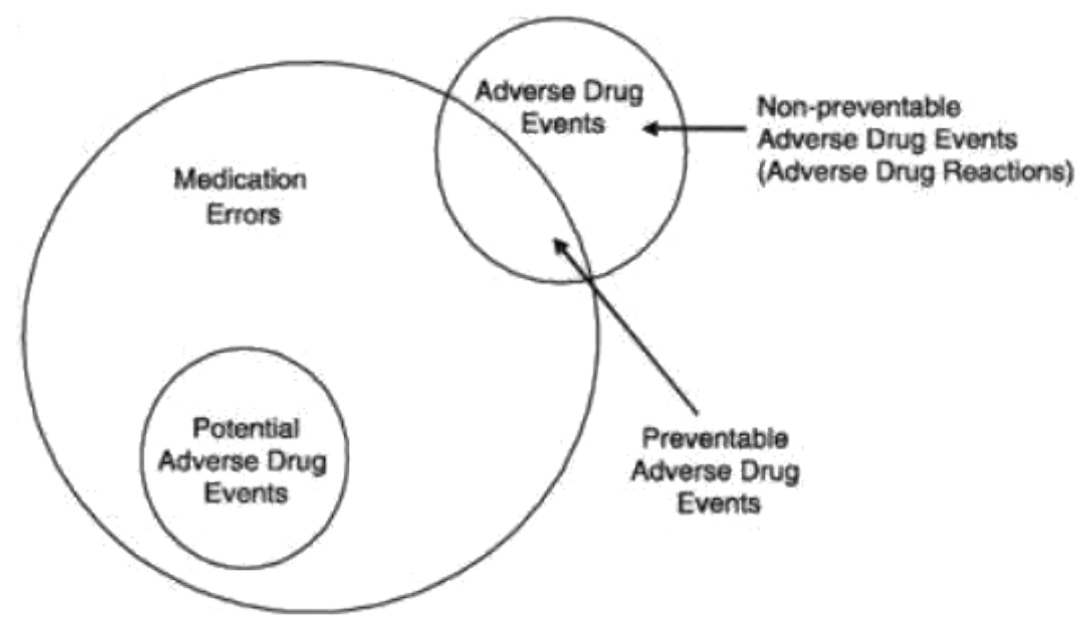

Figura E.1: Relação entre erros de medicação e eventos adversos (IOM, 2006).

A figura E.1 mostra que do grande número de erros de medicação, pequena parte significa um risco em potencial para o paciente, mas não resulta em evento adverso. Mostra também que há reações adversas que não podem ser evitadas e ocorrem em pequenas probabilidades, mas há uma porção que é proveniente de erros médicos.

Mesmo que a porção de reações adversas relacionadas a erros de medicação seja a menor, um estudo do Institute of Medicine (IOM) mostrou que cerca de 1,5 milhões de americanos adoecem, sofrem ou morrem todos os anos devido a essa parcela. Além disto, os custos relacionados ao tratamento são estimados modestamente em 3,5 bilhões de dólares em 2006, só nos Estados Unidos.

Tabela E.1: Prescrição e seleção de drogas para o paciente (IOM, 2006)

\begin{tabular}{|l|l|l|}
\hline \multicolumn{1}{|c|}{ Índice de Erro } & \multicolumn{1}{|c|}{ Amostra } & Método de detecção \\
\hline 190,0 (LaPointe e Jolis, 2003) & Cada 1000 internações & Farmácia clínica \\
\hline 53,0 (Bates et Al., 1995) & Cada 1000 pedidos & $\begin{array}{l}\text { Revisão de farmacêuticos, } \\
\text { comunicação voluntária }\end{array}$ \\
\hline 9,9 (van den Bemt et al., 2002) & $\begin{array}{c}\text { A cada 100 dos } \\
\text { oportunidades de erro }\end{array}$ & $\begin{array}{l}\text { Revisão } \\
\text { farmacêuticos das ordens }\end{array}$ \\
\hline
\end{tabular}




\begin{tabular}{|l|l|l|}
\hline Índice de Erro & Amostra & Método de detecção \\
\hline & & escritas \\
\hline
\end{tabular}

A utilização de medicamentos em hospitais pode envolver de 20 a 30 etapas, incluindo prescrição, transcrição, dispensação, administração e monitoramento (LEAPE et al. 2000). Se considerássemos uma eficácia dos profissionais de 99,9\%, ou seja, um erro de $0,1 \%$ que parece pequeno, poderia ser catastrófico em outros setores. Com essa taxa, por exemplo, dois aviões defeituosos seriam produzidos por dia, 16.000 cartas se extraviariam por hora, e 32.000 cheques seriam descontados em bancos errados, a cada hora, nos EUA.

Tabela E.2: Dispensação do medicamento (IOM, 2006)

\begin{tabular}{|c|c|c|}
\hline Índice de Erro & Amostra & Método de detecção \\
\hline 2,6 (Winterstein et al., 2004) & Cada 1000 internações & Relatórios voluntários \\
\hline
\end{tabular}

Os índices de incidência de erros podem variar muito de acordo com o método de detecção. As tabelas E.1, E.2 e E.3 ilustram alguns exemplos levantados pelo IOM.

Tabela E.3: Administração do medicamento (IOM, 2006)

\begin{tabular}{|l|l|l|}
\hline \multicolumn{1}{|c|}{ Índice de Erro } & Amostra & Método de detecção \\
\hline 10,8 (Barker et al., 2002) & Cada 100 doses & Observação direta \\
\hline 14,9 (Tissot et al., 2003) & Observação direta & Observação direta \\
\hline $6,6 \%$ (Tissot et al., 1999) & UTI & Observação direta \\
\hline
\end{tabular}




\begin{tabular}{|l|l|l|}
\hline Índice de Erro & Amostra & Método de detecção \\
\hline & & \\
\hline
\end{tabular}

Para se entender porque ocorre o erro, vale uma comparação com o setor industrial: baseado na premissa de que o erro humano é possível, são desenvolvidos vários métodos para a prevenção e detecção. Porém, a formação de profissionais da saúde preconiza a realização de um trabalho sem erros. Essa imposição de perfeição na prática médica, exigida não só de seus colegas como também de seus próprios pacientes, dificulta uma abordagem construtiva do erro, na medida em que marginaliza e estigmatiza o profissional envolvido no evento. (De Carvalho, 2002)

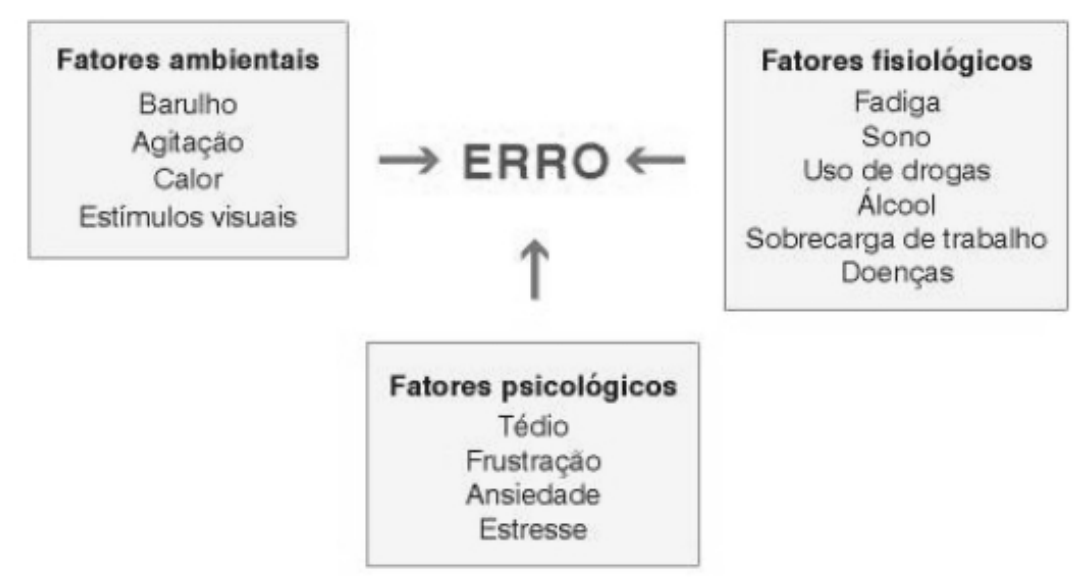

Figura E.2: Possíveis causas de erro (De Carvalho, 2002).

Para minimizar o erro médico, é necessário acima de tudo reconhecer o problema e ter uma abordagem sistêmica, não individualista. A tecnologia não substitui 0 profissional, mas pode ser de grande valor. Prescrição eletrônica, dispensação e administração com código de barras, por exemplo, farão o sistema potencialmente mais seguro e os personagens do ciclo da medicação terão menos tarefas mentais cansativas e mais atividades agradáveis e recompensadoras. 


\section{E.4 Visitas}

O desenvolvimento e estruturação do projeto foram baseados em dados reais colhidos durante visitas realizadas em alguns hospitais da cidade de São Paulo. A escolha dos hospitais deu-se de forma a abranger todos os níveis de informatização, ou seja, tentou-se abordar desde hospitais extremamente carentes de recursos de informática até aqueles detentores de tecnologias modernas e sofisticadas.

Seguindo a metodologia de projeto, o primeiro ponto a ser avaliado para cada hospital foi a existência de um planejamento estratégico, responsável por mobilizar os recursos dos hospitais para alcançar as metas propostas, na tentativa de melhorar a organização e solucionar erros médicos. Dentre os hospitais visitados, pôde-se observar que $80 \%$ deles estabeleceram um planejamento estratégico. Entretanto, apenas $40 \%$ conseguem colocar em prática as diretrizes estabelecidas. Como foi observado em uma das visitas, uma das principais razões para esse baixo índice é a escassez de recursos na área de informática, essenciais para a viabilização das metas. Já em um outro hospital, onde o planejamento é seguido o mais fielmente possível, é importante salientar que sua elaboração deu-se após a definição do FMEA (Failure Mode and Effects Analysis), cujo objetivo foi analisar todo o ciclo de medicação, de forma a detectar os problemas e erros para, então, propor o planejamento estratégico.

Após fazer a análise descrita acima, o foco do projeto foi transferido para o estudo da prescrição, dispensação e administração do medicamento, de acordo com a metodologia definida. Em quase $100 \%$ dos casos a prescrição é manual, ou seja, praticamente nenhum dos hospitais visitados adota a prescrição eletrônica. $O$ responsável por essa elevada taxa é o próprio corpo clínico do hospital. Segundo os médicos, a interface médico-sistema é pouco amigável, o que dificulta a realização da prescrição. Dessa forma, os médicos preferem prescrever o medicamento manualmente a perder seu tempo lutando contra o computador. Além disso, como em $40 \%$ dos hospitais o corpo clínico é aberto, a direção do hospital vê-se obrigada a acatar as decisões tomadas pelos médicos. Contudo, a adoção da prescrição eletrônica poderia reduzir drasticamente a taxa de erro médico, uma vez que a ilegibilidade da letra dos médicos não seria mais relevante.

Em relação à dispensação, menos de $50 \%$ das farmácias conta com um sistema informatizado que controle a quantidade de entrada, saída e estoque dos medicamentos e insumos hospitalares. Outro dado relevante observado em alguns 
dos hospitais visitados foi um horário de grande concentração de medicamentos dispensados contra um período de ociosidade. Além disso, apenas $20 \%$ dos hospitais garante completa rastreabilidade dos medicamentos, uma vez que todos os medicamentos e insumos são identificados com um novo código de barras que contém a data de validade e o número do lote, informações não fornecidas no código de barras oriundo da indústria farmacêutica.

A administração dos medicamentos ainda não atingiu um nível de informatização significativo em nenhum dos hospitais visitados. Idealiza-se a utilização de código de barras em todos os pacientes, a fim de tentar evitar erros de medicação e de dosagem, lembrando que esses códigos de barras individuais representariam a última chance para deter os erros médicos.

\section{E.5 Solução e Discussão}

Os problemas relacionados com o uso de medicamentos em hospitais podem ser divididos em administrativos e técnicos. Apesar desta separação, ambos se interrelacionam sob vários aspectos. É impossível, por exemplo, prescrever um medicamento em falta no estoque, e ao mesmo tempo a prescrição errônea pode levar a falsas demandas e problemas clínicos. Por outro lado, as altas taxas de erros médicos observadas no mundo e as deficiências nos processos observadas no levantamento da realidade das diferentes farmácias hospitalares visitadas apontam para a necessidade de buscar solução em modelagem de processos de negócios com o uso extensivo da automação, de acordo com o planejamento estratégico.

É importante ressaltar que a singularidade de cada hospital e de seu corpo clínico sempre constituiu obstáculo para a implantação e continuidade de sistemas de informação, muito embora existam algumas soluções já em uso. A queixa de alguns deles é que as soluções desenvolvidas por empresas terceirizadas tendem a homogeneizar o atendimento para todos, com pouca customização aos detalhes muito relevantes de cada centro de saúde ou time de profissionais, fazendo assim com se observem rejeições ou adulterações de processos por parte das participantes, especialmente os profissionais de saúde. Em geral, isso se deve a escolhas inadequadas de sistemas ou ao fato de que a comunicação entre as partes não é suficiente para que o processo de levantamento de requisitos seja suficiente e 
contínuo.

Já os sistemas que são desenvolvidos por uma equipe de informática própria do nosocômio muitas vezes causam insatisfação pela demora de implantação. Profissionais de tecnologia da informação ligados a esses serviços são bastante exigidos, principalmente porque os sistemas criados por eles não se mostram eficazes na etapa mais importante do desenvolvimento: o levantamento de requisitos. Normalmente, quando esta importante fase é executada pelos próprios usuários como médicos e enfermeiros, por exemplo, que não tem formação específica, os resultados normalmente não são alcançados.

A solução aqui proposta será diferente à medida que a modelagem da solução será executada de acordo com o planejamento estratégico de cada hospital, ou seja, sua missão, seus objetivos e metas mensuráveis para curto, médio e longo prazo. Com isso, o sistema não será considerado um "enlatado" e tentará ao máximo se encaixar de forma perfeita à rotina da instituição ao mesmo tempo em que utilizará a experiência de outras a fim de garantir as soluções mais inovadoras, eficientes e eficazes.

Para cada problema apresentado anteriormente, serão oferecidas múltiplas alternativas de solução, cada uma com seus custos de implementação, de manutenção e resultados pretendidos. Sabemos que o sistema terá diversos níveis de usuários, com seus respectivos acessos a determinados recursos e dispositivos para melhor aproveitamento. Para garantir o acesso restrito, por exemplo, o administrador terá a sua disposição recursos como nome de usuário e senha, crachás com códigos de barras ou RFID's ou até mesmo reconhecimento de impressões digitais, sendo que os mesmos recursos poderão ser utilizados para identificação dos pacientes.

O primeiro personagem do ciclo da medicação é o médico. É ele quem fará a prescrição para os pacientes internados. Ao realizar uma visita, o médico deverá tomar decisões baseadas em evidências. Essas decisões podem variar desde pedidos de exames, solicitações para a enfermagem, transferências, alta, prescrições de medicamentos, dietas, entre outros.

Dado o grande número de informações que devem ser visualizadas, é recomendado um display de grandes dimensões como desktop, laptop ou tablet PC. O desktop não alterará a rotina atual de um médico de prescrever em uma sala separada, porém o tablet PC, associado a uma rede sem fio abrirá a possibilidade para que o médico prescreva a beira do leito, enquanto faz a visita, melhorando seu contato com o 
paciente se assim for sua preferência. Além disso, os tablet PC também contam com um sistema inteligente de reconhecimento de escrita, o que faria o sistema ainda mais amigável e compatível com a realidade do médico.

Na sua tela inicial, uma interface bastante amigável poderá mostrar uma lista com seus pacientes, podendo aplicar filtros de acordo com seu interesse como ordem alfabética, ala, clínica, necessidade de prescrição, entre outros. Ao exibir os detalhes de cada paciente, o médico terá acesso a informações básicas como nome, peso, superfície corporal e outras que sejam necessárias para a prescrição. Outras informações como alergias ou histórico familiar de doenças crônicas podem estar ocultas, mas integradas com as decisões médicas.

As prescrições dos dias anteriores e inclusive de internações passadas estarão disponíveis para visualização e nelas o médico poderá visualizar, por exemplo, a hora exata em que cada medicamento foi administrado e se alguma droga que deveria ser administrada "se necessário", realmente foi. Também poderá repetir prescrições com pequenas alterações. A qualquer momento poderá gerar relatórios de interesse cruzando quaisquer informações desejadas.

No campo de prescrição de medicamentos, ao começar a preencher o nome do medicamento (que poderá ser comercial, genérico ou mesmo uma abreviação, pois - sistema fará eventual correção para a farmácia), o recurso "autocompletar" agilizará a seleção e já mostrará as opções de posologia e freqüência mais usuais. Se estas foram dependentes do peso ou superfície corporal, o sistema já fará o cálculo automaticamente. O médico sempre terá liberdade de alterar os campos se assim achar conveniente. Assim, será evitada a receita de drogas não-padronizadas caso isto seja necessário.

Alguns assistentes bastante úteis poderão fazer parte do sistema: um guia farmacoterapêutico pode oferecer todas as informações relevantes para o corpo clínico sobre medicamentos padronizados naquele nosocômio. Diferentes tipos de alertas podem ser emitidos no caso de duplicidade de prescrição, interações drogadroga e/ou droga-dieta, interferências com resultados de exames, superdosagem e alergias. Também pode ser possível cruzar as informações sobre medicamentos e indicações terapêuticas (como uma sugestão de prescrição).

Medicamentos com prazo de uso determinado poderão ter um contador do número de dias e respectivo assistente caso este prazo não seja cumprido. Os resultados de exames de laboratório que são algumas vezes necessários para a seleção de medicamentos podem estar visíveis na mesma tela ou surgir como help-boxes 
quando a droga apresenta interferência. Prescrições extraordinárias também não serão esquecidas: os médicos poderão fazê-las de seu computador doméstico ou de seu smartphone e encaminhar diretamente para o hospital, se o planejamento estratégico assim requisitar.

Dependendo do hospital, a equipe de enfermagem é responsável pela colocação de horários de administração. Dada a freqüência estipulada pelo médico, a partir do primeiro horário colocado pela enfermeira ou a partir do horário da última administração, os seguintes poderão ser automaticamente preenchidos.

Nas instituições que realizam farmácia clínica, esta também receberá atenção especial. Para avaliar a seleção do médico, o farmacêutico também precisará de diversas informações. A sua revisão poderá ser feita também em desktops, laptops, tablets ou PDA's, sendo que os últimos, desde que associados a uma rede sem fio. Todos os assistentes disponíveis para o corpo clínico também poderão ser disponibilizados e caso desejado, classes de medicamentos especiais podem receber algum destaque.

As sugestões de alteração podem ficar marcadas na forma de balões de aviso e a prescrição poderá ser reenviada ao médico que pode receber uma notificação pelo celular e aceitar ou declinar as sugestões em seu próprio Smart-Phone. Relatórios de interesse também poderão ser gerados. Esperamos que com as melhorias nos outros sistemas nos quais o farmacêutico é responsável, haja mais tempo para dedicação à farmácia clínica e assistência ao paciente, que muitas vezes é carente de informação.

Na farmácia hospitalar em si teremos grandes mudanças. O sistema de entrada de medicamentos será totalmente automatizado. O funcionário responsável pelo recebimento poderá visualizar o conteúdo do pedido em um dispositivo móvel, como um PDA e fará a conferência com código de barras sem fio. Após o término da conferência, o controle de estoque poderá já contabilizar a entrada.

No almoxarifado, cada medicamento terá um endereço e o controle será preciso com o uso de código de barras. Os pedidos de saída serão na maioria das vezes automáticos. Por exemplo, quando a quantidade de certo medicamento chegar ao limite crítico, uma requisição será automaticamente gerada. Esta requisição será visualizada pelo responsável em um PDA e se houver mais de um item, o sistema se encarregará de traçar a menor rota entre os corredores do almoxarifado para a coleta. Quando a reposição foi feita, o sistema será avisado e as alterações de estoque devidamente contabilizadas. 
Tais contabilizações de estoque e todas as suas variáveis de gestão como: demanda, sazonalidade, curva $\mathrm{ABC}$, ponto de requisição etc. serão devidamente utilizadas para gerar um pedido de compra que, se assim desejarem os administradores, poderá ser encaminhado por e-mail ou fax para os fornecedores, como um pedido de orçamento. O administrador poderá avaliar os orçamentos, juntamente com o histórico de pedidos e banco de informações sobre vendedores e decidir pela compra. Um novo e-mail ou fax será transmitido para confirmação e o prazo começará a ser contabilizado, podendo-se enviar e-mails automaticamente como lembrete para a entrega no dia prometido. Aqui também poderão ser gerados relatórios de interesse.

A solução abrange todos os sistemas de distribuição. Para o sistema coletivo, onde os medicamentos ficam disponíveis nas clínicas, a farmácia terá o controle da quantidade disponível de cada medicamento ou correlato (mesmo que gotas ou pomadas) de acordo com as prescrições. Principalmente quando contabilizar quantidade de gotas em um frasco ou massa um tubo de pomada, deve-se levar em conta uma margem de erro e aumentar o limite do ponto de requisição.

Para a distribuição por dose unitária, nossa solução pode abranger inclusive sistemas robotizados para unitarização de sólidos orais, etiquetagem de frascos, ampolas etc. Conforme necessidade, podem ser gerados relatórios de dispensação por período (manhã, tarde, noite) ou por horários (que normalmente são pares) e podem ser filtrados por local de armazenagem (medicamentos controlados, manipulados, sólidos orais, geladeira, etc.).

Também poderá ser utilizada uma impressora térmica que imprima cada prescrição para que, após a separação, esta seja anexada ao pacote de despacho para a conferência da enfermagem. A utilização de um sistema com PDA e código de barras evitará a conferência aumentando a eficiência e eficácia do processo como um todo. Em alguns hospitais, onde as ampolas serão dispensadas juntamente com o diluente, o sistema poderá imprimir etiquetas com instruções de diluição para serem coladas unindo estes dois componentes. Nos hospitais onde há setor farmacotécnico, o sistema contará com um assistente que exibirá as manipulações a serem realizadas e suas respectivas instruções de preparação.

Caso aplicável, o sistema poderá contar com dispositivos robotizados que façam estas manipulações. Estes podem ou não estar ligados com o sistema de prescrição eletrônica e impressão de rótulos. A separação de medicamentos industrializados (ou somente parte deles, como os controlados) também poderá ser robotizada, como já existe em alguns hospitais nos EUA. Neste setor também poderão ser gerados relatórios de interesse. 
A equipe de enfermagem também será privilegiada do sistema. Poderão receber em seus PDA's os guias de administração contendo informações sobre medicamentos, como posologia, forma de aplicação e diluição, entre outros. Com o auxílio do código de barras, terão o controle de que o medicamento prescrito seja aplicado no paciente certo e no horário adequado. O banco de dados arquivará estas informações, juntamente com o dado de qual enfermeira que fez a administração. Relatórios de interesse também poderão ser gerados a partir de quaisquer destes dados.

De uso da enfermagem e corpo clínico, o sistema de farmacovigilância contará com formulários completos, mas de fácil preenchimento que ajudem a reportar qualquer evento adverso ao uso da medicação. Estas informações poderão ser encaminhadas diretamente à ANVISA ou a quem interessar. Se o hospital assim desejar, a solução também poderá incentivar a reportagem de erros, não para que haja punição, mas sim para que eventualmente sejam reformuladas metas e sistemas de minimização de falhas.

O banco de dados gerado por este sistema também poderá levar a um sistema de Business Intelligence específico para ajudar a identificar tendências tanto no consumo quanto no custo e, possivelmente, ligado à epidemiologia clínica, auxiliar a melhorar o controle e o estabelecimento de melhores estratégias. A Organização Mundial de Saúde chama este processo de estudos de utilização de medicamentos.

Com todos estes recursos à sua disposição, o administrador também contará com um assistente informatizado que mostrará, de acordo com seu planejamento estratégico, quais são as soluções apresentadas anteriormente que melhor se adaptem à sua realidade e farão seus objetivos serem alcançados.

\section{E.6 Referências}

Leape, L.L. (1994) "Error in medicine" In: JAMA, 272(23):1851-7. http://bases.bireme.br/cgi-bin/wxislind.exe/iah/online/? IsisScript=iah/iah.xis\&nextAction=Ink\&base=MEDLINE 1966-1995\& exprSearch=7503827\&indexSearch=UI \&lang=p. Acessado em 12.Nov.2006 
Maia Neto, J.F. (2005) "Farmácia Hospitalar e suas interfaces com a saúde" RX editora, 1a. edição. p.32 a 37 e p. 40 a 45 e p. 279 a 290

Osório-de-Castro, C. G. S. \& De Castilho, S. R. et al.(2004) "Diagnóstico da Farmácia Hospitalar no Brasil” ENSP/FIOCRUZ, 20a ed. p.136 a 140.

IOM et al.(2006) "Preventing Medication Errors" The National Academic Press, p. 95 a 126 e p. 325 a 360 http://darwin.nap.edu/books/0309101476/html/R1.html. Acessado em 12.Nov.2006

De Carvalho, M. \& Veira, A.A. (2002) "Erro médico em pacientes hospitalizados" in J. Pediatr (Rio J) v.78 n.4. http://www.scielo.br/scielo.php?script=sci arttext\&pid= S0021 -75572002000400004\&lng=pt \&nrm=iso\&tlng=pt. Acessado em 12.Nov.2006

SBIS (2006). Sociedade Brasileira de Informática em Saude. Extraído de http://www.sbis.org.br. Acessado em 13.Nov.2006. 


\section{Apêndice F - Negócios com o eCampeonatos}

\section{CCampeonatos.com.br}




\section{F.1 Descrição do produto}

O eCampeonatos é uma ferramenta tecnológica de Internet cuja função principal é organizar e armazenar dados de competições esportivas de forma dinâmica, de maneira a se tornar a comunicação principal entre organizadores e usuários destas competições.

Desenvolvida através da união entre dois conhecimentos específicos - Tecnologia da Informação e Ciência do Esporte - a ferramenta é resultado dos esforços de um grupo de trabalho formado por especialistas nestas duas áreas de conhecimento demandadas.

Considerando que a grande parte da população brasileira tem acesso a meios de comunicações variados, tais como Internet e celulares, foi desenvolvida uma plataforma que permite as Secretarias de Esportes realizarem programas sociais que levem a inclusão sócio-digital e, conseqüentemente, a diminuição dos índices de violência. Essa plataforma, denominada eCampeonatos, foi concebida a partir de uma necessidade da Secretaria de Esportes da Cidade de São Paulo que precisava ter controle do processo de Gestão de Eventos Esportivos, com um caso especifico que são os Jogos da Cidade.

Durante o levantamento de requisitos para o desenvolvimento da solução, a equipe do d-lab identificou que o maior problema dos técnicos da Secretaria de Esportes estava na definição da agenda dos jogos, uma vez que esse processo tomava boa parte do tempo do pessoal e com um agravante: as alterações de disponibilidade de locais de jogos e arbitragem poderiam levar a equipe a refazer toda a agenda, o que era extremamente desgastante. 


\section{F.2 Descrição do problema resolvido}

Os programas sociais das Secretarias de Esportes, tanto municipais quanto estaduais, têm buscado gerar inclusão social da população, sobretudo da população jovem, como uma forma de ocupar o tempo livre do seu publico alvo, reduzindo assim os índices de violência nos grandes centros urbanos. Entretanto, tais programas sociais demandam estruturas administrativa e operacional que, na maioria das vezes, não pode ser encontrada nos quadros funcionais das Secretarias de Esportes. Além da falta de pessoal técnico qualificado, com freqüência pode-se notar a ausência de gestores que tenham a visão de que os participantes desses programas buscam atendimento comparado a de organizações da iniciativa privada, uma vez que nos dias atuais a população tem acesso aos veículos de comunicação que ate pouco tempo era privilegio de poucos. De certa forma, esse panorama pode ser explicado com a constatação do IBGE ${ }^{4}$, que apontou um investimento menor que $1 \%$ da receita das prefeituras do Brasil em programas ligados a Esportes e Lazer.

Decidiu-se pelo desenvolvimento incremental da plataforma eCampeonatos onde, na fase piloto foi possível verificar as principais necessidades e oportunidades para 0 atendimento dos envolvidos com a solução: de um lado os organizadores de eventos esportivos e de outro lado as equipes que participam das competições. Uma vez que o projeto se mostrou viável, foi elaborado um protótipo que mostra como será a solução que atendera a demanda das 5.557 prefeituras do Brasil.

\section{F.3 Análise do mercado potencial}

Os mercados inicialmente identificados como demandantes do eCampeonatos são:

- Poder Público (Secretarias Estaduais e Municipais)

4 Perfil dos Municípios Brasileiros - Esporte 2003 - Pesquisa do IBGE, disponível em http://www.ibge.gov.br/home/estatistica/economia/perfilmunic/esporte2003/default.shtm 
- Clubes

- Federações, Confederações e Ligas esportivas

- Eventos, Torneios independentes e Eventos empresariais

Entretanto, o eCampeonatos concentrará, no primeiro momento, nas 5.557 prefeituras das cidades brasileiras, com a motivação da interpretação dos dados da pesquisa do $\mathrm{IBGE}^{5}$, conforme segue.

\section{F.3.1 Prefeituras aplicam em esporte menos de 1\% das despesas}

O Suplemento de Esporte revelou que os recursos aplicados em desporto e lazer atingiram menos de $1 \%$ do total das despesas das prefeituras. Em 2002, representaram 0,96\% do total das despesas e, em 2003, 0,90\%. O menor percentual foi aplicado pelas prefeituras da região Norte: 0,66\%, em 2002, e 0,46\%, em 2003; e o maior no Sudeste: 1,10, em 2002, e 1,07, em 2003. Em relação ao tamanho da população, os menores percentuais das despesas das prefeituras, tanto em 2002 $(0,76 \%)$ quanto em 2003 (0,78\%), foram nos municípios com mais de 500 mil habitantes. O maior percentual em 2002 foi registrado nos municípios com 5 mil a 20 mil habitantes (1,18\%), e em 2003 nos municípios de 20 mil a 50 mil habitantes e 50 mil a 100 mil pessoas, ambos com 1,01\%.

As despesas dos municípios brasileiros com o esporte estavam fortemente concentradas na região Sudeste, que respondia por 58,9\%, em 2002, e $62,1 \%$ em 2003. A participação dos gastos na função desporto e lazer cresceu, em 2003 , em relação à 2002, nas regiões Sul (16,3\% para $17,7 \%)$ e Sudeste $(58,9 \%$ para $62,1 \%)$, enquanto decresceram nas regiões Norte (4,1\% para 3,0\%), Nordeste $(14,7 \%$ para $12,1 \%$ ) e Centro-Oeste (6\% para $5,1 \%$ ). Os recursos aplicados em esporte nos municípios do país, em relação às classes de tamanho da população cresceram entre 2002 e 2003 nas cidades com mais de 500 mil habitantes (26,8\% para 30,1\%), 
e nas de 100 mil a 500 mil habitantes (22,5\% para $23,6 \%$ ), e decresceram nas cidades com até 5 mil habitantes (4,7\% para 4,1\%); de 5 mil a 20 mil moradores (18,4\% para 15,6\%); de 20 mil a 50 mil habitantes (16\% a 15,1\%); e manteve-se praticamente estável nas cidades com 50 mil a 100 mil habitantes $(11,7$ para 11,6).

\section{F.3.2 Municípios maiores recebem mais valores da União e estados}

Caiu de 19,2\%, em 2002, para 16,6\%, em 2003, o percentual de municípios que receberam transferências da União ou estados vinculadas a gastos com desporto e lazer.

Excetuando-se as Regiões Sudeste (22,3\% e 18,3\%) e a Norte (32,7\% e 31,8\%), as demais apresentaram percentuais inferiores às médias nacionais dos municípios que receberam transferências em 2002 e 2003: Centro-Oeste (12,8\% e 15,6\%); Sul $(15,9 \%$ e 12,8\%); e Nordeste (16,8\% e 14,0\%). Em relação ao tamanho da população, as faixas que apresentaram o maior percentual de municípios que receberam transferências foi a de mais de 500 mil habitantes $(27,3 \%$, em 2002 , e $30,3 \%$, em 2003) e receberam menos transferências tanto em 2002 quanto em 2003, os municípios com até 5 mil habitantes $(16,8 \%$ e $13,4 \%$ dos municípios, respectivamente).

Do total de 5.557 municípios, 2.441 (43,9\%) efetivaram convênios ou outro tipo de parceria voltados para o esporte5. Na distribuição desse universo (2.441), o Sudeste foi responsável por $32,1 \%$ dos municípios com convênios ou parcerias, seguido pelas regiões Nordeste $(28,1 \%)$ e Sul $(23,9 \%)$, enquanto a região Norte ficou com o menor percentual $(7,7 \%)$; seguida pela Centro-Oeste $(8,2 \%)$.

Os dados mostram que, sendo as parcerias complementares às atividades do poder público, o estabelecimento de convênios municipais na área do esporte ainda está aquém de suas reais possibilidades. 
A distribuição dos convênios e parcerias por tipo de órgão participante indica que, dos quatro principais órgãos conveniados ou parceiros, três eram entidades da sociedade organizada - ligas esportivas $(36,0 \%)$, clubes $(34,9 \%)$ e empresas privadas $(25,6 \%)$ - enquanto um era público - órgãos públicos estaduais exceto os de ensino $(33,6 \%)$. No outro extremo, ONGs $(4,3 \%)$, instituições públicas federais, estaduais e municipais de ensino superior $(4,0 \%)$ e organismos internacionais, exceto ONGs $(0,6 \%)$ eram os parceiros menos freqüentes.

\section{F.3.3 Poucos projetos e programas esportivos para deficientes}

Entre as prefeituras brasileiras, $77,1 \%$ desenvolveram, em 2003, ações, projetos e programas voltados para o esporte e lazer; $70,3 \%$, no esporte educacional; e $47,8 \%$, no esporte de rendimento - ou competitivo.

Entre as grandes regiões, a Sul concentrava o maior percentual de municípios com ações, projetos e programas em esporte educacional $(81,8 \%)$. Nessa manifestação, o menor percentual ficava com o Sudeste $(64,9 \%)$. O Centro-Oeste liderava no esporte de rendimento (53,2\% dos municípios), manifestação na qual o Nordeste tinha a menor proporção $(40,9 \%)$. No esporte e lazer, a polarização se repetia, com o Centro-Oeste saindo na frente $(80,7 \%)$ e o Nordeste também em último lugar, mas ainda com um alto percentual $(72,2 \%)$.

Vale ressaltar que todas as 33 cidades com mais de 500 mil habitantes realizavam ações, projetos e programas em esporte e lazer. Os percentuais para esses municípios, os maiores do país, eram altos também em esporte educacional $(97 \%)$ e esporte de rendimento $(93,9 \%)$.

Dentre os tipos de ações, projetos e programas menos desenvolvidos pelos municípios estão aqueles destinados aos portadores de deficiência: nas manifestações de esporte educacional, só $5,6 \%$ das cidades realizavam algo direcionado para esse público; o percentual caía ainda mais quando se tratava de esporte de rendimento $(5,0 \%)$ e subia um pouco, mas ainda permanecia baixo, em esporte e lazer $(9,0 \%)$. 


\section{F.3.4 6,4\% das prefeituras não promoveram eventos em 2003}

Apenas $6,4 \%$ dos municípios brasileiros não realizaram, em 2003, nenhum evento esportivo executado pela prefeitura ou com a sua participação - ou seja, $93,6 \%$ das cidades promoveram ou co-promoveram eventos esportivos. Entre as regiões, os percentuais variaram de $97 \%$, no Centro-Oeste, a 92,3\%, no Nordeste; já na divisão por classe de tamanho da população, ficaram entre $89,9 \%$, nas cidades menores (menos de 5.000 habitantes), e 100\% nas cidades com mais de 100 mil moradores.

Dentre as modalidades esportivas investigadas, nos municípios que realizaram eventos esportivos, a mais freqüente foi o futebol, $94,5 \%$ das cidades promoveram eventos desse esporte, seguido pelo futsal $(66,0 \%)$, vôlei $(60,5 \%)$ e atletismo $(43,6 \%)$. No outro extremo, ficaram bocha $(13,9 \%)$, capoeira (16\%), tênis de mesa e futebol society ( $16,4 \%$ cada um).

Em todas as regiões, os eventos de futebol apresentaram participações expressivas dos municípios, variando de 92\% (Sul) a 98\% (Norte). Nos eventos de futsal, sobressaíram-se as regiões Centro-Oeste (74,8\% dos municípios) e Sul (70,4\%). Já nos que incorporavam o vôlei, destacou-se a relativamente baixa participação do Nordeste (47,8\%), com exceção dos estados da Bahia e do Ceará.

Quanto às cidades que realizaram eventos de atletismo, o Sudeste apresentou a menor participação $(36,8 \%)$, determinada em grande parte pelo comportamento do estado do Rio de Janeiro, onde só $56,0 \%$ dos municípios realizaram eventos dessa modalidade. Por fim, vale ressaltar a bocha, que possui um caráter marcadamente regional, com seus eventos fortemente concentrados na região Sul $(41,3 \%)$.

A participação dos municípios que realizaram eventos esportivos em 2003 cai à medida que se amplia a abrangência dos eventos. No geral, os eventos de caráter municipal contaram com a participação de $97,8 \%$ dos municípios; os intermunicipais, com $60,1 \%$; os estaduais, com $25,2 \%$; os interestaduais com, $7,5 \%$; os nacionais, com $5,0 \%$; e os internacionais, com $2,7 \%$. Destaca-se a menor a participação das cidades nordestinas nos eventos intermunicipais, $43,1 \%$. 


\section{F.3.5 Ginásios são recursos esportivos municipais mais presentes}

Em 31 de dezembro de 2003, 54,2\% dos municípios brasileiros tinham ginásios, e $27,7 \%$ tinham estádios de futebol. A presença, nas cidades, dos demais equipamentos esportivos pesquisados era bastante reduzida: $7,4 \%$ tinham complexos esportivos; $1,6 \%$, complexos aquáticos; 1,1\%, kartódromos; $0,2 \%$, autódromos; e 0,03\% tinham hipódromos ou similares.

Entre as grandes regiões, a Centro-Oeste e a Sul foram as que apresentaram maiores participações entre os municípios cujas prefeituras eram donas ou gestoras de ginásios: $82,3 \%$ e $75,5 \%$ respectivamente. Os estados que se destacaram nessas regiões foram Paraná $(83,2 \%)$ no Sul e Goiás $(86,6 \%)$ no Centro-Oeste. Quanto aos estádios de futebol, destacaram-se as participações dos municípios das regiões Sudeste $(36,1 \%)$ e Centro- Oeste $(34,4 \%)$ e dos estados de São Paulo $(51,6 \%)$ e Mato Grosso do Sul $(50,6 \%)$.

Embora tenham sido significativas as participações dos municípios que possuíam ginásios no Centro-Oeste, era no Sudeste e no Sul que se concentravam a maior parte $(68,3 \%)$ dos 4.186 ginásios brasileiros. Já os estádios de futebol estavam mais presentes no Sudeste $(40,3 \%)$ e no Nordeste $(24,2 \%)$, aí destacando-se a Bahia e, num segundo plano, o Ceará.

Dos 139 complexos aquáticos, 130 (93,5\%) localizavam-se no Sudeste e 120 (86,3\%), no estado de São Paulo. A situação dos complexos esportivos era parecida: dos 701 existentes, 470 (67,0\%) estavam no Sudeste e 331 (47,2\%), em São Paulo. No outro extremo, a região Norte e Centro-Oeste não tinham nenhum complexo aquático.

Quanto à capacidade média de público, no que diz respeito aos ginásios e estádios de futebol, ela era, no geral, reduzida: 1.565 pessoas, em média, no primeiro caso e 4.286 pessoas no segundo. Os complexos aquáticos também comportavam, em geral, pouco público (média de 662 pessoas).

No que diz respeito às instalações esportivas das prefeituras, em 2003 as mais freqüentes eram os campos de futebol (presentes em $74,8 \%$ dos municípios) e as quadras cobertas e não-cobertas (que existiam em $66,2 \%$ das cidades). As 
instalações menos freqüentes eram as pistas de skate, patins e similares, presentes em só $4 \%$ das cidades, seguidas pelos campos de malha $(4,3 \%)$ e as piscinas recreativas $(5,2 \%)$. Na região Sudeste, concentrava-se a grande maioria de todas as instalações selecionadas.

\section{F.4 Análise SWOT}

Segue a análise SWOT do projeto.

\section{F.4.1 Pontos Fortes}

- Equipe formada por pesquisadores e profissionais altamente qualificados nas áreas de atuação;

- Equipe de desenvolvimento própria;

- Infra-estrutura tecnológica própria;

- Resposta rápida para desenvolvimentos e evoluções com poucos profissionais;

- Grande capacidade para lançamento de projetos inovadores; 
- Parceria com laboratório de pesquisa da USP;

- Convênio com a Secretaria Municipal de Esportes de São Paulo, através do projeto Jogos da Cidade, iniciado em 2004;

- Principais modalidades esportivas praticadas no cenário nacional já desenvolvidas;

- Alta capacidade de implementação

- Projetos com infra-estrutura própria eCampeonatos - ilimitado

\section{F.4.2 Oportunidades}

- Grande aceitação dos projetos de Governo Eletrônico

- Mais de $40 \%$ dos municípios brasileiros adotam alguma solução;

- Número crescente de usuários de tecnologia de Internet e celulares;

- Fácil aceitação de novas tecnologias;

- Ausência de soluções similares no Brasil

- "Timing" de entrada proporcionará forte barreira de entrada a concorrentes. 


\section{F.4.3 Pontos Fracos}

- Recursos financeiros próprios limitados;

- Estrutura comercial limitada;

- Ausência de algumas modalidades esportivas praticadas no Brasil e da maioria daquelas praticadas no exterior.

\section{F.4.4 Ameaças}

- Ambiente tecnológico dinâmico e inovador;

- Resistência para projetos inovadores;

- Tecnologicamente há poucas barreiras de entrada

- Possibilidade dos grandes players lançarem solução similar;

- Capacidade limitada dos usuários de tecnologia;

- Falta de treinamento;

- Inexistência de modelo de negócios para Internet. 


\section{F.5 A empresa}

A thinkUP Engenharia de Software \& Internet, constituída em 1998 com a missão de prover soluções em Engenharia de Requisitos, focou a partir de 2003 na pesquisa e desenvolvimento de um ambiente de Design, compreendendo um investimento significativo no desenvolvimento de uma infra-estrutura de fabrica de software baseado em Internet de nova geração, a Web 2.0.

Em 2003 foi firmada uma parceria estratégica firmada com o d-lab, onde os sócios fundadores da thinkUP mantém atividades regulares de pesquisa acadêmica. Essa parceria viabilizou a concepção do ambiente de Design da thinkUP, que apóia de forma estrutural todos os projetos desenvolvidos na empresa.

Seguindo com o seu planejamento estratégico, em 2004 a thinkUP concebeu uma unidade de negócios para o desenvolvimento de projetos na área de bem-estar: Entretenimento e Saúde.

\section{F.6 A equipe}

A equipe esta constituída por um professor doutor, que é o orientador, dois integrantes da empresa, com qualificação de mestrado e doutorado, e dois alunos de iniciação científica. Todos os membros estão vinculados à Escola Politécnica da Universidade de São Paulo. 


\title{
Apêndice G - Artigo do eCampeonatos
}

\section{Aplicação da Tecnologia na Inclusão Sócio-Digital: Um estudo de caso na Secretaria de Esportes da Prefeitura de São Paulo}

\author{
Melina T. Guedes, Daniel Almansa, Tiago S. Vaquero, Eston A. Santos \\ d-lab - Escola Politécnica da USP
}

Av. Prof. Mello Moraes, 2231 - 05508-900 - São Paulo - SP - Brasil

melina.guedes@poli.usp.br, dalmansa@usp.br , tiago.vaquero@poli.usp.br , eston@usp.br

\begin{abstract}
Take care of customers was, until little time, an exclusive action of the private organizations, but the public organizations had recently felt pressured, for the society, for a rendering of services next to that one practiced by the private institutions, what it has taken them to consider the citizens as customers. This work presents the importance that the Information Technology had for the Public Administration, making possible a bigger approach of the government with the citizen, generating social-digital inclusion. The results are observed in the Case of the eGovernment pilot project in the Secretariat of Sports of the City of São Paulo.
\end{abstract}

Resumo: $A$ necessidade de atender bem aos clientes era, até pouco tempo, exclusiva das organizações da iniciativa privada, mas recentemente as organizações públicas se sentiram pressionadas, pela sociedade, para uma prestação de serviço mais próxima daquela praticada pelas instituições privadas, o que as tem levado a considerar os cidadãos como clientes. Esse trabalho apresenta a importância que a Tecnologia da Informação teve para a Administração Pública, possibilitando uma maior aproximação do governo com o cidadão, gerando inclusão sócio-digital. Os resultados são observados no Estudo de Caso do projeto piloto de Governo 
Eletrônico na Secretaria de Esportes da Cidade de São Paulo.

\section{G.1 Introdução}

O advendo da Internet tem revolucionado a forma com a qual as organizações atuais têm se comportado no mercado, haja vista a possibilidade de alcance dos negócios em locais antes inatingíveis. Essa possibilidade de expansão de negócios, além de outras vantagens, vem da importância que a tecnologia da informação (TI) tem exercido nas instituições. Dentre as nomenclaturas mais recentes para as soluções de TI, destacam-se o e-commerce, e-business, e-government, ...

A evolução da TI permitiu que as organizações se adequassem as necessidades da nova economia, no sentido de atender as expectativas de seus consumidores (DAVENPORT, 1998, 2000). Isso levou essas entidades a buscar maior eficácia operacional em função da competitividade, apoiando-se nas soluções de TI. Essa tendência não tem sido exclusiva das instituições privadas, mas também das organizações públicas.

Atualmente, em função do acesso facilitado a informações nos diversos meios de comunicação, as pessoas tem se tornado mais exigentes com relação a qualidade de produtos e serviços, além do conhecimento dos seus direitos, o que gerou questionamentos, até então não praticados, a esses fornecedores.

O governo eletrônico surgiu da tendência de incorporar os cidadãos no planejamento estratégicos da administração pública (WEBLER \& TULER, 2000). A busca por maior transparência e efetividade das ações sociais, além do esforço para a redução das diferenças e aumento da inclusão social, levam à procura permanente de soluções tecnológicas que atendam os objetivos do governo. Equalizar o potencial das aplicações de $\mathrm{TI}$ aos requisitos de negócios da organização se torna, consequentemente, uma tarefa não trivial. Entretanto, o alcance desse equilíbrio leva a organização à uma vantagem competitiva.

O artigo mostra como a Secretaria dos Esportes da Cidade de São Paulo, através de 
uma competição esportiva, possibilitou que os munícipes aproveitem mais as vantagens advindas da adoção de uma solução de governo eletrônico para a área esportiva. O trabalho apresenta um estudo de caso gerado da observação da terceira edição dos Jogos da Cidade de São Paulo. A seção a seguir apresenta alguns pontos que definem a Tecnologia da Informação na Administração Pública, além do Governo Eletrônico. Na seção seguinte é apresentado o estudo de caso, sendo discutidos os resultados observados do trabalho na seção final do artigo.

\section{G.2 Tecnologia da Informação (TI)}

Segundo LAURINDO (LAURINDO, 2002), o conceito de Tecnologia da Informação (TI) vai além do Processamento de Dados, pois agrupa os recursos de hardware e software com as aplicações desenvolvidas nesse contexto, como é o caso das soluções em Internet.

As seções a seguir ilustram, repectivamente, as estratégias do uso da TI nas organizações públicas e a importância da informação nas organizações.

\section{G.2.1 Estratégias de Uso da TI na Administração Pública}

As organizações, de uma forma geral, necessitam administrar recursos para a produção dos bens e serviços oferecidos a seus clientes. No caso das empresas, este público é o consumidor, enquanto para as organizações públicas o público-alvo é o contribuinte, ou seja, o cidadão. No caso do uso da TI nas empresas, a justificativa vem da busca da competitividade, além do lucro como fator principal. Já no caso das instituições públicas, a justificativa para o uso da $\mathrm{TI}$ vem da necessidade de melhorar o ambiente interno da organização, pelo aumento da 
eficácia organizacional e, principalmente, melhorar o atendimento da população e os serviços prestados ao cidadão (TAN \& PAN, 2003).

Quando uma organização, pública ou privada, não consegue desempenhar adequadamente sua missão, surgem forças externas que concorrem com essas organizações deficitárias, assumindo seu papel, no caso do setor público a competência, levando-a à extinção. Quando a organização pública deixa de executar de forma eficaz seu papel, surgem grupos organizados que proverão à população suas necessidades, passando a exercer um forte domínio sobre a mesma, influenciando-a conforme seus interesses (CUNHA, 1994). Ainda segundo CUNHA (CUNHA, 1994), "a gestão da TI na administração pública deve vislumbrar não apenas o contexto interno da organização que visa obter a eficácia organizacional, mas principalmente o ambiente externo, que diferencia a qualidade dos serviços prestados ao cidadão, contribuindo para uma atuação eficaz do poder público na área de atuação de sua competência".

\section{G.2.2 Importância da Informação na Organização}

Segundo MEIRELLES (MEIRELLES, 1990), "a tendência natural é tentar medir o valor da informação pelo quanto adicional ela traz, entretanto, o conceito mais amplo e correto é o custo de oportunidade - quanto custa não tê-la. Neste sentido, medir o valor da informação passa a ser um processo semelhante ao de um seguro ou propaganda - quanto custa não ter".

Nesta abordagem, a informação é tratada como recurso, possuindo então custo e valor, taxa de retorno, custo de oportunidade de não se ter a informação; pode existir uma sinergia ao combinar dados cujo resultado final é maior que a soma das partes (MEIRELLES, 1990).

Assim, a informação exerce um papel importante na organização pública, uma vez que os recursos de informações de qualidade são fundamentais para a tomada de decisão, de maneira a garantir uma atuação eficaz da organização nas áreas sob sua responsabilidade. 


\section{G.3 Governo Eletrônico}

Segundo ZWEERS \& PLANQUÉ (ZWEERS \& PLANQUÉ, 2001), "Governo Eletrônico é um tema emergente que visa fornecer ou disponibilizar informações, serviços ou produtos através de meio eletrônico, a partir de orgãos públicos, a qualquer momento, local e cidadão, de modo a agregar valor a todos os envolvidos com a organização pública".

Para o presente trabalho, foram pesquisadas algumas literaturas que classificam os projetos de Governo Eletrônico, segundo o ponto de vista dos diferentes autores, conforme segue:

\section{G.3.1 Objetivos para a implantação do Governo Eletrônico}

A implantação do Governo Eletrônico, segundo TAKAHASHI (TAKAHASHI, 2000), geralmente tem como objetivos:

- Reduzir custos;

- Aumentar a eficiência;

- Responder às expectativas dos cidadãos;

- Facilitar o desenvolvimento econômico;

- Incrementar as relações com o cidadão. 


\section{G.3.2 O Governo Eletrônico segundo seu relacionamento}

As classificações utilizadas para o Governo Eletrônico, quanto ao relacionamento, são (TAKAHASHI, 2000):

- Governo para Governo (G2G)

- Governo para Cidadão (G2C)

- Governo para Negócios (G2B)

- Governo para Empregados (G2E)

\section{G.3.3 O Governo Eletrônico segundo sua evolução}

A evolução das implantações é classificada segundo as fases a seguir (GARTNER, 2000): 


\section{G.3.3.1 Presença}

É a fase inicial onde são colocadas na Internet informações sobre os órgãos do governo tais como missão de agências, endereços, horários de atendimento, divulgação de projetos e alguns documentos oficiais;

\section{G.3.3.2 Interação}

Nesta fase são acrescentadas funcionalidades básicas de buscas, download de formulários que podem ser preenchidos e encaminhados para as repartições, links para outros sites além de iterações por e-mail com repartições e funcionários responsáveis;

\section{G.3.3.3 Transação}

É a fase onde é oferecido aos contribuintes facilidades de auto serviço envolvendo tarefas completas on-line (preenchimento de formulários, recebimento, processamento e resposta ao usuário). Há o compartilhamento de recursos, passando a Web a ser vista como um canal de distribuição de serviços, 24 horas por dia e 7 dias por semana; 


\section{G.3.3.4 Transformação}

Esta fase é caracterizada pela redefinição dos processos de entrega de serviços do governo, designando um ponto único de contato do contribuinte (portal) que torna a organização do governo totalmente transparente para os cidadãos.

\section{G.3.4 Obstáculos para a implantação do Governo Eletrônico}

Segundo TAKAHASHI (TAKAHASHI, 2000), podem ser destacados os principais obstáculos observados nas implantações do Governo Eletrônico:

- Fatores sociais - Exclusão social e digital;

- Fatores tecnológicos - Atualização e treinamento;

- Fatores políticos - Descontinuidade nas gestões;

- Fatores econômicos - Escassez de recursos, necessidade de grandes investimentos;

- Fatores organizacionais - cultura política e organizacional, mudança do foco interno para o externo. 


\section{G.4 Estudo de Caso: Os Jogos da Cidade de São Paulo}

Os Jogos da Cidade de São Paulo 2005, na sua terceira edição, é uma iniciativa da Secretaria de Esportes da Prefeitura de São Paulo, que permite aos atletas amadores de diferentes modalidades esportivas a disputa dos seus respectivos campeonatos em duas fases, a regional, com a participação das 31 subprefeituras da cidade, e a municipal. Para essa edição dos Jogos da Cidade, a Secretaria de Esportes estabeleceu uma parceria com uma empresa privada, após testar a solução na fase municipal da edição de 2004 , onde essa forneceu uma solução de TI para o problema da Secretaria de Organização de eventos esportivos, "sem custos" para a Prefeitura. Essa solução está disponibilizada na internet, no endereço eletrônico http://www.eCampeonatos.com.br.

Segundo a descrição do projeto (PORTALPMSP, 2004), os Jogos da Cidade beneficiam a população através da:

\section{G.4.1 Valorização da identidade local}

São Paulo é a cidade dos mil povos e cada um deles contribui para a diversidade que faz da capital uma cidade culturalmente rica. A presença de imigrantes das mais diversas etnias e continentes torna cada bairro paulistano um universo particular. Afora os povos que vêm de fora, temos os migrantes do Nordeste, do Sul, de Minas e de outras regiões brasileiras. Os Jogos têm o propósito de valorizar essa identidade particular, ao mesmo tempo que contribuem para a integração entre todas. 


\section{G.4.2 Participação popular}

A ocupação do tempo livre do homem moderno deve incorporar a prática esportiva com ênfase na sociabilização e suas expressões lúdicas, entendendo-a como patrimônio cultural da humanidade e mais uma opção de lazer a ser apropriada por toda a população, capaz de contribuir para a democratização da cidade e fortalecer os laços de solidariedade entre os indivíduos. Os Jogos da Cidade serão uma oportunidade de participação da população, democratizando e incentivando a prática esportiva, na busca de melhor qualidade de vida para todos, indistintamente. Além disso, contribuirão para o resgate do orgulho do paulistano.

\section{G.4.3 Cultura da paz}

Os Jogos da Cidade estão comprometidos com a Cultura da Paz, seguindo recomendações específicas da UNESCO sobre as responsabilidades do esporte com a paz mundial, a importância da promoção do esporte popular a todos os grupos humanos e da preservação dos valores éticos e morais do esporte. Este entendimento torna o fenômeno esportivo comprometido com o próprio destino da humanidade.

\section{G.4.4 Responsabilidade social}

Também é recomendação da UNESCO a convivência cooperativa entre governos e organizações voluntárias. Para sua realização, os Jogos da Cidade contam com a 
disseminação do conceito de responsabilidade social que atinge amplos setores da sociedade. Participar dos Jogos da Cidade é uma forma inovadora e eficaz de atuar em parceria com as comunidades na construção do bem-estar comum.

Com o objetivo de verificar como os Jogos da Cidade se classificam de acordo com os ítens apresentados na seção 3, foi elaborada uma pesquisa com o coordenador técnico dos Jogos da Cidade 2005, funcionário da Secretaria de Esportes, com a equipe desenvolvedora da solução de $\mathrm{Tl}$ e analisada uma amostragem das mensagens eletrônicas enviadas pelos atletas e responsáveis pelas equipes participantes desta edição dos Jogos da Cidade. Seguem as questões feitas para a equipe entrevistada.

- Quais os objetivos para a implantação do eCampeonatos?

- Com quais agentes o eCampeonatos permitiu que o relacionamento fosse estreitado?

- Quais os processos disponibilizados pelo eCampeonatos?

- Quais os principais obstáculos encontrados para a implantação do eCampeonatos?

O artigo ilustra o contexto de evolução dos principais processos administrados pela organização dos Jogos da Cidade, a partir das respostas às questões abaixo:

- Como foi o processo de inscrição dos atletas?

- Como foi o cadastro dos locais dos jogos com agenda de disponibilidade?

- Como foi o processo de geração da tabela dos jogos e a divulgação do resultado dos jogos e geração das próximas fases, como ocorreu?

- Quantos jogos aconteceram nos Jogos da Cidade?

Para efeito de análise das respostas, para cada questão acima ainda se questionou 
a equipe sobre alguns indicadores para se identificar qual a impressão dos envolvidos nas diferentes fases estudadas dos Jogos da Cidade, tais como:

- O item analisado aumentou, diminuiu ou não foi afetado?

- O item analisado melhorou, piorou ou não foi afetado?

Segundo o coordenador técnico dos Jogos da Cidade, com o advento da parceria com o eCampeonatos, três fases ao longo das edições dos Jogos podem ser destacadas, como descritas abaixo:

\section{G.4.5 Jogos da Cidade antes do eCampeonatos}

Na primeira fase, neste caso antes do eCampeonatos, os Jogos da Cidade de 2003 contou com a participação de aproximadamente 40.000 atletas amadores, divididos nas 31 subprefeituras em 14 modalidades (PORTALPMSP, 2004).

\section{G.4.5.1 Inscrição dos atletas}

O processo de inscrição foi centralizado na Secretaria de Esportes, para onde os responsáveis dos times se dirigiam para a inscrição de sua entidade nos Jogos da Cidade de 2003. 


\section{G.4.5.2 Cadastro dos locais dos jogos com agenda de disponibilidade}

A Secretaria cadastrou a disponibilidade dos locais dos jogos em formulários impressos, na maioria dos casos através de ofícios enviados aos responsáveis dos locais.

\section{G.4.5.3 Geração da tabela dos jogos}

A atividade de geração das tabelas dos jogos, segundo o coordenador técnico, sempre foi a tarefa que mais exigiu da organização dos Jogos da Cidade. Em média essa etapa consumia 03 (três) meses de trabalho árduo da organização, envolvendo uma equipe de 06 (seis) pessoas. Para se fazer a alocação dos jogos nos locais a equipe precisava ter uma visão global dos jogos alocados, para se evitar conflitos de locais e horários. A solução encontrada foi a confecção de um mapa colorido, conhecido como "mapão".

Após resolvido o problema da alocação dos jogos, preparava-se as tabelas dos jogos de cada subprefeitura em planilhas eletrônicas que, após impressas eram disponibilizadas nas respectivas subprefeituras e na sede da Secretaria dos Esportes. Nos casos de torneios eliminatórios, as tabelas eram geradas semanalmente.

$\mathrm{Na}$ fase municipal, havia a necessidade de se enviar cópias das tabelas para as subprefeituras. 


\section{G.4.5.4 Divulgação dos resultados e geração das próximas fases}

Após o acontecimento dos Jogos, a comissão de arbitragem encaminhava a súmula dos jogos para a organização dos Jogos da Cidade lançar os resultados. Em função dos resultados, a equipe gerava a "rodada" do próximo final de semana, encaminhando cópias das tabelas de resultados e próximos jogos para as respectivas subprefeituras.

\section{G.4.5.5 Número de Jogos}

Em 2003, nas diferentes modalidades, durante pouco mais de 04 (quatro) meses, aconteceram mais de 2000 disputas nos Jogos da Cidade.

\section{G.4.6 Jogos da Cidade testando o eCampeonatos}

Nesta fase dos Jogos da Cidade, apesar do acréscimo de categorias sub 17 em algumas modalidades esportivas, segundo a informação do Portal da Prefeitura (PORTALPMSP, 2004) o número de atletas também ficou próximo dos 40.000 .

O teste piloto do eCampeonatos aconteceu na fase municipal dos Jogos da Cidade, provocando alteração na geração da tabela e resultados dos jogos, conforme segue: 


\section{G.4.6.1 Inscrição dos atletas}

Similar aos Jogos da Cidade de 2003.

\section{G.4.6.2 Cadastro dos locais dos jogos com agenda de disponibilidade}

Similar aos Jogos da Cidade de 2003.

\section{G.4.6.3 Geração da tabela dos jogos}

O eCampeonatos possui uma solução em Internet que resolveu o problema de geração de tabelas dos jogos da Secretaria de Esportes. A equipe dos Jogos da Cidade precisou fazer o cadastro das equipes classificadas na fase regional nas respectivas modalidades. Após isso, para a organização a geração dos jogos acontecia com o "clique do mouse". Nesta fase, a alocação dos locais ainda era feita jogo a jogo.

A divulgação da tabela dos jogos passou a ser feita pela Internet, exclusivamente. 


\section{G.4.6.4 Divulgação dos resultados e geração das próximas fases}

$\mathrm{Na}$ fase municipal, o lançamento dos resultados dos jogos passou a ser realizado através da Internet e, conseqüentemente, o resultado já era disponibilizado ao público.

\section{G.4.6.5 Número de Jogos}

Assim como em 2003, nas diferentes modalidades, durante pouco mais de 04 (quatro) meses, aconteceram mais de 3000 disputas nos Jogos da Cidade.

\section{G.4.7 Jogos da Cidade com o eCampeonatos}

Atualmente estão ocorrendo os Jogos da Cidade de 2005 que, diferentemente das edições anteriores, já foi iniciada com o eCampeonatos. Neste ano a maioria dos principais processos executados durante a competição estarão acontecendo no eCampeonatos.

Seguem as principais alterações nos Jogos da Cidade com o eCampeonatos: 


\section{G.4.7.1 Inscrição dos atletas}

As inscrições das entidades ocorreram, exclusivamente pela internet. Todo o processo de inscrição é on-line. Para isso cada responsável precisou fornecer os dados da entidade e seus dados pessoais enquanto responsável pela entidade. Após um processo de aprovação das entidades inscritas, o pessoal de apoio nas subprefeituras se encarregou de aprovar as inscrições após análise dos dados fornecidos. Basicamente verificar se o endereço fornecido pertencia à subprefeitura inscrita. Isso foi possível através da verificação do CEP fornecido.

Com a aprovação da entidade, o responsável recebeu uma mensagem para o cadastramento dos atletas, o que era possível após autenticação do mesmo.

\section{G.4.7.2 Cadastro dos locais dos jogos com agenda de disponibilidade}

Diferentemente das edições anteriores, o eCampeonatos disponibiliza o cadastro de locais de jogos, chamados recursos, com as respectivas disponibilidades para os Jogos da Cidade. Esses locais agora são utilizados pelo algoritmo de alocação de recursos.

\section{G.4.7.3 Geração da tabela dos jogos}

Com as inscrições das entidades nas modalidades e categorias do evento, por subprefeitura, todos os dados necessários para a geração dos grupos já estavam 
disponíveis. Com base no cadastro dos recursos, a geração das tabelas dos jogos passou a ser uma tarefa simples, reduzindo o tempo para aproximadamente 06 (seis) minutos.

\begin{tabular}{|c|c|c|}
\hline Questão & Aderência & Indicador \\
\hline \multicolumn{3}{|c|}{ Objetivos para a Implantação } \\
\hline Reduzir custos & $(\mathrm{)}) 0(\mathrm{)}) 1(\mathrm{)}(\mathrm{X}) 3(\mathrm{)}) 4(\mathrm{)})$ & ปิ \\
\hline Aumentar a eficiência & () 0() 1() 2() $3(\mathrm{X}) 4(\mathrm{)}) 5$ & ৩ \\
\hline Responder às expectativas dos cidadãos & () 0() 1() 2() $3(\mathrm{X}) 4(\mathrm{)}) 5$ & 了 \\
\hline Facilitar o desenvolvimento econômico & () 0() 1() $2(X) 3() 4() 5$ & 七 \\
\hline \multicolumn{3}{|c|}{ Relacionamento do Governo Eletrônico } \\
\hline Governo para Governo (G2G) & $(\mathrm{X}) 0(\mathrm{)}) 1(\mathrm{)}) 2() 3() 4() 5$ & $\Leftrightarrow$ \\
\hline Governo para Cidadão (G2C) & $($ ) 0() 1() 2() 3() $4(\mathrm{X}) 5$ & $\Leftrightarrow$ \\
\hline Governo para Negócios (G2B) & $(\mathrm{X}) 0() 1() 2() 3() 4() 5$ & \\
\hline Governo para Empregados (G2E) & $(\mathrm{X}) 0(\mathrm{)}) 1(\mathrm{)}) 2(\mathrm{)}) 3(\mathrm{)})(\mathrm{)}) 5$ & $\Leftrightarrow$ \\
\hline \multicolumn{3}{|c|}{ Evolução do Governo Eletrônico } \\
\hline Presença & $(\mathrm{)}) 0(\mathrm{)}) 1(\mathrm{)})(\mathrm{)} 3(\mathrm{X}) 4(\mathrm{)}) 5$ & ૫ \\
\hline Interação & 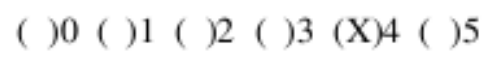 & [1] \\
\hline Transação & $(\mathrm{)}) 0(\mathrm{)}) 1(\mathrm{)}(\mathrm{)}) 3(\mathrm{X}) 4(\mathrm{)}) 5$ & \\
\hline Transformação & $(\mathrm{X}) 0(\mathrm{)}) 1(\mathrm{)}) 2(\mathrm{)}) 3(\mathrm{)}) 4(\mathrm{)}) 5$ & $\Leftrightarrow$ \\
\hline \multicolumn{3}{|c|}{ Obstáculos para o Governo Eletrônico } \\
\hline Fatores sociais & $(\mathrm{)}) 0(\mathrm{)}) 1(\mathrm{)})(\mathrm{X}) 3(\mathrm{)}) 4(\mathrm{)})$ & \\
\hline Fatores tecnológicos & $(\mathrm{)}) 0(\mathrm{)}) 1(\mathrm{)}) \mathrm{(X)3()4( \textrm {) } )}$ & \\
\hline Fatores políticos & () 0() 1() 2() 3() $4(X) 5$ & \\
\hline Fatores econômicos & $(\mathrm{X}) 0() 1() 2() 3() 4() 5$ & \\
\hline Fatores organizacionais & () 0() 1() 2() $3(X) 4() 5$ & $\Omega$ \\
\hline \multicolumn{3}{|c|}{ Legenda } \\
\hline $\begin{array}{l}\widetilde{1} \text { Aumentou e melhorou } \\
\square \text { Aumentou e piorou } \\
\text { 乙 Diminuiu e melhorou } \\
\beth \text { Diminuiu e piorou } \\
\Leftrightarrow \text { Não foi afetado }\end{array}$ & & \\
\hline
\end{tabular}

Figura G.1: Perfil do projeto Jogos da Cidade como Governo Eletrônico. 


\section{G.4.7.4 Divulgação dos resultados e geração das próximas fases}

A Secretaria dos Esportes agora já tem a possibilidade de gerar o resultado dos jogos logo após o seu término.

Além do resultado, os grupos já tem automaticamente as informações da tabela de classificação, como por exemplo saldo de gols e pontos ganhos.

\section{G.4.7.5 Número de Jogos}

Até o dia 22/05/2005, com somente duas rodadas da fase regional dos Jogos da Cidade, já haviam acontecido 513 jogos. É importante ressaltar que os jogos ocorrem nos fins de semana.

Com base nas entrevistas realizadas em aproximadamente 12 horas, foi possível verificar o perfil do projeto de Governo Eletrônico da Secretaria de Esportes da Cidade de São Paulo, com uma escala de aderência, conforme a figura G.1.

A figura G.2 mostra alguns dados retirados dos relatórios de acesso dos Jogos da Cidade no site eCampeonatos, assim como uma amostragem das mensagens eletrônicas enviadas pelos atletas e responsáveis pelos times. 


\begin{tabular}{lc}
\hline \multicolumn{3}{c}{ Acessos ao site } \\
\hline Jogos da Cidade 2004 - Agosto 2004 & 747 acessos \\
Jogos da Cidade 2004 - Setembro 2004 & 1056 acessos \\
Jogos da Cidade 2005 - Março 2005 & 3987 acessos (a partir de 15/03) \\
Jogos da Cidade 2005 - Abril 2005 & 13544 acessos \\
Jogos da Cidade 2005 - Maio 2005 & Mensagens eletrônicas \\
\hline \multicolumn{3}{c}{ 18390 acessos (até 22/05) } \\
\hline Dúvidas & 4874 mensagens \\
Elogios & 47 mensagens \\
\hline
\end{tabular}

Figura G.2: Dados dos Jogos da Cidade.

\section{G.5 Considerações finais}

Os Jogos da Cidade de São Paulo se mostra como uma iniciativa em alinhamento com as definições de Governo Eletrônico. Algumas questões ainda precisam ser trabalhadas, pois foi observado que, apesar do acesso da equipe coordenadora ao eCampeonatos, ainda existe uma grande necessidade de adaptação aos novos recursos tecnológicos, ou seja treinamento, pois como observado na figura G.2, boa parte das dúvidas recebidas através das mensagens diz respeito a falta de habilidade no manuseio do eCampeonatos e as demais estão relacionadas a procedimentos administrativos ainda não resolvidos, ou a falta de recursos humanos necessários para o bom desempenho das tarefas da organização dos Jogos da Cidade.

Por outro lado, o lado positivo do projeto é que foi possível atingir os objetivos identificados na pesquisa, alguns diretamente, tais como aumentar a eficiência e atender às expectativas dos cidadãos, outros indiretamente como contribuir para a redução de custos, pois verificou-se que o eCampeonatos permitiu que vários deslocamentos deixassem de acontecer, como é o caso dos atletas e responsáveis pelas entidades quando precisavam saber sobre o resultado e a agenda para os próximos jogos, além da economia significativa com cópias de tabelas de jogos, pois agora são acessíveis pela Internet. 


\section{G.6 Agradecimentos}

O autor agradece a Secretaria de Esportes da Cidade de São Paulo, representada pelo coordenador técnico dos Jogos da Cidade 2005 e à equipe do eCampeonatos, pelas informações e disponibilidade que foram indispensáveis para a realização do artigo. Ao CNPq, pelo apoio financeiro.

\section{G.7 Referências}

CUNHA, M.A.V.C. (1994) - Administração dos Recursos de Informática Pública: Estudo de Caso do Modelo Paranaense. Dissertação de Mestrado. EAESP, Fundação Getúlio Vargas, São Paulo.

DAVENPORT, T.H. (1998). Putting the Enterprise into the Enterprise System. Harvard Business Review Vol. 76, n. 4, p.121-131.

DAVENPORT, T.H. (2000). Mission Critical: Realizing the Promise of Enterprise Systems. Harvard Business School Press. Boston.

GARTNER (2000). Gartner's Four Phases of E-Government Model, Gartner Group Research Note.

LAURINDO, F.J.B. (2002). Tecnologia da Informação: eficácia nas organizações. Editora Futura. São Paulo.

MEIRELLES, F.S. (1990). Administração da implementação dos recursos de informática. Tese de Doutorado - EAESP, Fundação Getúlio Vargas, São Paulo. 
PORTALPMSP. (2004). Portal de Internet da Prefeitura da Cidade de São Paulo. Disponível em: http://portal.prefeitura.sp.gov.br/secretarias/esportes/jogosdacidade/apresentacao/ini ciativa/0001. Acessado em 22.Mai.2005.

TAN, C.W. \& PAN, S.L. (2003). Managing e-transformation in the public sector: an egovernment study of the Inland Revenue Authority of Singapore (IRAS). European Journal of Information Systems Vol. 12, n. 1, p.269-281.

TAKAHASHI, T. (2000). Sociedade da Informação no Brasil - Livro Verde. Disponível em: http://www.mct.gov.br/Temas/Socinfo/Livro_Verde/Default.htm. Acessado em 14.Mai.2005.

WEBLER, T. \& TULER, S. (2000). Fairness and competence in citizen participation theoretical reflections from a case study. Administration \& Society Vol. 32, n. 5, p.566-595.

ZWEERS K \& PLANQUÉ K. (2001). Electronic Government. From a Organizational Based Perspective Towards a Client Oriented Approach, In: Designing EGovernment, Prins J.E.J. (ed.), Kluwer Law International, pp. 92. 


\section{Apêndice H - Negócios com o itSIMPLE}

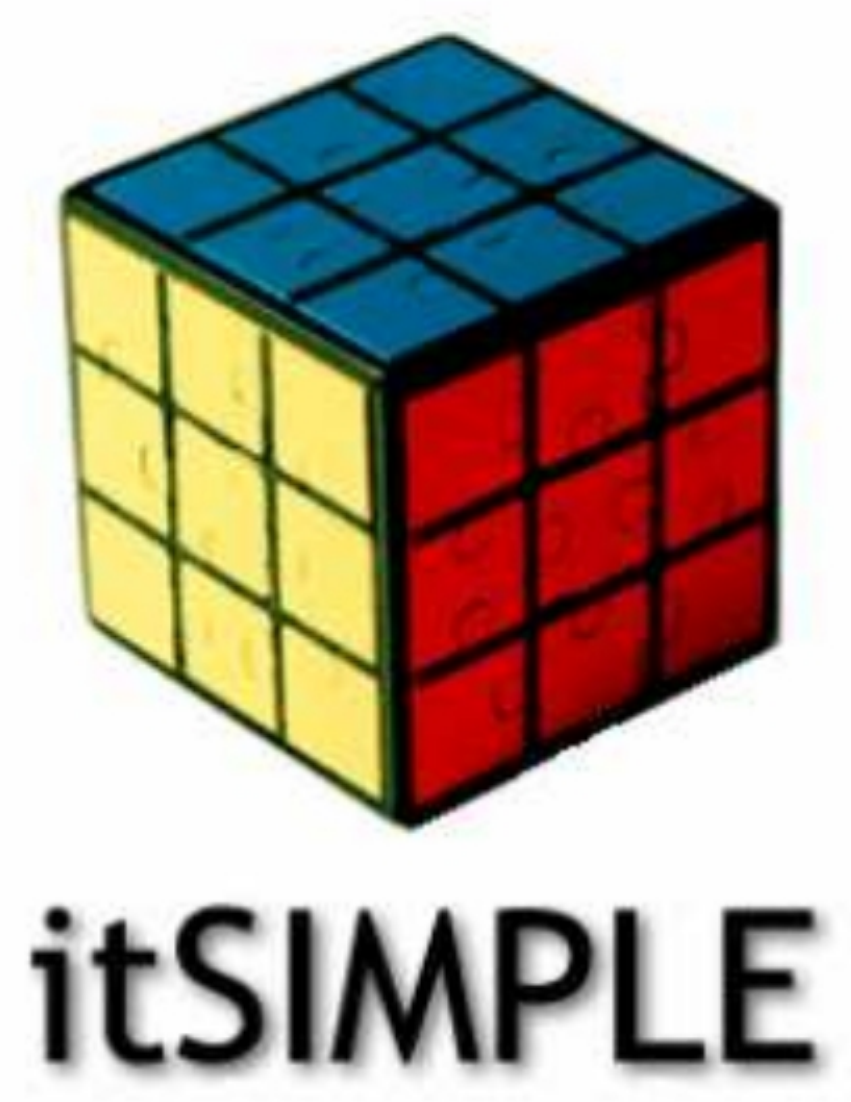

Integrated Tools Software Interface for Modeling PLanning Environments 


\section{H.1 Descrição do produto}

O itSIMPLE é um ambiente de design que integra ferramentas de análise, especificação e modelagem através de linguagens consolidadas como XML, UML e Redes de Petri. Integração com outras ferramentas que são utilizadas nas fases iniciais do ciclo de vida do desenvolvimento de sistemas (como o IBM Rational Suite, Together Center, Visual Studio, etc.) também é possível, dando suporte às mais diferentes aplicações de engenharia (software, manufatura, planejamento, etc.), negócios (gestão de projetos, controle de processos, etc.) e qualquer outra atividade onde existam problemas de design.

A plataforma visa utilizar o conceito de service oriented architecture (SOA), sendo totalmente configurável com funções personalizadas que possuem capacidades adequadas para cada organização ou individuo. Dessa forma, busca-se permitir a integração das diversas ferramentas que existem no mercado atualmente para modelagem de sistemas, mas que trabalham de maneira independente, sem uma linguagem comum.

Esta comunicação, baseada em XML, permitirá ao designer trabalhar com diversas visões do sistema, integrando as diversas técnicas de modelagem existentes atualmente. O itSIMPLE utilizará toda essa informação para auxiliar o processo de design, e conseqüentemente 0 de desenvolvimento, facilitando a validação $e$ verificação do modelo em qualquer etapa do processo.

Outra inovação importante diz respeito à utilização do conceito de running specification, que permite ao usuário acessar as diferentes perspectivas (utilizando linguagens formais e semi-formais) em qualquer momento do processo de modelagem. Isto auxilia o processo de verificação e validação do modelo que esta sendo desenvolvido, pois aumenta o poder de análise e permite que os diversos profissionais possam ver o sistema da forma que lhes é mais familiar.

No estágio atual, a ferramenta é capaz de integrar a definição de requisitos em UML (Unified Modeling Language), utilizada como forma de captar o conhecimento 
necessário para o design, com a linguagem de planejamento automático em inteligência artificial PDDL (Planning Domain Definition Language), que pode ser entendida por planejadores para a resolução de problemas de planejamento, e as redes de Petri, que permitem a verificação e validação do comportamento dinâmico do sistema.

Hoje, o ambiente possui uma orientação de desenvolvimento orientada a Casos de Uso (Use Case Driven Development), no entanto, no futuro, o ambiente será capaz de agregar novos pontos de vista e permitirá que o desenvolvimento siga demais orientações existentes (como a Test Driven Development) e outras que surgirem.

\section{H.2 Descrição dos serviços}

O ambiente de desenvolvimento itSIMPLE possui uma estrutura básica (core) e uma biblioteca de processos que podem ser utilizados para agregar determinadas funcionalidades, dependendo da necessidade especifica de cada projeto. Nesse contexto, outra área de atuação da empresa será na prestação de serviços relacionados à criação de aplicações específicas para as necessidades do cliente, bem como treinamento no processo de design de sistemas.

Assim, a empresa será responsável pelo treinamento do pessoal, desenvolvimento das ferramentas necessárias e da implementação. Isto envolve a mudanças de processos internos da empresa cliente, introdução de novas metodologias de design e técnicas de modelagem. A empresa venderia o know- how adquirido ao longo de sua experiência para equipes de projetos, bem como soluções de software (plugins que agregam funcionalidade ao ambiente itSIMPLE) para integração de softwares específicos e suporte a novos modelos e análises.

Seguindo esta mesma linha, a empresa poderá fornecer soluções prontas para problemas de design de seus clientes, e não o know-how mencionado anteriormente. Apesar de esta atividade requerer o desenvolvimento de ferramentas e metodologias específicas para o problema em questão, estas não serão divulgadas, mas permaneceram internas à empresa, como ferramentas de projeto. No entanto, à medida que esses métodos se consolidam, poderão ser vendidos em módulos para 
outras empresas.

Este foco segue a tendência atual das empresas de se focarem cada vez mais em suas atividades principais, delegando cada vez mais a terceiros as atividades necessárias, mas não diretamente relacionadas ${ }^{6}$ aos seus ramos de atuação. Dessa forma, as empresas se tornam mais eficientes, pois utilizam seus recursos nas atividades onde ela é mais lucrativa.

\section{H.3 Descrição do problema resolvido}

Atualmente, existem muitas ferramentas dedicadas a determinadas áreas que utilizam metodologias e técnicas de modelagem específicas. Assim, existem aplicações para modelagem e desenvolvimento de software, manufatura, business processes modeling, arquitetura, entre outras. Como exemplos, podemos citar o Rational Rose, da IBM, o Together, da Borland e o Visual Studio, da Microsoft.

No entanto, existe pouca integração ou comunicação entre estas ferramentas (geralmente trabalham de forma independente) e principalmente, não se percebe a integração dos diferentes viewpoints. Isto insere uma serie de limitações ao processo de desenvolvimento:

- O designer só pode enxergar o sistema através de uma única perspectiva, perdendo capacidade de análise e comunicação com outros integrantes da equipe

- Como as pessoas fornecem informação de acordo com a sua visão do sistema, a utilização de uma única técnica de modelagem dificulta a inserção de muitas das informações obtidas com o cliente no modelo

- A comunicação com os diversos departamentos da empresa envolvidos no projeto (desde o gerente de processo ao presidente) é prejudicada, pois cada

6 Associação Brasileira de Empresas de Software (ABES) 
uma possui sua própria linguagem.

- A validação e verificação do modelo tornam-se mais difícil, pois muitas vezes o processo de análise se limita ao poder de uma única técnica, não podendo contar com o auxílio de outras. Além disso, poucos realizarão e entenderão os processos de análise utilizados. Falhas no modelo que não forem detectadas podem causar sérias perdas (principalmente custos de correções ${ }^{7}$, como mostra a figura H.1) ao projeto, especialmente quando somas de dinheiro importantes (como é caso dos projetos que utilizarão o ambiente itSIMPLE) estão envolvidas. Atualmente, sabe-se que o custo para corrigir erros cresce exponencialmente a cada fase do projeto.

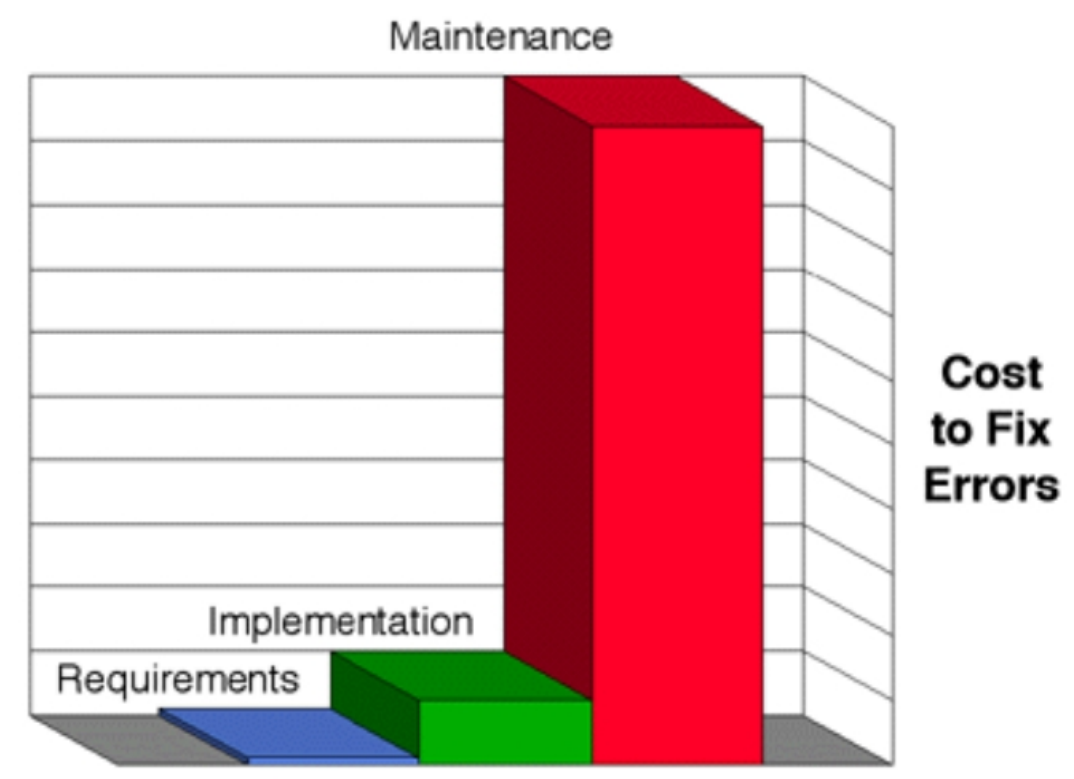

\section{Project Phase}

Figura H.1: Custo para corrigir erros X Fase do Projeto.

Dessa forma, surge a necessidade de um ambiente que seja capaz de integrar as ferramentas e técnicas de modelagem existentes, mas que coexistem de maneira independente, sem que exista comunicação entre elas. Assim, o itSIMPLE busca suprir esta deficiência das plataforma atuais e unir as diversas ferramentas e metodologias (software, gestão de projeto, etc.) existentes, mas que ainda se encontram isoladas.

7 Sanders, B.W. A software engineer's guide to the galaxy: unpublished notes for senior software engineering project. Colorado: University of Colorado at Boulder Department of Computer Science, 1987- 2001. Disponível em: <http://www.cs.colorado.edu/ sanders/ cs4308/class/guide/lifecycle/lifecycle.html>. Acesso em 20 de julho de 2002. 


\section{H.4 Análise do mercado potencial}

O mercado mundial de softwares e serviços atinge em 2006, segundo divulagação da $\mathrm{ABES}^{8}$, o valor de US\$ 666 bilhões, com previsão de crescimento médio de 5,9\% ate 2009 , quando atingiria valores próximos de US $\$ 800$ bilhões. Os maiores centros consumidores desses produtos são os Estados Unidos, a Europa e a Ásia. Na América Latina, o mercado se reduz para 18,5 bilhões, sendo Brasil e México os principais centros de consumo desses produtos.

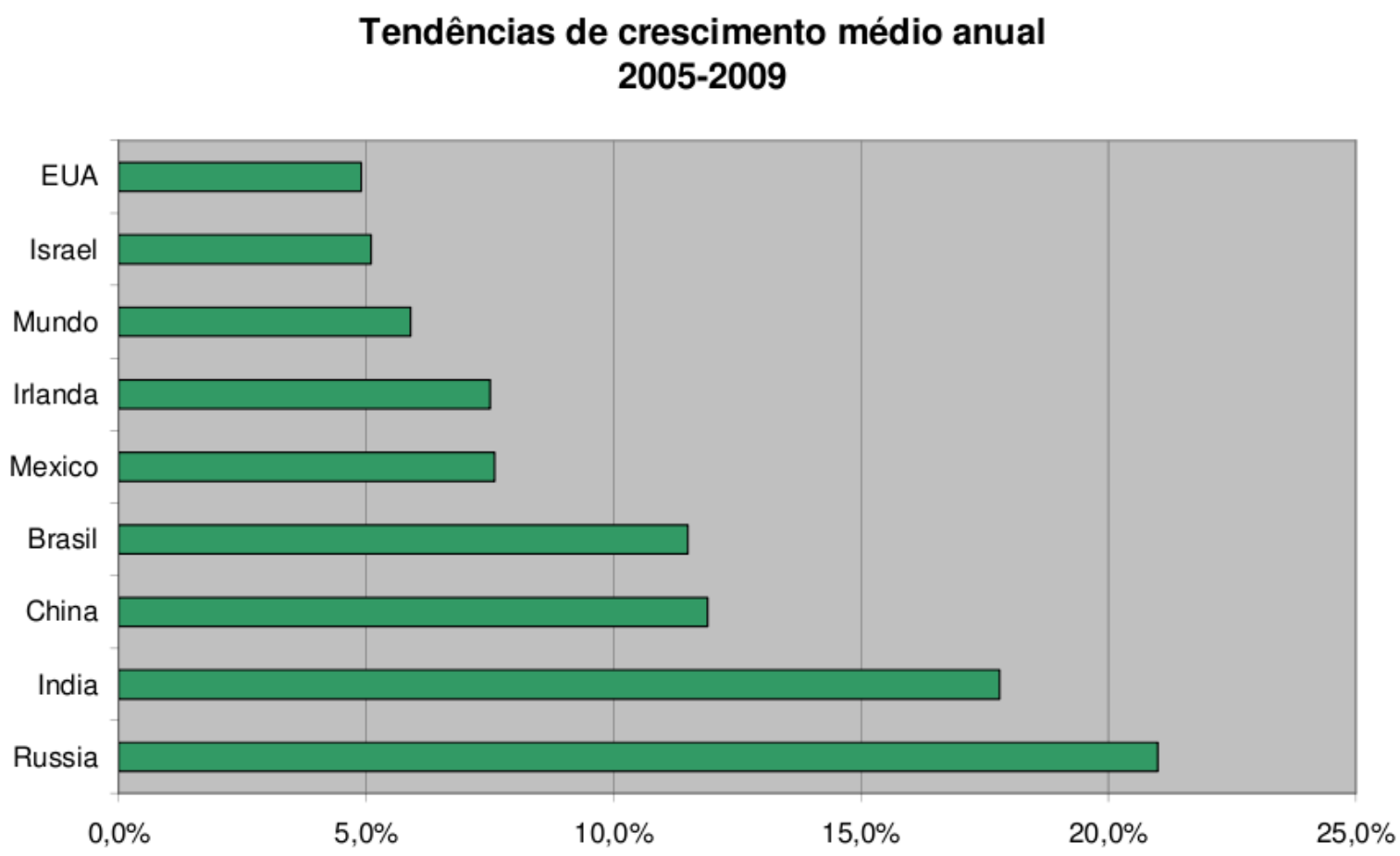

Figura H.2: Crescimento médio anual da área de TI de 2005 até 2009.

Fonte: Associação Brasileira de Empresas de Software (ABES), 2004.

Olhando um pouco mais de perto para o mercado brasileiro, podemos observar que no segmento de software, os ambientes de desenvolvimento (onde se encaixa o itSIMPLE) respondem por $20,7 \%$ do volume total de vendas. No segmento de serviços, as áreas onde a empresa poderá atuar (consultoria e treinamento) respondem por $17 \%$ do volume total de serviços prestados no país. Dessa forma, os 
segmentos nos quais a empresa estará atuando respondem por cerca de $11 \%$ do mercado total de software e serviços. Levando em consideração o mercado brasileiro, isto representa um mercado absoluto de US\$ 658 milhões. Se levarmos em consideração o mercado mundial e considerando o mesmo segmento também com $11 \%$, este número salta para US\$ 73 bilhões.

No entanto, o mercado mundial de softwares e serviços de tecnologia da informação (TI) é um setor um tanto quanto fragmentado. A IBM, maior fornecedora de softwares e serviços de $\mathrm{TI}$ do mundo, possui uma fatia de apenas $5 \%$ desse mercado (US\$ 33 bilhões) ${ }^{9}$.

Atualmente, estima-se que nos EUA sejam feitos 300,000 projetos em tecnologia da informação ( $\mathrm{TI})$, como o mercado americano representa $36 \%$ do mercado mundial de $\mathrm{TI}$, o numero de projetos nesta área por ano em todo mundo se encontra ao redor de 830,000 projetos. No segmento de software e serviços $(61,7 \%$ do mercado de $\mathrm{TI})$, temos um total de 512,000 projetos.

Utilizando os $11 \%$, mencionados anteriormente, que representa os segmentos de mercado onde poderemos atuar, o mercado potencial possui um volume de 56,000 projetos (sendo 560 projetos no Brasil). O valor médio desses projetos esta próximo de US\$1,4 milhão.

A empresa, utilizando o ambiente de desenvolvimento proposto, focará inicialmente o Brasil objetivando o mercado mundial, com um único produto em sua carteira, neste segmento de atuação, e prestando serviços de consultoria e treinamento, espera estar operando com 4 projetos anuais no final de cinco anos de operação. Inicialmente, a empresa focará na verificação do impacto do ambiente itSIMPLE no processo de desenvolvimento dessas grandes aplicações. Esta fase tem um horizonte de três anos, onde, durante os primeiros dois anos a empresa espera utilizar o ambiente para o desenvolvimento de um projeto de grande porte por ano. No terceiro ano espera-se aplicar a ferramenta a dois grandes projetos. 
Tabela H.1: Segmentação do mercado de software e serviços no Brasil ${ }^{10}$

\begin{tabular}{|l|r|r|}
\hline \multicolumn{1}{|c|}{ Segmento } & Volume (US\$ milhões) & Participação (\%) \\
\hline Aplicativos & $1.074,8$ & $\mathbf{4 5 , 5 \%}$ \\
\hline Ambientes de desenvolvimento & 488,8 & $20,7 \%$ \\
\hline Infra-estrutura & 796,4 & $33,8 \%$ \\
\hline Sub total Software & $\mathbf{2 . 3 6 0}$ & $\mathbf{1 0 0 \%}$ \\
\hline Consultoria & 470,5 & $13,0 \%$ \\
\hline Integração de Sistemas & 740,3 & $20,5 \%$ \\
\hline Outsourcing & $1.117,4$ & $30,8 \%$ \\
\hline Suporte & $1.146,6$ & $31,6 \%$ \\
\hline Treinamento & 145,2 & $4,1 \%$ \\
\hline Sub total Serviços & 3.620 & $\mathbf{1 0 0 \%}$ \\
\hline Total Software e Serviços & $\mathbf{5 . 9 8 0}$ & -- \\
\hline
\end{tabular}

Com relação aos serviços de consultoria relacionados à resolução de projetos de grande porte que envolve problemas de design, a equipe, por estar inserida no meio acadêmico e de pesquisa, entende que esta é uma área de grande potencial para atuação. No entanto, é muito difícil mensurar o mercado para esta prestação de serviço.

\section{H.5 Melhorias Planejadas}

Anteriormente, já foram mencionadas algumas limitações referentes a presente situação do itSIMPLE, como sua orientação a Casos de Uso e a existência de apenas dois módulos (PDDL e Redes de Petri) integrados à definição de requisitos em UML. No entanto, para atingir os objetivos e suprir a necessidade descrita nos itens anteriores, existem outras melhorias que serão implementadas. 
A primeira, e mais importante, é a implantação no ambiente de um suporte a plugins que permitam ao usuário agregar funcionalidades de acordo com suas necessidades. Este é um dos principais requisitos para que o itSIMPLE possua a abrangência necessária para se tornar um ambiente de integração que possa ser utilizado em qualquer problema de design.

Para acelerar o processo de desenvolvimento (do software e das suas funcionalidades) é necessário permitir que pessoas do mundo inteiro possam acessar e fazer mudanças ao código original do ambiente, concertando bugs e desenvolvendo novos plugins com diferentes funcionalidades. O itSIMPLE ainda não possui um sistema que permita este nível de interação com os seus usuários, apesar ser um software de código aberto. Este é um passo imprescindível para o desenvolvimento da ferramenta e da sua capacidade de atender as necessidades da comunidade de designer.

Além de melhorias diretamente relacionadas ao produto, para que seja possível fornecer os serviços mencionados anteriormente de consultoria e desenvolvimento de soluções, torna-se necessário o refinamento da metodologia de trabalho. Em outras palavras, desenvolver nossa capacidade de atacar problemas através de uma abordagem eficiente que permita chegar em soluções ótimas para o cliente.

\section{H.6 Análise SWOT}

Segue a análise SWOT do projeto. 


\section{H.6.1 Pontos Fortes}

- Produto inovador: não existe um ambiente que permita a integração das diversas ferramentas e técnicas de modelagem existentes hoje para design

- Service oriented architecture (SOA): no mundo empresarial atual, as necessidades mudam de maneira cada vez mais rápida, tornando inviáveis projetos que não possuam um alto nível de flexibilidade para se ajustar aos novos requisitos do mercado. Neste sentido a utilização da arquitura SOA permite 0 acesso a funcionalidades externas ao ambiente original, facilitando a integração do itSIMPLE com novas ferramentas e aumentando a sua capacidade de se adaptar rapidamente as necessidades do mercado

- Running Specification: a integração de ferramentas e técnicas de modelagem, unidas ao conceito de running specification, permite ao usuário utilizar as diferentes perspectivas de modelagem e ferramentas de analise para validar e verificar o modelo em todos os estágios do processo de design. Assim, a partir da especificação de requisitos, o usuário tem acesso a diferentes modelos do seu sistema. Isto e um grande diferencial para o itSIMPLE, pois não existem ferramentas que suportem o tratamento e construção automática e paralela de modelos

- Suporte a diversas orientações de desenvolvimento: as ferramentas atuais restringem o processo de desenvolvimento a uma única orientação. Assim, o designer e forcado a utilizar ferramentas diferentes quando deseja realizar projetos com orientações distintas. Um dos grandes diferenciais do itSIMPLE será o suporte a diversas orientações de desenvolvimento, como a Use Case Driven Development e a Test Driven Development

- Know-how: ao sermos os únicos a desenvolver um ambiente que propõe o suporte a qualquer ferramenta e técnica de design, detemos um grande knowhow das metodologias envolvidas na resolução de problemas, das diversas técnicas de modelagem, sem mencionar a ampla familiaridade com a ferramenta. Dessa forma, possuímos grande vantagem competitiva tanto na implantação da ferramenta em equipes de design como na resolução de problemas desse tipo 


\section{H.6.2 Oportunidades}

- Ausência de concorrentes diretos: como foi mencionado acima, o itSIMPLE e um produto inovador, não existindo nada no mercado atualmente que possa ser qualificado como seu competidor direto: estamos preenchendo uma lacuna no mercado ao suprir uma necessidade da comunidade de designer, que requer um ambiente capaz de integrar as diversas ferramentas existentes, dando maior robustez ao processo de desenvolvimento. Dessa forma, o itSIMPLE entra como pioneiro em um mercado praticamente inexplorado e sem concorrentes, o que possibilita níveis de crescimento e lucratividade altíssimos no curto e médio prazo

- Necessidade de integração das diversas ferramentas de design: o mercado demanda soluções cada vez mais complexas e que exigem a utilização conjunta de uma gama extensa de conhecimentos e técnicas, tornando necessária a integração entre os diferentes níveis hierárquicos e os diferentes profissionais que atuam no projeto. Apesar de a maioria dos problemas de design possuir ferramentas especificas capazes de auxiliar no processo de desenvolvimento, existe pouca comunicação entre estes softwares, o que impede uma maior integração entre as diferentes técnicas utilizadas em um projeto. Neste contexto, o itSIMPLE se torna uma ferramenta fundamental para suprir a crescente necessidade

- Tendência à terceirização: hoje a terceirização (ou outsourcing) é usada em larga escala por grandes corporações brasileiras. Esta prática visa a redução de custo e o aumento da qualidade dos produtos. Alem disso, existe uma grande tendência das empresas, devido a crescente concorrência e complexidade do mercado, de alocarem seus recursos a suas atividades principais, delegando aquilo que não esta diretamente relacionado a seu ramo de atuação. Existe, portanto, uma grande oportunidade de prestação de serviços para empresas que necessitem de soluções para problemas de design, mas que não possam desviar recursos para esta atividade

- Grande mercado potencial: ao contrario das ferramentas existentes hoje, que se restringiram a determinadas aplicações, o itSIMPLE e uma plataforma que suporta o desenvolvimento de qualquer problema de design, podendo ter sua capacidade ampliada a qualquer momento para incorporar novas técnicas e funcionalidades. Dessa forma, o mercado potencial que se abre ao utilizar tal 
abordagem se torna muito extenso, pois se torna possível atuar em todas as áreas do design: desde a arquitetura a projetos de manufatura. Por ser pioneiro e inovador, o itSIMPLE entra neste enorme mercado potencial sozinho e com uma grande capacidade de crescimento no curto e médio prazo

\section{H.6.3 Pontos Fracos}

- Mercado desconhecido: a ausência de produtos com uma proposta de integração tão abrangente no mercado, na área de design, apresenta uma grande ameaça em relação ao desconhecimento do mercado real para o produto. Não é possível utilizar números existentes, pois mercado ainda não foi explorado, para fazer estimativas de vendas, necessidade de investimentos e viabilidade do projeto. Isto aumenta o risco associado ao empreendimento

- Escassez de recursos financeiros para alavancar o projeto no mercado

\section{H.6.4 Ameaças}

- Grandes empresas de software: apesar da ausência de concorrentes diretos ao itSIMPLE, existem muitas ferramentas já consagradas capazes de resolver diferentes problemas de design. Apesar de não estarem integradas nem possuírem as funcionalidades do ambiente itSIMPLE, já possuem a confiança do mercado atual. Assim, as grandes empresas de software, altamente capitalizadas, podem lançar grandes campanhas promocionais que poderiam inviabilizar a utilização da ferramenta pelo mercado consumidor por um longo período de tempo. Isto, portanto, e uma seria ameaça a lucratividade do 
empreendimento

- Dinâmica do mercado de softwares: o mercado de software e um dos mais dinâmicos da atualidade, pois gira em torno do conhecimento, mais do que do capital imobilizado. Dessa forma, apesar de ainda não existirem concorrentes diretos ao itSIMPLE, as empresas de software, munidas de grandes recursos, podem ser capazes de lançar produtos com a mesma orientação, a preços mais competitivos e aliados a uma forte campanha de marketing

- Resistência dos consumidores potenciais: como mencionado anteriormente, já existem muitas ferramentas de design consagradas capazes de resolver diferentes problemas: AutoCAD, Rational Rose, Visual Studio, Together, entre outras. Apesar de atuarem de forma independente, elas possuem a confiança do publico devido a seu histórico de sucesso. Assim, por já terem adquirido toda uma gama de conhecimentos técnicos necessários para a utilização dessas ferramentas e estarem familiarizados com elas, os consumidores podem resistir à utilização de um novo ambiente, o que exigiria tempo e dinheiro para sua implantação

- Grande tamanho do mercado potencial: os concorrentes indiretos, apesar de não possuírem ferramentas com as funcionalidades que o ambiente itSIMPLE proporciona, atuam em mercados restritos e, portanto, possuem um relacionamento muito próximo e um conhecimento profundo sobre seus segmentos específicos. Ao atuar em um mercado muito mais extenso (toda a comunidade que trabalha com problemas de design), as estratégias de marketing, comunicação e o relacionamento com o cliente se tornam mais complexos. Além disso, o volume de requisitos necessários para atender a este mercado será muito mais extenso, exigindo a criação mais dinâmica de novas funcionalidades para atender os diferentes mercados. 


\section{H.7 A empresa}

A thinkUP Engenharia de Software \& Internet, constituída em 1998 com a missão de prover soluções em Engenharia de Requisitos, focou a partir de 2003 na pesquisa e desenvolvimento de um ambiente de Design, compreendendo um investimento significativo no desenvolvimento de uma infra-estrutura de fabrica de software baseado em Internet de nova geração, a Web 2.0.

Em 2003 foi firmada uma parceria estratégica firmada com o d-lab, onde os sócios fundadores da thinkUP mantém atividades regulares de pesquisa acadêmica. Essa parceria viabilizou a concepção do ambiente de Design da thinkUP, que apóia de forma estrutural todos os projetos desenvolvidos na empresa.

Seguindo com o seu planejamento estratégico, em 2004 a thinkUP concebeu uma unidade de negócios para o desenvolvimento de projetos na área de bem-estar: Entretenimento e Saúde.

\section{H.8 A equipe}

A equipe esta constituída por um professor doutor, que é o orientador, dois integrantes da empresa, com qualificação de mestrado e doutorado, e dois alunos de iniciação científica. Todos os membros estão vinculados à Escola Politécnica da Universidade de São Paulo. 


\title{
Apêndice I - Artigo do itSIMPLE
}

\section{Um Ambiente Integrado de Modelagem e Análise de Sistemas}

\author{
Victor M. C. Romero, Fernando M. Sette, Tiago S. Vaquero, Eston A. Santos \\ d-lab - Escola Politécnica da USP
}

Av. Prof. Mello Moraes, 2231 - 05508-900 - São Paulo - SP - Brasil

victor.romero@poli.usp.br, fernando.sette@poli.usp.br, tiago.vaquero@poli.usp.br, eston@usp.br

\begin{abstract}
The great effort present today in the area of Artificial Intelligence for defining systems that can be flexible and integrated leads to the need of a systematic process, in which the initial design phases are not neglected. In this work we try to show the importance of those initial phases and that an approach that neglects them may ruin all the system analysis and the following development. Thus, we propose a modeling and analyzing environment, called itSIMPLE, which specially contemplates the concept of viewpoints, from the Requirements Engineering, and the Engineering Design, that concern those initial definitions, which are indispensable for the success of the analysis process. In this environment, it's possible to integrate many forms of systems representations and analysis, like Petri Nets, UML and PDDL for planning domains.
\end{abstract}

Resumo: O grande esforço presente hoje na área de Inteligência Artificial em definir sistemas que possam ser flexíveis e integrados leva à necessidade de um processo sistemático em que as fases iniciais de design não sejam desprezadas. Neste trabalho procura-se mostrar a importância dessas fases iniciais e que uma abordagem que as despreza pode comprometer toda a análise do sistema e posterior o desenvolvimento. É proposto, nesse sentido, um ambiente de modelagem $e$ análise, chamado itSIMPLE, que contempla principalmente o conceito de 
viewpoints, da Engenharia de Requisitos, e o Design em Engenharia, que levam em conta essas definições iniciais indispensáveis para o sucesso do processo de análise. Nesse ambiente é possível integrar várias formas de representação e de análise de sistemas, como as Redes de Petri, a UML e a PDDL para domínio de planejamentos.

\section{l.1 Introdução}

Há uma crescente demanda por métodos estruturados de desenvolvimento em sistemas de engenharia modernos, de modo especial nos automatizados, o que inclui não só o problema crítico em gerenciar a fusão do hardware com o software, como também os requisitos para o sistema de software.

Esquemas, conceituais ou práticos, são apresentados freqüentemente na literatura, alguns associados com o desenvolvimento de técnicas de software, outros relacionados com áreas específicas da Engenharia (como o planejamento automático em Inteligência Artificial, por exemplo), ou mesmo com o conhecimento adquirido no desenvolvimento de ferramentas específicas. Entretanto, apesar do consenso de que as etapas iniciais do processo de desenvolvimento são as mais importantes para garantir que determinado sistema funcione corretamente, a maioria das ferramentas que tratam de desenvolvimento de sistemas dão mais atenção à fase de implementação.

É importante, dessa forma, que os conceitos de design em Engenharia e dos viewpoints, oriundos da Engenharia de Requisitos, sejam bem explorados na modelagem de sistemas reais, pois estes representam a primeira fase no desenvolvimento de projetos que visem ao tratamento de problemas reais. Esses conceitos estão se tornando fundamentais para caracterizar, entender e especificar domínios e, deste modo, permitir o avanço dos sistemas de design e planejamento automático, inclusive para casos mais complexos e aplicações reais da indústria e de negócios.

Para a fase inicial de design, é necessária uma representação informal ou semiformal, e a linguagem UML [OMG 2001], com os Casos de Uso e todos os seus 
diagramas torna- se uma boa opção. Ainda assim, deve-se providenciar os requisitos numa representação que possa ser usada para analisar o sistema em questão e que também leve o processo de modelagem a uma representação formal. Assim, tornase necessário um ambiente completo que possa lidar com todas as transformações do informal para o formal.

Para que o transporte e armazenamento de dados sejam feitos de forma apropriada, assim como tradução de uma linguagem para outra, é necessária uma metalinguagem, que de preferência possa ser simples de ser usada. A XML (eXtensible Markup Language) [Bray et al. 2004] tem executado tal papel pois, sendo uma metalinguagem, pode ser usada para se referir a outra linguagem. Assim, a XML pode armazenar a semântica de uma sentença sem se comprometer com a sintaxe da linguagem de representação, possibilitando a passagem para uma outra linguagem de representação.

Há, atualmente, uma grande lacuna de uma ferramenta que alie todas essas fases necessárias na especificação de um domínio que represente um sistema ou problema real. Programas como o Rational Rose e o Requisite Pro não contemplam todos os processos que utilizam os conceitos acima explicitados.

Este trabalho procura, então, mostrar como as definições iniciais de um sistema estão ligadas ao processo de Engenharia de Requisitos assim como à geração das especificações do sistema e a formação do modelo do mesmo. Além disso, é apresentado um ambiente em que os requisitos são representados utilizando Casos de Uso e os diagramas UML, que podem ser suficientes para a análise de requisitos, no caso de um sistema ou produto simples. Entretanto, se o sistema tratado é complexo, há um grande número de dependências oriundas dos requisitos iniciais, e uma tradução para uma linguagem mais formal se faz necessária. Isso pode ser feito primeiro traduzindo-se a UML para XML e então desta para a linguagem mais apropriada. Se o problema é apenas de planejamento automático, pode-se passar da XML para PDDL (Planning Domain Definition Language) [McDermott 1998]. Se, em outro caso, o problema é a modelagem de processos de produção, pode-se transferir a representação para Redes de Petri [Murata 1989], para que os requisitos possam ser analisados. É possível utilizar ambas as representações para usufruir os potenciais de análise e verificação presentes em cada uma delas.

Este trabalho propõe o uso de uma ferramenta gráfica integrada que utiliza a UML como uma linguagem de modelagem de domínios de planejamento enfatizando a análise estática, a XML como uma linguagem comum (intermediária) para ser compatível com outras linguagens, incluindo a PDDL, e a Rede de Petri como um linguagem de modelagem para a análise do comportamento dinâmico do domínio. 
Esta ferramenta, chamada itSIMPLE (Integrated Tools Software Interface for Modeling Planning Environment) [Vaquero et al. 2005] [Vaquero et al. 2006] tem por objetivo criar meios de preencher a lacuna existente no mercado hoje em dia e, principalmente, unificar ambas as comunidades, tanto a de pesquisa quanto a de aplicações de negócios.

É importante destacar também que essa ferramenta tem também como objetivo utilizar o conceito de Service Oriented Architecture (SOA), sendo totalmente configurável com funções personalizadas que possuem capacidades adequadas para cada organização ou indivíduo. Dessa forma, busca-se permitir a integração das diversas ferramentas que existem no mercado atualmente para design de sistemas, mas que trabalham de maneira independente, sem uma linguagem comum.

\section{I.2 A Representação em XML}

A linguagem XML foi criada pelo WWW Consortium em 1996 e teve sua primeira versão disponível em 1998. Faz parte do esforço em se criar uma meta-linguagem que permita a troca e transferência de dados e a integração de diferentes tipos de dados.

O elemento principal na XML é a possibilidade de se definir DTDs, ou seja, Document Type Definitions (definições de tipo de documento), que podem estar relacionadas não só com o formato do documento final, mas também com a sua semântica pretendida.

Dessa forma, a XML define notações ao mesmo tempo em que expressa dados que poderiam ser representados nessa mesma notação. Essa característica foi amplamente explorada na versão atual no que concerne à transferência estruturada entre requisitos informais e semânticas mais formais. 


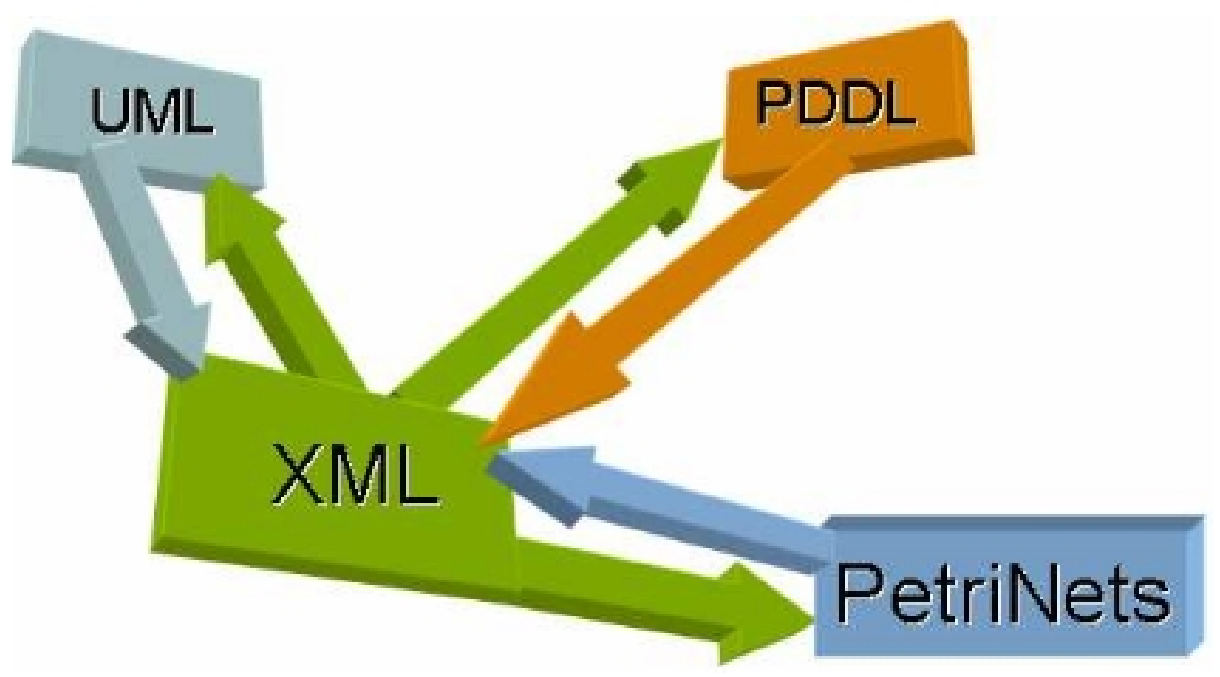

Figura I.1: A integração de linguagens no itSIMPLE (Santos et al., 2005).

Dessa forma, a XML representa a ponte entre a linguagem UML, que é usada na modelagem e nas definições dos sistemas dentre do ambiente itSIMPLE, e qualquer outro tipo de representação consistente. No caso do planejamento, por exemplo, pode-se traduzir essa representação para a linguagem PDDL. Já no caso de análise de modelos dinâmicos, pode-se construir Redes de Petri a partir da especificação do sistema. Sendo assim, a XML se mostra uma ferramenta indispensável na flexibilidade do ambiente e nos vários tipos de representação inerentes a qualquer sistema. A figura l.1 exemplifica esse conceito.

A proposta de uso da XML neste trabalho é, portanto, oferecer um modelador de informação [DeRose, 1999] capaz de integrar representações distintas, como as descritas na próxima seção, enquanto mantém a semântica do sistema a ser descrito. Esse tipo de situação é muito comum durante o processo de transferência de dados entre requisitos informais e semânticas mais formais.

\section{I.3 Verificação de Requisitos baseada em Viewpoints}

Segundo Kotonya e Somerville (1996), "requisitos refletem as necessidades de consumidores e usuários de um sistema. Eles devem incluir a justificativa para esse 
sistema, o que se pretende que o sistema realize e quais restrições de design devem ser observadas". Este trabalho pretende verificar se os requisitos do usuário de um sistema de engenharia estão de acordo com essas restrições, baseado nos diferentes viewpoints (pontos de vista) dos usuários.

Um método efetivo de engenharia de requisitos deve possuir [Kotonya e Somerville 1996]:

- precisão na definição de sua notação;

- compatibilidade, visando a um acordo com o usuário final;

- assistência na formulação de requisitos, o que pode ser compreendido sob dois aspectos:

- como a notação organiza a estrutura dos requisitos para o sistema;

- como a notação lida com a distinção de interesses.

- definição do ambiente do sistema;

- interesse em evolução;

- interesse em integração, que pode ser compreendido em termos das diferentes abordagens de requisitos:

- não há uma única abordagem que possa adequadamente articular todos os requisitos de um sistema, seja do viewpoint do usuário ou do desenvolvedor;

- requisitos não funcionais tendem a se relacionar a um ou mais requisitos funcionais .

- interesse em comunicação; 
- suporte do ambiente ou ferramenta utilizada.

O trabalho de Silva e Santos (2003) propõe a verificação de requisitos baseada em descrições com Casos de Uso e, após isso, a validação do modelo com os stakeholders (partes interessadas) envolvidos. Dessa forma, as diferenças entre os viewpoints de cada stakeholder devem ser consideradas pelos modeladores, com a utilização de diferentes abordagens na especificação das tarefas. Por exemplo, o financiador está mais preocupado com as estratégias de negócio, enquanto a prioridade para o usuário final pode estar nas tarefas diárias.

Nesse ponto, a estratégia está baseada na proposta do processo de engenharia de design como uma metáfora para sucessivas traduções entre representações do sistema a ser modelado. Os diversos viewpoints podem ser representados por diagramas UML distintos [OMG 2001]. A tabela I.1 mostra as relações propostas entre os viewpoints dos stakeholders e o melhor diagrama UML que as representam.

Tabela I.1: Viewpoints X Diagramas UML

\begin{tabular}{|c|c|}
\hline Viewpoint do Stakeholder & Diagrama UML \\
\hline Patrocinador & $\begin{array}{l}\text { - Caso de Uso } \\
\text { - Diagrama de Atividade }\end{array}$ \\
\hline Usuário Final & $\begin{array}{l}\text { - } \text { Caso de Uso } \\
\text { - Diagrama de Atividade } \\
\text { - } \text { Diagrama de Seqüência }\end{array}$ \\
\hline Desenvolvedor & $\begin{array}{l}\text { - } \text { Caso de Uso } \\
\text { - Diagrama de Atividade } \\
\text { - Diagrama de Sequência } \\
\text { - Diagrama de Estados } \\
\text { - Diagrama de Classes } \\
\text { - Diagrama de Deployment } \\
\text { - Diagrama de Componentes } \\
\text { - Diagrama de Colaboração }\end{array}$ \\
\hline
\end{tabular}

Sendo assim, a especificação dos requisitos seria feita a partir de um conjunto de diagramas, cada um com o viewpoint de uma das classes de usuários definidas na coluna esquerda da tabela I.1. Naturalmente, todos esses diagramas devem 
descrever propriedades do mesmo sistema, e seus conteúdos são ou iguais ou complementares, mas nunca contraditórios. Em Silva e Santos (2003), apenas Casos de Uso são considerados, uma vez que eles são os mais usados normalmente. Entretanto, na prática, é impossível utilizar apenas Casos de Uso para especificar os requisitos.

Baseando-se em alguns experimentos no processo de especificação e documentação, decidiu-se por uma integração, já no início da definição do sistema, dos requisitos e viewpoints utilizando a UML como base para uma nova representação. A característica de meta-linguagem da XML, por sua vez, se ajusta perfeitamente à necessidade de integração, com a vantagem adicional da possibilidade de seu conteúdo poder ser transferido e representado em qualquer outro esquema ou linguagem de especificação.

No caso de problemas de planejamento automático, por exemplo, o comum é descrever problemas e domínios utilizando uma linguagem especial chamada PDDL [Bachhus 2003][Boddy 2003].

\section{I.4 Um Ambiente Gráfico para Modelagem e Análise de Sistemas}

Segue a apresentação do desenvolvimento do itSIMPLE.

\section{I.4.1 Desenvolvimento}

Como foi dito anteriormente, há hoje uma forte demanda de um ambiente que possa integrar todos esses conceitos da Engenharia de Requisitos e dos viewpoints. Com a 
finalidade de satisfazer essa necessidade é que a ferramenta itSIMPLE vem sendo desenvolvida. Além disso, esse ambiente deve, no futuro, englobar todas as etapas de definição e implementação na resolução de um problema real, desde o seu modelamento e design até o seu planejamento de execução. Há também uma tendência em que o programa assuma versões modulares, com os chamados plugin's, que envolveriam apenas algumas funções específicas e poderiam ser utilizados em conjunto com as ferramentas já existentes hoje em dia, como o Rational Rose e o Requisite Pro.

A versão atual do itSIMPLE foi desenvolvida em ambiente Java. Essa linguagem foi escolhida devida à sua grande portabilidade (softwares desenvolvidos em Java podem ser executados em qualquer sistema operacional) e por ser altamente difundida hoje na comunidade de programação. Além disso, a maioria dos projetos feitos em Java seguem a filosofia open source (fonte aberta), facilitando muito o desenvolvimento e extensão das funcionalidades da ferramenta. Nesse sentido, o itSIMPLE também deve, futuramente, tornar-se um projeto de fonte aberta, ainda que parcialmente.

Além da linguagem de programação, é importante que haja uma plataforma de desenvolvimento que auxilie o desenvolvimento de uma ferramenta. Por isso, a versão atual do itSIMPLE foi totalmente desenvolvida no Eclipse, plataforma desenvolvida e disponibilizada pela IBM e que também possui seu código aberto. Essa plataforma, com a gradual evolução da ferramenta, se mostrou indispensável para o bom andamento do projeto, principalmente devido a seu grande número de funcionalidades e à sua interface bastante amigável.

\section{I.4.2 O Ambiente itSIMPLE}

Podemos definir o itSIMPLE como um ambiente que visa o design e especificação de projetos ou sistemas a partir dos vários viewpoints e seus respectivos requisitos, reunindo todos os conceitos apresentados nas seções anteriores. 


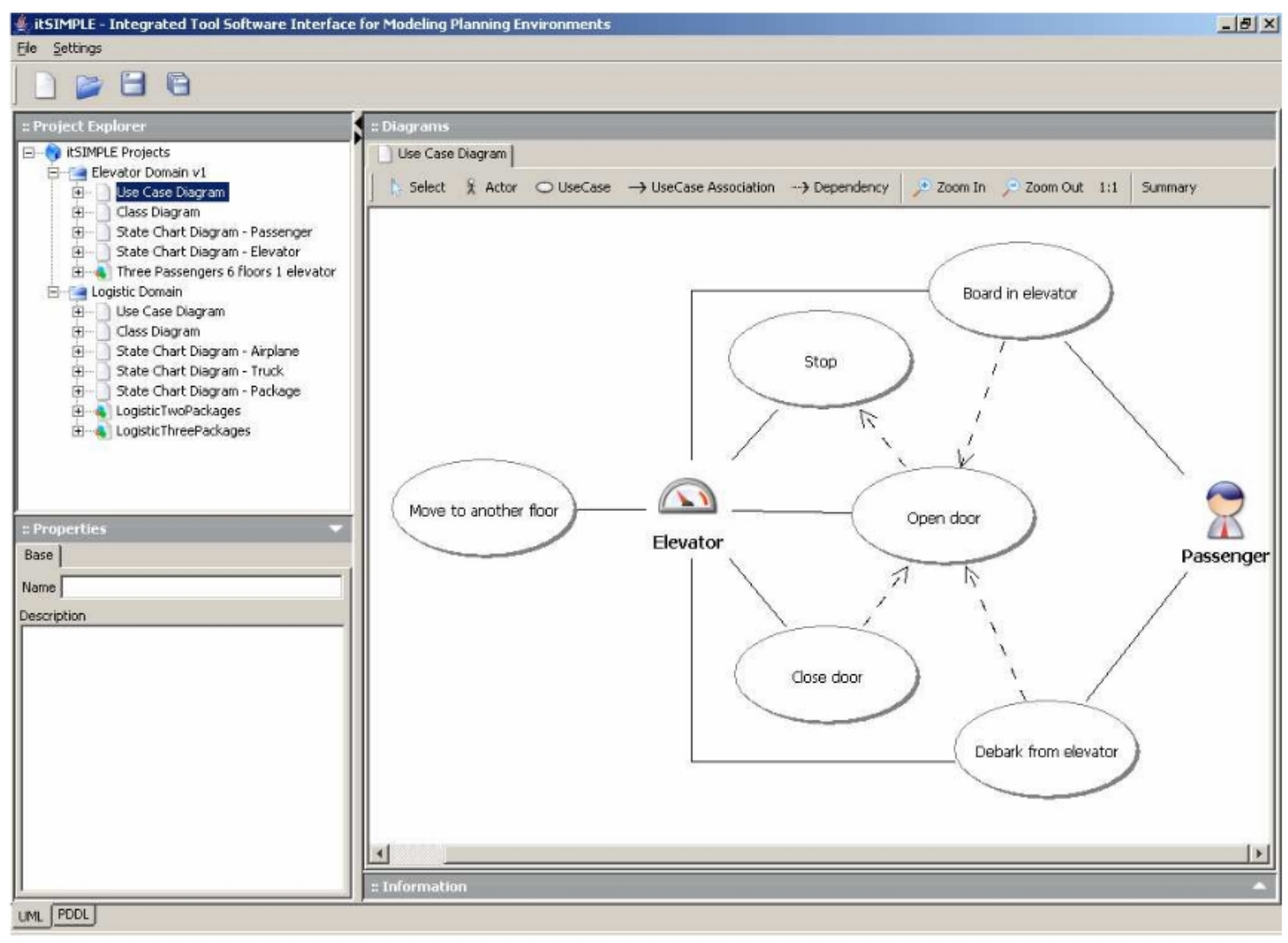

Figura I.2: Exemplo de Caso de Uso do problema clássico de elevadores.

Nesse sentido, o itSIMPLE foi desenvolvido para ser um ambiente do tipo Use Case Driven, ou seja, a fase inicial de modelagem é feita com Casos de Uso e, baseandose nos requisitos definidos nos mesmos, todo o processo posterior de design é então realizado. Além disso, o ambiente proporciona a possibilidade de validação dos Casos de Uso e a construção, a partir dos mesmos, de Redes de Petri [Silva e Santos 2004].

Um exemplo de Caso de Uso é o mostrado na Figura I.2, correspondente ao conhecido problema dos elevadores inteligentes.

Após os Casos de Uso, deve-se partir para a modelagem do domínio, com a definição no Diagrama de Classes dos elementos que fazem parte desse domínio e das características estáticas do mesmo. Um exemplo de Diagrama de Classes é mostrado na Figura I.3. 


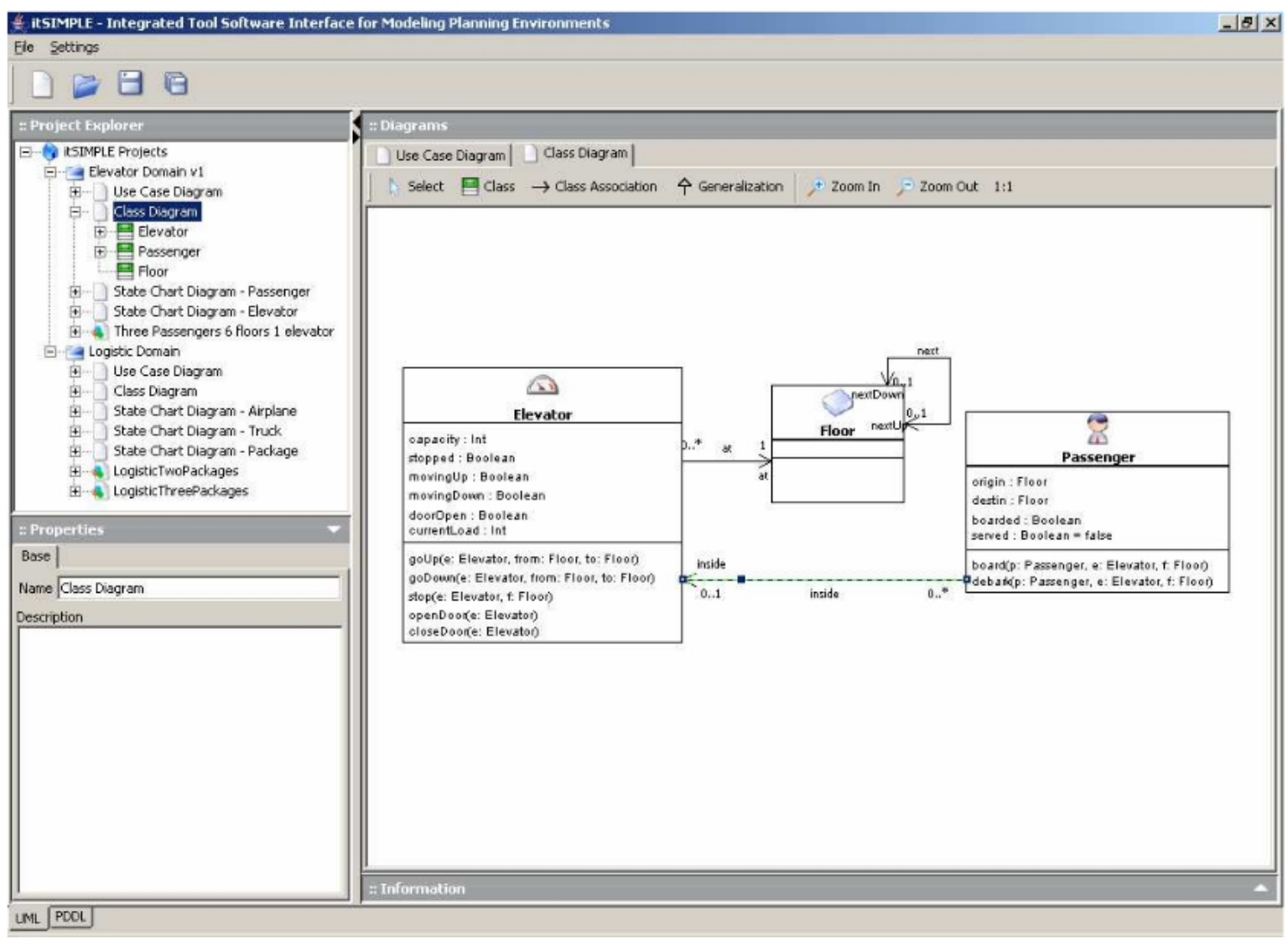

Figura I.3: Diagrama de Classes do problema clássico dos Elevadores.

Após as definições das classes que formam o domínio, parte-se para o Diagrama de Estados, onde são definidas como as ações pertencentes àquele sistema modificam os estados dos elementos que o compõem. No Digrama de Estados, as definições da cada estado e as pré e pós-condições de cada ação são definidas com a linguagem OCL (Object Constraint Language) [OMG 2003], já que a própria UML usa freqüentemente essa linguagem em suas definições, além do fato dela ter se mostrado bastante completa para esse tipo de definição. Um exemplo de diagrama de estados é mostrado na Figura I.4.

Essa seqüência, naturalmente, não é obrigatória. Pode-se, por exemplo, executar o processo de Action Driven, ou seja, a especificação é feita baseada nas ações que podem ser realizadas dentro do ambiente do sistema, que é uma abordagem muito comum em problemas de planejamento automático. Outra abordagem que poderá estar presente é o chamado Test Driven Development, em que a modelagem é feita já com base nos testes a serem feitos com aquele sistema. 


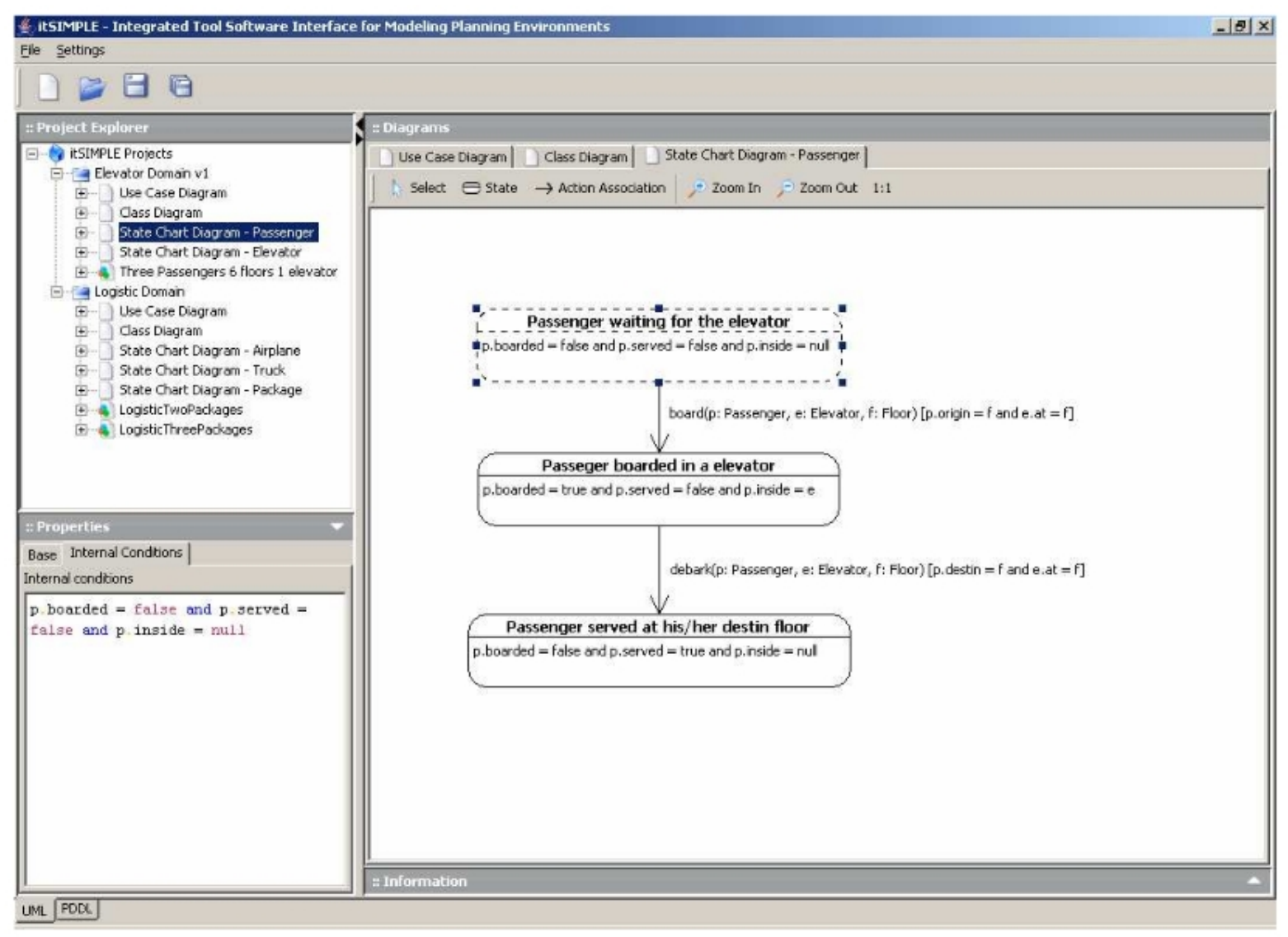

Figura I.4: Diagrama de Estados da classe Passageiro dos Elevadores.

Após a definição do domínio, define-se, por fim, as situações que podem ocorrer com seus elementos, passando-se, portanto, à modelagem de problemas que podem representar situações reais. Para isso são utilizados os Diagramas de Objetos da UML, onde são representadas instâncias das classes definidas no Diagrama de Classes em situações e estados bem definidos. Um exemplo de Diagrama de Objetos é mostrado na Figura I.5.

A UML é uma poderosa linguagem de modelagem que pode ser utilizada para aumentar o poder de expressividade dos domínios e problemas de planejamento. Uma grande vantagem do uso da UML é que esta pode ser facilmente exportada para XML.

A XML é uma linguagem de marcação, que descreve dados estruturados, bastante útil nas declarações de conteúdo e na obtenção de resultados mais significativos de busca através de múltiplas plataformas. Isto faz com que a XML seja uma linguagem apropriada para troca de dados e informação entre sistemas de informação [Bray et al. 2004]. 


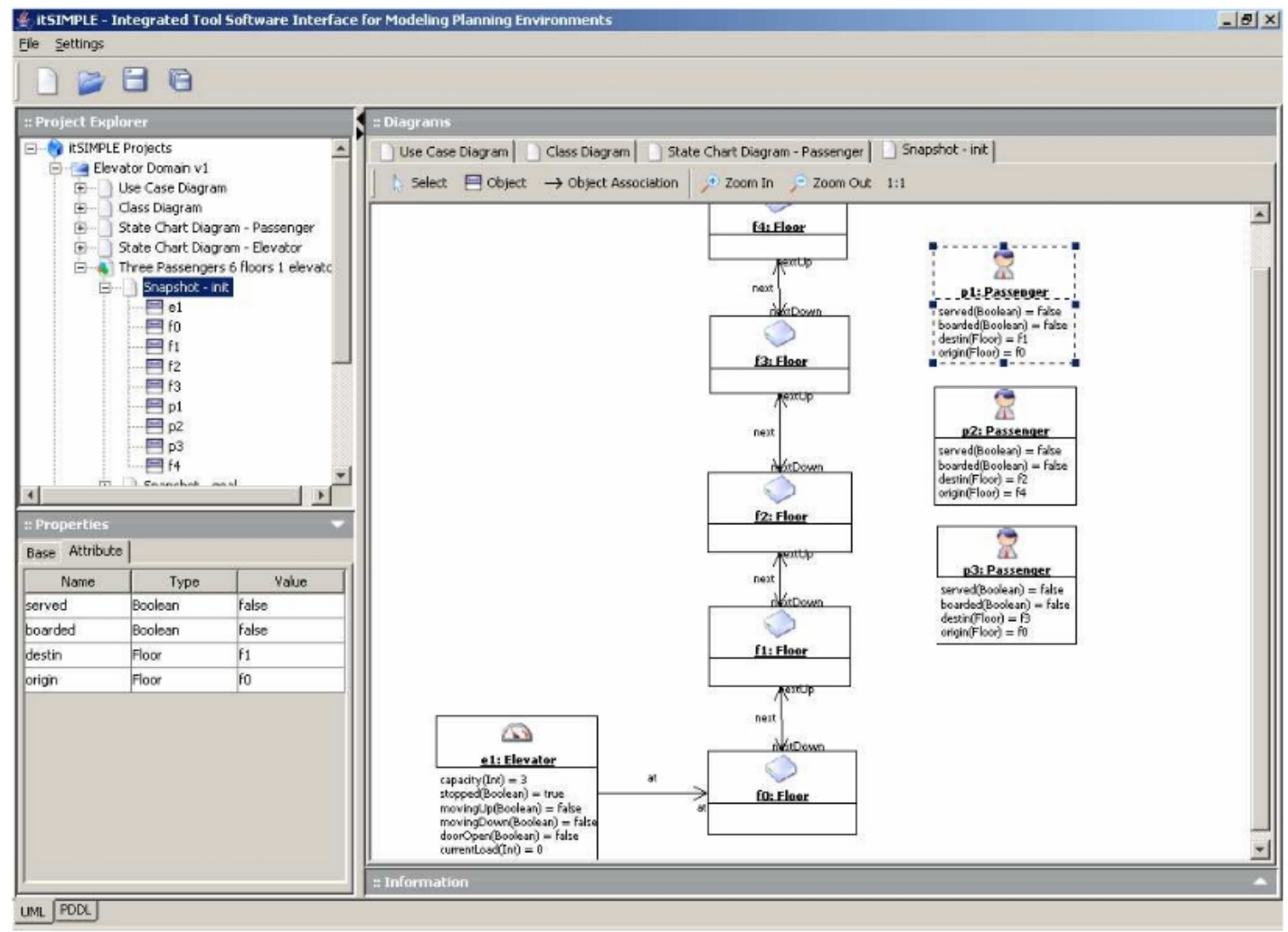

Figura I.5: Exemplo de Diagrama de Objetos do problema dos Elevadores.

A XML é baseada no conceito de tags (marcações) que auxiliam na estruturação dos dados e da própria representação. Utilizando a XML é possível declarar dados como, por exemplo, preços de livros, tipos de transporte, taxas comerciais, e qualquer outro tipo de dado. Com o uso das tags é possível criar estruturas específicas para cada tipo de aplicação, de forma flexível, desde que todos os sistemas que irão utilizar a estrutura saibam interpretá-la.

Todos os diagramas criados em UML podem ser armazenados na forma de um arquivo XML, mantendo a estrutura do modelo de planejamento. Os elementos constituintes destes diagrama como, por exemplo, classes, estados, associações e objetos são representados em XML na forma de tags que garantem a consistência do modelo.

A versão atual do itSIMPLE apresenta ainda uma funcionalidade específica de problemas de planejamento automático, que é a tradução da definição de domínios e problemas em UML para a linguagem PDDL, que é a linguagem usual para essa área da engenharia. 


\section{I.5 Trabalhos futuros}

Grande parte dos diagramas da UML já estão presentes no ambiente itSIMPLE, como os Casos de Uso, Diagramas de Classe, de Estados e de Objetos. Para uma melhor definição e visualização dos sistemas, versões futuras deverão apresentar outros diagramas da linguagem, como os de Atividade, de Seqüência e de Tempo, que são úteis na análise das variáveis presentes em um sistema.

Visando ao conceito de flexibilidade e modularização, as versões posteriores do ambiente itSIMPLE, algumas funcionalidades atuais da ferramenta, como a exportação para PDDL, poderão tomar a versão de plug-in's, tanto para ferramentas já existentes, como para o próprio itSIMPLE. Neste caso, o ambiente deve tomar uma postura cada vez mais modular, possuindo um núcleo básico de representação e podendo ser extendido de acordo com as necessidades do usuário.

Por fim, há trabalhos constantes de melhorias visuais na interface e na usabilidade do ambiente, procurando sempre facilitar a entrada de dados para representação dos sistemas e tornar a ferramenta amigável e intuitiva para o usuário. Esses trabalhos devem prosseguir e estarão sempre presentes nas suas versões futuras.

\section{I.6 Conclusão}

Neste trabalho, procurou-se apresentar um conjunto de ações para transformar requisitos informais em uma representação formalizada, que pode ser usada para um conjunto genérico de projetos incluindo, principalmente, a especificação de sistemas flexíveis integrados. Como esperado, devido a sua complexidade, esse processo não poderia ser totalmente automatizado e formal, mas é uma abordagem sistemática que pode ser feita com o uso do ambiente itSIMPLE. 
A integração dos diversos viewpoints e seus respectivos requisitos, além da importância na fase inicial da definição do sistema foram explicitadas, tornando-se clara a necessidade de um ambiente em que todos esses conceitos possam estar presentes e integrados, o que não existe atualmente. Apesar do itSIMPLE ainda não apresentar completamente todas essas características, a ferramenta caminha cada vez mais para essa integração entre os inúmeros stakeholders que fazem parte de um sistema.

\section{I.7 Referências}

Bachhus, F. (2003) "The Power of Modeling - a Response to PDDL 2.1", Journal of Artificial Intelligence Research, v. 20, pp. 125-132.

Boddy, M. (2003) "Imperfect Match: PDDL 2.1 and Real Applications", Journal of Artificial Intelligence Research, v. 20, pp. 133-137.

Bray, T., Paoli, J., McQueen, C.M., Maler, E., Yergeau, F. (2004) "Extensible Markup Language (XML) 1.0 - Third Edition", http://www.w3.org/TR/REC-xml/.

DeRose, S. J. (1999) "XML Linking". ACM Computing Surveys, vol. 31, no. 4es, December.

Kotonya, G., Sommerville, I. (1996) "Requirements engineering with viewpoints", Software Engineering Journal, v.11, n.1, p.5-18.

McDermott, D. (1998) "The PDDL Planning Domain Definition Language" - The AIPS-98 Planning Competition Committee.

Murata, T. (1989) "Petri Nets: Properties, Analysis and Applications", In Proceedings of IEEE, v. 77, n. 4, pp. 541-580. 
OMG (2001) "Unified modeling language specification: version 1.4", http://www.omg.org/uml.

OMG - Object Management Group, 2003. OCL 2.0 - Object Constraint Language. http://www.omg.org/cgi-bin/doc?ptc/2003-10-14.

Santos, E. A., Silva, J. R., Vaquero, T. S. (2005) Specification And Analysis For Automated Flexible Manufacturing. In Proceedings of COBEM 2005 - 18th International Congress of Mechanical Engineering, 6 to 11 November 2005, Ouro Preto, Minas Gerais, Brazil.

Silva, J. R. and Santos, E. A. (2003) "Viewpoint Requirement Validation Based on Petri Nets", In 17th International Congress of Mechanical Engineering, Sao Paulo.

Silva, J. R. and Santos, E. A. (2004) "Applying Petri nets to requirements validation" In: IFAC Symposium on Information Control Problems in Manufacturing, INCOM'04, Salvador, p. 1-8.

Vaquero, T. S., Tonidandel, F., Silva, J. R. (2005) "The itSIMPLE Tool for Modeling Planning Domains". Proceeding of ICAPS (International Conference on Advanced Planning Systems), AAAI, Monterey, CA.

Vaquero, T. S., Tonidandel, F., Barros, L. N., Silva, J. R. (2006) "On The Use of UML.P for Modeling a Real Application as a Planning Problem" - Short paper in Proceedings of ICAPS 2006 International Conference on Automated Planning and Scheduling, Cumbria, UK. June 2006. 


\section{Apêndice $\mathbf{J}$ - Resultado do Concurso IBM inSites}

Este apêndice apresenta a participação dos três projetos em um concurso nacional de inovação tecnológica promovido pela IBM, o concurso IBM inSites.

Para todos os projetos, o concurso exigia a participação de uma equipe formada por alunos da Universidade, no caso representados pelos integrantes do d-lab, colaboradores de uma empresa parceira da IBM em um dos programas IBM DeveloperWorks ou PartnerWorld Industry Networks, aqui representados pelos integrantes da thinkUP, que é uma empresa ligada ao d-lab e parceira da IBM no PartnerWorld Industry Networks, focada no desenvolvimento de aplicações para as pesquisas desenvolvidas no laboratório.

As atividades desenvolvidas para o concurso foram as seguintes:

- Submissão do resumo do projeto

- Preparação de um artigo com a contribuição acadêmica

- Submissão do artigo do projeto

- Submissão do Business Case

- Desenvolvimento de um protótipo do projeto

- Apresentação do aplicativo em evento nacional

Abaixo são descritos, sucintamente, os projetos com o respectivo resultado no concurso. 


\section{J.1 eDrugControl}

Este projeto mostra uma aplicação da especificação de um negócio relacionado com automação na área da saúde. Do planejamento do negócio, passando pelo plano estratégico, até a implementação do mesmo, as atividades devem ser orientadas pelos dados obtidos na fase inicial que é a Engenharia de Requisitos.

\section{J.1.1 Produção acadêmica}

A contribuição acadêmica do projeto, foi apresentada em forma de artigo sob o título "A Farmácia Hospitalar no Brasil precisa de Automação" [2]. O resumo do artigo ilustra o estágio atual do eDrugControl, conforme segue:

Hoje em dia, a farmácia hospitalar (FH) detém não apenas importância técnica, mas também administrativa e contábil. No Brasil, poucas FH conseguem alcançar metas básicas como controle de estoque. A utilização de medicamentos em hospitais pode envolver de 20 a 30 etapas e uma falha em qualquer uma destas etapas é denominada erro médico. Nos EUA, cerca de 1,5 milhões de pessoas adoecem por ano e os gastos extras decorrentes destes erros chegam a US\$3,5 bilhões. A minimização destes problemas converge para uma solução em modelagem de processos de negócios com o uso extensivo de automação, como uma ferramenta de incremento da eficiência e eficácia em vários sentidos. Os recursos da solução em diferentes níveis de controle, mobilidade e interatividade variam de acordo com as metas do hospital, definidas no planejamento estratégico. 


\section{J.1.2 Business Case}

Enquanto produto, para fins da competição, foi preparado o Business Case, que mostra a visão de um produto para atender ao mercado de Farmácia.

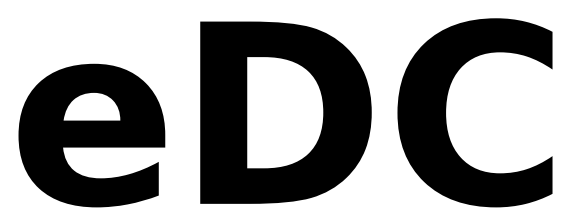

\section{electronic Drug Control}

O eDC é uma solução em modelagem de processos de negócios com o uso extensivo da automação como ferramenta no incremento da eficiência e eficácia em farmácias hospitalares. Sendo um sistema bastante moldável, de fácil implementação e utilização poderá ser utilizado em hospitais que possuam qualquer nível de automação de seus processos.

O serviço de assistência à saúde é cobrado por todos os seus personagens: por médicos, para aumentar a qualidade do atendimento; por administradores, para reduzir custos e aumentar margens de lucro; por agencias reguladoras, a fim de garantir padrões mínimos de qualidade e por instituições acadêmicas, para que sejam fornecidas informações e motivações à pesquisa. O eDC tende a satisfazer todas essas demandas.

Os recursos do eDC visam a melhoria do armazenamento, transporte e uso da informação necessária para o bom funcionamento do ciclo do uso de medicamentos em um hospital. Para tal, serão necessários bancos de dados seguros, uma infraestrutura de rede veloz e um software competente que faça do avanço tecnológico também um avanço de produtividade e facilidade.

A solução visa utilizar uma plataforma web com interface que possua os máximos recursos em interatividade, mobilidade e facilidade de uso. Não basta que as tarefas relativas à informação sejam cumpridas de forma extremamente funcional se a acessibilidade não for adequada ao perfil dos profissionais que irão utilizá-lo. Por isso, a interface homem-máquina será a principal preocupação do desenvolvimento do eDC.

eDC possui recursos para cada etapa do ciclo do uso de medicamentos e sua possibilidade de modelamento fará com que cada possibilidade seja escolhida de acordo com o planejamento estratégico do hospital: sua missão, objetivos e metas a curto, médio e longo prazo.

No planejamento e aquisição, eDC terá recursos suficientes para elaborar automaticamente um pedido de compra, comunicar-se com fornecedores e mostrar ao responsável a melhor opção segundo seus critérios pré-determinados.

A distribuição e logística, seja ela realizada por dose coletiva, individualizada ou 
unitária, poderá contar com diversas opções de automação que levarão a diferentes resultados no que compete a eficiência e eficácia do processo. Este setor está intimamente ligado com um solicitação, que também deverá ser eletrônica e contar com todos os recursos de interatividade.

As melhoria no setor de dispensação será o ponto forte do eDC. Os recursos disponíveis irão desde simples componentes do software que farão a contagem da quantidade disponível em cada clínica até um sistema robotizado com uso de tubos pneumáticos. Tudo aliado a um componente de prescrição eletrônica de uso extremamente simples.

O controle de estoque será planejado de forma a garantir total confiabilidade e segurança dos dados sem a menor necessidade de contagem visual. Estará intimamente ligado ao setor de compras e logística, mantendo a contagem física exatamente igual à exibida no software.

Para farmácias hospitalares que possuam um setor farmacotécnico, o eDC contará com um guia para a realização destas manipulações. E para os hospitais que contam com um serviço de farmácia clínica, partes do sistema de prescrição eletrônica será destinada às eventuais correções do farmacêutico e seguinte encaminhamento para o médico.

O eDC ainda contará com um arquivo onde ficarão armazenados os dados de cada paciente para fins de rastreabilidade e estudos acadêmicos. Com isso, cobriremos todas as etapas do ciclo e tornaremos o serviço de assistência à saúde mais eficiente e eficaz.

\section{J.1.3 Protótipo}

O protótipo implementado do eDC mostrou a aplicação de dispositivos móveis que permitam uma experiência diferente para os profissionais ligados ao atendimento de pacientes internados em hospitais de grande porte. 


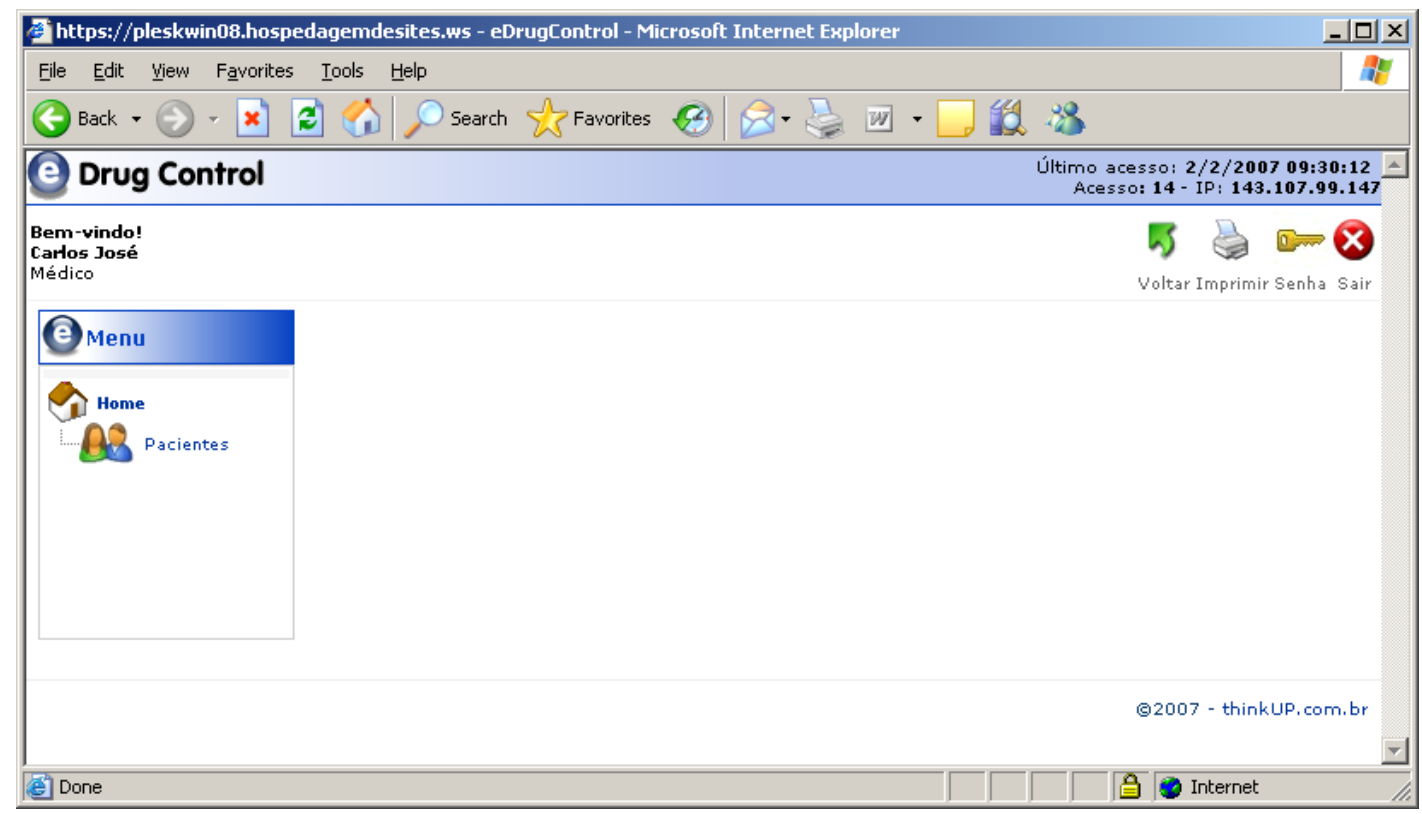

Figura J.1: O protótipo do eDrugControl.

O protótipo foi idealizado para ser executado em um portal de Internet, o que permite que qualquer usuário tenha acesso ao sistema a partir de qualquer dispositivo com acesso a rede. No caso da apresentação, foram utilizados TabletPC e PocketPC, além de celulares com acesso a Internet. Todos esses equipamentos possuem mobilidade de forma a facilitar o acesso as informações do paciente por qualquer dos profissionais envolvidos com o tratamento do mesmo.

O protótipo está disponível no site da thinkUP.com.br.

\section{J.1.4 Resultado no concurso IBM inSites}

- Classificado na I Fase eliminatória nacional - Avaliação do artigo acadêmico

- Classificado na II Fase eliminatória nacional - Apresentação do Business Case

- Classificado na III Fase eliminatória nacional - Apresentação do protótipo

- Classificado entre os 10 finalistas para exposição do projeto no evento Connect and Play 2006

- Resultado no concurso: 5‥ Lugar - Menção honrosa 


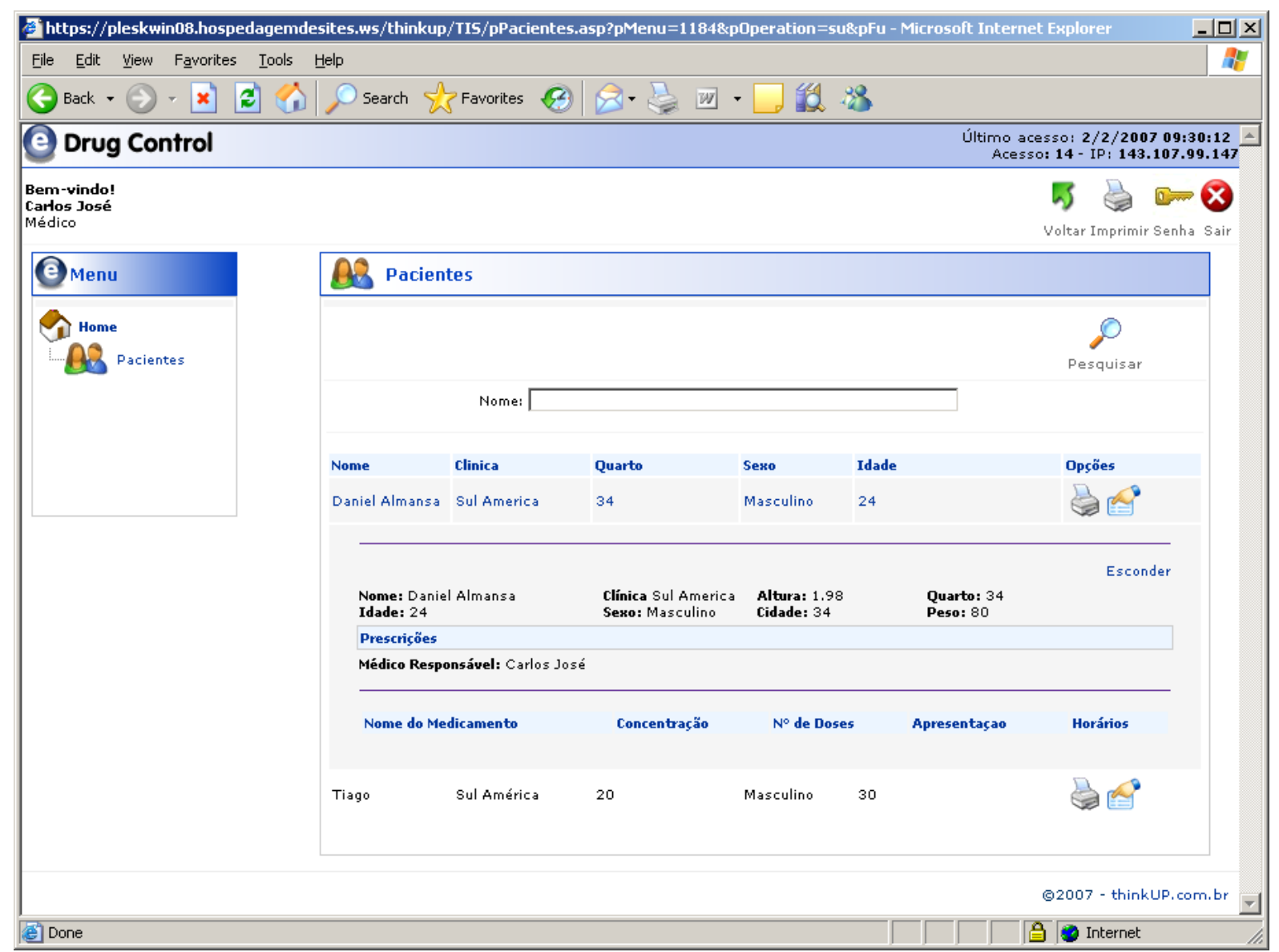

Figura J.2: Interface do eDrugControl. 


\section{J.2 itSIMPLE}

Dando continuidade ao protótipo do ambiente de análise e verificação de requisitos anteriormente desenvolvido, o aluno participou da definição e desenvolvimento de uma ferramenta que suporte a especificação de requisitos de sistemas. Em uma atividade colaborativa com outros pesquisadores do d-lab, foi criado o itSIMPLE, que utiliza os conceitos de especificação de requisitos para a solução dos problemas de modelagem de domínio em planejamento. A ferramenta implementa a especificação de requisitos em Diagrama de Use Cases, permitindo a descrição do mesmo para a verificação em redes de Petri [3], segundo especificado anteriormente [4].

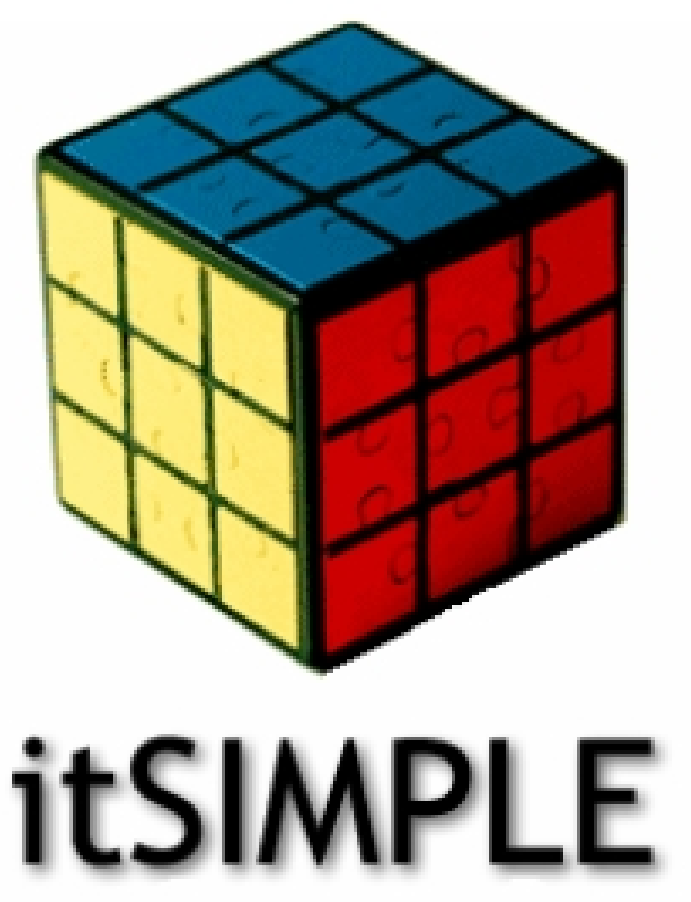

Figura J.3: Logotipo do itSIMPLE.

Durante este período, foi introduzido o conceito de viewpoints destacado na publicação em [5].

A ferramenta está disponível para avaliação no seguinte endereço eletrônico: http://designlab.grupoe.com.br/. 


\section{J.2.1 Produção acadêmica}

A contribuição acadêmica do projeto, foi apresentada em forma de artigo sob o título "Um Ambiente Integrado de Modelagem e Análise de Sistemas" [6]. O resumo do artigo ilustra o estágio atual do futuro ambiente de design, agora chamado itSIMPLE, conforme segue:

O grande esforço presente hoje na área de Inteligência Artificial em definir sistemas que possam ser flexíveis e integrados leva à necessidade de um processo sistemático em que as fases iniciais de design não sejam desprezadas. Neste trabalho procura-se mostrar a importância dessas fases iniciais e que uma abordagem que as despreza pode comprometer toda a análise do sistema e posterior o desenvolvimento. É proposto, nesse sentido, um ambiente de modelagem $e$ análise, chamado itSIMPLE, que contempla principalmente o conceito de viewpoints, da Engenharia de Requisitos, e o Design em Engenharia, que levam em conta essas definições iniciais indispensáveis para o sucesso do processo de análise. Nesse ambiente é possível integrar várias formas de representação e de análise de sistemas, como as Redes de Petri, a UML e a PDDL para domínio de planejamentos.

\section{J.2.2 Business Case}

Enquanto produto, para fins da competição, foi preparado o Business Case, que mostra a visão de um produto para atender a profissionais da área de Design.

O itSIMPLE é um ambiente de design que integra ferramentas de análise, especificação e modelagem através de linguagens consolidadas como XML, UML e Redes de Petri. Integração com outras ferramentas que são utilizadas nas fases iniciais do ciclo de vida do desenvolvimento de sistemas (como o IBM Rational Suite, Together Center, Visual Studio, etc.) também é possível, dando suporte às mais diferentes aplicações de engenharia (software, manufatura, planejamento, etc.), negócios (gestão de projetos, controle de processos, etc.) e qualquer outra atividade onde existam problemas de design.

A plataforma visa utilizar o conceito de service oriented architecture (SOA), sendo totalmente configurável com funções personalizadas que possuem capacidades adequadas para cada organização ou individuo. Dessa forma, busca-se permitir a integração das diversas ferramentas que existem no mercado atualmente para 
modelagem de sistemas, mas que trabalham de maneira independente, sem uma linguagem comum.

Esta comunicação, baseada em XML, permitirá ao designer trabalhar com diversas visões do sistema, integrando as diversas técnicas de modelagem existentes atualmente. $O$ itSIMPLE utilizará toda essa informação para auxiliar o processo de design, e conseqüentemente 0 de desenvolvimento, facilitando a validação e verificação do modelo em qualquer etapa do processo.

Outra inovação importante diz respeito à utilização do conceito de running specification, que permite ao usuário acessar as diferentes perspectivas (utilizando linguagens formais e semi-formais) em qualquer momento do processo de modelagem. Isto auxilia o processo de verificação e validação do modelo que esta sendo desenvolvido, pois aumenta o poder de análise e permite que os diversos profissionais possam ver o sistema da forma que lhes é mais familiar.

No estágio atual, a ferramenta é capaz de integrar a definição de requisitos em UML (Unified Modeling Language), utilizada como forma de captar o conhecimento necessário para o design, com a linguagem de planejamento automático em inteligência artificial PDDL (Planning Domain Definition Language), que pode ser entendida por planejadores para a resolução de problemas de planejamento, e as redes de Petri, que permitem a verificação e validação do comportamento dinâmico do sistema.

Hoje, o ambiente de desenvolvimento é orientado a Casos de Uso (Use Case Driven Development), no entanto, no futuro, o ambiente será capaz de agregar novos pontos de vista e permitirá que o desenvolvimento siga demais orientações existentes (como a Test Driven Development) e outras que surgirem.

\section{J.2.3 Protótipo}

\section{J.2.3.1 Desenvolvimento}

Como foi dito anteriormente, há hoje uma forte demanda de um ambiente que possa integrar todos esses conceitos da Engenharia de Requisitos e dos viewpoints. Com a 
finalidade de satisfazer essa necessidade é que a ferramenta itSIMPLE vem sendo desenvolvida. Além disso, esse ambiente deve, no futuro, englobar todas as etapas de definição e implementação na resolução de um problema real, desde o seu modelamento e design até o seu planejamento de execução. Há também uma tendência em que o programa assuma versões modulares, com os chamados plugin's, que envolveriam apenas algumas funções específicas e poderiam ser utilizados em conjunto com as ferramentas já existentes hoje em dia, como o Rational Rose e o Requisite Pro.

A versão atual do itSIMPLE foi desenvolvida em ambiente Java. Essa linguagem foi escolhida devida à sua grande portabilidade (softwares desenvolvidos em Java podem ser executados em qualquer sistema operacional) e por ser altamente difundida hoje na comunidade de programação. Além disso, a maioria dos projetos feitos em Java seguem a filosofia open source (fonte aberta), facilitando muito 0 desenvolvimento e extensão das funcionalidades da ferramenta. Nesse sentido, 0 itSIMPLE também deve, futuramente, tornar-se um projeto de fonte aberta, ainda que parcialmente.

Além da linguagem de programação, é importante que haja uma plataforma de desenvolvimento que auxilie o desenvolvimento de uma ferramenta. Por isso, a versão atual do itSIMPLE foi totalmente desenvolvida no Eclipse, plataforma desenvolvida e disponibilizada pela IBM e que também possui seu código aberto. Essa plataforma, com a gradual evolução da ferramenta, se mostrou indispensável para o bom andamento do projeto, principalmente devido a seu grande número de funcionalidades e à sua interface bastante amigável. 


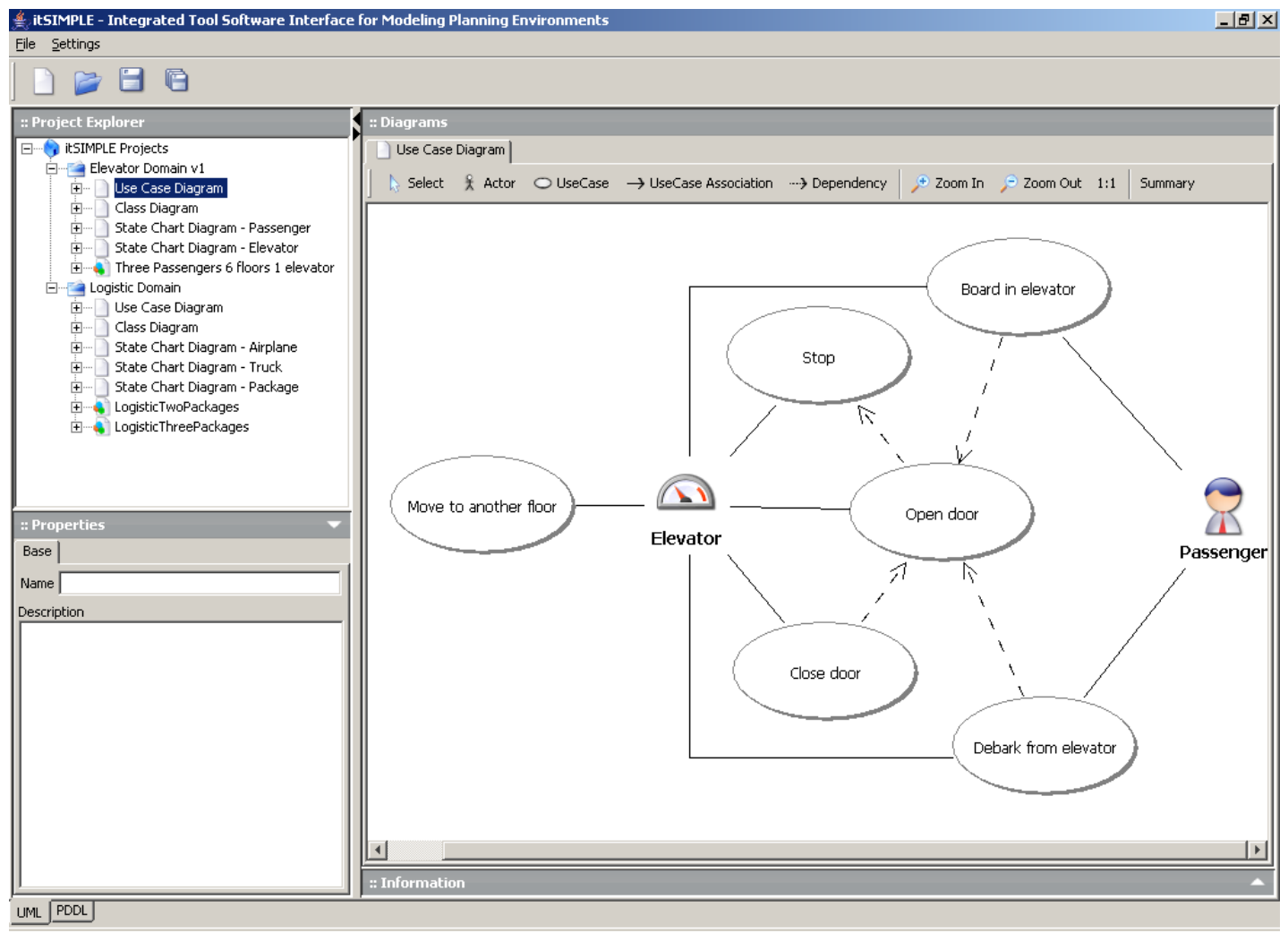

Figura J.4: Exemplo de Caso de Uso do problema clássico de elevadores.

\section{J.2.3.2 O Ambiente itSIMPLE}

Podemos definir o itSIMPLE como um ambiente que visa o design e especificação de projetos ou sistemas a partir dos vários viewpoints e seus respectivos requisitos, reunindo todos os conceitos apresentados nas seções anteriores.

Nesse sentido, o itSIMPLE foi desenvolvido para ser um ambiente do tipo Use Case Driven, ou seja, a fase inicial de modelagem é feita com Casos de Uso e, baseandose nos requisitos definidos nos mesmos, todo o processo posterior de design é então realizado. Além disso, o ambiente proporciona a possibilidade de validação dos Casos de Uso e a construção, a partir dos mesmos, de Redes de Petri. Um exemplo de Caso de Uso é o mostrado na Figura J.4, correspondente ao conhecido problema dos elevadores inteligentes. 


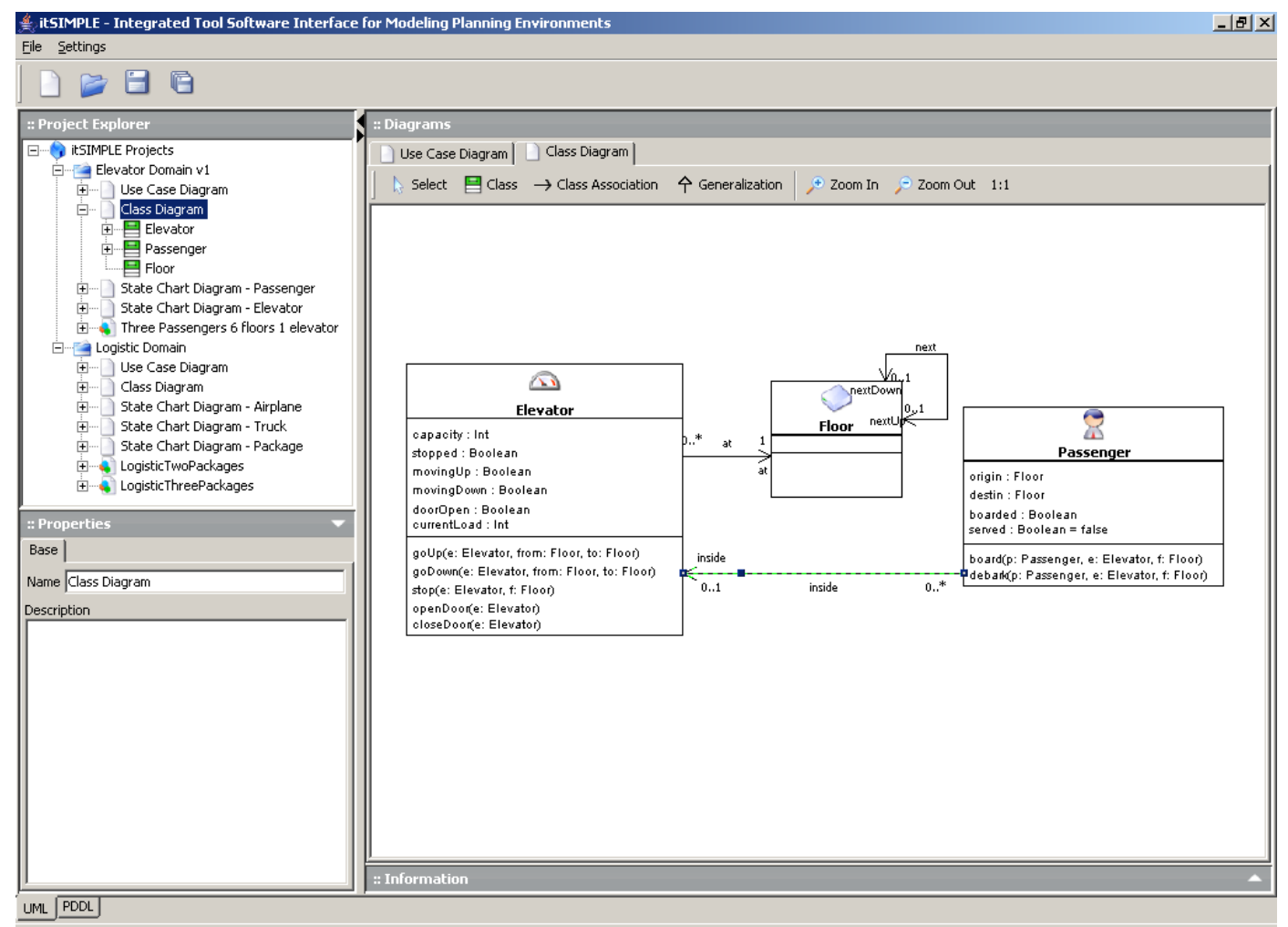

Figura J.5: Diagrama de Classes do problema clássico dos Elevadores.

Após os Casos de Uso, deve-se partir para a modelagem do domínio, com a definição no Diagrama de Classes dos elementos que fazem parte desse domínio e das características estáticas do mesmo. Um exemplo de Diagrama de Classes é mostrado na Figura J.5.

Após as definições das classes que formam o domínio, parte-se para o Diagrama de Estados, onde são definidas como as ações pertencentes àquele sistema modificam os estados dos elementos que o compõem. No Digrama de Estados, as definições da cada estado e as pré e pós-condições de cada ação são definidas com a linguagem OCL (Object Constraint Language), já que a própria UML usa freqüentemente essa linguagem em suas definições, além do fato dela ter se mostrado bastante completa para esse tipo de definição. Um exemplo de diagrama de estados é mostrado na Figura J.6.

Essa seqüência, naturalmente, não é obrigatória. Pode-se, por exemplo, executar o processo de Action Driven, ou seja, a especificação é feita baseada nas ações que podem ser realizadas dentro do ambiente do sistema, que é uma abordagem muito comum em problemas de planejamento automático. Outra abordagem que poderá estar presente é o chamado Test Driven Development, em que a modelagem é feita já com base nos testes a serem feitos com aquele sistema.

Após a definição do domínio, define-se, por fim, as situações que podem ocorrer com seus elementos, passando-se, portanto, à modelagem de problemas que podem representar situações reais. Para isso são utilizados os Diagramas de Objetos da UML, onde são representadas instâncias das classes definidas no Diagrama de Classes em situações e estados bem definidos. Um exemplo de 
Diagrama de Objetos é mostrado na figura J.7.

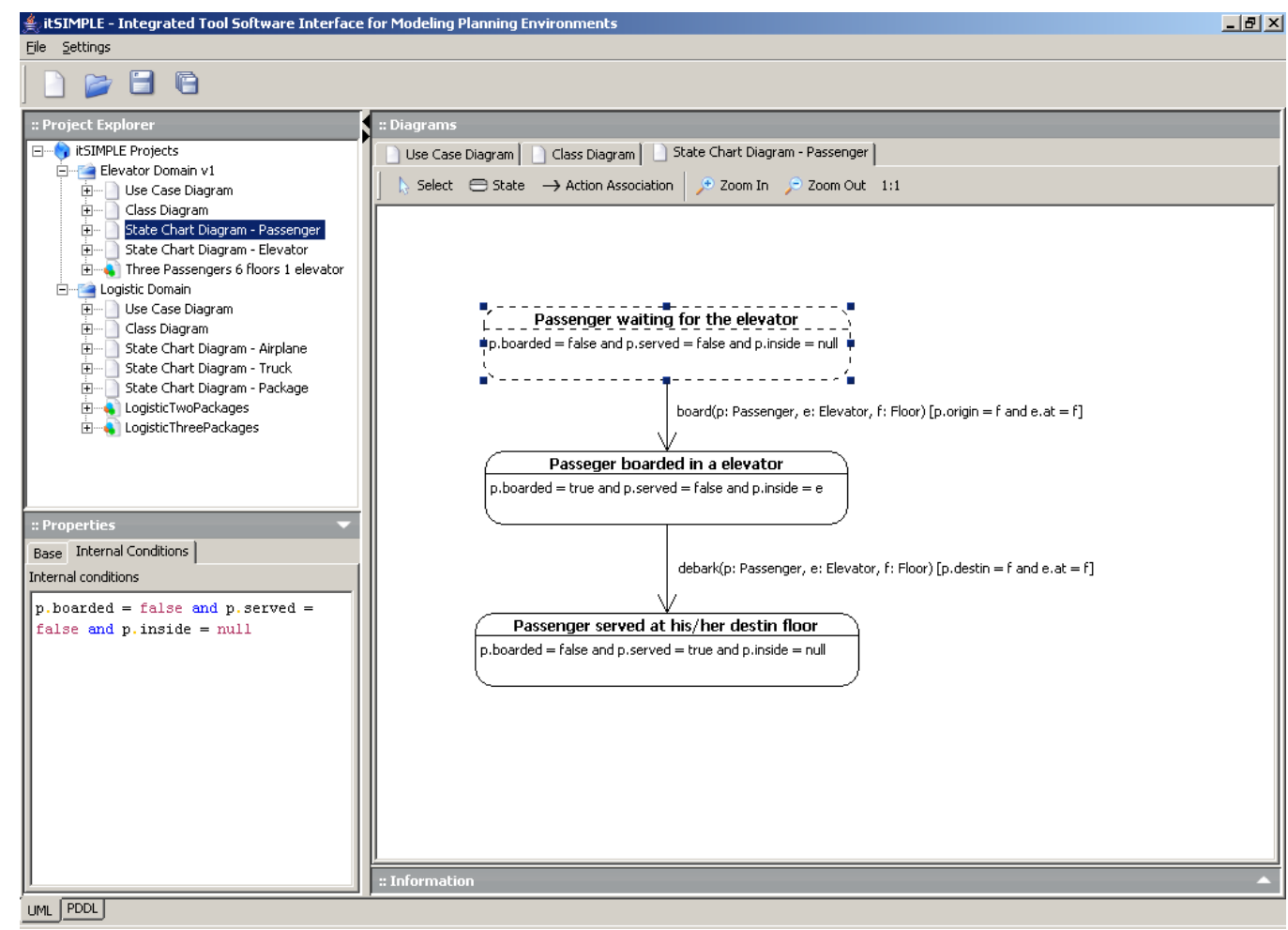

Figura J.6: Diagrama de Estados da classe Passageiro dos Elevadores.

A UML é uma poderosa linguagem de modelagem que pode ser utilizada para aumentar o poder de expressividade dos domínios e problemas de planejamento. Uma grande vantagem do uso da UML é que esta pode ser facilmente exportada para XML.

A XML é uma linguagem de marcação, que descreve dados estruturados, bastante útil nas declarações de conteúdo e na obtenção de resultados mais significativos de busca através de múltiplas plataformas. Isto faz com que a XML seja uma linguagem apropriada para troca de dados e informação entre sistemas de informação.

A XML é baseada no conceito de tags (marcações) que auxiliam na estruturação dos dados e da própria representação. Utilizando a XML é possível declarar dados como, por exemplo, preços de livros, tipos de transporte, taxas comerciais, e qualquer outro tipo de dado. Com o uso das tags é possível criar estruturas específicas para cada tipo de aplicação, de forma flexível, desde que todos os sistemas que irão utilizar a estrutura saibam interpretá-la. 


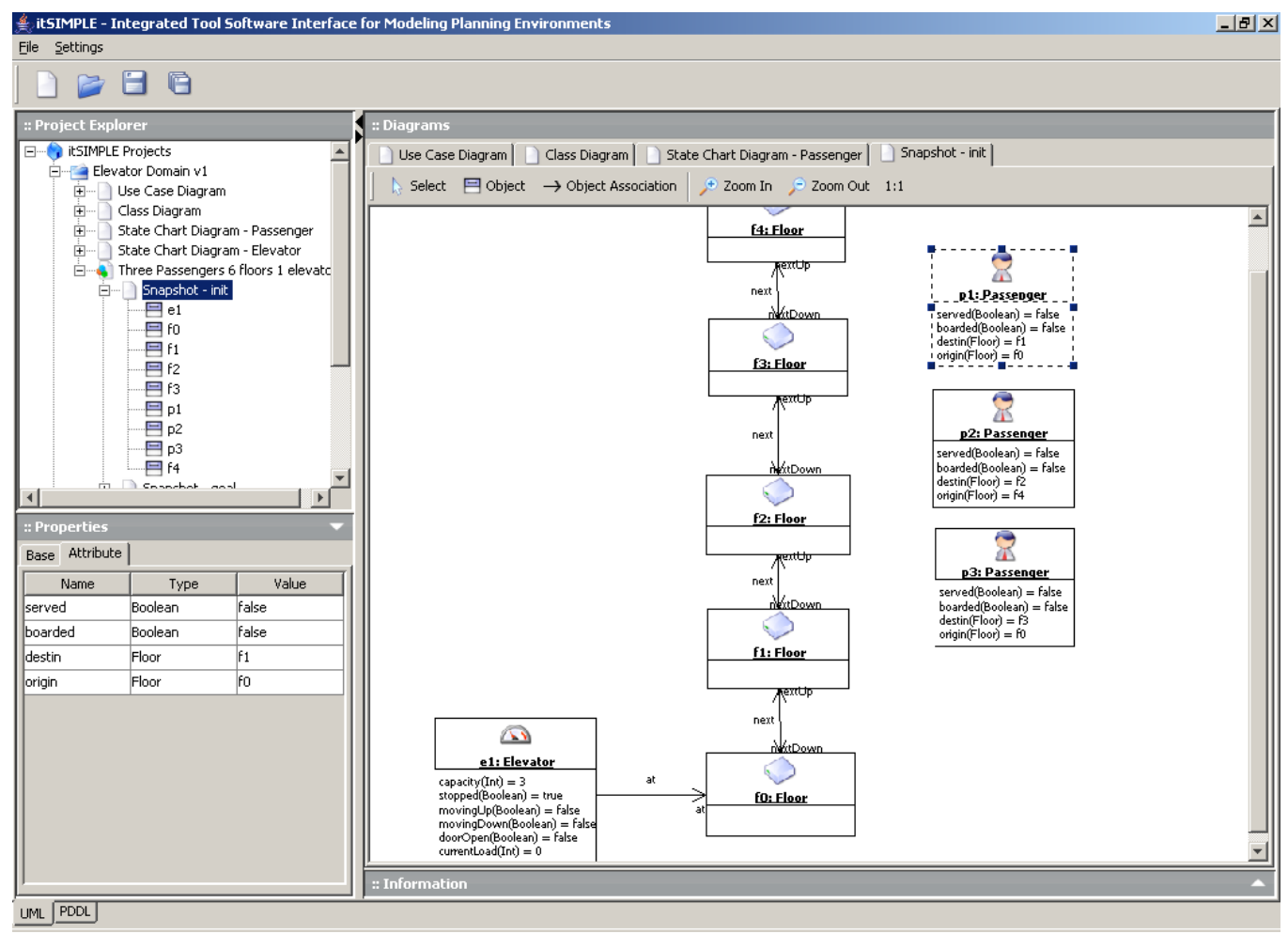

Figura J.7: Exemplo de Diagrama de Objetos do problema dos Elevadores.

Todos os diagramas criados em UML podem ser armazenados na forma de um arquivo XML, mantendo a estrutura do modelo de planejamento. Os elementos constituintes destes diagrama como, por exemplo, classes, estados, associações e objetos são representados em XML na forma de tags que garantem a consistência do modelo.

A versão atual do itSIMPLE apresenta ainda uma funcionalidade específica de problemas de planejamento automático, que é a tradução da definição de domínios e problemas em UML para a linguagem PDDL, que é a linguagem usual para essa área da engenharia.

\section{J.2.4 Resultado no concurso IBM inSites}

- Classificado na I Fase eliminatória nacional - Avaliação do artigo acadêmico

- Classificado na II Fase eliminatória nacional - Apresentação do Business Case

- Classificado na III Fase eliminatória nacional - Apresentação do protótipo

- Classificado entre os 10 finalistas para exposição do projeto no evento 
Connect and Play 2006

- Resultado no concurso: 4‥ Lugar - Menção honrosa 


\section{J.3 eCampeonatos}

Este projeto mostra uma aplicação da especificação de um negócio relacionado com automação na área social. O projeto foi implementado a partir de uma necessidade de organização de grandes competições educacionais e esportivas, o que claramente mostra a necessidade de automação aplicada a eventos sociais, baseado em artigo escrito anteriormente sobre Planejamento e Gestão de Tecnologia de Informação [7].

\section{J.3.1 Produção acadêmica}

A contribuição acadêmica do projeto, foi apresentada em forma de artigo sob o título "Aplicação da Tecnologia na Inclusão Sócio-Digital: Um estudo de caso na Secretaria de Esportes da Prefeitura de São Paulo" [8]. Segue o resumo do artigo:

A necessidade de atender bem aos clientes era, até pouco tempo, exclusiva das organizações da iniciativa privada, mas recentemente as organizações públicas se sentiram pressionadas, pela sociedade, para uma prestação de serviço mais próxima daquela praticada pelas instituições privadas, o que as tem levado a considerar os cidadãos como clientes. Esse trabalho apresenta a importância que a Tecnologia da Informação teve para a Administração Pública, possibilitando uma maior aproximação do governo com o cidadão, gerando inclusão sócio-digital. Os resultados são observados no Estudo de Caso do projeto piloto de Governo Eletrônico na Secretaria de Esportes da Cidade de São Paulo. 


\section{J.3.2 Business Case}

Enquanto produto, para fins da competição, foi preparado o Business Case, que mostra a visão de um produto para atender ao mercado de Entretenimento e Governo Eletrônico no Brasil.

\section{CCampeonatos.com.br}

Figura J.8: Logotipo do eCampeonatos.

O eCampeonatos é uma ferramenta tecnológica de Internet cuja função principal é organizar e armazenar dados de competições esportivas de forma dinâmica, de maneira a se tornar a comunicação principal entre organizadores e usuários destas competições. Desenvolvida através da união entre dois conhecimentos específicos Tecnologia da Informação e Ciência do Esporte - a ferramenta é resultado dos esforços de um grupo de trabalho formado por especialistas nestas duas áreas de conhecimento demandadas.

Considerando que a grande parte da população brasileira tem acesso a meios de comunicações variados, tais como Internet e celulares, foi desenvolvida uma plataforma que permite as Secretarias de Esportes realizarem programas sociais que levem a inclusão sócio-digital e, conseqüentemente, a diminuição dos índices de violência. Essa plataforma, denominada eCampeonatos, foi concebida a partir de uma necessidade da Secretaria de Esportes da Cidade de São Paulo que precisava ter controle do processo de Gestão de Eventos Esportivos, com um caso especifico que são os Jogos da Cidade.

Durante o levantamento de requisitos para o desenvolvimento da solução, a equipe do d-lab identificou que o maior problema dos técnicos da Secretaria de Esportes estava na definição da agenda dos jogos, uma vez que esse processo tomava boa parte do tempo do pessoal e com um agravante: as alterações de disponibilidade de locais de jogos e arbitragem poderiam levar a equipe a refazer toda a agenda, o que era extremamente desgastante. 


\section{J.3.3 Protótipo}

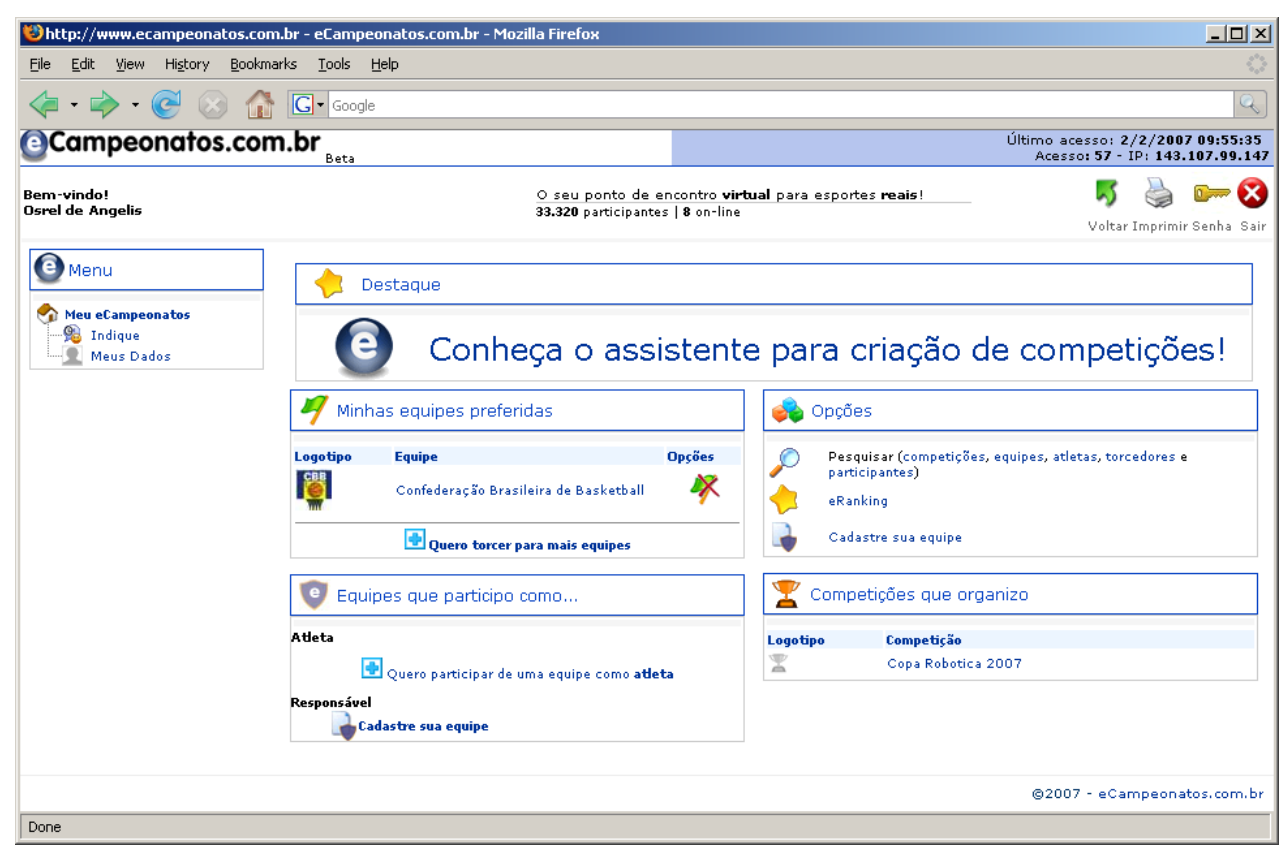

Figura J.9: Home page do acesso restrito do eCampeonatos.

O eCampeonatos foi criado para oferecer, no mesmo portal, ferramentas que permitam:

- cadastrar e gerenciar equipes, além de convidar amigos para participar

- organizar competições e convidar as equipes para participar

- torcer para o time preferido

- acumular pontos no eRanking - o ranking de participantes do eCampeonatos

- participar das competições realizadas no eCampeonatos

\section{J.3.3.1 O Assistente de Competições}

Com o assistente de competições, organizadores de eventos podem criar grandes eventos com a facilidade proporcionada pela infra-estrutura baseada em framework, conforme proposta de Zachman [9]. 


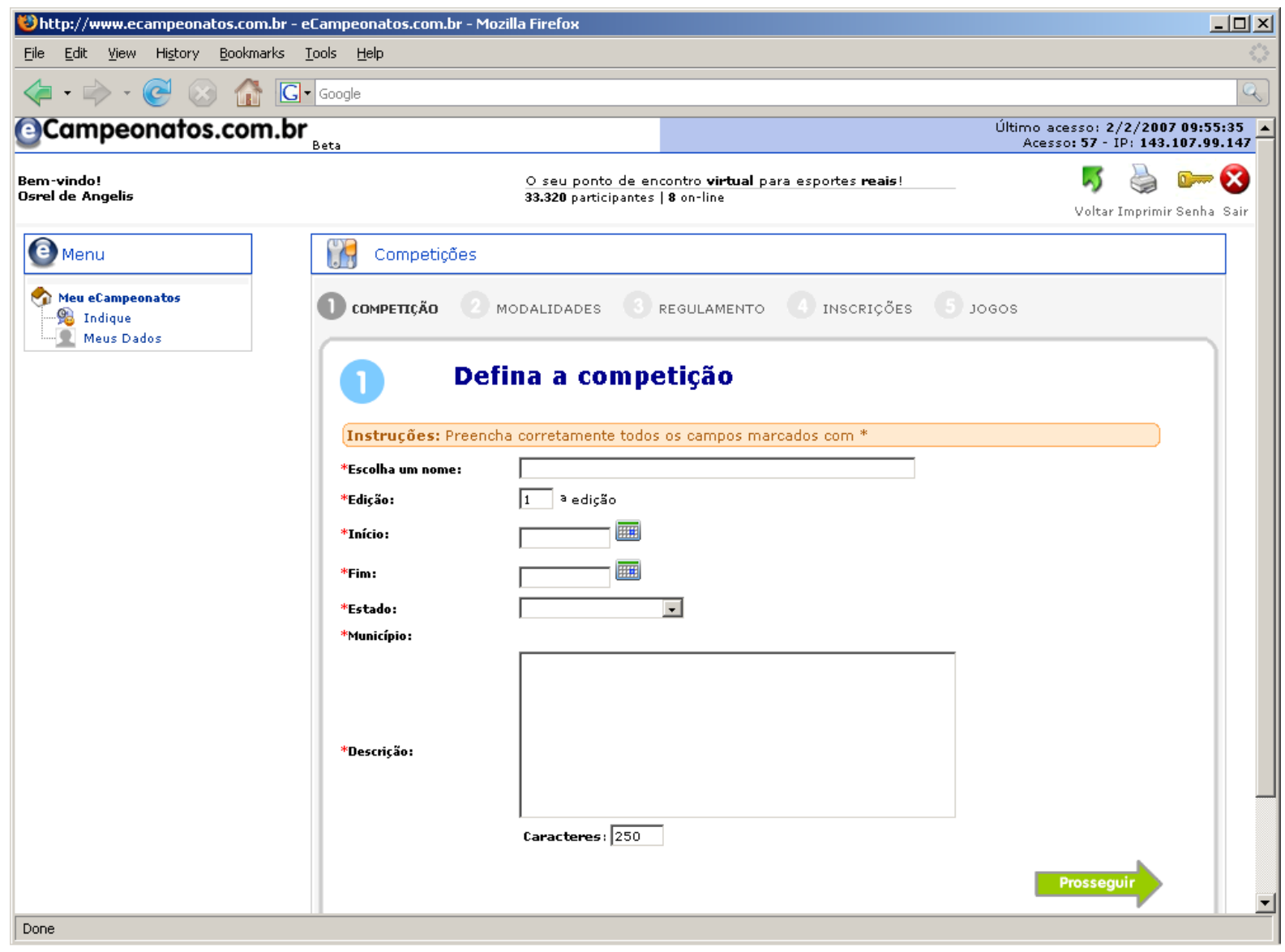

Figura J.10: O assistente de competições do eCampeonatos.

Uma contribuição relevante do eCampeonatos foi permitir à equipe da Secretaria de Esportes da Cidade de São Paulo a redução drástica do tempo de criação, desenvolvimento e implantação dos Jogos da Cidade de São Paulo. Em função da participação de mais de 50 mil atletas, a alocação dos jogos se dava de forma manual, o que demandava o trabalho de aproximadamente 04 (quatro) meses para a definição da tabela dos jogos. Através do desenvolvimento de um algoritmo que envolve alocação de recursos e considera pesos atribuídos às equipes em função de seu desempenho em competições anteriores, a tabela dos jogos agora é uma atividade de segundos, obviamente depois de todos os dados necessários terem sido informados ao eCampeonatos. 


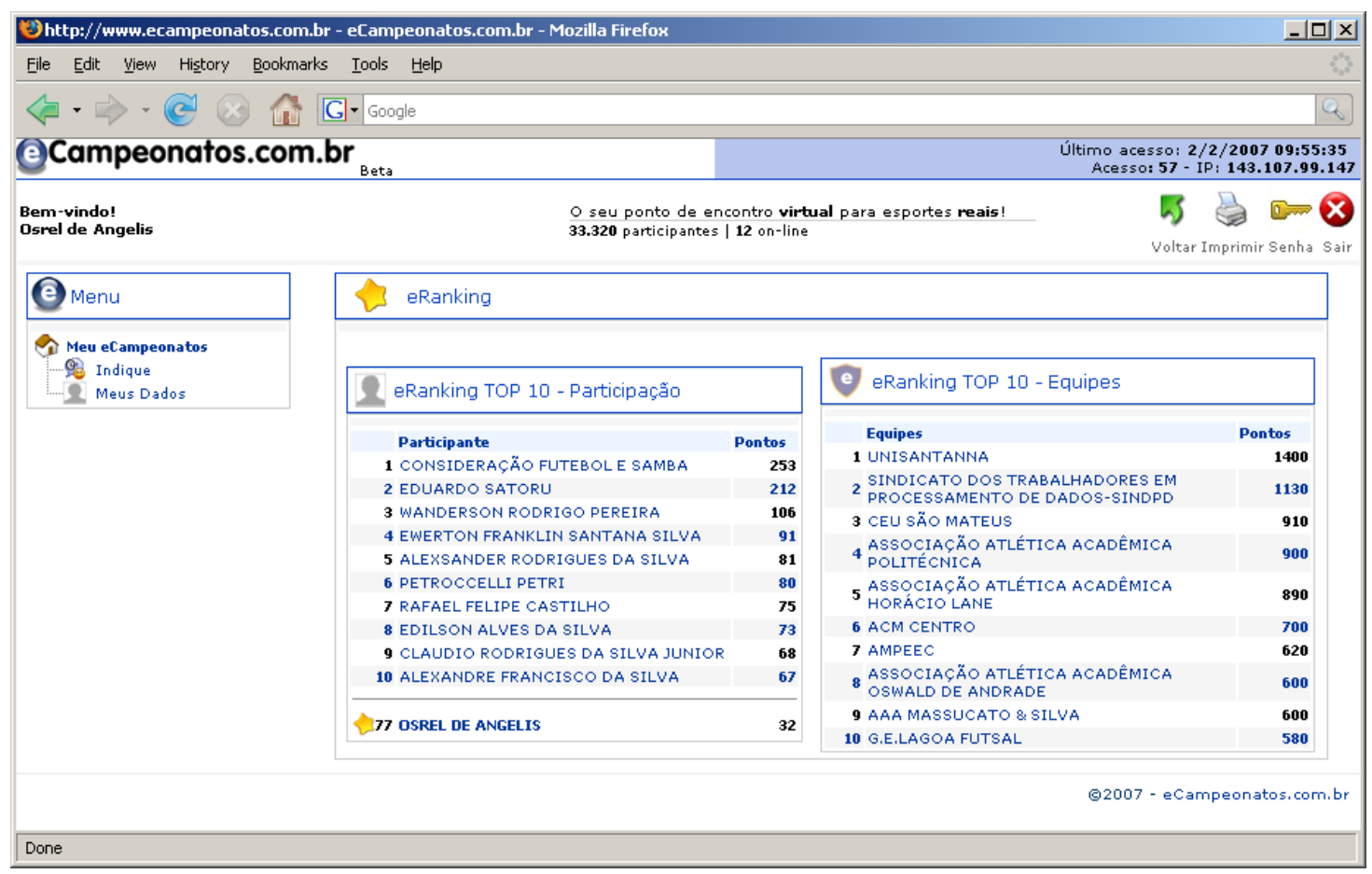

Figura J.11: eRanking no eCampeonatos.

De forma similar, está sendo desenvolvido o assistente de competições escolares, que permitirá a professores e coordenadores pedagógicos o desenvolvimento de competições que incentivem o desenvolvimento dos alunos.

\section{J.3.3.2 O eRanking}

O ranking do eCampeonatos visa incentivar os participantes a desenvolverem atividades que permitam o desenvolvimento acadêmico através da pontuação com maior peso para a participação em atividades ou eventos de conteúdo pedagógico.

Na página principal do portal eCampeonatos são veiculadas notícias relacionadas a educação e esportes, eventos de competições organizadas no eCampeonatos, fórum de discussão, blog, dentre outras ferramentas que permitam a interação dos usuários do portal. 


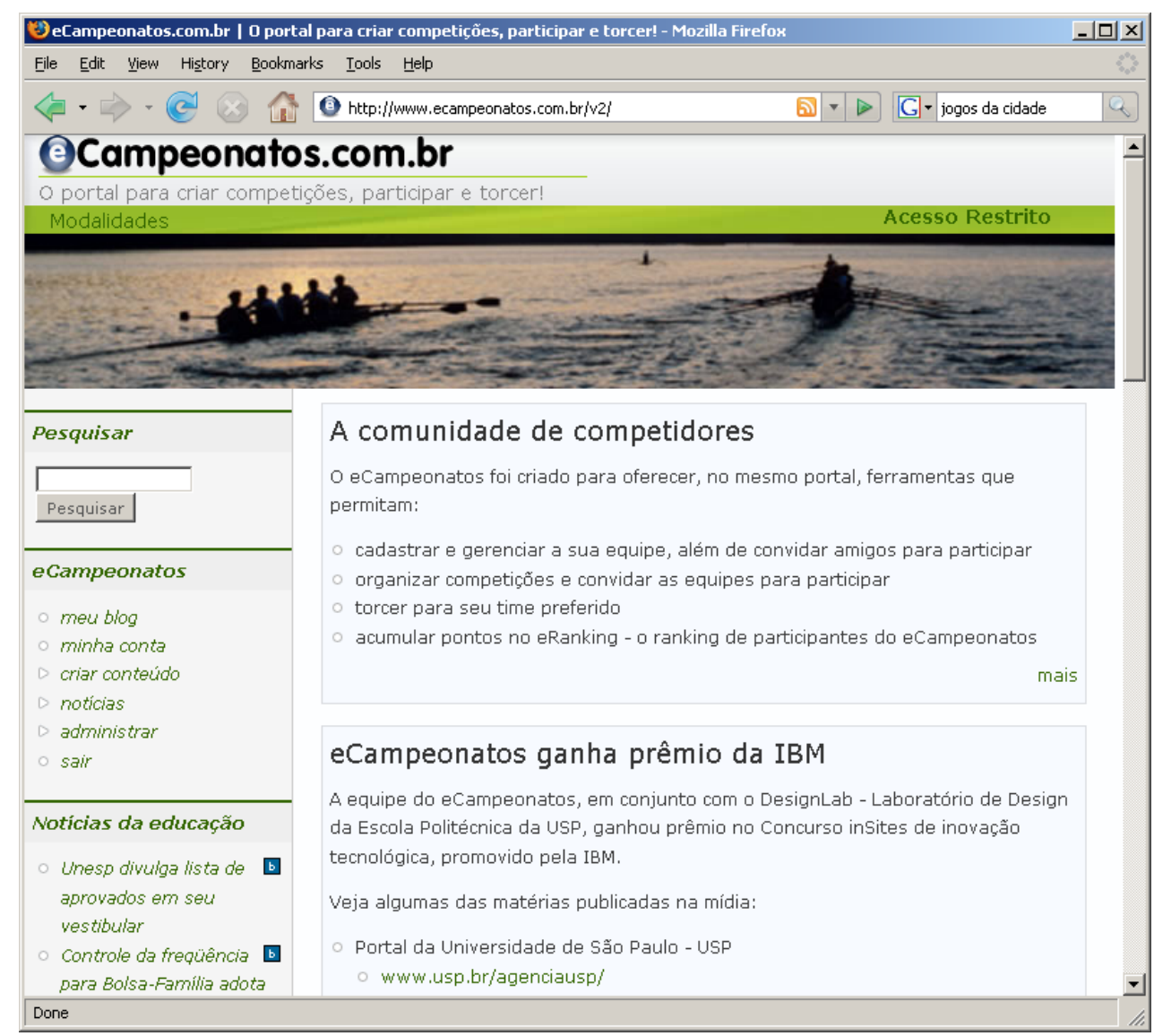

Figura J.12: O portal eCampeonatos.

\section{J.3.4 Resultado no concurso IBM inSites}

- Classificado na I Fase eliminatória nacional - Avaliação do artigo acadêmico

- Classificado na II Fase eliminatória nacional - Apresentação do Business Case

- Classificado na III Fase eliminatória nacional - Apresentação do protótipo

- Classificado entre os 10 finalistas para exposição do projeto no evento Connect and Play 2006

- Resultado no concurso: 3‥ Lugar

- Prêmio de $\mathbf{R} \mathbf{2 0 . 0 0 0 , 0 0}$ em Vale viagem para os participantes

- Prêmio de $\mathbf{R} \mathbf{1 0 . 0 0 0 , 0 0 ~ e m ~ m a r k e t i n g ~ p a r a ~ d i v u l g a c ̧ a ̃ o ~ d o ~ p r o j e t o ~}$

Em função do resultado dos projetos no concurso, foram desenvolvidos trabalhos de divulgação dos resultados das atividades do d-lab, contando com as assessorias de imprensa da POLI e da USP. Com isso, segue a relação do clipping da veiculação 
das notícias nos principais veículos de imprensa, sobretudo os canais da Internet.

\section{J.3.4.1 Jornais e revistas}

- Jornal do Comércio

o Local: Porto Alegre-RS

o Data: 29/12/2006 a 01/01/2007

o Coluna: $2^{\circ}$. Caderno

o Página: 3

- Título: USP cria programa para torneios esportivos

- DCI - Diário do Comércio, Indústria e Serviços

- Local: São Paulo-SP

o Data: 30/12/2006 a 02/01/2007

- Coluna: S. Paulo

o Página: C-4

o Título: Software reduz em $40 \%$ gastos com jogos

- A Folha

- Local: São Carlos-SP

o Data: 31/12/2006

- Coluna: Caderno 2

o Página: 1

o Título: Software organiza e gerencia competições esportivas

- Jornal da Tarde

- Local: São Paulo-SP

o Data: 01/01/2007

- Coluna: Opinião

o Página: A-2

o Título: Notícia boa

- $\mathrm{DCl}$ - Diário do Comércio, Indústria e Serviços

- Local: São Paulo-SP

o Data: 19/01/2007

o Coluna: S. Paulo

o Página: C-4

o Título: Software vai organizar competição de escola

- Jornal da USP

- Local: São Paulo-SP

o Data: 15/01/2007 a 21/01/2007

o Coluna: Pesquisa - Computação 
o Página: 5

o Título: A informática entra em campo

- Revista www

o Local: São Paulo-SP

o Data: Janeiro 2007

o Coluna: Notícias

o Página: 6

- Título: IBM anuncia vencedores do concurso inSites

\section{J.3.4.2 Internet}

- IBM International

0 http://www.ibm.com/br/news/events/software/ibm insites/

- Universidade de São Paulo - USP

0 http://www.usp.br/agen/repgs/2006/pags/269.htm

0 http://www.usp.br/jorusp/arquivo/2007/jusp788/pag05b.htm

- http://noticias.usp.br/acontece/obterNoticia?codntc=14675\&codnucjirn=1

- Portal do Governo do Estado de São Paulo

0 http://www.saopaulo.sp.gov.br/sis/lenoticia.php?id=80834

0 http://www.saopaulo.sp.gov.br/sis/lenoticia.php?id=81439

- Secretaria de Ciência e Tecnologia do Estado de São Paulo - SCTDE

0 http://www.ciencia.sp.gov.br/noticias/?ID=483

- UOL - Tecnologia - IDGNow

o http://idgnow.uol.com.br/especiais/

0 http://idgnow.uol.com.br/internet/2006/12/29/idgnoticia.2006-12-29.2697 361021/IDGNoticia view

- UOL - Cidade do Futebol

0 http://cidadedofutebol.uol.com.br/cidade2006/Materia.aspx? IdArtigo $=4761$

- Secretaria de Esportes da Cidade de São Paulo - SEME

0 http://portal.prefeitura.sp.gov.br/noticias/sec/esportes/2007/01/0016

- Universia Brasil

o http://www.universia.com.br/html/noticia/noticia dentrodocampus deidh $\underline{\mathrm{html}}$ 


\section{J.4 Referências}

1. Vernadat, F. (2002). UEML: Towards a Unified Enterprise Modelling Language. International Journal of Production Research, 40 (17), pp. 4309-4321

2. Follador, D. D., Dutra, D. S., Guedes, M. T., Santos, E. A. (2006). A Farmácia Hospitalar no Brasil precisa de Automação, Concurso IBM inSites, IBM Brasil, Dezembro de 2006, São Paulo, SP, Brasil.

3. Santos, E. A. (2002). Verificação de requisitos de sistemas utilizando redes de Petri. Dissertação de Mestrado, Universidade de São Paulo, Escola Politécnica, Dezembro 2002, São Paulo, SP, Brasil.

4. Sabanai, R., Horikawa, R., Curdulino, R. (2003). Ferramenta de Validação de Requisitos utilizando Redes de Petri. Relatório Final da disciplina PMR 2500 Projeto de Conclusão de Curso, Dezembro 2003, São Paulo, SP, Brasil.

5. Santos, E. A. e Tavares, J. J. P. Z. (2004). Verificando requisitos na fabricação de blanks soldados: um estudo de caso com redes de Petri. Artigo submetido ao $3^{\circ}$ COBEF - Congresso Brasileiro de Engenharia de Fabricação, 12-15 Abril 2005, Joinville, SC, Brasil.

6. Romero, V. M. C., Sette, F. M., Vaquero, T. S., Santos, E. A. (2006). Um Ambiente Integrado de Modelagem e Análise de Sistemas. Concurso IBM inSites, IBM Brasil, Dezembro de 2006, São Paulo, SP, Brasil.

7. Santos, E. A. (2005). A Tecnologia da Informação e o Governo Eletrônico: Um estudo de caso na Secretaria de Esportes da Cidade de São Paulo. Artigo de conclusão do curso PRO-5805. Junho de 2005.

8. Santos, E. A. (2006). Aplicação da Tecnologia na Inclusão Sócio-Digital: Um estudo de caso na Secretaria de Esportes da Prefeitura de São Paulo. Concurso IBM inSites, IBM Brasil, Dezembro de 2006, São Paulo, SP, Brasil.

9. Zachman, J. A. (1987). A framework for information systems architecture. IBM Systems Journal, 26, 276-292. 